\title{
Endothelial cell function from a tissue engineering perspective
}

Citation for published version (APA):

Geenen, I. L. A. (2014). Endothelial cell function from a tissue engineering perspective. [Doctoral Thesis, Maastricht University]. Maastricht University. https://doi.org/10.26481/dis.20140620ig

Document status and date:

Published: 01/01/2014

DOI:

10.26481/dis.20140620ig

Document Version:

Publisher's PDF, also known as Version of record

\section{Please check the document version of this publication:}

- A submitted manuscript is the version of the article upon submission and before peer-review. There can be important differences between the submitted version and the official published version of record.

People interested in the research are advised to contact the author for the final version of the publication, or visit the DOI to the publisher's website.

- The final author version and the galley proof are versions of the publication after peer review.

- The final published version features the final layout of the paper including the volume, issue and page numbers.

Link to publication

\footnotetext{
General rights rights.

- You may freely distribute the URL identifying the publication in the public portal. please follow below link for the End User Agreement:

www.umlib.nl/taverne-license

Take down policy

If you believe that this document breaches copyright please contact us at:

repository@maastrichtuniversity.nl

providing details and we will investigate your claim.
}

Copyright and moral rights for the publications made accessible in the public portal are retained by the authors and/or other copyright owners and it is a condition of accessing publications that users recognise and abide by the legal requirements associated with these

- Users may download and print one copy of any publication from the public portal for the purpose of private study or research.

- You may not further distribute the material or use it for any profit-making activity or commercial gain

If the publication is distributed under the terms of Article $25 \mathrm{fa}$ of the Dutch Copyright Act, indicated by the "Taverne" license above, 


\section{ENDOTHELIAL CELL FUNCTION}

FROM A TISSUE ENGINEERING PERSPECTIVE 
Copyright @ I.L.A. Geenen, Amsterdam 2014

Cover: Bram Geenen

Layout: Tiny Wouters

Printed by: Proefschriftmaken.nl || Uitgeverij BOXPress

ISBN: 978-90-8891-888-9

The research described in this thesis was financially supported by the Smart Mix Program of the Netherlands Ministry of Economic Affairs and the Netherlands Ministry of Education, Culture and Science. 


\title{
ENDOTHELIAL CELL FUNCTION
}

\section{FROM A TISSUE ENGINEERING PERSPECTIVE}

\author{
PROEFSCHRIFT \\ ter verkrijging van de graad van doctor aan de Universiteit Maastricht, \\ op gezag van de Rector Magnificus, Prof. dr. L.L.G. Soete \\ volgens het besluit van het College van Decanen, \\ in het openbaar te verdedigen \\ op vrijdag 20 juni 2014 om 12:00 uur \\ door \\ Irma Laurentia Antonia Geenen \\ Geboren op 11 december 1983 te Valkenswaard
}




\section{Promotores}

Prof. dr. M.J. Post

Prof. dr. G.W.H. Schurink

\section{Copromotor}

Dr. D.G.M. Molin

\section{Beoordelingscommissie}

Prof. dr. H.A.J. Struijker-Boudier (voorzitter)

Prof. dr. C.V.C. Bouten (Eindhoven University of Technology)

Prof. dr. T.M. Hackeng

Prof. dr. S. Jockenhövel (RWTH Aachen University, Germany)

Prof. dr. C.J. Zeebregts (University Medical Center Groningen)

Financial support by the Dutch Heart Foundation for the publication of this thesis is gratefully acknowledged. 


\section{CONTENTS}

$\begin{array}{lll}\text { Chapter } 1 & \text { General introduction } & 7\end{array}$

Chapter 2 Coagulation on Endothelial Cells; the Underexposed 27

Part of Virchow's Triad

Chapter $3 \quad$ Endothelial Cells (ECs) for Vascular Tissue Engineering; $\quad 45$

Venous ECs are Less Thrombogenic than Arterial ECs

Chapter $4 \quad$ Phenotypic Fitness of Primary Endothelial Cells Cultured 71

from Patients with High Cardiovascular Risk or Chronic

Kidney Disease for Vascular Tissue Engineering

Chapter $5 \quad$ NO Resistance Reduces AV Fistula Maturation in

Chronic Kidney Disease

Chapter 6 Feasibility of Tissue-engineered Vascular Grafts in a

Porcine Model

Chapter $7 \quad$ General Discussion

Summary

155

Nederlandse Samenvatting

Dankwoord

165

About the Author

169

List of Publications

173 



\section{CHAPTER 1}

General Introduction 
CHAPTER 1 


\section{PRINCIPLES OF TISSUE ENGINEERING}

Tissue engineering comprises the process of artificially engineering tissues or organs either in vitro or in vivo by using a biomaterial, which serves as a scaffold to host and/or attract living cells. The combination of these two components (i.e. biomaterial and cells) together with additional external factors results in the formation of new tissue that can replace the diseased tissue in vivo. Using this regenerative engineering approach, substitutes for bone, cartilage, trachea, liver, heart valves and blood vessels can be produced. To prevent rejection of the newly engineered tissue an autologous approach is preferentially used, whereby cells are isolated from the patient's own tissue or blood and subsequently expanded in vitro, to generate sufficient numbers for the final seeding procedure.

Degenerative disorders cause substantial mortality and morbidity, with cardiovascular disease remaining the leading cause of death. ${ }^{1}$ The prevalence of other degenerative diseases like osteoarthritis is rising ${ }^{2-4}$, due to Western life style and diet habits ${ }^{5}$ together with an increase in life expectancy. ${ }^{6}$ Modern therapies for degenerative disorders are not optimal yet as current treatment strategies with prosthetic replacements for joint, vascular and heart valve defects do not offer a life-long solution to patients. Tissue-engineered, living grafts might offer supreme function and improved long-term outcome compared to prosthetic materials. In particular, risk for infection is expected to be much lower as development of a biofilm containing bacteria ${ }^{7,8}$ is less likely to occur on tissue-engineered constructs. Furthermore, in the case of replacements in the circulatory system, thrombotic and stenotic complications could be prevented by using cellularized grafts with anti-thrombogenic and antiimmunologic properties. Besides the therapeutic potential for degenerative disorders, congenital anomalies could also be treated more effectively by viable tissueengineered replacements, as tissue-engineered grafts offer the capacity to grow and adapt to the physical need. Hereby, repeated surgeries that are currently required to implant size-matching devices for children having heart valve defects for example, can be avoided. ${ }^{9}$

The structural basis of tissue-engineered constructs is usually a biodegradable scaffold. The most often used materials for cardiovascular tissue engineering are based on polyglycolic acid (PGA), polylactic acid or polycaprolone ( $P C L$ ) based biodegradable polymers. Decellularized tissues from donors or animal origin can also be applied as a scaffold to seed cells on. After seeding, cells are allowed to proliferate, differentiate and produce extracellular matrix $(E C M)$ during a prolonged culture time in vitro. 
Usually, grafts are placed in a bioreactor to apply mechanical stimuli to the new-grown tissue, like flow, stretch or pressure. Addition of certain growth factors to the culture medium is another approach to provoke cells to gain the desired phenotype. The final shape of the graft is determined by the $3^{D}$ structure of the scaffold used. By employing a cylindrical shape, a vascular graft can be created. In case of vascular tissue engineering, endothelial cells (ECs) will also be seeded on the luminal side of the graft. When the construct has obtained sufficient strength after in vitro culturing, it can be implanted in vivo (Figure 1.1). An alternative technique to this classical in vitro tissue engineering practice comprises in vivo graft formation, by allowing cells to grow around a silicon tube placed intraperitoneally ${ }^{10}$ or by attracting cells to biofunctionalized acellular scaffolds in vivo. ${ }^{11}$

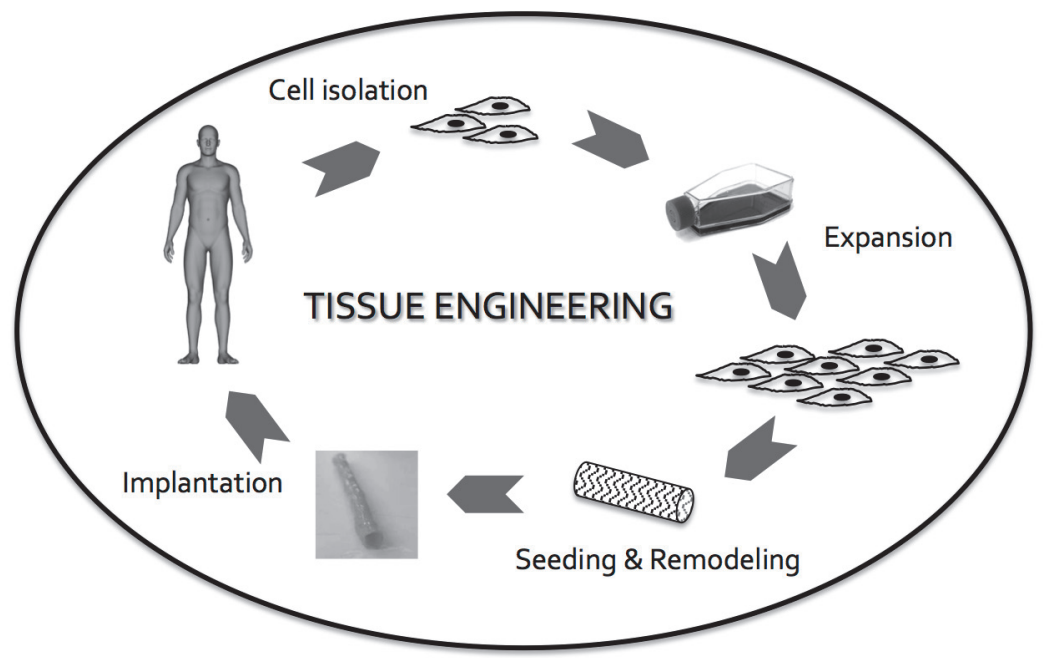

Figure 1.1. Process of tissue engineering. Cells are isolated from a donor, which also serves as the recipient at the end of the process (autologous approach). Cells are expanded in vitro to obtain a sufficient amount for seeding on a biodegradable scaffold. Graft remodeling is induced by using biochemical and mechanical stimuli. When the graft has gained sufficient biomechanical, anti-immunologic and anti-thrombogenic properties, it can be implanted in vivo.

\section{VASCULAR TISSUE ENGINEERING}

Tissue engineering of vascular grafts provides substitutes for diseased blood vessels thereby offering new treatment options to three patient categories (i.e. hemodialysis patients, patients requiring vascular bypasses and children with congenital anomalies). 
Weinberg and Bell were the first showing the concept of vascular tissue engineering by seeding ECs, smooth muscle cells (SMCs) and fibroblasts on layers of collagen integrated with a dacron mesh. ${ }^{12}$ Goal of their research was to avoid the most frequent occurring complications of synthetic materials used for vascular bypass grafting, being stenosis, thrombosis and infection.

Patients with end-stage renal disease who rely on hemodialysis need vascular access. Arteriovenous (AV) fistulas are the preferred type of vascular access but can only be created if patients have patent veins in their extremities with a sufficient diameter $(>2.5 \mathrm{~mm})$ and in the absence of ipsilateral central venous stenosis. ${ }^{13}$ Patients presenting with unsuitable veins for creation of a native $A \bigvee$ fistula are currently treated with prosthetic acellular grafts, which have considerable complication rates due to high risk of infection, thrombosis and development of stenosis. ${ }^{14-16}$ For these patients, tissue-engineered AV shunts could be a solution. Hence, this category is the first patient group for clinical testing of tissue-engineered constructs due to a high failure rate of current therapies. Concurrently, the first clinical trial applying tissue-engineered vascular grafts as an AV shunt has shown the feasibility of this approach, demonstrating results comparable with current prosthetic AV shunts. Follow-up was completed up to 12 months and no adverse events were reported. ${ }^{17}$ Grafts were created using sheet-based tissue engineering. Hereby, skin fibroblasts were grown for 6 weeks after which they formed sheets that were wrapped around a mandrel. ECs were seeded on the luminal side before implantation. ${ }^{18}$

Another group with potential benefit from tissue-engineered vascular grafts consists of patients that need replacement of a vascular circuit because of arterial stenosis or occlusion with clinically evident distal ischemia. The underlying process in stenosed arteries is atherosclerosis, which is characterized by local inflammation of the vessel wall. This will eventually lead to luminal narrowing and finally occlusion or plaque rupture and hemorrhage that can result in a local thrombus and obstruction of the vessel. $^{19}$

Atherosclerosis can manifest in the coronary arteries where a stenosis can lead to angina pectoris. In case of rupture of an atherosclerotic plaque, myocardial infarction can occur. Peripherally located atherosclerosis can manifest in the legs as 'claudication'. This clinical syndrome of peripheral arterial disease is characterized by ischemic pain either during exercise or at rest, and in the latest stadium can involve chronic non-healing ulcers. For treatment of clinically evident atherosclerosis, the common approach is conservative medical treatment with platelet-aggregation inhibitors and lipid-lowering drugs (statins). ${ }^{20,21}$ However, when a stenosis or occlusion 
causes severe ischemia and conservative therapies fail, radiologic and cardiologic interventions can be used to retain sufficient flow through the lumen. Unfortunately, not all lesions can be treated with percutaneous transluminal angioplasty (PTA) or percutaneous coronary interventions $(\mathrm{PCl})$ including stent placement, hence certain patients require invasive bypass surgery. Currently used conduits for bypass surgery are native arteries, veins or prosthetic grafts. Native arteries like the internal mammary artery have excellent outcomes but are usually insufficient in length to cover the need for grafts. Therefore, also venous conduits like the saphenous vein are often used for coronary or peripheral bypass constructions. However, such veins cannot be used in all patients due to pre-existing varicosis or insufficient venous diameter. In case of multiple bypass procedures, patients run out of veins as well.

CABG patients and patients requiring below the knee bypasses are in need of small diameter $(<6 \mathrm{~mm})$ grafts to prevent large diameter differences at the anastomotic site. However, prosthetic small diameter grafts are not available. They come with high thrombotic risks exceeding clinically acceptable levels as a result of the relatively low flow rates. ${ }^{22,23}$ Taken together, there is a rather urgent need for alternatives for venous bypass grafting for these patient groups.

The third category of patients waiting for further development of tissue-engineered vascular grafts consists of children with congenital anomalies who are currently depending on repetitive replacements of grafts during their growth. The first successful clinical application of these kinds of grafts has been reported by Shinoka et al. They implanted tissue-engineered cellularized patches in 42 patients for congenital heart defects and extracardiac total cavopulmonary connections, created from bone marrow-derived cells seeded on biodegradable scaffolds. No graft-related complications occurred during a median follow-up of 16.7 months, and implants showed remodeling over time. ${ }^{9}$

\section{ENDOTHELIUM}

The wall of arteries and veins consists of three layers; an outer layer called the adventitia, which contains fibroblasts and connective tissue; a medial layer with elastin, collagen and circumferentially orientated SMCs that provide contractility and an intimal layer comprising ECs. Between the intima and the media, a basement membrane is present. Depending on the vessel size, an elastic layer called the lamina elastic interna can be present underneath the basal membrane, and an elastica externa 
can be found between the adventitia and the media. The arterial adventitia comprises a vaso vasorum.

The intima consists of the endothelium, a single cell layer on the luminal side, present in every blood vessel in the human body. The endothelium encompasses approximately 60 trillion $\mathrm{ECs}^{24}$ in total, covering a surface area of $350 \mathrm{~m}^{2}{ }^{25}$ This layer primarily serves as an anti-thrombogenic and anti-immunologic cellular coating separating the blood stream from the extravascular compartment. In its resting, quiescent state, inflammatory cells will not pass and platelets will not bind either to this cellular interface. ECs secrete several factors and present receptors for cell-cell and cell-matrix signaling to maintain its quiescent state. Nitric oxide (NO) and prostacyclin $(P G / 2)$ are produced by ECs and prevent platelet adhesion. These substances are also capable of controlling underlying layers of the vessel wall by inducing vasodilation and inhibiting proliferation of SMCs.26-28 Prostacyclin is an eicosanoid produced in ECs from prostaglandin $\mathrm{H}_{2}$ by prostacyclin synthase, and acts through $\mathrm{G}$-protein coupled receptors on ECs, SMCs and platelets.

Nitric oxide is produced intracellularly by ECs amongst others, by the enzyme endothelial nitric oxide synthase (eNOS) by means of conversion of L-arginine to citrulline. It is able to diffuse through the vessel wall into the subendothelial layers where it can bind to soluble guanylate cyclase (sGC), the receptor for NO present in the cytoplasm of SMCs.

sGC is a heterodimer protein consisting of an alpha- and a beta-unit comprising a heme group that in its normal $\mathrm{Fe}^{2+}$ state acts as the binding site for NO. Activation of sGC by NO will lead to conversion of guanosine-5'-triphosphate into cyclic guanosine monophosphate (cGMP). Increased cGMP levels result in SMC relaxation via protein kinase $\mathrm{G}$ activation that reduces intracellular calcium levels. In case of oxidative stress, sGC can become oxidized resulting in an altered redox state $\left(\mathrm{Fe}^{3+}\right)$ and/or loss of the heme group, after which SGC can no longer be activated by NO, also referred to as NO resistance (figure 2). ${ }^{29,30}$ A new group of pharmacologic compounds able to activate oxidized sGC includes BAY 60-2770, which can resemble NO-signaling in NO-resistant SMCs (Figure 1.2). BAY 58-2667 (Cinaciguat), a similar pharmacologic compound, is currently under clinical investigation for the treatment of acute decompensated heart failure. ${ }^{31}$

ECs regulate vascular tone through the secretion of the vasodilators $\mathrm{NO}$ and $\mathrm{PGI}$, and the vasoconstrictive substances endothelin and endothelium-derived hyperpolarizing factor. Vasoconstriction occurs through an increase in SMC intracellular calcium, which activates myosin light chain kinase leading to phosphorylation of the light chain of myosin and, subsequently stimulation of actin-myosin cross bridging, thereby 
shortening the contractile apparatus of the SMCs. Relaxation of SMCs -resulting in vasodilation- takes place when intracellular calcium levels decrease to baseline or by dephosphorylation of the myosin light chain.

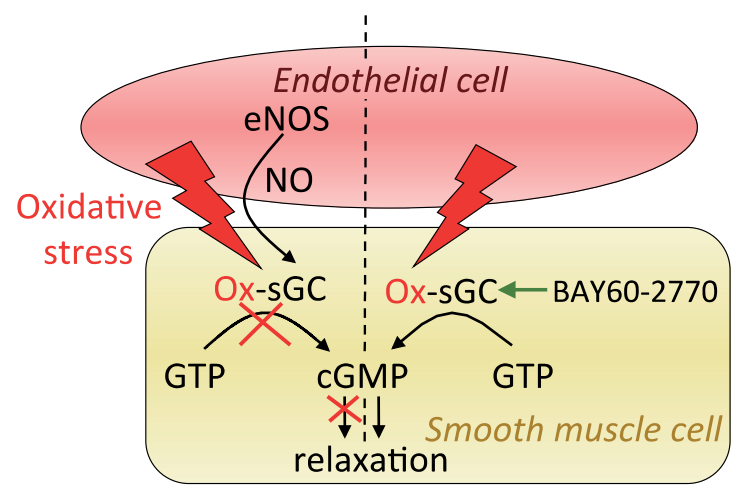

Figure 1.2. Nitric oxide (NO)-resistance. Oxidative stress can oxidize the NO-receptor in smooth muscle cells (SMCs), soluble guanylate cyclase (sGC), leading to an altered redox state and/or loss of the heme group. After NO stimulation, guanosine triphosphate (GTP) is no longer converted into cyclic guanosine monophosphate (cGMP), and relaxation of SMCs, usually a result of increased cGMP levels that activate protein kinases thereby decreasing intracellular calcium, will no longer take place. BAY60-2770 can strongly activate oxidized $\mathrm{sGC}{ }^{29}$

Furthermore, the endothelium displays a barrier function that allows selective transport of molecules and cells between the blood and adjacent tissues. ECs are connected to neighbouring cells by tight junctions, adherens junctions and gap junctions. Specialized proteins and adhesive molecules like occludins and cadherins are anchored to the cytoplasmic/cytoskeletal proteins. Several substances can increase vascular permeability leading to extracellular edema. Histamine, atrial natriuretic factor or thrombin have rapid, temporarily effects while vascular endothelial growth factor (VEGF) has a more sustained influence. ${ }^{32}$

The quiescent status of ECs is regulated by shear stress: the shearing force of blood on the vessel wall that can be sensed by ECs. When the normal, laminar shear stress profile is lost and ECs are exposed to low, non-laminar or highly variable (turbulent) shear stress, they can become activated. ${ }^{33,34}$ Furthermore, inflammatory cytokines like tumor necrosis factor alpha (TNF $\alpha$ ) and interleukin-1 ${ }^{35,36}$, and exposure to cardiovascular risk factors can lead to an activated state of the endothelium, also referred to as 'endothelial dysfunction'. This state is characterized by decreased 
production of $\mathrm{NO}$ and $\mathrm{PG} / 2$, shedding of endothelial microparticles and expression of adhesion molecules on the cellular membrane. ${ }^{37}$ In particular Intercellular adhesion molecule-1 (ICAM-1), vascular cell adhesion molecule-1 (VCAM-1) and P- and Eselectins are important adhesion molecules, which are all able to bind monocytes, resulting in a local inflammatory response. ${ }^{38}$ Expression of these adhesion molecules is the result of activation of the nuclear factor kappa B (NF-KB) pathway. After exposure to cytokines ${ }^{39}$, oxidative stress ${ }^{40,41}$ and exposure to disturbed shear stress ${ }^{42}, \mathrm{NF}-\mathrm{kB}$ is rapidly activated via mitogen-activated protein kinases (MAPKs). NF-KB is a transcription factor present in the cytoplasm that will translocate to the nucleus when it is activated. In the nucleus it can bind to DNA response elements, allowing transcription of specific genes that will eventually affect vascular function (i.e. cell adhesion molecules, cytokines and chemokines).

\section{HEMOSTASIS \& THROMBOSIS}

Hemostasis involves the formation of a blood clot that can prevent blood loss from the circulation upon vessel damage. Injury to the vessel wall and extravasation of blood initiate several events in the blood and in the vessel wall leading to sealing of the breach. ${ }^{43}$ Thrombosis is characterized by the formation of excessive quantities of fibrin, a result of extensive hemostatic activation by pathologic processes. Thrombotic events can result in arterial complications like myocardial infarction and stroke, and venous problems like deep venous thrombosis and pulmonary embolism.

During physiological hemostatic processes, the endothelium needs to be disrupted to allow exposure of collagen and tissue factor (TF) to the circulating blood. Collagen will trigger activation and aggregation of platelets, while TF is able to initiate the coagulation cascade resulting in thrombin generation that converts fibrinogen to fibrin and which can also activate platelets. Platelets express receptors like glycoprotein $\mathrm{VI}$ that interact with collagen and glycoprotein Ib-V-IX, which can be activated by collagen-bound von Willebrand Factor (vWF). ${ }^{43}$ Activation of both receptors results in adherence of platelets to the vessel wall. In presence of thrombin, protease-activated receptor 1 (Par1) gets cleaved, which subsequently, leads to activation of platelets ${ }^{44}$ and the release of serotonin, thromboxane $A_{2}$ and adenosine diphosphate (ADP). ${ }^{45}$ These substances activate other platelets and induce platelet aggregation, thereby amplifying thrombus formation.

Next to platelets, fibrin is another component of the thrombus, which is the final result of activation of the coagulation cascade. Several serine proteases present in plasma 
can be activated in a consecutive cascade of activation steps. TF is constitutively expressed on fibroblasts and SMCs. In the normal resting state, ECs do not express TF. After disruption of the endothelial layer, TF of the underlying SMCs becomes exposed to circulating factor VIla (FVIIa) in the blood stream. The formed TF:FVIla complex subsequently activates factors $I X(F I X)$ and $X(F X)$. FXa is able to form the prothrombinase complex with factor $\mathrm{Va}(\mathrm{FVa})$ and this complex can enzymatically cleave prothrombin leading to formation of thrombin. The pleiotropic effects of thrombin result in conversion of fibrinogen to fibrin, activation of factor XIII -that induces fibrin polymerization-, and activation of factor V (FV), VIII (FVIII) and XI (FXI) (Figure 1.3).

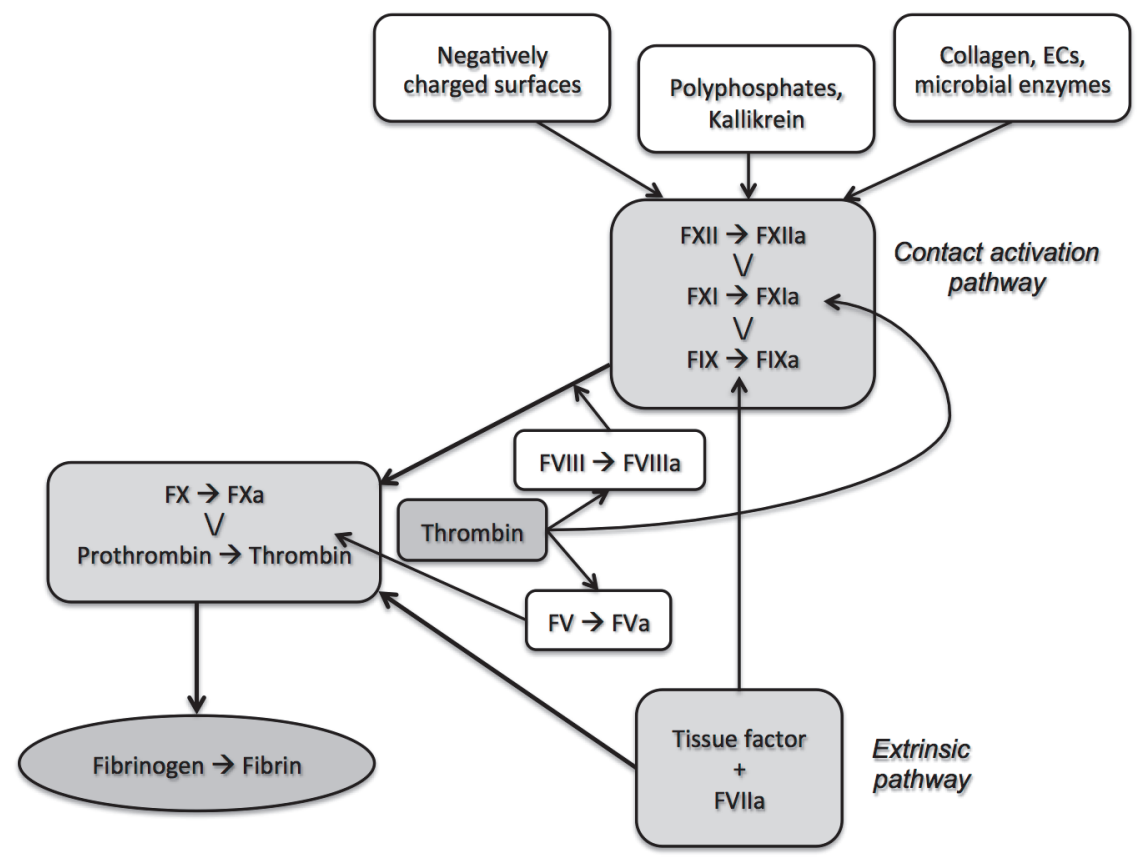

Figure 1.3. Schematic overview of the coagulation cascade. The extrinsic pathway starts with tissue factor (TF) exposure after disruption of the vessel wall, which will form a complex with sparsely present circulating factor VIla (FVIla). This complex activates the common pathway involving factor X (FX), which subsequently activates prothrombin, resulting in small quantities of thrombin. Thrombin then activates factor $\mathrm{V}$ (FVa) which sets an amplification mechanism in motion, activating FX into FXa to generate more thrombin. An alternative substrate of thrombin is factor $\mathrm{XI}(\mathrm{FXI})$, part of the contact activation pathway. FXla can also be activated via factor XIla (FXIla), the first factor in the contact activation pathway that is generated on negatively charged surfaces, collagen, ECs and by polyphosphates, kallikrein or microbial enzymes. FXla then activates factor IX (FIX), followed by factor X activation and thrombin formation. FIX can also be activated via the TF:FVIla pathway. The final result of both pathways is the conversion of fibrinogen to fibrin by thrombin. ${ }^{43,62}$ 
FXI is one of the factors involved in the contact activation pathway, which is the other route of coagulation activation next to the extrinsic pathway comprising TF. The contact activation pathway can be initiated via factor XII (FXII) that is activated by exposure to negatively charged surfaces, by microbial enzymes ${ }^{46}$ or in a proteasedriven way on the endothelium in presence of high molecular weight kininogen. ${ }^{47}$ Both activated FXII and thrombin can activate FXI that will trigger FIX and subsequently FX, thereby reaching the common part of both pathways (Figure 1.3). The relevance of the contact activation pathway is currently under debate, as patients with FXII-deficiency do not have a bleeding phenotype. Yet, this factor might play a role in pathologic thrombus formation, as shown in thrombus formation models in mice. ${ }^{48,49}$

Several inhibitory factors can decrease coagulation activity, like anti-thrombin that inactivates FVIIa, FIXa, FXa, FXla, FXIla and to a greater extent Flla (thrombin). The activated protein $C$ (APC) system involves the activation of protein $C$ by thrombin in combination with two endothelial proteins; thrombomodulin and the endothelial protein $\mathrm{C}$ receptor, with protein S serving as a cofactor. APC inactivates FVa and FVIIIa, thereby limiting coagulation activity.

The concept of pathological thrombosis is based on a disturbance of one of three main factors, also known as Virchow's triad. The triad includes 1) alterations in blood flow, (e.g. venous stasis and turbulence); 2) endothelial injury as a result of disturbed shear stress or trauma; and 3) hypercoagulability of the blood. When a tissue-engineered graft is implanted, it can be assumed that coagulability of the circulating blood will remain the same. Blood flow will change due to altered biomechanical forces, as is the case with venous or prosthetic conduits. The one factor potentially leading to thrombosis that can be influenced in the manufacturing process of a tissue-engineered graft remains the endothelial integrity. This can easily be compromised if ECs are not present or dysfunctional due to donor comorbidity, isolation or culture effects. Assessment of thrombogenicity of ECs is therefore of relevance for tissue engineering of blood vessels.

Thrombosis can be studied in vivo in several thrombotic models in which endothelial injury is induced by ferric chloride ${ }^{50}$ or photochemical injury ${ }^{51}$ leading to clot formation that can be quantified. Application of mechanical trauma ${ }^{52}$ or induction of blood stasis can also be used to initiate venous thrombosis. For studying the process of coagulation in vitro, anticoagulated whole blood can be used ${ }^{53,54}$, or plasma in which thrombin levels ${ }^{55}$ are determined. The calibrated automated thrombogram method allows for continuous monitoring over time of thrombin generation, for which a minimal quantity of platelet-poor plasma is required. ${ }^{56,57}$ In contrast with the large amount of reports on 
coagulation in plasma, the vessel wall component, one of the three factors in Virchow's $\operatorname{triad}^{58}$, is often ignored in hemostatic studies. Campbell showed a limiting effect of ECs on coagulation via the protein C system, but the experiments were performed in presence of corn-trypsin inhibitor (CTI), an inhibitor of the contact activation system. ${ }^{59}$ Other groups used specific stimuli like cytokines to induce a procoagulant state in ECs. ${ }^{33,60,61}$

\section{FROM BENCH TO BEDSIDE}

According to I'Heureux ${ }^{63}$ four criteria should be met by vascular tissue-engineered constructs before successful transition to clinical practice can take place:

- Sufficient burst pressure (>1700 $\mathrm{mmHg}$ )

- Appropriate fatigue resistance (30 days of in vitro cycling under physiological loading without marked dilation)

- Presence of an autologous endothelial layer

- Demonstration of these characteristics using human cells

However, for final application of tissue-engineered vascular grafts in daily clinical practice, several other hurdles should be taken beyond the fulfilling of abovementioned basic criteria. For optimal demonstration of the required characteristics by using human cells, the use of patient-derived cells would give superior proof of principle of the created constructs. Currently, there is a lack of conclusive studies on performance and quality of cells derived from candidates for tissue-engineered therapies. The target population for vascular tissue-engineered grafts consists of older patients usually presenting with several comorbidities and risk factors such as diabetes, hypertension, hyperlipidemia, obesity or smoking history. ${ }^{64,65}$ In particular the CKD patient who is a highly suitable candidate for clinical trials of tissueengineered vascular grafts ${ }^{17}$, has severely compromised general health as a result of renal failure and often a confounding presence of cardiovascular disease. ${ }^{65,66}$ For successful in vitro expansion of cells derived from such diseased patient populations, insight regarding in vitro characteristics and behavior of patient-derived cells is required.

During subculturing in vitro, cells divide many times, resulting in an exponential increase in cell amounts. Cells undergoing many cell divisions are at risk for developing senescence. Senescence is defined by a state of permanent growth arrest in which cells are alive but refractory to mitogenic stimuli. ${ }^{67,68}$ Telomere shortening occurs during every cell division and when a certain threshold is reached, cells go into replicative 
senescence. Ageing is associated with telomere shortening ${ }^{69,70}$ and cells derived from aged subjects possess a higher risk of developing senescence. Senescence in ECs has been associated with reduced cellular function ${ }^{71}$ and pro-atherogenic changes. ${ }^{72,73}$ In contrast with stem cells, which theoretically can divide endlessly, primary cells usually go into senescence after a certain amount of population doublings in vitro ${ }^{74}$, as referred to as the Hayflick limit. This number refers to the amount of cell divisions a cell can undergo before senescence will occur. ${ }^{75}$ Senescence could be a risk factor for primary cells cultured for several passages in vitro leading to diminished expansion rates and possibly a different cellular phenotype.

Besides the detrimental effect of ageing on cellular function and proliferation capacity, exposure to (cardiovascular) risk factors can also be harmful for the performance of isolated cells. Decreased growth rates of ECs from smokers ${ }^{76}$, hyperlipidemic patients ${ }^{77}$ and increased oxidative stress in ECs from older persons ${ }^{78}$ have been reported and could be disadvantageous when the cells of these individuals are used for tissue engineering.

Next to a paucity of reports studying patient-derived cells, only two studies with tissue-engineered vascular constructs have been conducted in patients so far. Except for the studies of Shinoka ${ }^{9}$ and McAllister ${ }^{17}$ all other in vivo studies were limited to animal models. Koch et al. reported successful long-term follow-up of 6 months of vascular grafts seeded with fibroblasts, SMCs and ECs implanted in ovine carotid arteries. ${ }^{79}$ The group of Niklason published several reports on tissue-engineered vascular grafts ${ }^{80,81}$ including data on satisfactory in vivo results in a porcine model. ${ }^{82,83}$ Campbell et al. described an approach that involved intraperitoneally and intrapleurally culturing of vascular grafts in various species (rats, dogs and rabbits), which were implanted respectively in aorta, carotid and femoral arteries. ${ }^{10,84}$ Although large animals are preferred for vascular research, smaller animal models have also been used, offering the advantage of lower costs and the possibility to study a larger number of animals. Nieponice et al. implanted small diameter grafts seeded with muscle-derived stem cells in rat aorta resulting in a higher patency of cell-seeded constructs compared to unseeded controls. ${ }^{85}$ I'Heureux et al. used immunodeficient nude rats, which received grafts made out of human cells that showed long-term stability and absence of thrombosis. ${ }^{18}$

A major drawback of these studies is that all experiments were performed with healthy, young animals. For ultimate proof of principle, usage of older animals and/or disease models should be considered. For evaluation of grafts for the purpose of vascular access, a uremic animal model is needed in which repetitive cannulation of the 
graft should be carried out to resemble the human situation. So far, however, no results on tissue-engineered grafts in animals with renal failure have been published. 


\section{AIMS AND OUTLINE OF THIS THESIS}

The ultimate goal of vascular tissue engineering is to provide an in vitro produced small diameter tubular graft based on a biodegradable scaffold and vascular cells including an endothelial layer, which possesses sufficient strength and comes with nonimmunologic, non-thrombogenic properties, allowing safe implantation in patients. Many efforts in the field of tissue engineering research have been put into in vitro optimization and testing of constructs in animal models but risks and challenges for transition towards clinical application are currently underexposed. Translational research facilitates the translation of findings in basic research into medical practice. In this thesis a translational approach is followed in which several preclinical aspects of vascular tissue engineering are addressed in order to bring clinical application closer.

The following aims were subject of this thesis:

1. To develop a high-throughput assay for assessment of endothelial thrombogenicity.

2. To investigate endothelial cell sources.

3. To investigate performance of endothelial cells derived from the target population for tissue-engineered vascular grafts.

4. To set-up a uremic animal model for testing small-diameter vascular grafts and evaluation of AV shunt function.

5. To evaluate feasibility of tissue-engineered vascular grafts in vivo.

Chapter 2 describes the novel combination of an established method for studying coagulation in vitro, the calibrated automated thrombogram method, together with an EC layer. For reliable measurements of thrombin generation, specific serum-free cell culture conditions were developed. The importance of the contact activation pathway of coagulation in the presence of ECs is demonstrated in this study.

In Chapter 3, arterial and venous ECs are compared for their potential for usage for tissue engineering. Several endothelial functions were evaluated including proliferation, migration, and thrombogenicity.

The assays developed and optimized in the first two chapters were used for the assessment of patient-derived ECs in Chapter 4. ECs from cardiovascular-diseased, patients with end-stage renal disease and control patients were isolated, subcultured and functional outcomes were compared between the three categories.

Chapter 5 comprises data on AV-fistula function in a uremic model in the rat. Oxidative stress in uremic animals appeared to cause NO resistance of SMCs, which could 
hamper AV fistula maturation. Therefore, the effect of BAY 60-2770, a potent activator of the oxidized NO-receptor SGC, on AV fistula function was studied.

Another in vivo model presented in this thesis concerns the evaluation of tissueengineered vascular grafts implanted as carotid interposition grafts in the pig. Results of this feasibility study are described in Chapter 6. 


\section{REFERENCES}

1. The golbal burden of disease: 2004 update. Geneva: World Health Organization; 2008.

2. Helmick CG, Felson DT, Lawrence RC, Gabriel S, Hirsch R, Kwoh CK, et al. Estimates of the prevalence of arthritis and other rheumatic conditions in the United States: Part I. Arthritis Rheum. 2008; 58(1): 15-25.

3. Lawrence RC, Felson DT, Helmick CG, Arnold LM, Choi H, Deyo RA, et al. Estimates of the prevalence of arthritis and other rheumatic conditions in the United States: Part II. Arthritis Rheum. 2008; 58(1): 26-35.

4. Kurtz S, Mowat F, Ong K, Chan N, Lau E, Halpern M. Prevalence of primary and revision total hip and knee arthroplasty in the United States from 1990 through 2002. J Bone Joint Surg Am. 2005; 87(7): 1487-97.

5. Eaton SB, Konner $M$, Shostak $M$. Stone agers in the fast lane: chronic degenerative diseases in evolutionary perspective. Am J Med. 1988; 84(4): 739-49.

6. Leon DA. Trends in European life expectancy: a salutary view. Int J Epidemiol. 2011; 40(2): 271-7.

7. Zimmerli W, Trampuz A, Ochsner PE. Prosthetic-joint infections. N Engl J Med. 2004; 351(16): 164554.

8. Leroy O, Meybeck A, Sarraz-Bournet B, d'Elia P, Legout L. Vascular graft infections. Curr Opin Infect Dis. 2012; 25(2): 154-8.

9. Shin'oka T, Matsumura G, Hibino N, Naito Y, Watanabe M, Konuma T, et al. Midterm clinical result of tissue-engineered vascular autografts seeded with autologous bone marrow cells. J Thorac Cardiovasc Surg. 2005; 129(6): 1330-8.

10. Chue WL, Campbell GR, Caplice N, Muhammed A, Berry CL, Thomas AC, et al. Dog peritoneal and pleural cavities as bioreactors to grow autologous vascular grafts. J Vasc Surg. 2004; 39(4): 859-67.

11. Pratt AB, Weber FE, Schmoekel HG, Müller R, Hubbell JA. Synthetic extracellular matrices for in situ tissue engineering. Biotechnol and Bioeng. 2004; 86(1): 27-36.

12. Weinberg $C B$, Bell E. A blood vessel model constructed from collagen and cultured vascular cells. Science. 1986; 231(4736): 397-400.

13. Clinical practice guidelines for vascular access. Am J Kidney Dis. 2006; 48 Suppl 1: S176-247.

14. Munda R, First MR, Alexander JW, Linnemann CC, Jr., Fidler JP, Kittur D. Polytetrafluoroethylene graft survival in hemodialysis. JAMA. 1983; 249(2): 219-22.

15. Huber TS, Carter JW, Carter RL, Seeger JM. Patency of autogenous and polytetrafluoroethylene upper extremity arteriovenous hemodialysis accesses: a systematic review. J Vasc Surg. 2003; 38(5): 1005-11.

16. Perera GB, Mueller MP, Kubaska SM, Wilson SE, Lawrence PF, Fujitani RM. Superiority of autogenous arteriovenous hemodialysis access: maintenance of function with fewer secondary interventions. Ann Vasc Surg. 2004; 18(1): 66-73.

17. McAllister TN, Maruszewski M, Garrido SA, Wystrychowski W, Dusserre N, Marini A, et al. Effectiveness of haemodialysis access with an autologous tissue-engineered vascular graft: a multicentre cohort study. Lancet. 2009; 373(9673): 1440-6.

18. L'Heureux N, Dusserre N, Konig G, Victor B, Keire P, Wight TN, et al. Human tissue-engineered blood vessels for adult arterial revascularization. Nat Med. 2006; 12(3): 361-5.

19. Ross R. Atherosclerosis - An Inflammatory Disease. N Engl J Med. 1999; 340(2): 115-26.

20. Fraker TD, Fihn SD, Committee WobotCSAW, MEMBERS WC, Gibbons RJ, Abrams J, et al. 2007 Chronic Angina Focused Update of the ACC/AHA 2002 Guidelines for the management of patients with chronic stable angina. Circulation. 2007; 116(23): 2762-72. 
21. Hirsch AT, Haskal ZJ, Hertzer NR, Bakal CW, Creager MA, Halperin JL, et al. ACC/AHA 2005 Practice Guidelines for the management of patients with peripheral arterial disease (lower extremity, renal, mesenteric, and abdominal aortic): a collaborative report from the American Association for Vascular Surgery/Society for Vascular Surgery, Society for Cardiovascular Angiography and Interventions, Society for Vascular Medicine and Biology, Society of Interventional Radiology, and the ACC/AHA Task Force on Practice Guidelines (Writing Committee to Develop Guidelines for the Management of Patients With Peripheral Arterial Disease): endorsed by the American Association of Cardiovascular and Pulmonary Rehabilitation; National Heart, Lung, and Blood Institute; Society for Vascular Nursing; TransAtlantic Inter-Society Consensus; and Vascular Disease Foundation. Circulation. 2006; 113(11): e463-654.

22. Veith FJ, Gupta SK, Ascer E, White-Flores S, Samson RH, Scher LA, et al. Six-year prospective multicenter randomized comparison of autologous saphenous vein and expanded polytetrafluoroethylene grafts in infrainguinal arterial reconstructions. Journal of vascular surgery: official publication, the Society for Vascular Surgery [and] International Society for Cardiovascular Surgery, North American Chapter. 1986; 3(1): 104-14.

23. Sapsford RN, Oakley GD, Talbot S. Early and late patency of expanded polytetrafluoroethylene vascular grafts in aorta-coronary bypass. J Thorax Cardiovasc Surg. 1981; 81(6): 860-4.

24. Aird WC. Spatial and temporal dynamics of the endothelium. J Thromb Haemost. 2005; 3(7): $1392-406$.

25. Pries AR, Secomb TW, Gaehtgens P. The endothelial surface layer. Pflugers Archiv : Eur J Physiol. 2000; 440(5): 653-66.

26. Garg UC, Hassid A. Nitric oxide-generating vasodilators and 8-bromo-cyclic guanosine monophosphate inhibit mitogenesis and proliferation of cultured rat vascular smooth muscle cells. The J Clin Invest. 1989; 83(5): 1774-7.

27. Moncada S, Higgs A. The L-arginine-nitric oxide pathway. N Engl J Med. 1993; 329(27): 2002-12.

28. Fleming I, Bauersachs J, Busse R. Paracrine functions of the coronary vascular endothelium. Mol Cell Biochem. 1996; 157(1-2): 137-45.

29. Stasch J-P, Schmidt PM, Nedvetsky PI, Nedvetskaya TY, H.S AK, Meurer S, et al. Targeting the hemeoxidized nitric oxide receptor for selective vasodilatation of diseased blood vessels. J Clin Invest. 2006; 116(9): 2552-61.

30. Evgenov OV, Pacher P, Schmidt PM, Hasko G, Schmidt HH, Stasch JP. NO-independent stimulators and activators of soluble guanylate cyclase: discovery and therapeutic potential. Nat Rev Drug Discov. 2006; 5(9): 755-68.

31. Lapp H, Mitrovic V, Franz N, Heuer H, Buerke M, Wolfertz J, et al. Cinaciguat (BAY 58,Äi2667) improves cardiopulmonary hemodynamics in patients with acute decompensated heart failure. Circulation. 2009; 119(21): 2781-8.

32. Michiels C. Endothelial cell functions. J Cell Physiol. 2003; 196(3): 430-43.

33. Mazzolai L, Silacci P, Bouzourene K, Daniel F, Brunner H, Hayoz D. Tissue factor activity is upregulated in human endothelial cells exposed to oscillatory shear stress. Thromb Haemost. 2002; 87(6): 1062-8.

34. Houston P, Dickson MC, Ludbrook V, White B, Schwachtgen J-L, McVey JH, et al. Fluid shear stress induction of the tissue factor promoter in vitro and in vivo is mediated by Egr-1. Arterioscler Thromb Vac Biol. 1999; 19(2): 281-9.

35. Bevilacqua MP, Pober JS, Majeau GR, Cotran RS, Gimbrone MA, Jr. Interleukin 1 (IL-1) induces biosynthesis and cell surface expression of procoagulant activity in human vascular endothelial cells. J Exp Med. 1984; 160(2): 618-23.

36. Pober JS, Gimbrone MA, Lapierre LA, Mendrick DL, Fiers W, Rothlein R, et al. Overlapping patterns of activation of human endothelial cells by interleukin 1, tumor necrosis factor, and immune interferon. J Immunol. 1986; 137(6): 1893-6.

37. Szmitko PE, Wang C-H, Weisel RD, de Almeida JR, Anderson TJ, Verma S. New markers of inflammation and endothelial cell activation. Circulation. 2003; 108(16): 1917-23.

38. Ross R. Atherosclerosis is an inflammatory disease. Am Heart J. 1999; 138(5 Pt 2): S419-20.

39. Collins T, Read MA, Neish AS, Whitley MZ, Thanos D, Maniatis T. Transcriptional regulation of endothelial cell adhesion molecules: NF-kappa B and cytokine-inducible enhancers. FASEB J. 1995; 9(10): 899-909. 
40. Marui N, Offermann MK, Swerlick R, Kunsch C, Rosen CA, Ahmad M, et al. Vascular cell adhesion molecule-1 (VCAM-1) gene transcription and expression are regulated through an antioxidantsensitive mechanism in human vascular endothelial cells. J Clin Invest. 1993; 92(4): 1866-74.

41. Weber C, Erl W, Pietsch A, Strobel M, Ziegler-Heitbrock HW, Weber PC. Antioxidants inhibit monocyte adhesion by suppressing nuclear factor-kappa B mobilization and induction of vascular cell adhesion molecule-1 in endothelial cells stimulated to generate radicals. Arterioscler Thromb. 1994; 14(10): 1665-73.

42. Khachigian LM, Resnick N, Gimbrone MA, Jr., Collins T. Nuclear factor-kappa B interacts functionally with the platelet-derived growth factor $B$-chain shear-stress response element in vascular endothelial cells exposed to fluid shear stress. J Clin Invest. 1995; 96(2): 1169-75.

43. Furie B, Furie BC. Mechanisms of Thrombus Formation. N Engl J Med. 2008; 359(9): 938-49.

44. Vu TK, Hung DT, Wheaton VI, Coughlin SR. Molecular cloning of a functional thrombin receptor reveals a novel proteolytic mechanism of receptor activation. Cell. 1991; 64(6): 1057-68.

45. Coughlin SR. Thrombin signalling and protease-activated receptors. Nature. 2000; 407(6801): 258-64.

46. Kaminishi H, Hamatake H, Cho T, Tamaki T, Suenaga N, Fujii T, et al. Activation of blood clotting factors by microbial proteinases. FEMS Microbiol Lett. 1994; 121(3): 327-32.

47. Reddigari SR, Shibayama Y, Brunnee T, Kaplan AP. Human Hageman factor (factor XII) and high molecular weight kininogen compete for the same binding site on human umbilical vein endothelial cells. J Biol Chem. 1993; 268(16): 11982-7.

48. Renné T, Pozgajova M, Gruner S, Schuh K, Pauer HU, Burfeind P, et al. Defective thrombus formation in mice lacking coagulation factor XII. J Exp Med. 2005; 202(2): 271-81.

49. Hagedorn I, Schmidbauer S, Pleines I, Kleinschnitz C, Kronthaler U, Stoll G, et al. Factor XIla inhibitor recombinant human albumin infestin-4 abolishes occlusive arterial thrombus formation without affecting bleeding. Circulation. 2010; 121(13): 1510-7.

50. Kurz KD, Main BW, Sandusky GE. Rat model of arterial thrombosis induced by ferric chloride. Thromb Res. 1990; 6o(4): 269-8o.

51. Matsuno H, Uematsu T, Nagashima S, Nakashima M. Photochemically induced thrombosis model in rat femoral artery and evaluation of effects of heparin and tissue-type plasminogen activator with use of this model. J Pharmacol Methods. 1991; 25(4): 303-17.

52. Pierangeli SS, Barker JH, Stikovac D, Ackerman D, Anderson G, Barquinero J, et al. Effect of human IgG antiphospholipid antibodies on an in vivo thrombosis model in mice. Thromb Haemost. 1994; 71(5): 670-4.

53. Mc KD, Shapiro SS, Shanberge JN. Alterations in the blood coagulation system induced by bacterial endotoxins. II. In vitro. J Exp Med; 107(3): 369-76.

54. Chavez JJ, Foley DE, Snider CC, Howell JC, Cohen E, Muenchen RA, et al. A novel thrombelastograph tissue factor/kaolin assay of activated clotting times for monitoring heparin anticoagulation during cardiopulmonary bypass. Anesth Analg. 2004; 99(5): 1290-4.

55. Beguin S, Lindhout $\mathrm{T}$, Hemker HC. The effect of trace amounts of tissue factor on thrombin generation in platelet rich plasma, its inhibition by heparin. Thromb Haemost. 1989; 61(1): 25-9.

56. Hemker HC, Giesen P, AlDieri R, Regnault V, de Smed E, Wagenvoord R, et al. The calibrated automated thrombogram (CAT): a universal routine test for hyper- and hypocoagulability. Pathophysiol Haemost Thromb. 2002; 32(5-6): 249-53.

57. Hemker HC, Wielders S, Kessels H, Beguin S. Continuous registration of thrombin generation in plasma, its use for the determination of the thrombin potential. Thromb Haemost. 1993; 70(4): 617-24.

58. Virchow R. Gesammelte Abhandlungen zur wissenschaftlichen Medicin. Frankfurt a. M.: Meidinger; 1856.

59. Campbell JE, Brummel-Ziedins KE, Butenas S, Mann KG. Cellular regulation of blood coagulation: a model for venous stasis. Blood. 2010; 116(26): 6082-91.

6o. Bevilacqua MP, Pober JS, Majeau GR, Fiers W, Cotran RS, Gimbrone MA, Jr. Recombinant tumor necrosis factor induces procoagulant activity in cultured human vascular endothelium: characterization and comparison with the actions of interleukin 1. Proc Natl Acad Sci U S A. 1986; 83(12): 4533-7. 
61. Nawroth PP, Stern DM. Modulation of endothelial cell hemostatic properties by tumor necrosis factor. J Exp Med. 1986; 163(3): 740-5.

62. Borissoff Jl, Spronk HM, ten Cate H. The hemostatic system as a modulator of atherosclerosis. New Eng J Med. 2011; 364(18): 1746-6o.

63. L'Heureux N, Dusserre N, Marini A, Garrido S, de la Fuente L, McAllister T. Technology insight: the evolution of tissue-engineered vascular grafts--from research to clinical practice. Nat Clin Pract Cardiovasc Med. 2007; 4(7): 389-95.

64. Conte MS, Belkin M, Upchurch GR, Mannick JA, Whittemore AD, Donaldson MC. Impact of increasing comorbidity on infrainguinal reconstruction: a 20-year perspective. Ann Surg. 2001; 233(3): 445-52.

65. Cheung AK, Sarnak MJ, Yan G, Dwyer JT, Heyka RJ, Rocco MV, et al. Atherosclerotic cardiovascular disease risks in chronic hemodialysis patients. Kidney Int. 2000; 58(1): 353-62.

66. Himmelfarb J, Stenvinkel P, Ikizler TA, Hakim RM. The elephant in uremia: Oxidant stress as a unifying concept of cardiovascular disease in uremia. Kidney Int. 2002; 62(5): 1524-38.

67. Ben-Porath I, Weinberg RA. The signals and pathways activating cellular senescence. Int J Biochem Cell Bio. 2005; 37(5): 961-76.

68. Chen J, Goligorsky MS. Premature senescence of endothelial cells: Methusaleh's dilemma. Am J Physiol Heart Circ Physiol. 2006; 290(5): H1729-39.

69. Chang E, Harley CB. Telomere length and replicative aging in human vascular tissues. Proc Natl Acad Sci U S A. 1995; 92(24): 11190-4.

70. Slagboom PE, Droog S, Boomsma DI. Genetic determination of telomere size in humans: a twin study of three age groups. Am J Hum Genet. 1994; 55(5): 876-82.

71. Benetos A, Okuda K, Lajemi M, Kimura M, Thomas F, Skurnick J, et al. Telomere length as an indicator of biological aging: the gender effect and relation with pulse pressure and pulse wave velocity. Hypertension. 2001; 37(2 Part 2): 381-5.

72. Serrano AL, Andres V. Telomeres and cardiovascular disease: does size matter? Circ Res. 2004; 94(5): 575-84.

73. Edo MD, Andres V. Aging, telomeres, and atherosclerosis. Cardiovas Res. 2005; 66(2): 213-21.

74. Wagner M, Hampel B, Bernhard D, Hala M, Zwerschke W, Jansen-Durr P. Replicative senescence of human endothelial cells in vitro involves $\mathrm{G}_{1}$ arrest, polyploidization and senescence-associated apoptosis. Exp Gerontol. 2001; 36(8): 1327-47.

75. Hayflick L, Moorhead PS. The serial cultivation of human diploid cell strains. Exp Cell Res. 1961; 25: 585-621.

76. Zilla P, Siedler S, Fasol R, Sharefkin JB. Reduced reproductive capacity of freshly harvested endothelial cells in smokers: a possible shortcoming in the success of seeding? J Vasc Surg. 1989; 10(2): 143-8.

77. Meinhart J, Halbmayer W-M, Deutsch M, Zilla P. Hyperlipidemia coincides with reversible growth impairment of cultured human autologous endothelial cells. Endothelium.. 2002; 9(4): 239 - 46.

78. Donato AJ, Eskurza I, Silver AE, Levy AS, Pierce GL, Gates PE, et al. Direct evidence of endothelial oxidative stress with aging in humans. Circ Res. 2007; 100(11): 1659-66.

79. Koch S, Flanagan TC, Sachweh JS, Tanios F, Schnoering H, Deichmann T, et al. Fibrin-polylactidebased tissue-engineered vascular graft in the arterial circulation. Biomaterials. 31(17): 4731-9.

8o. Gong Z, Niklason LE. Small-diameter human vessel wall engineered from bone marrow-derived mesenchymal stem cells (hMSCs). FASEB J. 2008; 22(6): 1635-48.

81. Poh M, Boyer M, Solan A, Dahl SL, Pedrotty D, Banik SS, et al. Blood vessels engineered from human cells. Lancet. 2005; 365(9477): 2122-4.

82. Niklason LE, Gao J, Abbott WM, Hirschi KK, Houser S, Marini R, et al. Functional arteries grown in vitro. Science. 1999; 284(5413): 489-93.

83. Quint C, Kondo Y, Manson RJ, Lawson JH, Dardik A, Niklason LE. Decellularized tissue-engineered blood vessel as an arterial conduit. Proc Natl Acad Sci USA 2011; 108(22): 9214-9.

84. Campbell JH, Efendy JL, Campbell GR. Novel vascular graft grown within recipient's own peritoneal cavity. Circ Res. 1999; 85(12): 1173-8.

85. Nieponice A, Soletti L, Guan J, Hong Y, Gharaibeh B, Maul TM, et al. In vivo assessment of a tissueengineered vascular graft combining a biodegradable elastomeric scaffold and muscle-derived stem cells in a rat model. Tissue Eng Part A. 2010; 16(4): 1215-23. 


\section{CHAPTER 2}

\section{Coagulation on Endothelial Cells; the Underexposed Part of Virchow's Triad}

Irma LA Geenen IL, Mark J Post, Daniel GM Molin, Geert Willem H Schurink, Jos G Maessen, Rene van Oerle, Hugo Ten Cate, Henri M Spronk

Thrombosis and Haemostasis. 2012;108:863-871 


\section{ABSTRACT}

The process of thrombin generation involves numerous plasma proteases and cofactors. Interaction with the vessel wall, in particular endothelial cells (ECs), influences this process but data on this interaction is limited. We evaluated thrombin generation on EA.hy926, human coronary arterial ECS (HCAECs) and patient-derived human venous ECS (HVECS) by means of a modified calibrated automated thrombogram (mCAT) method and especially looked into contribution of the intrinsic and extrinsic pathways.

Thrombin generation was measured in presence of confluent ECs with normal pooled and factor XII-deficient (FXII- deficient) platelet-poor plasma, with/without active site inhibited factor VIla (ASIS) to block the extrinsic pathway and corn trypsin inhibitor for blocking contact activation (intrinsic pathway). Fetal bovine serum (FBS) was removed from culture conditions as FXIla from the serum retained on ECs apparently, thereby inducing strong contact activation. In serum-free conditions, EA.hy926 and patientderived HVECs induced thrombin generation mainly via the contact activation pathway with minor influence of ASIS on peak height and very low thrombin generation curves in FXII-deficient plasma.

HVECs derived from coronary arterial bypass graft (CABG) patients showed increased thrombin generation compared to control patients, which could be ascribed to increased contact activation. Contribution of the extrinsic pathway on patient-derived ECs was limited.

We conclude that the mCAT method in combination with serum-free cultured ECs offers a valuable high-throughput method to evaluate endothelial influences on thrombin generation, which appears to involve predominantly contact activation on ECs. Contact activation-mediated thrombin generation was increased on ECs from CABG patients compared to controls. 


\section{INTRODUCTION}

Thrombin generation is the result of step-wise activation of several serine proteases, which ultimately leads to conversion of fibrinogen to fibrin. ${ }^{1}$ Formation of a fibrin clot is important for hemostasis in order to prevent blood loss from injured vessels, though under pathological conditions it can also result in arterial thrombus formation in atherosclerotic disease or massive venous thrombosis. Most coagulation factors involved in thrombin generation are tightly regulated plasma proteases and cofactors. Besides these circulating factors, the vessel wall also plays a role in thrombin generation, and can both initiate and inhibit the coagulation cascade. ${ }^{2}$ Disruption of the vessel wall results in exposure of TF to blood, enabling activation of the extrinsic pathway of coagulation. ${ }^{1}$ Activated endothelial cells (ECs) can also express $\mathrm{TF}^{3-5}$, which results in a procoagulant state that is in contrast with the natural resting, anticoagulant state of the endothelium.

The intrinsic pathway, or contact activation, is considered to be irrelevant for thrombin generation in vivo, as factor XII (FXII) deficiency does not lead to a bleeding phenotype despite prolonged activated partial thromboplastin time (aPTT) clotting times. ${ }^{6}$ However, recent data in mice deem FXII critical for clot structure and stability and in baboons, inhibition of FXII reduced platelet-rich thrombus growth. ${ }^{7-9}$ Therefore, FXIla has been suggested a potential therapeutic target of antithrombotic treatment. ${ }^{10} \mathrm{FXII}$ can be activated upon exposure to negatively charged surfaces such as glass or kaolin. Recently, it has been postulated that activation in vivo also occurs on polyphosphates released from activated platelets ${ }^{11}$, on collagen ${ }^{12}$ and on ECs via binding sites of FXII and high molecular weight kininogen $(\mathrm{HK}) .^{13,14}$

A few studies have looked into endothelial contribution to thrombin generation, but contact activation on ECs has been neglected so far. In the three studies of thrombin generation in the presence of ECs either corn trypsin inhibitor (CTI) $)^{15,16}$ or plasma deficient in several coagulation factors ${ }^{17}$ were used to eliminate the intrinsic pathway. The aim of this study was to investigate the initiation and inhibition of thrombin generation by ECs with special attention to contact activation. The modified calibrated automated thrombogram (mCAT) method was used to measure thrombin generation on a confluent layer of ECs. To this purpose we used EA.hyg2 6 cells as these ECs are considered to exhibit a more stable and physiological phenotype compared to primary in vitro cultured $\mathrm{ECs} .{ }^{16,18,19}$ Results were verified using human coronary arterial endothelial cells (HCAECs) and finally, the assay was applied to analyze the thrombogenic capacity of patient-derived primary ECs and which was compared with 
ECs from control subjects. By adding FXII-deficient plasma instead of normal pooled (NP) plasma and by blocking FVIla with active site inactivated FVIIa (ASIS) we were able to elucidate the role of contact activation. The influence of the endothelium on contact activation can be important for the recent interest in therapeutic options for inhibitors of the intrinsic pathway in the treatment and (secondary) prevention of thromboembolic disorders.

\section{MATERIALS AND METHODS}

\section{CELL CULTURE}

EA.hy926 cells were obtained from LGC Standards GmbH (Wesel, Germany) and cultured in DMEM with 10\%FBS (Lonza, Basel, Switzerland) according to the protocol of the manufacturer. For serum-free conditions, Human Endothelial serum-free medium (SFM) (Life Technologies Europe BV, Bleiswijk, Netherlands) was used for 2 passages supplemented with $1 \%$ FBS, as cells did not survive in $100 \%$ SFM. Cells were seeded for the mCAT assay in SFM with addition of heat inactivated (30 minutes at $56^{\circ} \mathrm{C}$ ) $5 \%$ human FXIl-deficient plasma instead of FBS. HCAECs (Lonza, Basel, Switzerland) were cultured in EBM2-medium supplemented with the EGM-2-MV bullet kit including 5\%FBS (Lonza). Cells were used in passage 5-7. Two days before application of the thrombin generation assay (CAT), cells were seeded in 96-wells plates (Greiner Bio-One, Alphen a/d Rijn, The Netherlands) with a high seeding density $(>90 \%)$ in order to create a confluent layer and were starved overnight.

\section{PATIENT-DERIVED ENDOTHELIAL CELLS}

Human venous ECs (HVECs) were isolated from small venous biopsies $(>1 \mathrm{~cm}$ ) of patients undergoing coronary artery bypass grafting (CABG) $(n=10)$. Kidney donors or patients undergoing inguinal hernia repair without a history of cardiovascular disease served as control subjects $(n=10)$. The study protocol was approved by the Institutional Review Board of the Maastricht University Medical Center and patients signed informed consent prior to inclusion in the study. Patient characteristics, cardiovascular risk factors and relevant medical history were collected from medical records.

Samples were collected in the operating theatre and transferred to Dulbecco's Modified Eagle Medium (DMEM) with penicillin/streptomycin for transport to the laboratory. ECs were isolated by means of collagenase digestion the same day. Vessels were filled with collagenase type $\mathrm{I}(0.1 \%)$ in DMEM/BSA $0.1 \%$ and incubated for 
15 minutes at $37^{\circ} \mathrm{C}$. Then, vessels were flushed with DMEM/FBS 10\% (Lonza, Basel, Switzerland) and the solution containing cells was centrifugated at $220 \mathrm{~g}$ for 5 minutes. Cells were resuspended and cultured in fibronectin $(10 \mu \mathrm{g} / \mathrm{mL})$ coated 12 -wells plates in EBM2-medium supplemented with the EGM-2-MV bullet kit (Lonza) at $37^{\circ} \mathrm{C} / 5 \% \mathrm{CO} 2$. When cells reached confluence, cells were trypsinized and cultured until cryo-freezing. Cells were cultured again for one passage before application of the thrombin generation assay (mCAT) and seeded in 96-well plates with a seeding density of 50,000 cells $/ \mathrm{cm}^{2}$ in normal EC medium, supplemented with $5 \%$ human FXII-deficient plasma instead of FBS. Thrombin generation assays (mCAT) were performed with cells from passage $3-5$.

\section{MODIFIED CALIBRATED AUTOMATED THROMBOGRAM (MCAT)}

Thrombin generation on ECs in human platelet-poor plasma was measured by means of the calibrated automated thrombogram (CAT) method (Thrombinoscope BV, Maastricht, The Netherlands), which employs a low affinity fluorogenic substrate for thrombin (Z-Gly-Gly-Arg-AMC) to continuously monitor thrombin activity in clotting plasma. Before start of the assay, cells were washed with warmed HEPES buffer. According to the instructions (internal SOP), measurements were conducted in $80 \mu \mathrm{l}$ human platelet-poor normal pooled plasma (NP), human factor XII deficient (FXIIdeficient) or factor XI deficient (FXI-deficient) plasma (volunteers, Maastricht University), in a total volume of $120 \mu \mathrm{l}$. To the $80 \mu \mathrm{l}$ plasma sample, $20 \mu \mathrm{L}$ trigger reagent (o pM TF, $24 \mu \mathrm{M}$ phospholipids at 20:20:60 mol\% PS:PE:PC) was added. After 10 minutes incubation at $37^{\circ} \mathrm{C}, 20 \mu \mathrm{FluCa}$ (fluorogenic substrate and calcium chloride) was added to start recording of the thrombin generation. Recombinant active site inhibited factor VIla (ASIS; kindly provided by L.C. Petersen, Health Care Discovery, Novo Nordisk A/S, Måløv and Bagsværd, Denmark) was added to a final concentration of $30 \mathrm{nM}$ and corn trypsin inhibitor (CTl; Haematologic Technologies Inc., Essex Junction, VT, US) was applied at a reaction concentration of $25 \mu \mathrm{g} / \mathrm{ml}$.

To correct for inner-filter effects and substrate consumption, each thrombin generation measurement was calibrated against the fluorescence curve obtained in a sample from the same plasma $(80 \mu \mathrm{l})$, added with a fixed amount of thrombin- $\alpha 2-$ macroglobulin complex ( $20 \mu \mathrm{l}$ Thrombin Calibrator, Thrombinoscope BV) and $20 \mu \mathrm{l}$ FluCa. Fluorescence was read in a Fluoroskan Ascent reader (Thermo Labsystems OY, Helsinki, Finland) equipped with a 390/460 filter set and thrombin generation curves were calculated with the Thrombinoscope software (Thrombinoscope BV). Three parameters were derived from the thrombin generation curves: lag time (initiation 
phase of coagulation), peak height, and endogenous thrombin potential (ETP; area under the thrombin generation curve).

\section{TF-ACTIVITY}

TF-activity in EC homogenates was determined in quadruplicate using a home-made activity assay. ${ }^{20}$ In brief, dissolved cell homogenates with a concentration of $5 \mathrm{mg} / \mathrm{ml}$ total protein were diluted 160 times in HN-buffer. Samples were incubated for 10 minutes at $37^{\circ} \mathrm{C}$ in the presence of activated recombinant FVII (rFVIIa) (Novo Nordisk, Bagsværd, Denmark), 0.2 mM 20/80 PS/PC vesicles, 1 U/ml Bovine FX (Sigma-Aldrich) and $100 \mathrm{mM} \mathrm{Ca}^{2+}$. The formation of $\mathrm{FXa}$ was then measured kinetically using the chromogenic substrate 2765 (Chromogenix, final concentration of $0.7 \mathrm{mg} / \mathrm{ml}$ diluted in $50 \mathrm{mM}$ Tris- $\mathrm{HCl}, 175 \mathrm{nM} \mathrm{NaCl}, 30 \mathrm{mM} \mathrm{Na} 2 \mathrm{EDTA}, \mathrm{pH} 7.4$ ) by measuring the OD at $405 \mathrm{~nm}$ each 15 seconds, for 15 minutes at $37^{\circ} \mathrm{C}$.

\section{STATISTICAL ANALYSIS}

All data are expressed as mean \pm SD. Data were analyzed with Prism $5.0 \mathrm{c}$ for Mac (GraphPad Software, San Diego, CA, USA) and Microsoft Excel for Mac 2011. Pair wise comparisons were performed by Student $t$-test and the Mann-Whitney- $U$ test was used when data were not normally distributed. $P$-values $<0.05$ were considered significant.

\section{RESULTS}

\section{COAGULATION ON EA.HY926 CELLS IS MAINLY INITIATED VIA CONTACT ACTIVATION}

Thrombin generation in normal pooled plasma (NP) was triggered by and evaluated in the presence of ECs. Cells were cultured until confluence and starved overnight where after thrombin generation was assessed with the mCAT assay. Through application of different types of human plasma, as well as specific blockers for FXIla and TF:fVIla, specific parts of the coagulation cascade could be analyzed. Normal pooled plasma was added to EA.hyg26 with and without addition of ASIS to inhibit the extrinsic pathway and with/without CTI to block contact activation. Although the lag time in the presence of ASIS significantly prolonged suggesting some TF-activity, this activity was not sufficient to induce thrombin generation when contact activation was blocked by $\mathrm{CTI}$ (Figure 2.1A). Addition of $\mathrm{CTI}$ resulted in complete inhibition of thrombin 
generation, which suggests that activation of coagulation by EA.hyg26 was FXIIdependent.

To elucidate the initiation of contact activation on EA.hy926, FXII-deficient plasma was used instead of normal pooled plasma. Thrombin generation curves obtained in FXIIdeficient plasma were characterized by lag times comparable to normal pooled plasma and inhibition of the TF pathway by ASIS had almost no influence on initiation of thrombin generation. In presence of $\mathrm{CTI}$, however, no thrombin generation occurred (Figure 2.1B). Overall, the generation of thrombin on EA.hy926 in FXII-deficient plasma in presence of ASIS suggests an additional source of FXII. To ensure that activation of coagulation involves the classic contact pathway upon FXI activation by FXIla, experiments were repeated with FXI-deficient plasma. As expected, no thrombin was generated (Figure 2.1C), confirming that plasma-derived FXI is essential for endothelial-mediated contact activation.

We further pursued a potential additional source of FXII in the setup. Despite cell starvation in DMEM/0.5\% FBS prior to the CAT, culture conditions could have influenced contact activation as FBS-derived FXII can adsorb to ECs. ${ }^{21}$ Thrombin generation in presence of freshly trypsinized cells showed indeed absence of contact activation in FXII-deficient plasma in presence of ASIS (Figure 2.1D). Therefore, EA.hyg26 were cultured in serum-free conditions and thrombin generation analyses were repeated. FBS was completely removed from the culture medium as even very low amounts (1\%) resulted in persistent thrombin generation in FXII-deficient plasma with ASIS (data not shown). To replace FBS, human FXII-deficient plasma (5\%) was added to the culture medium, which did not affect endothelial morphology (Figure 2.1E). As shown in Figure 2.1F, cells cultured under these conditions did not induce thrombin generation in FXII-deficient plasma. In normal pooled plasma, thrombin generation curves were characterized by lower peaks and longer lag times compared to FBS-culture conditions. Addition of ASIS significantly prolonged the lag time suggesting TF-activity on the cells. Contact activation contributed appreciably to thrombin generation as addition of CTI to normal pooled plasma containing ASIS, prolonged the lag time and both reduced peak height and ETP. Thrombin generation curves in FXII-deficient plasma represent extrinsic activation, which appeared to be rather low with a significant decreased peak height compared to normal pooled plasma. As expected, ECs failed to induce thrombin generation in FXII-deficient plasma in the presence of ASIS, excluding the possibility of thrombin generation by mechanisms other than the extrinsic and intrinsic pathway (Figure 2.1F). We further confirmed by RT-qPCR that EA.hy926 did not express FXII with liver tissue serving as positive control (data not shown), so we concluded that for cells cultured in FBS 
containing medium FXII from FBS was responsible for the observed thrombin generation in FXII-deficient plasma in the presence of ASIS (Figure 2.1B).

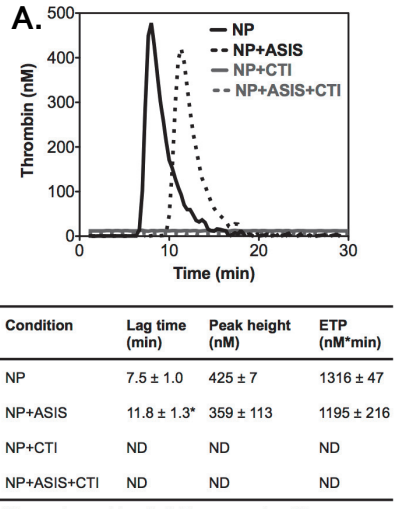

$\mathrm{ND}=$ not detectable, ${ }^{*} P<0.01$ compared to $\mathrm{NP}$

D.

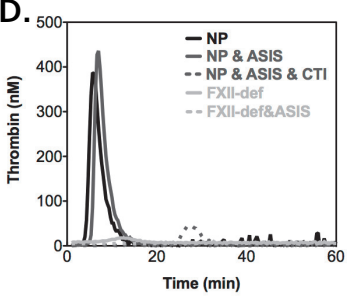

\begin{tabular}{llll}
\hline Condition & $\begin{array}{l}\text { Lag time } \\
(\mathrm{min})\end{array}$ & $\begin{array}{l}\text { Peak height } \\
(\mathrm{nM})\end{array}$ & $\begin{array}{l}\mathrm{ETP} \\
(\mathrm{nM} \text { min })\end{array}$ \\
\hline $\mathrm{NP}$ & $4.1 \pm 0.4$ & $389 \pm 13$ & $1340 \pm 15$ \\
$\mathrm{NP}+\mathrm{ASIS}$ & $5.2 \pm 0.2^{*}$ & $428 \pm 2^{*}$ & $1384 \pm 5^{*}$ \\
$\mathrm{NP}+\mathrm{ASIS}+\mathrm{CTI}$ & $27.1 \pm 4.3^{\dagger}$ & $40 \pm 4^{\dagger}$ & $244 \pm 17^{\dagger}$ \\
FXII-def & $5.8 \pm 0.2^{\ddagger}$ & $10 \pm 1^{\ddagger}$ & $81 \pm 4^{\ddagger}$ \\
FXII-def+ASIS & $\mathrm{ND}$ & $\mathrm{ND}$ & $\mathrm{ND}$ \\
\hline
\end{tabular}

${ }^{*} P<0.05$ vs. without $A S I S,{ }^{+} P<0.01$ vs. without $C T 1$, ${ }^{*} P<0.01$ vs NP
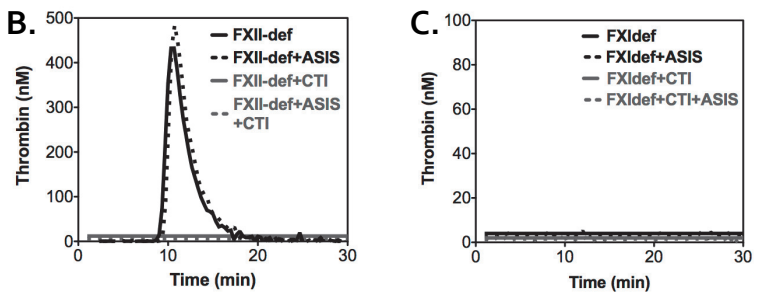

\begin{tabular}{llll}
\hline Condition & $\begin{array}{l}\text { Lag time } \\
(\mathbf{m i n})\end{array}$ & $\begin{array}{l}\text { Peak height } \\
(\mathrm{nM})\end{array}$ & $\begin{array}{l}\text { ETP } \\
(\mathbf{n M} \text { min) }\end{array}$ \\
\hline FXII-def & $12 \pm 3$ & $397 \pm 37$ & $1321 \pm 119$ \\
FXII-def+ASIS & $11 \pm 2$ & $423 \pm 21$ & $1387 \pm 40$ \\
FXII-def+CTI & ND & ND & ND \\
FXIIdef+ASIS+CTI & ND & ND & ND \\
\hline ND $=$ not detectable & & &
\end{tabular}

E.
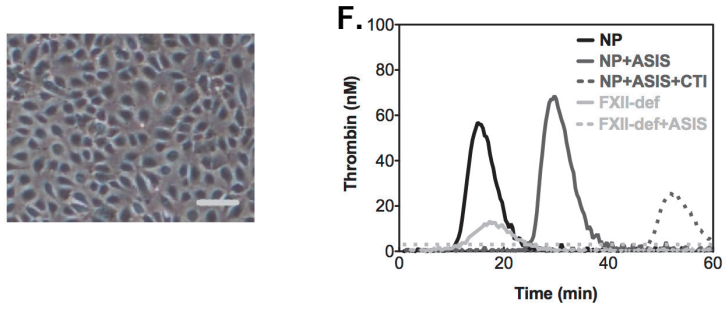

\begin{tabular}{llll}
\hline Condition & $\begin{array}{l}\text { Lag time } \\
(\mathrm{min})\end{array}$ & $\begin{array}{l}\text { Peak height } \\
(\mathrm{nM})\end{array}$ & $\begin{array}{l}\text { ETP } \\
\left(\mathrm{nM}^{*} \mathrm{~min}\right)\end{array}$ \\
\hline $\mathrm{NP}$ & $10.4 \pm 3.1$ & $56 \pm 28$ & $386 \pm 163$ \\
$\mathrm{NP}+$ ASIS & $21.6 \pm 4.8^{*}$ & $76 \pm 21$ & $506 \pm 111$ \\
NP+ASIS+CTI & $47.1 \pm 11^{\dagger}$ & $33 \pm 20^{\dagger}$ & $265 \pm 138^{\dagger}$ \\
FXII-def & $12.7 \pm 5.0$ & $12 \pm 5^{\ddagger}$ & $124 \pm 45^{\ddagger}$ \\
FXII-def+ASIS & $\mathrm{ND}$ & $\mathrm{ND}$ & $\mathrm{ND}$ \\
\hline
\end{tabular}

${ }^{*} P<0.001$ vs. without $A S I S, P<0.01$ vs. without $C T$, $\ddagger_{P<0.01}$ vs NP

Figure 2.1. Thrombin generation curves in presence of confluent EA.hyg2 6 cells. A) Addition of ASIS leads to increased lag time suggesting TF-pathway activity, although CTI blocks thrombin generation completely which indicates only intrinsic activation is present. B) In FXII-deficient (FXII-def) plasma thrombin generation occurs even in presence of ASIS hence cells deliver FXIla. This phenomenon can be blocked by CTI.

C) Thrombin generation curves are absent in FXI-deficient plasma. D) Addition of freshly trypsinised cells $\left(60,000 / \mathrm{cm}_{2}\right)$ to the CAT results in absence of thrombin generation in FXII-deficient plasma. Cells were cultured in $1 \%$ FBS in SFM prior to trypsinisation $(n=3)$. E) Normal endothelial morphology of EA.hyg 26 cells cultured in medium supplemented with human FXII-deficient plasma (5\%). Scale bar represents $100 \mu \mathrm{m}$. F) EA.hyg2 6 cultured in serum-free conditions show increase in lag time and peak height after addition of ASIS. In FXII-deficient plasma, thrombin generation is minimal and can completely be blocked by ASIS $(n=8)$. Representative curves are shown. The data are presented as mean \pm SD. 


\section{TNFa INCREASES EXTRINSIC ACTIVATION ON EA.HY926 CELLS}

TNF $\alpha$ was used to induce a proinflammatory profile in EA.hyg26 where after thrombin generation was evaluated. In both normal pooled plasma and FXII-deficient plasma, lag time decreased significantly indicating increased TF activity. Peak height increased in FXII-deficient plasma, which can be ascribed to stronger extrinsic activation by TNF $\alpha$ (Figure 2.2).

\section{TF-ACTIVITY OF EA.HY926 CELLS}

The amount of active TF in EA.hy926 was measured with a chromogenic assay for FXa formation in confluent cell cultures $(n=4)$. The average TF amount was $1.44 \mathrm{pM}$ $\pm 0.02 \mathrm{pM}$ per well $\left(9.6 \mathrm{~cm}^{2} /\right.$ well, 6 -wells plate). Correcting for the surface area per well of a 96 -wells plate $\left(0.34 \mathrm{~cm}^{2} /\right.$ well), results in $0.05 \mathrm{pM} \mathrm{TF-activity} \mathrm{per} \mathrm{well,} \mathrm{a} \mathrm{rather} \mathrm{low}$ amount which is in accordance with the thrombin generation assay results (Figure 2.1F).

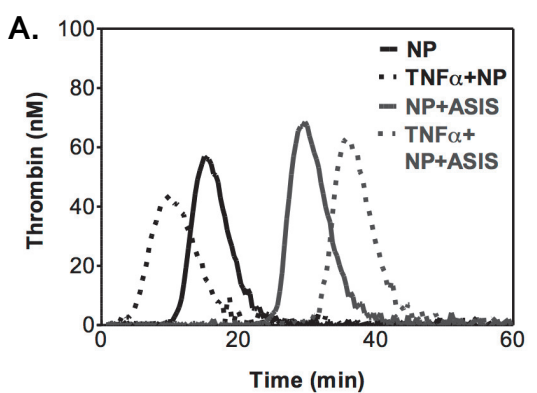

\begin{tabular}{llll}
\hline Condition & $\begin{array}{l}\text { Lag time } \\
(\mathbf{m i n})\end{array}$ & $\begin{array}{l}\text { Peak height } \\
(\mathbf{n M})\end{array}$ & $\begin{array}{l}\text { ETP } \\
\left(\mathbf{n M} \mathbf{M}^{*} \text { min) }\right.\end{array}$ \\
\hline $\mathrm{NP}$ & $10.4 \pm 3.1$ & $56 \pm 28$ & $386 \pm 163$ \\
TNFa+NP & $6.2 \pm 1.6^{*}$ & $44 \pm 10$ & $346 \pm 77$ \\
$\mathrm{NP}+$ ASIS & $21.6 \pm 4.8$ & $76 \pm 21$ & $506 \pm 111$ \\
TNFa+NP+ASIS & $33.5 \pm 24.2$ & $58 \pm 27$ & $416 \pm 177$ \\
\hline
\end{tabular}

${ }^{*} P<0.01$ vs. without TNFa

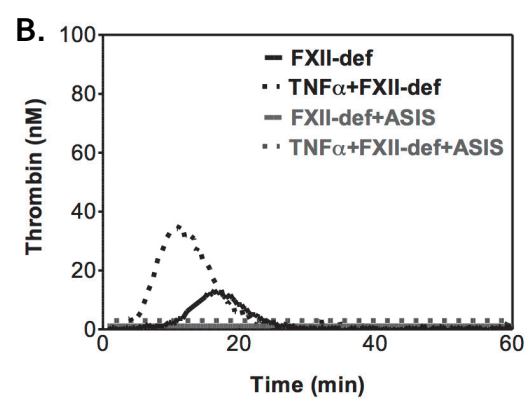

\begin{tabular}{llll}
\hline Condition & $\begin{array}{l}\text { Lag time } \\
(\mathbf{m i n})\end{array}$ & $\begin{array}{l}\text { Peak height } \\
(\mathbf{n M})\end{array}$ & $\begin{array}{l}\text { ETP } \\
\left(\mathbf{n M} M^{*} \mathbf{m i n}\right)\end{array}$ \\
\hline FXII-def & $12.7 \pm 5.0$ & $12 \pm 5$ & $124 \pm 45$ \\
TNFa+FXII-def & $6.8 \pm 1.9^{*}$ & $36 \pm 10^{*}$ & $335 \pm 76^{*}$ \\
FXII-def+ASIS & ND & ND & ND \\
TNFa+FXII-def+ASIS & ND & ND & ND \\
\hline
\end{tabular}

${ }^{\star} P<0.01$ vs. without TNF $\alpha$

Figure 2.2. Influence of TNF $\alpha$ stimulation on thrombin generation on EA.hy926. Cells were stimulated for $4 \mathrm{~h}$ with TNF $\alpha(10 \mathrm{ng} / \mathrm{ml})$ after which thrombin generation was assayed. A) TNF $\alpha$ in normal pooled plasma (NP) induces earlier thrombin generation $(n=8)$. B) In FXII-deficient plasma (FXII-def), thrombin generation is enhanced after TNF $\alpha$, as shown by decreased lag time and increased peak height $(n=8)$. Representative curves are shown. The data are presented as mean \pm SD. 


\section{THE CONTACT ACTIVATION PATHWAY AND EXTRINSIC PATHWAY ARE BOTH ACTIVATED BY HCAECS}

In addition to EA.hy926, thrombin generation was studied on HCAECs to see whether the strong contact activation could be observed in primary ECs as well. In normal pooled plasma, thrombin was generated, whereas addition of ASIS resulted in lower peaks (Figure 2.3) with a slightly prolonged lag time, suggesting TF-activity on the cells. In presence of ASIS, thrombin generation was evident and can be ascribed to contact activation. In FXII-deficient plasma, thrombin generation decreased as compared to normal pooled plasma as shown by lower peaks. Blocking the extrinsic pathway by ASIS in FXII-deficient plasma attenuated thrombin generation (Figure 2.3), suggesting contribution of the extrinsic pathway on HCAECs as well.

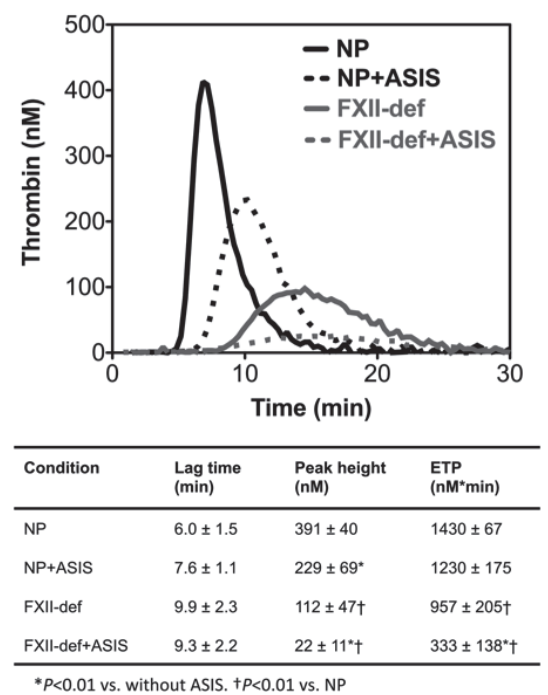

Figure 2.3. Thrombin generation in primary HCAEC. ASIS decreases peak height in normal pooled (NP) and FXII-deficient (FXII-def) plasma. Curves in FXII-deficient plasma are lower and have decreased ETP compared to NP $(n=4)$. Representative curves are shown. The data are presented as mean \pm SD.

\section{CABG PATIENT-DERIVED HVECS SHOW INCREASED CONTACT ACTIVATION-MEDIATED THROMBIN GENERATION}

The cell-based thrombin generation assay offers the potential to study the thrombogenic phenotype of ECs in different conditions in a high throughput manner. HVECs can quite easily be isolated and cultured from patients undergoing surgery 
during which a small vessel biopsy can be obtained. By using this harvesting approach, thrombin generation on patient-derived HVECs was assessed in both normal pooled and FXII-deficient plasma.

Patient characteristics are presented in Table 2.1. Lag time of thrombin generation measured on ECs derived from CABG patients was shorter when measured in normal pooled plasma in presence of ASIS compared to control patients (Figure 2.4A, Table 2.2).

Table 2.1. Patient characteristics

\begin{tabular}{lll}
\hline & Control $(n=10)$ & CABG $(n=10)$ \\
\hline Age (years) & $49[28-68]$ & $69[52-77]^{*}$ \\
Gender (M/F) & $6 / 4$ & $7 / 3$ \\
BMI $\left(\mathrm{kg} / \mathrm{m}^{2}\right)$ & $24 \cdot 6[20.6-35 \cdot 2]$ & $25 \cdot 7[22.1-32.1]$ \\
CAD (\%) & 0 & 100 \\
DM (\%) & 0 & 10 \\
Hypertension (\%) & 0 & 40 \\
Hyperlipidemia (\%) & 0 & 80 \\
Smoking (\%) & 0 & 0 \\
Family history (\%) & 0 & 60 \\
\hline
\end{tabular}

$\mathrm{M}=$ Male, $\mathrm{F}=$ Female, $\mathrm{BMI}=$ Body mass index, $\mathrm{CAD}=$ Coronary artery disease, $\mathrm{DM}=$ Diabetes mellitus. ${ }^{*} P<0.01$ compared to control subjects. Median and range are shown or percentage positive patients.

Table 2.2. Thrombin generation parameters

\begin{tabular}{|c|c|c|c|c|}
\hline Group & Condition & $\begin{array}{l}\text { Lag time } \\
(\min )\end{array}$ & $\begin{array}{c}\text { ETP } \\
(n M * \min ) \\
\end{array}$ & $\begin{array}{c}\text { Peak height } \\
(\mathrm{nM})\end{array}$ \\
\hline \multirow[t]{4}{*}{ Control } & NP & $17.0 \quad[10.3-22.2]$ & $379 \quad[218-513]$ & 53 [31-77] \\
\hline & NP+ASIS & $23.1 \quad[16.3-28.2]$ & $431 \quad[307-546]$ & $64 \quad[47-86]$ \\
\hline & $\mathrm{NP}+\mathrm{ASIS}+\mathrm{CTI}$ & $30.8[24.0-36.6]$ & $353 \quad[212-425]$ & $50 \quad[29-60]$ \\
\hline & FXII-def & $4.3 \quad[3.5-5.0]$ & $153 \quad[141-164]$ & $14 \quad[12-16]$ \\
\hline \multirow[t]{4}{*}{ CABG } & NP & $14.7 \quad[12.4-19.8]$ & $580^{*}[466-747]$ & $90 *$ [67-112] \\
\hline & NP+ASIS & $15.8^{*}[14.2-20.5]$ & $620^{*}[533-759]$ & $98^{*}[74-121]$ \\
\hline & $\mathrm{NP}+\mathrm{ASIS}+\mathrm{CTI}$ & $24.1 \quad[21.4-31.1]$ & 452 [293-570] & $61 \quad[44-71]$ \\
\hline & FXII-def & $19.7^{*}[14.6-22.2]$ & $84 \quad[73-318]$ & $5 \quad[4-34]$ \\
\hline
\end{tabular}

${ }^{*} P<0.05$ compared to control patients. Medians and interquartile ranges [ ] are shown.

In FXII-deficient plasma, patient-derived ECs from only two control patients and three CABG patients supported thrombin generation with relatively low ETP and peaks, implying once more that contact activation is the main route of coagulation on cultured ECs from these patients. 
In this condition peak height and ETP were also increased for this group as well as in normal pooled plasma alone (Figure 2.4B,C, Table 2.2). The significant difference in thrombin generation between both groups when the TF-pathway was blocked by ASIS indicates more contact activation on cells from CABG patients.
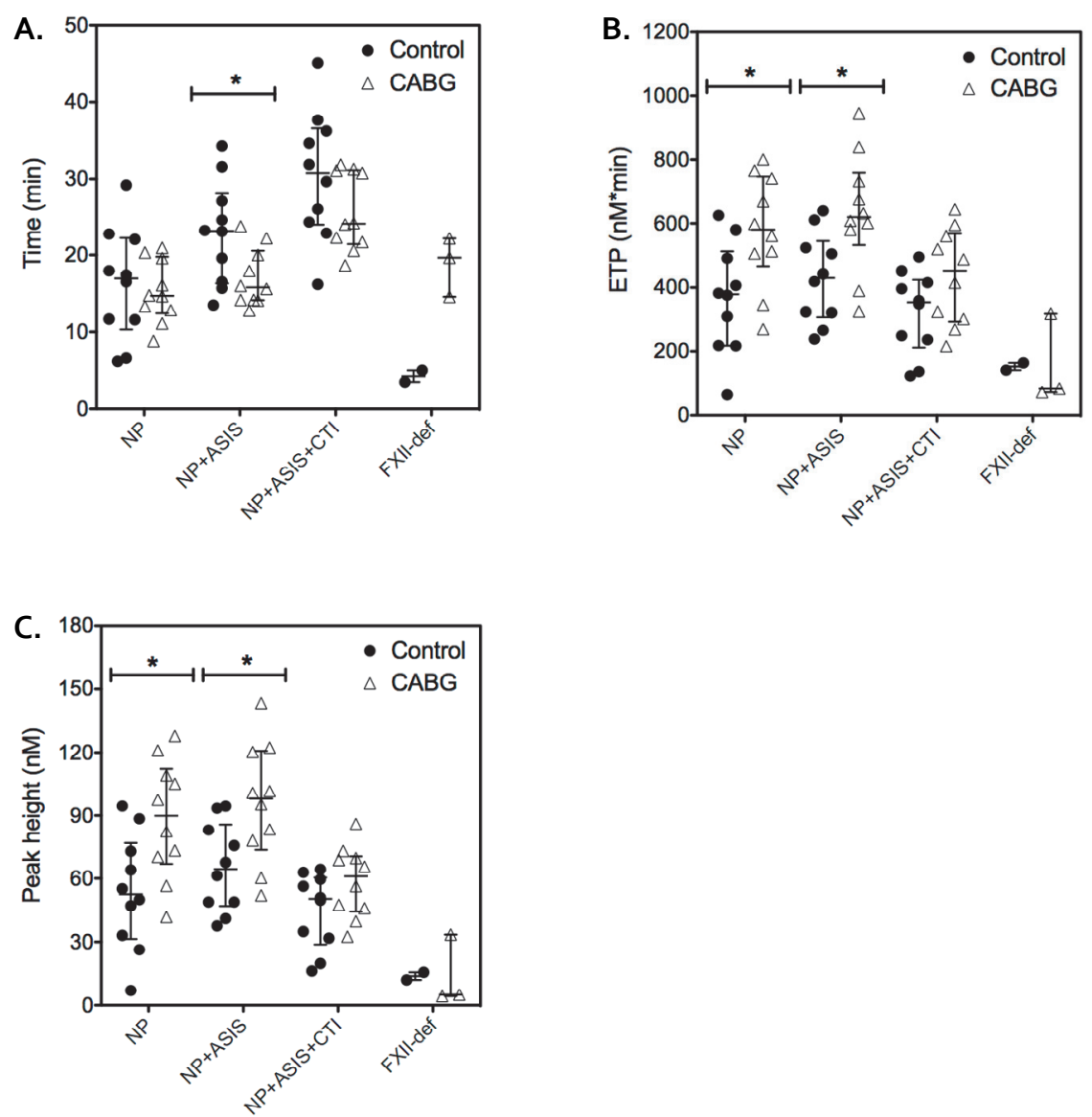

Figure 2.4. Thrombin generation parameters from CAT measurements on patient-derived HVECs in the absence or presence of ASIS and CTI. A) Lag time is significantly shorter in ECs from CABG patients in normal pooled plasma (NP) in presence of ASIS. B) ETP is increased in NP and NP with ASIS for the CABG group. C) The peak height is also higher in NP and NP with ASIS for CABG patients. ECs from two control patients and three CABG patients induced thrombin generation in FXII-deficient (FXII-def) plasma. ${ }^{*} P<0.05$. Medians and interquartile ranges are shown. 


\section{DISCUSSION}

Complications of thromboembolic disease are associated with significant morbidity and mortality. Together with the high prevalence of thromboembolic disorders this has led to a major research focus on the pathophysiology of thrombus formation. Most of these studies have focused on plasma-related factors and for practical reasons the endothelium is usually not taken into account when investigating coagulation disorders. However, it was already postulated by Virchow in 1856 that flow disturbances and the composition of the vessel wall also contribute to thrombosis. ${ }^{22}$ The recently developed CAT method for thrombin generation is an established index of plasma coagulability ${ }^{23-25}$ and can be modified to include vascular wall components such as ECs (mCAT). In combination with in vitro cultured ECs we describe a high throughput mCAT method to investigate both the plasma compartment and the vessel wall in one assay. Besides this, the contribution of different parts of the coagulation cascade can be investigated by using pharmacological blockers of specific pathways or by studying coagulation in plasma with coagulation factor deficiencies. Previous investigations into the contribution of the endothelium to coagulation focused on specific parts of the coagulation cascade like the protein $C$ pathway ${ }^{26}$, studied TF-induced coagulation in presence of $\mathrm{CTI}^{16,17}$, applied specific stimuli ${ }^{27-29}$ or looked at fibrin structure. ${ }^{15,3^{\circ}}$ We decided to include normal pooled plasma without CTI to obtain insight into the interaction between the endothelium and contact activation and also investigated the balance between extrinsic and contact activation-mediated thrombin generation in the presence of ECs. As shown by the limited effect of ASIS and low amounts of thrombin formed in FXII-deficient plasma, contact activation turned out to be a stronger regulator of thrombin generation compared to the extrinsic pathway. These data have not been reported yet and give additional insight into the synergy between the plasma compartment and the vascular wall with regards to coagulation.

Thrombin generation was studied on the endothelial cell line EA.hyg 26 because of its consistent phenotype and low TF expression. ${ }^{16,19}$ Despite the stable phenotype, cell culture conditions influenced cellular characteristics as FBS-derived FXIla seemed to be retained in the presence of cultured cells, as suggested by the observed thrombin generation in FXII-deficient plasma with the TF pathway blocked, as well as by the lack of thrombin generation under these conditions after ECs had been cultured in FXIIdeficient medium. The latter culture condition resulted in thrombin generation curves with predominantly contact activation and a limited contribution of the extrinsic pathway in normal pooled plasma. 
It has been shown that FXII can bind to ECs in a zinc-dependent manner via urokinaselike plasminogen activator receptor (U-PAR), cytokeratin 1 and the complement receptor $\mathrm{gC}_{1 \mathrm{qRI}^{14,31,32}}$. ECs are also able to produce an extracellular matrix protein which can serve as a zinc-independent binding site for FXII. ${ }^{13}$ Another possible route of assembly and activation of the intrinsic pathway involves binding of FXI and FXIa to ECs in the presence of HK, which in turn can activate FIX. ${ }^{21,33}$ Shariat-Madar et al. also showed FBS-related FXI activation on HUVECs as measured in conditions with pure $\mathrm{FXI}, \mathrm{HK}$ and zinc ions. ${ }^{21}$

TF is not expressed by healthy, quiescent ECs lining the vessel wall in vivo. ${ }^{3,5}$ In atherosclerotic-prone regions ${ }^{4}$ and after cytokine treatment, TF-activity can rise in the endothelium. ${ }^{3}$ Cultured ECs exposed to oscillatory ${ }^{28}$ and low shear stress of $1.5 \mathrm{~N} / \mathrm{m}^{2} 34$ in vitro showed increased TF-expression. Other studies have reported that exposure to laminar shear stress ${ }^{35}$ and cyclic strain $^{36}$ in vitro also resulted in augmented TF-expression. Taking into account the above mentioned in vivo observations on TF-expression, we consider low or absent TF expression to reflect the natural antithrombogenic state of ECs indicating that our findings of very low TF-activity in EA.hyg26 and patient-derived ECs resemble the thrombogenic profile of the endothelium in vivo. ${ }^{3,5}$ Regarding the contact activation potential as shown in this study and the possible effects of endothelial contact activity in vivo, further studies are required to clarify the pathophysiological circumstances in which contact activationmediated coagulation will occur.

To verify the known procoagulant effect of cytokines on ECs, we stimulated cells with TNF $\alpha$. This resulted in increased extrinsic activation and is in accordance with previous reports. ${ }^{27,29}$ We could confirm our results obtained with EA.hyg26 cells in primary HCAECs, which showed also considerable contribution of the extrinsic pathway in addition to contact activation.

For the first time, patient-derived ECs were evaluated for their thrombogenic potential by means of the mCAT method. We found increased thrombin generation on ECS derived from CABG patients compared to subjects lacking major cardiovascular risk factors and free from symptomatic cardiovascular disease. By blocking the TF-pathway we revealed increased contact activation on cells that were derived from CABG patients. Contribution of the TF-pathway was limited and was only seen in five out of twenty patients.

The relevance of the intrinsic pathway for thrombus formation was recently confirmed in vivo in mice and baboons $s^{7-9,37}$ and it is thought that the intrinsic pathway might offer new therapeutic options for antithrombotic therapies. Borissoff et al. reported 
increased FXII activity in human early atherosclerotic lesions ${ }^{38}$, which also supports the link between cardiovascular disease and the contact activation system as suggested by our findings. FXII also seems to play an essential role in the procoagulant effects of particulate matter as proven in vitro and in a mouse model. ${ }^{39}$ Together with our data, we infer that the contact activation pathway is of considerable relevance for (pathologic) thrombus formation.

Future research is required to elucidate the mechanisms of increased contact activation on ECs derived from CABG patients. A possible link between increased expression of $\mathrm{gC} 1 \mathrm{qR}$, part of the FXII-receptor complex on ECs, and cardiovascular disease has been proposed by Ghebrehiwet et al. ${ }^{40}$ Endothelial dysfunction has attracted ample scientific interest with respect to cardiovascular morbidity ${ }^{41,42}$, but the relationship of this phenomenon with coagulation remains to be further elucidated. Our system comprising the thrombin generation assay in combination with ECs offers great potential to study the anticoagulant protein C pathway in which ECs play a substantial role and will be the scope of future research.

In this report we show the relevance of contact activation on ECs for coagulation and the importance of standardizing culture conditions when evaluating thrombin generation in vitro in combination with vascular cells. These conditions appear to have major influence on the thrombogenic profile of ECs. In the field of vascular tissue engineering, cells are cultured for later in vivo implantation. For this purpose it is important to take into account the antithrombotic properties of cultured ECs before seeding and implanting them, thereby applying FBS-free culture conditions as serumderived FXIla shows retention to cultured ECs.

\section{CONCLUSION}

Thrombin generation in presence of cultured ECs is mainly initiated by contact activation. A valid assay for measuring thrombin generation in the presence of cultured vascular cells should take into account that culture medium, in particular the serum component, affects the mechanism of coagulation. ECs derived from CABG patients show enhanced thrombin generation compared to control patients, which can be ascribed to increased contact activation. 


\section{REFERENCES}

1. Furie B, Furie BC. Mechanisms of Thrombus Formation. N Engl J Med. 2008; 359(9): 938-49.

2. Bombeli $T$, Mueller $M$, Haeberli A. Anticoagulant properties of the vascular endothelium. Thromb Haemost. 1997; 77(3): 408-23.

3. Drake TA, Cheng J, Chang A, Taylor FB, Jr. Expression of tissue factor, thrombomodulin, and E-selectin in baboons with lethal Escherichia coli sepsis. Am J Pathol. 1993; 142(5): 1458-70.

4. Kaikita K, Takeya M, Ogawa H, Suefuji H, Yasue H, Takahashi K. Co-localization of tissue factor and tissue factor pathway inhibitor in coronary atherosclerosis. J Path. 1999; 188(2): 180-8.

5. Wilcox JN, Smith KM, Schwartz SM, Gordon D. Localization of tissue factor in the normal vessel wall and in the atherosclerotic plaque. Proc Natl Acad Sci U S A. 1989; 86(8): 2839-43.

6. Lammle B, Wuillemin WA, Huber I, Krauskopf M, Zurcher C, Pflugshaupt R, et al. Thromboembolism and bleeding tendency in congenital factor XII deficiency--a study on 74 subjects from 14 Swiss families. Thromb Haemost. 1991; 65(2): 117-21.

7. Renné T, Pozgajova M, Gruner S, Schuh K, Pauer HU, Burfeind P, et al. Defective thrombus formation in mice lacking coagulation factor XII. J Exp Med. 2005; 202(2): 271-81.

8. Kleinschnitz $C$, Stoll G, Bendszus M, Schuh K, Pauer H-U, Burfeind P, et al. Targeting coagulation factor XII provides protection from pathological thrombosis in cerebral ischemia without interfering with hemostasis. J Exp Med. 2006; 203(3): 513-8.

9. Cheng $Q$, Tucker El, Pine MS, Sisler I, Matafonov A, Sun M-f, et al. A role for factor XIla-mediated factor XI activation in thrombus formation in vivo. Blood. 2010; 116(19): 3981-9.

10. Hagedorn I, Schmidbauer S, Pleines I, Kleinschnitz C, Kronthaler U, Stoll G, et al. Factor XIla Inhibitor Recombinant Human Albumin Infestin-4 Abolishes Occlusive Arterial Thrombus Formation Without Affecting Bleeding. Circulation. 2010; 121(13): 1510-7.

11. Smith SA, Mutch NJ, Baskar D, Rohloff P, Docampo R, Morrissey JH. Polyphosphate modulates blood coagulation and fibrinolysis. Proc Natl Acad Sci U S A. 2006; 103(4): 903-8.

12. van der Meijden PE, Munnix IC, Auger JM, Govers-Riemslag JW, Cosemans JM, Kuijpers MJ, et al. Dual role of collagen in factor XII-dependent thrombus formation. Blood. 2009; 114(4): 881-90.

13. Schousboe I. Endothelial cells express a matrix protein which binds activated factor XII in a zincindependent manner. Thromb Haemost. 2006; 95(2): 312-9.

14. Joseph K, Tholanikunnel BG, Ghebrehiwet B, Kaplan AP. Interaction of high molecular weight kininogen binding proteins on endothelial cells. Thromb Haemost. 2004; 91(1): 61-70.

15. Campbell RA, Overmyer KA, Selzman CH, Sheridan BC, Wolberg AS. Contributions of extravascular and intravascular cells to fibrin network formation, structure, and stability. Blood. 2009; 114(23): 488696.

16. Campbell JE, Brummel-Ziedins KE, Butenas S, Mann KG. Cellular regulation of blood coagulation: a model for venous stasis. Blood. 2010; 116(26): 6082-91.

17. Roberts HR, Hoffman M, Monroe DM. A Cell-Based Model of Thrombin Generation. Semin Thromb Hemost. 2006; 32(S 1): 032,8.

18. Edgell CJ, McDonald CC, Graham JB. Permanent cell line expressing human factor VIII-related antigen established by hybridization. Proc Natl Acad Sci U S A. 1983; 80(12): 3734-7.

19. Bouïs D, Hospers G, Meijer C, Molema G, Mulder N. Endothelium in vitro: A review of human vascular endothelial cell lines for blood vessel-related research. Angiogenesis. 2001; 4(2): 91-102.

20. Loubele ST, Spek CA, Leenders $P$, van Oerle R, Aberson HL, Hamulyak $K$, et al. Activated protein $C$ protects against myocardial ischemia/ reperfusion injury via inhibition of apoptosis and inflammation. Arterioscler Thromb Vac Biol. 2009; 29(7): 1087-92.

21. Shariat-Madar Z, Mahdi F, Schmaier AH. Factor XI assembly and activation on human umbilical vein endothelial cells in culture. Thromb Haemost. 2001; 85(3): 544-51.

22. Virchow R. Gesammelte Abhandlungen zur wissenschaftlichen Medicin. Frankfurt a. M.: Meidinger; 1856. 
23. Hemker HC, Giesen P, AIDieri R, Regnault V, de Smed E, Wagenvoord R, et al. The calibrated automated thrombogram (CAT): a universal routine test for hyper- and hypocoagulability. Pathophysiol Haemost Thromb. 2002; 32(5-6): 249-53.

24. Spronk HM, Dielis AW, De Smedt E, van Oerle R, Fens D, Prins MH, et al. Assessment of thrombin generation II: Validation of the Calibrated Automated Thrombogram in platelet-poor plasma in a clinical laboratory. Thromb Haemost. 2008; 100(2): 362-4.

25. ten Cate-Hoek AJ, Dielis AW, Spronk HM, van Oerle R, Hamulyak K, Prins $\mathbf{M H}$, et al. Thrombin generation in patients after acute deep-vein thrombosis. Thromb Haemost. 2008; 100(2): 240-5.

26. Hockin MF, Kalafatis M, Shatos M, Mann KG. Protein C activation and factor Va inactivation on human umbilical vein endothelial cells. Arterioscler Thromb Vac Biol. 1997; 17(11): 2765-75.

27. Bevilacqua MP, Pober JS, Majeau GR, Fiers W, Cotran RS, Gimbrone MA, Jr. Recombinant tumor necrosis factor induces procoagulant activity in cultured human vascular endothelium: characterization and comparison with the actions of interleukin 1. Proc Natl Acad Sci USA. 1986; 83(12): 4533-7.

28. Mazzolai L, Silacci P, Bouzourene K, Daniel F, Brunner H, Hayoz D. Tissue factor activity is upregulated in human endothelial cells exposed to oscillatory shear stress. Thromb Haemost. 2002; 87(6): 1062-8.

29. Nawroth PP, Stern DM. Modulation of endothelial cell hemostatic properties by tumor necrosis factor. J Exp Med. 1986; 163(3): 740-5.

30. Campbell RA, Overmyer KA, Bagnell $C R$, Wolberg AS. Cellular procoagulant activity dictates clot structure and stability as a function of distance from the cell surface. Arterioscler Thromb Vac Biol. 2008; 28(12): 2247-54.

31. Schousboe I, Thomsen P, Van Deurs B. Factor XII binding to endothelial cells depends on caveolae. Eur J Biochem. 2004; 271(14): 2998-3005.

32. Mahdi F, Madar ZS, Figueroa CD, Schmaier AH. Factor XII interacts with the multiprotein assembly of urokinase plasminogen activator receptor, $\mathrm{gC} 1 \mathrm{qR}$, and cytokeratin 1 on endothelial cell membranes. Blood. 2002; 99(10): 3585-96.

33. Berrettini M, Schleef RR, Heeb MJ, Hopmeier P, Griffin JH. Assembly and expression of an intrinsic factor IX activator complex on the surface of cultured human endothelial cells. J Biol Chem. 1992; 267(28): 19833-9.

34. Houston P, Dickson MC, Ludbrook V, White B, Schwachtgen J-L, McVey JH, et al. Fluid shear stress induction of the tissue factor promoter in vitro and in vivo is mediated by Egr-1. Arterioscler Thromb Vac Biol. 1999; 19(2): 281-9.

35. Lin MC, Almus-Jacobs F, Chen HH, Parry GC, Mackman N, Shyy JY, et al. Shear stress induction of the tissue factor gene. J Clin Invest. 1997; 99(4): 737-44.

36. Silverman MD, Manolopoulos VG, Unsworth BR, Lelkes PI. Tissue factor expression is differentially modulated by cyclic mechanical strain in various human endothelial cells. Blood Coagul Fibrinolysis. 1996; 7(3): 281-8.

37. Renné T, Gailani D. Role of Factor XII in hemostasis and thrombosis: clinical implications. Expert Rev Cardiovasc Ther. 2007; 5(4): 733-41.

38. Borissoff Jl, Heeneman S, Kilinc E, Kassak P, Van Oerle R, Winckers K, et al. Early atherosclerosis exhibits an enhanced procoagulant state. Circulation. 2010; 122(8): 821-30.

39. Kilinç E, van Oerle R, Borissoff Jl, Oschatz C, Gerlofs-Nijland ME, Janssen NA, et al. Factor XII activation is essential to sustain the procoagulant effects of particulate matter. J Thromb Haemost. 2011; 9: 1350-67.

40. Ghebrehiwet B, CebadaMora C, Tantral L, Jesty J, Peerschke EIB. gC1qR/p33 Serves as a molecular bridge between the complement and contact activation systems and Is an important catalyst in inflammation. In: Lambris JD, editor. Curent Topics in Complement: Springer US; 2006. p. 95-105.

41. Celermajer DS, Sorensen KE, Gooch VM, Miller, Sullivan ID, Lloyd JK, et al. Non-invasive detection of endothelial dysfunction in children and adults at risk of atherosclerosis. The Lancet. 1992; 340(8828): 1111-5.

42. Ross R. Atherosclerosis--an inflammatory disease. N Engl J Med. 1999; 340(2): 115-26. 


\section{CHAPTER}

\section{Endothelial Cells (ECs) for Vascular Tissue Engineering; Venous ECs are Less Thrombogenic than Arterial ECs}

Irma LA Geenen, Daniel GM Molin DG, Nynke M van den Akker, Fabiënne Jeukens, Henri M Spronk, Geert Willem H Schurink, Mark J Post Journal of Tissue Engineering and Regenerative Medicine. 2012 Nov; 19 


\section{ABSTRACT}

Primary endothelial cells (ECs) are the preferred cellular source for luminal seeding of tissue-engineered (TE) vascular grafts. Research into the potential of ECs for vascular TE has focussed particularly on venous rather than arterial ECs. In this study we evaluated the functional characteristics of arterial and venous ECs, relevant for vascular TE.

Porcine ECs were isolated from femoral artery (PFAECs) and vein (PFVECs). Proliferation rate was comparable for both EC sources whereas migration, determined through a wound-healing assay, was less profound for PFVECs. EC adhesion was lower for PFVEC on collagen-I measured after 10 minutes of arterial shear stress. Gene expression was analyzed by RT-qPCR for ECs cultured under static conditions and after exposure to arterial shear stress and revealed differences in gene expression with lower expression of EphrinB2 and VCAM-1 and higher levels of VWF and COUP-TFII in PFVECs compared to PFAECs.

PFVECs exhibited diminished platelet adhesion under flow and cell-based thrombin generation was delayed for PFVECs, indicating diminished TF-activity. After stimulation, prostacyclin secretion but not nitric oxide (NO), was lower in PFVECs. Our data support the use of venous ECS for TE because of their beneficial antithrombogenic profile. 


\section{INTRODUCTION}

In vascular tissue engineering (TE), primary endothelial cells (ECs) are widely used for seeding the luminal surface of tubular constructs. The stable endothelium is expected to provide the graft with low thrombo- and immunogenic reactivity. ${ }^{1-4}$ The general approach to obtain ECs is to isolate them from a peripheral vein such as the saphenous or cephalic vein. Possible alternative sources for generating an endothelial layer are microvascular ECs from adipose tissue ${ }^{5}$ or circulating endothelial progenitor cells, which can be differentiated into endothelial-like cells. ${ }^{6,7}$ TE vascular grafts are predominantly used in the arterial circulation with venous ECs as the first choice to generate an endothelial layer. Venous ECs might be a suboptimal source for creating the endothelial layer as a substantial amount of venous grafts utilized as bypass in the arterial circulation fail due to early thrombosis, neointima formation or accelerated atherosclerosis. ${ }^{8}$ Within TE, maladapted or dysfunctional venous endothelium might contribute to early graft failure and development of intima hyperplasia. ${ }^{1,9,10}$ The differences in endothelial behaviour and maladaptation might relate to intrinsic differences between arterial and venous endothelial phenotype and function, likely as a result of distinct patterns in gene expression of for instance EphrinB2, NRP-1 and 2, Delta-like 4, EphB4 and COUP-TFII. ${ }^{11-13}$ Also, higher venous expression of von Willebrand Factor (vWF) reflects this phenotypical difference and could correlate with higher thrombogenicity found in veins. ${ }^{14}$ Other endothelial dissimilarities include tighter junctions (zona occludens) ${ }^{15}$, enhanced vasodilatory properties of arterial endothelium $^{16}$, increased permeability ${ }^{17}$ and a stronger inflammatory response of venous ECs. ${ }^{18,19}$ Both prostacyclin release and NO production based on endotheliumdependent relaxation measurements seem to be higher in arteries. ${ }^{20-23}$

In order to seed ECs successfully onto a TE graft five features are important: (A) Sufficient in vitro proliferative potential to procure adequate numbers of cells for seeding, (B) Strong adhesion to the graft substrate that will sustain shearing forces in vivo, (C) Inhibition of intima hyperplasia formation and, arguably most important, (D) prevention of graft thrombosis through inhibition of platelet adhesion and coagulation. ${ }^{24}$ (E) Besides these features, cells must be easily obtainable from an autologous and reliable tissue source. Previous studies supporting the use of venous cells for vascular TE only included co-cultures with myofibroblasts ${ }^{25}$, but pertinent characteristics of EC sources for TE from different vascular beds have not been investigated sufficiently, yet. Therefore, the aim of this study was to compare phenotypical and functional characteristics of ECs from arterial and venous anatomically related origin in vitro. Primary porcine ECs isolated from femoral artery 
and vein were cultured and their proliferation rate, migration and cellular adhesion capacity were measured. Furthermore, the expression of adhesion molecules as markers of endothelial activation ${ }^{26,27}$, was evaluated under static and flow conditions and the prothrombogenic properties were investigated with a thrombin generation assay and platelet adhesion assay. Prostacyclin and NO production, important for preventing platelet aggregation and inducers of vasodilation, were measured in cell culture supernatant.

\section{MATERIALS AND METHODS}

\section{ENDOTHELIAL CELL ISOLATION AND CULTURE}

ECs were isolated from femoral artery (PFAECs) $(n=2)$ and femoral vein (PFVECs) $(n=2)$ from three months old Dutch Landrace pigs $(n=3)$, IDDLO, Lelystad, The Netherlands. Animal handling was conducted according to the NIH principles of laboratory animal care. After dissection, vessels were placed in PBS with penicillin/streptomycin. The lumen was washed with PBS three times and cannulated for incubation with collagenase type I, $0.05 \%$ (Worthington, Lakewood, NJ, USA) for 15 minutes at $37^{\circ} \mathrm{C}$. Then, the collagenase solution containing detached cells was collected and the lumen was flushed with DMEM (Lonza, Basel, Switzerland) to gather remaining cells. After centrifugation, cells were resuspended and cultured on fibronectin $(10 \mu \mathrm{g} / \mathrm{mL})$ coated flasks (Greiner Bio-One, Alphen a/d Rijn, The Netherlands) in EBM2-medium supplemented with the EGM-2-MV bullet kit (Lonza) at $37^{\circ} \mathrm{C} / 5 \% \mathrm{CO} 2$. When cells reached confluency, cells were detached using trypsin/EDTA and afterwards treated with a trypsin neutralization solution (Lonza). After centrifugation cells were resuspended, counted with the Countess ${ }^{\mathrm{TM}}$ Automated Cell Counter (Invitrogen, Carlsbad, CA, USA) and subcultured with a seeding density of 3,500 cells $/ \mathrm{cm}^{2}$. When fibroblasts were observed in culture, pre-plating on collagen type I (Millipore, Billerica, MA, USA) coated flasks ( $5 \mu \mathrm{g} / \mathrm{mL}$ ) was applied after trypsinization for 10 minutes and adherent cells were cultured until a pure population was obtained, based on morphologic evaluation. Experiments were performed on cells during passage 7-12.

For gene expression, proliferation, adhesion and platelet adhesion experiments, cells were cultured under flow conditions in a biofluidic system (Ibidi, Munich, Germany). Unless otherwise stated, cells were seeded on tissue-culture treated $\mu$-Slides lo.4 Luer (Ibidi) (75,00o cells/slide) and were allowed to adhere for 24 hours before physiological arterial shear stress of $2.0 \mathrm{~Pa}$ (flow rate $15.19 \mathrm{ml} / \mathrm{min}$ ) was applied for 72 hours. 


\section{ENDOTHELIAL CELL PHENOTYPE}

EC phenotype was confirmed by immunohistochemical staining for $\mathrm{CD}_{31}$ and $\mathrm{VWF}$ and acetylated (Ac)-LDL uptake. For immunohistochemistry, cells were incubated overnight (CD31) or for 1 hour (VWF) with monoclonal mouse anti-pig CD31 (1:200, AbD Serotec, Oxford, UK) or polyclonal rabbit anti-human vWF (1:60o, DakoCytomation, Glostrup, Denmark). Corresponding secondary antibodies were applied for 1 hour and cells were visualized with DAB and counterstained with Mayer's haematoxilin. Ac-LDL uptake was assessed in confluent cells by incubation with $2.5 \mathrm{\mu g} / \mathrm{ml}$ Ac-LDL (Invitrogen) for 4 hours at $37^{\circ} \mathrm{C} / 5 \% \mathrm{CO} 2$. After washing with PBS, photographs were taken with a Leica DMl3000B inverted microscope with a DFC 350 FX camera (Leica, Bannockburn, IL, USA).

FACS analysis for defining presence of $C_{31}$ was performed with the same FITC conjugated antibody as for immunohistochemistry and IgG isotype (AbD Serotec). After incubation for 30 minutes with either $C_{31}$ or isotype control, cells were washed and fixated in $1 \%$ PFA and samples were acquired using a FACS Canto II (BD, San Jose, CA USA) and data-analysis was performed using Kaluza-software (Beckman Coulter, Brea, CA, USA).

\section{ENDOTHELIAL GENE EXPRESSION ANALYSIS}

Expression of general endothelial markers $C_{31}$, vWF, eNOS and VE-cadherin, and arterial markers Ephrin $\mathrm{B}_{2}$ and neuropilin-1 (NRP1) and venous markers COUP-TFII and EphB4, was determined for endothelial cells cultured under static and flow conditions. The expression of adhesion molecules ICAM-1, VCAM-1, P-selectin and E-selectin was also analyzed, as well as expression of anti-thrombogenic thrombomodulin (TM) and pro-thrombogenic TF. Furthermore, the levels of the shear responsive, antiinflammatory Krüppel-like factor $2(K L F 2)$ and the apoptosis regulatory genes $\mathrm{BCl}$-2-associated $\mathrm{X}$ protein $(\mathrm{BAX})$ and $\mathrm{B}$-cell lymphoma $2(\mathrm{Bcl}-2)$ were evaluated. Experiments were performed in triplicate in two independent experiments. Total RNA from EC cultures was isolated by using the RNeasy micro-kit Qiagen with DNAse treatment (Qiagen, $\mathrm{GmbH}$, Hilden, Germany). The concentration of isolated RNA was determined with the NanoDrop microspectrophotometer (NanoDrop Products, Wilmington, DE, USA). A total of $100 \mathrm{ng}$ RNA per sample was subjected to reverse transcription (RT) with QScript cDNA synthese kit (Quanta Biosciences, Gaithersburg, MD, USA). PCR was performed by using PerfeCTa SYBR Green for iQ (Quanta Biosciences) and primer concentration of $10 \mu \mathrm{M}$. qPCR reactions were run on a MyiQ Single-Color Real time PCR detection system (Bio-Rad, Veenendaal, the Netherlands). 
Primers were designed with Oligoperfect ${ }^{\mathrm{TM}}$ Designer (Invitrogen), Primerz and Mfold (http://www.idtdna.com/scitools/Application/mfold/) and were synthesized by Eurogentec (Seraing, Belgium). Primer sequences are shown in Table 3.1. Samples were normalized for input based on both $\beta$-Actin and GAPDH values. Expression levels of PFAECs were used as reference and set at 1.0.

Table 3.1. Primer sequences

\begin{tabular}{|c|c|c|c|}
\hline Gene & Forward & Reverse & Accession nr. \\
\hline $\mathrm{CD}_{31}$ & $5^{\prime}$-GGGTCTATAACTCAGGGAGATAC-3' & $5^{\prime}$-CTTCGATCACCTCCTTCTTG-3' & NM_213907 \\
\hline vWF & $5^{\prime}$-AGGTCAGATTCAACCACCTG-3' & $5^{\prime}$-TTCTCATCACAGATCCCACA-3' & AYoo 4876 \\
\hline eNOS & $5^{\prime}$-CATGGATGAGTATGACGTGG-3' & 5'-AACTCTCTCCATTCTCTGGG-3' & NM_214295 \\
\hline VE-cadherin & $5^{\prime}$-GACAAGGAGTAACACCACGAGA-3' & $5^{\prime}$-TCCCGTTGTCCGAGATGAGTA- $3^{\prime}$ & 100135673 \\
\hline EphrinB2 & $5^{\prime}$-CCCAGTGACATTATCATCCC-3' & $5^{\prime}$-CATCTCCTGGACTATGTACACC-3' & NM_001111 \\
\hline$N R P-1$ & $5^{\prime}$-СATCTCCTGGTTATCCTCACTC- $3^{\prime}$ & $5^{\prime}$-GTCATACTTGCAGTCTCTGTCC-3' & NM_001024628 \\
\hline COUP-TFII & $5^{\prime}$-CCATAGTCCTGTTCACCTCA-3' & $5^{\prime}$-GGTACTGGCTCCTAACGTATTC- $3^{\prime}$ & NM_001145155.1 \\
\hline $\mathrm{EphB}_{4}$ & $5^{\prime}$-GCAACATCCTGGTCAATAGC-3' & $5^{\prime}$-GTAGGTGGGATCAGATGAGTTC-3' & NM_004444 \\
\hline ICAM-1 & $5^{\prime}$-GACCTGACCAGAAGGTGTGT-3' & 5'-GTGGGTGAGCTTCAATGTTT- $3^{\prime}$ & NM_213816 \\
\hline VCAM-1 & $5^{\prime}$-ATACGACCATCTCCGTCAAC-3' & 5'-GAGGCTCTAGATTCCCATCC-3' & NM_213891.1 \\
\hline E-selectin & 5'-GGTGCTGTGTGTACATTTGC-3' & $5^{\prime}$-CAGGAGCTTCACAAGTAGGC-3' & NM_214268 \\
\hline P-selectin & $5^{\prime}$-GTCAACTACGATGCCAACCT-3' & $5^{\prime}$-CCTTAACAGAGCCAGGAGTG-3' & NM_214078 \\
\hline TF & $5^{\prime}$-ATTGAGGTGAAGCCAGGTCATCCA-3' & 5'-AAGTCCACCAACTCCCATCTTGCT-3' & NM_213785 \\
\hline Thrombomodulin & 5'-TTTGGTTGTTTCCCTGCCCTTGTG-3' & $5^{\prime}$-GCTGAAGAAAGCGCCATTCACCAA-3' & NM_001130732 \\
\hline BAX & $5^{\prime}$-CTGAGCAGATCATGAAGACAGG-3' & $5^{\prime}$-CACTCGCTCAACTTCTTGGTAG-3' & NM_004324 \\
\hline $\mathrm{BCl}-2$ & '5-GGATTGTGGCCTTCTTTGAG-3' & '5-GTTCAGGTACTCAGTCATCCAC-3' & NM_000633.2 \\
\hline KLF2 & 5'-CTACACTAGAGGATCGAGGCTT-3' & $5^{\prime}$-CCACCTGCCTTCCTATTTACAG-3' & NM_016270 \\
\hline GAPDH & 5'-GTGTCGGTTGTGGATCTGA-3' & $5^{\prime}$-CCTGCTTCACCACCTTCTT-3' & AFo69649 \\
\hline Beta-Actin & $5^{\prime}$-GCATCCTGACCCTCAAGTAC- $3^{\prime}$ & $5^{\prime}$-CACGCAGCTCGTTGTAGAAG-3' & $A Y_{550069}$ \\
\hline
\end{tabular}

\section{IMMUNOFLUORESCENCE}

To determine cellular localization of VE-cadherin and adhesion molecules ICAM- 1 , VCAM-1, E-selectin and P-selectin, immunofluorescent stainings were performed. Cells were grown in 96-wells imaging plates (BD) until confluence, fixed with $2 \%$ paraformaldehyde for 1 hour at $4^{\circ} \mathrm{C}$ and washed with PBS. After that, cells were incubated for 4 hours at room temperature with one of the following primary antibodies diluted in PBS/1\%BSA: anti-VE-Cadherin-FITC (LSBio, Seattle, WA, USA), anti-ICAM-AF488, anti-VCAM-AF488, anti-E-selectin-FITC or anti-P-selectin-AF488 (all Antibodies online, Aachen, Germany). Cells were counterstained with Hoechst 33342 (BD) and imaged using a Leica $\mathrm{DM} / 3000 \mathrm{~B}$ inverted fluorescence microscope equipped with a DFC350 FX camera (Leica). 


\section{PROLIFERATION}

Cellular proliferation was determined with the CellTiter $96^{\circledR}$ Aqueous Non-Radioactive Cell Proliferation Assay (Promega, Madison, WI, USA) using 3-(4,5-dimethylthiazol2-yl)-5-(3-carboxymethoxyphenyl)-2-(4-sulfophenyl)-2H-tetrazolium (MTS) according to the manufacturer's protocol. In brief, cells were seeded in a 96-wells plate with 5,000 cells $/ \mathrm{cm}^{2}$, and proliferation rate was evaluated at $24,48,72$, and 96 hours after incubation with $20 \mu \mathrm{l}$ of MTS agent for 2 hours. Absorbance was measured at $490 \mathrm{~nm}$ with a multiplate reader (VICTOR 1420, Perkin Elmer, Waltham, MA, USA). Proliferation was also assessed under flow. $\mu$-Slides lo.4 Luer (Ibidi) were coated with fibronectin in PBS $10 \mu \mathrm{g} / \mathrm{ml}$ and incubated for two hours $\left(37^{\circ} \mathrm{C} / 5 \% \mathrm{CO} 2\right)$ or $10 \mu \mathrm{g} / \mathrm{mL}$ collagen-I dissolved in ethanol at room temperature until ethanol was evaporated. Per slide, 37,500 cells were seeded and allowed to adhere for 24 hours before arterial shear stress $(2.0 \mathrm{~Pa}$ ) was applied. Cells were stained with Hoechst and pictures were obtained (4 per slide) with the BD Pathway High-Content Bioimager 855 with BD AttoVision software (BD Biosciences, Heidelberg, Germany). This was repeated at 24, 48 , and 72 hours after the start of shear stress. Amount of cells quantified at $t=0$ was used as a reference and set at 1.0.

\section{MIGRATION}

The wound-healing assay was performed as previously described. ${ }^{28}$ Briefly, $4 \times 10^{4}$ cells were seeded into six-well plates and incubated for 72-96 hours to reach confluence, and were then made quiescent overnight in starvation medium (EC medium without VEGF-A and FGF-2 with $0.5 \%$ FBS). A scratch wound was made with a sterile $200 \mu \mathrm{L}$ pipette tip, and detached cells were removed by washing with PBS. The cells were further cultured in fresh EC-medium (stimulated condition) or starvation medium (nonstimulated condition) and photographed immediately (o hours), and after 8 and 24 hours with an Eclipse TS10o-F inverted microscope (Nikon, Tokyo, Japan). Four photographs were taken per well. Migration of cells across the wound was evaluated by phase-contrast microscopy and the freeware program, Tscratch ${ }^{29}$ (http://www.cselab.ethz.ch), which provides automated segmentation and percentage wound closure. See supplemental material for representative images of the scratch assay at $t=0$ hours (Figure $\mathrm{S}_{3.1 \mathrm{~A}}$ ) and $\mathrm{t}=24$ hours (Figure $\mathrm{S}_{3.1 \mathrm{~B}}$ ) and the corresponding output of Tscratch

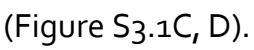




\section{ADHESION}

24-wells plates were coated with fibronectin in PBS $10 \mu \mathrm{g} / \mathrm{mL}$ and incubated for two hours $\left(37^{\circ} \mathrm{C} / 5 \% \mathrm{CO} 2\right)$ or $10 \mu \mathrm{g} / \mathrm{ml}$ collagen-I dissolved in ethanol at room temperature until ethanol was evaporated. Wells were post-coated with $1 \%$ BSA for one hour at room temperature, which also served as a control. Static adhesion to different coatings was assessed with fluorescence measurement after labelling the cells with calcein AM (Invitrogen). Cells were resuspended in $0.5 \mathrm{ml} \mathrm{EC-medium} \mathrm{per} \mathrm{well} \mathrm{and} \mathrm{allowed} \mathrm{to}$ adhere for 30 minutes at $37^{\circ} \mathrm{C} / 5 \% \mathrm{CO}_{2}$. To remove non-adhering cells the culture was gently washed with PBS and fluorescence was measured at $490 \mathrm{~nm}$ with a multiplate reader (VICTOR 1420, Perkin Elmer). A representative image of static adhesion of ECS to BSA is shown in the supplemental material (Figure $\mathrm{S}_{1} \mathrm{E}$ ).

Adhesion under flow was assessed with collagen-I and fibronectin coated $\mu$-Slides $\mathrm{VI}{ }^{0.4}$ Luer (Ibidi) equipped with 6 micro channels. Per channel $\left(0.6 \mathrm{~cm}^{2}\right), 9,500$ cells were seeded and allowed to adhere for 30 minutes. Then, images for $\mathrm{t}=0$ were taken by the BD Pathway High-Content Bioimager. Subsequently, arterial shear stress (2.0 Pa) was applied for 10 minutes using Gelofusin after which images were made again. Amount of cells quantified at $\mathrm{t}=0$ was used as a reference and set at 1.0.

\section{EVALUATION OF THROMBOGENICITY BY THROMBIN GENERATION}

ECs induced thrombin generation in human platelet-poor plasma was measured by means of the modified calibrated automated thrombogram (mCAT) method (Thrombinoscope BV, Maastricht, The Netherlands), which employs a low affinity fluorogenic substrate for thrombin (Z-Gly-Gly-Arg-AMC) to continuously monitor thrombin activity in clotting plasma. This assay is designed for plasma analysis but was modified to utilize on cell layers in order to study the contribution of ECs on the activation and progression of thrombin generation. Normal platelet poor-plasma was obtained from pooling plasmas of 80-9o healthy donors, according to the standard procedure of the Laboratory of Haematology, Maastricht University Medical Center. Cells were seeded in a 96-wells plate and cultured up to a confluent monolayer. Cells were either kept in control conditions or stimulated with TNF $\alpha$ (R\&D Systems) with $80 n g / m L$ for 16 hours. Then, cells were washed with HEPES buffer and a previously described thrombin generation assay was performed. ${ }^{30}$ According to the instructions, measurements were conducted in $80 \mu$ human platelet-poor pooled plasma or protein $\mathrm{C}$ deficient plasma in a total volume of $120 \mu \mathrm{l}$. To the $80 \mu \mathrm{l}$ plasma sample, $20 \mu \mathrm{l}$ trigger reagent (24 $\mu \mathrm{M}$ phospholipids at 20:20:60 mol\% PS:PE:PC) was added. After 10 minutes incubation at $37^{\circ} \mathrm{C}, 20 \mu \mathrm{FluCa}(2.5 \mathrm{mM}$ fluorogenic substrate, $87 \mathrm{mM}$ Calcium 
chloride) was added to start recording of the thrombin generation. In order to correct for inner-filter effects and substrate consumption, each thrombin generation measurement was calibrated against the fluorescence curve obtained in a sample from the same plasma $(80 \mu \mathrm{l})$, added with a fixed amount of thrombin- $\alpha 2$-macroglobulin complex (20 $\mu \mathrm{l}$ Thrombin Calibrator, Thrombinoscope BV) and $20 \mu \mathrm{l}$ FluCa. Fluorescence was read in a Fluoroskan Ascent reader (Thermo Labsystems OY, Helsinki, Finland) equipped with a $390 / 460 \mathrm{~nm}$ filter set and thrombin generation curves were calculated with the Thrombinoscope software (Thrombinoscope BV). Two parameters were derived from the thrombin generation curves: lag time (initiation phase of coagulation) and peak height. Lag time was defined as the time to reach onesixth of the peak height.

\section{PLATELET ADHESION}

Cells were cultured on $\mu$-Slides $I^{0.4}$ Luer (Ibidi) up to $100 \%$ confluence and then arterial shear stress of 2.0 Pa (flow rate $15.19 \mathrm{ml} / \mathrm{min}$ ) was applied for 72 hours. In addition, cells were either stimulated with TNF $\alpha$ 8ong/ $\mathrm{ml}$ for 24 hours or vehicle treated. Platelet poor plasma (PPP) was prepared from fresh whole human blood with citrate buffer after 2 spins for 10 minutes at 2,000g. Platelets were extracted from fresh human blood with acid citrate dextrose (ACD) buffer centrifuged for 15 minutes at $200 \mathrm{~g}$. This platelet rich plasma (PRP) was centrifuged again for 2 minutes at 3,000g and HEPES buffer ( $\mathrm{pH}$ 6.6), Apyrase (100 U/ml) was added. Then, platelets were labelled with carboxyfluorescein diacetate succinimidyl ester (CFSE) (Invitrogen) $6 \mu \mathrm{g} / \mathrm{ml}$ for 10 minutes and added to PPP with a final concentration of $10^{8}$ platelets $/ \mathrm{ml}$. Platelets were activated with MeS-ADP 10mM for 5 minutes just prior to the experiment. Red blood cells were isolated from the remaining PPP and PRP fractions by means of two centrifugation rounds at $850 \mathrm{~g}$ and $1,950 \mathrm{~g}$ in order to remove white blood cells and supernatant. Then, they were added to the PRP resulting in a final hematocrit of $45 \%$. PRP was perfused over the cells with a flow rate of $2.28 \mathrm{~mL} / \mathrm{min}$. Immediately afterwards, cells were washed with Gelofusin for the same amount of time and flow rate in order to remove non-adherent platelets. 5 pictures were taken per slide with a Leica DMI $3000 \mathrm{~B}$ inverted microscope and a DFC 350 FX camera (Leica) (representative image; Figure $\mathrm{S}_{1} \mathrm{~F}$ ) and area covered by platelets was analyzed with ImageJ version 1.43 (National Institutes of Health, Bethesda, MD, USA). 


\section{PROSTACYCLIN AND NO PRODUCTION}

6-keto-PGF1alpha, a stable hydrolysis product of prostacyclin, and the sum of nitrate and nitrite, two stable breakdown products of NO, were measured in cell culture supernatant using an enzyme immunoassay (Assay Designs, Inc, Ann Harbor, MI, USA) for prostacyclin and the Griess reaction for NO detection (Assay Designs), respectively. Cells were grown in a 6 -wells plate up to $80 \%$ confluency and subsequently stimulated with $1 \mu \mathrm{g} / \mathrm{ml}$ lipopolysaccharide (LPS) (Sigma, St. Louis, MO, USA), or $150 \mathrm{mM} \mathrm{H}_{2} \mathrm{O}_{2}$ for 24 hours or kept non-stimulated. Then, $250 \mu \mathrm{L}$ supernatant per well was collected and frozen at $-20^{\circ} \mathrm{C}$ for analysis at a later time point. Analysis was run according to the manufacturer's protocol.

\section{STATISTICAL ANALYSIS}

In case of two experimental groups, the $t$-test was used for statistical analysis. Differences between more than two groups were evaluated by means of one-way ANOVA with Tukey's post-hoc testing. When data were not normally distributed, the Mann-Whitney $U$ test was applied. $P$ values $<0.05$ were considered to be significant. Analyses were performed with SigmaStat v2.03 (Systat Software, San Jose, CA, USA) and Prism 5.o for Windows (GraphPad Software Inc., San Diego, CA, USA).

\section{RESULTS}

\section{CONFIRMATION OF ENDOTHELIAL PHENOTYPE}

Cells in culture showed typical cobblestone morphology and could be cultured up to passage 25 without significant growth delay. Doubling time was approximately 22 hours. All cells stained positive for the typical endothelial marker CD31 (Figure 3.1A, $B)$, which was confirmed by uniform $C_{31}$ expression assessed by flow cytometric analysis (Figure $3.1 \mathrm{G}, \mathrm{H}$ ). Intracellular vWF was clearly present in PFVECs, but weakly expressed in PFAECs (Figure 3.1C, D). Quantification of the positively stained area showed a higher ratio for PFVECs compared to PFAECs (relative values; $7.4 \pm 2.19$ vs. $1.0 \pm 0.62, P<0.05$, Figure S3.2). Both PFAECs and PFVECs revealed uptake of Ac-LDL, but this appeared stronger in PFAECs (Figure 3.1 E, F). 

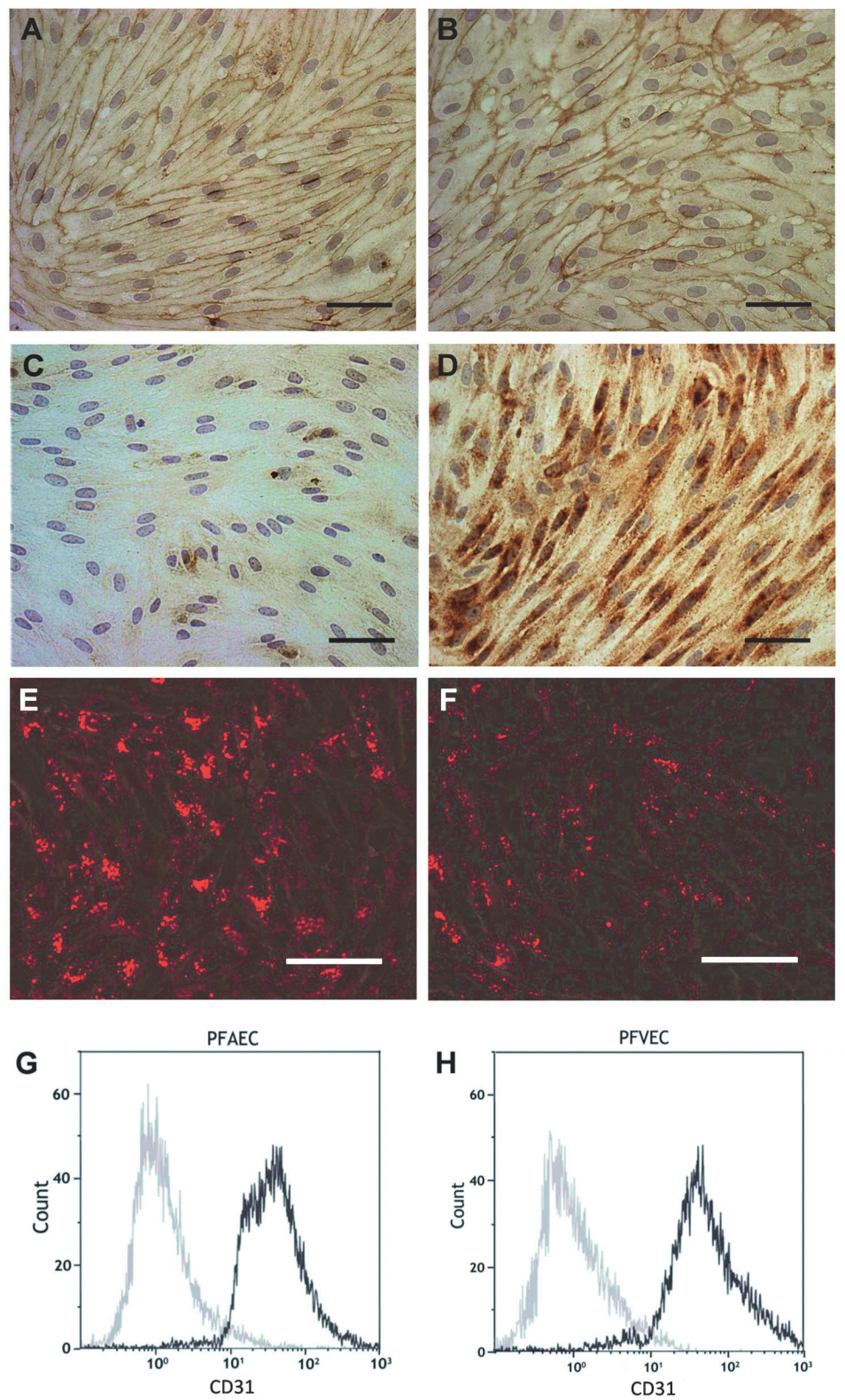

Figure 3.1. Endothelial phenotype of PFAECs $(A, C, E, G)$ and $\operatorname{PFVECs}(B, D, F, H)$. Immunohistochemical staining was performed for $C_{31}(A, B)$ and $v W F(C, D)$. PFVECs (D) showed higher expression of vWF as compared to PFAECs (C). Ac-LDL uptake (E, F), a typical endothelial feature, was most prominent for PFAECS (E). FACS analysis for presence of $C_{31}$ showed a cell population with only high expression for both cultures (black lines in $G, H$ ). The gray lines represent isotype controls. On the $X$-axis fluorescence intensity is presented using a log scale. Scale bars represent $100 \mu \mathrm{m}$ 


\section{DIFFERENCES IN ENDOTHELIAL GENE EXPRESSION}

Cells were exposed to arterial shear stress $(2.0 \mathrm{~Pa})$ for 72 hours or kept in static conditions before sampling for gene expression. Cells in flow conditions aligned in the direction of the flow and adhered properly for at least 72 hours. Gene expression levels are shown in Table 3.2. Under both static and flow conditions, CD31, NRP-1, EphB4, ICAM-1, P-selectin, E-selectin, thrombomodulin and KLF-2 were present at comparable levels for PFAECs and PFVECs (Table 2). VWF was higher expressed in PFVECs, which was in accordance to the results of the immunohistochemical staining for $v W F$, while eNOS and VE-cadherin showed lower expression in PFVECs. As expected, the typical arterial marker EphrinB2 was higher expressed in PFAECs and the venous marker COUP-TFII was more prominent for PFVECs, although $\mathrm{EphB}_{4}$ and NRP1 did not show any differences. VCAM-1 expression was lower expressed in PFVECs but only under flow conditions. In static conditions, the procoagulant glycoprotein TF was lower expressed in PFVECs, as well as the apoptosis-associated genes BAX and $\mathrm{BCl}-2$ (Table 3.2).

Table 3.2. Gene expression under static and flow conditions

\begin{tabular}{lllll}
\hline & Static & & Flow & \\
& PFAEC & PFVEC & PFAEC & PFVEC \\
\hline CD31 & $1.00 \pm 0.08$ & $0.97 \pm 0.15$ & $1.00 \pm 0.18$ & $1.18 \pm 0.09$ \\
vWF & $1.00 \pm 0.43$ & $64 \pm 9 \ddagger$ & $1.00 \pm 0.20$ & $45 \pm 23^{*}$ \\
eNOS & $1.00 \pm 0.06$ & $0.39 \pm 0.04^{\ddagger}$ & $1.00 \pm 0.15$ & $0.95 \pm 0.09$ \\
VE-cadherin & $1.00 \pm 0.10$ & $0.62 \pm 0.10^{*}$ & $1.00 \pm 0.16$ & $0.53 \pm 0.07^{*}$ \\
EphrinB2 & $1.00 \pm 0.11$ & $0.22 \pm 0.07^{\ddagger}$ & $1.00 \pm 0.10$ & $0.09 \pm 0.04^{\ddagger}$ \\
NRP-1 & $1.00 \pm 0.30$ & $0.87 \pm 0.24$ & $1.00 \pm 0.23$ & $0.88 \pm 0.28$ \\
COUP-TFII & $1.00 \pm 0.06$ & $8.7 \pm 1.6 \ddagger$ & $1.00 \pm 0.13$ & $23 \pm 9^{*}$ \\
EphB4 & $1.00 \pm 0.08$ & $1.36 \pm 0.20$ & $1.00 \pm 0.17$ & $1.38 \pm 0.21$ \\
ICAM-1 & $1.00 \pm 0.12$ & $1.21 \pm 0.26$ & $1.00 \pm 0.14$ & $1.09 \pm 0.14$ \\
VCAM-1 & $1.00 \pm 0.35$ & $0.62 \pm 0.57$ & $1.00 \pm 0.27$ & $0.21 \pm 0.03^{*}$ \\
P-selectin & $1.00 \pm 0.73$ & $0.80 \pm 0.19$ & $1.00 \pm 0.63$ & $2.2 \pm 0.6$ \\
E-selectin & $1.00 \pm 0.57$ & $3.1 \pm 1.1$ & $1.00 \pm 0.78$ & $1.72 \pm 0.43$ \\
TF & $1.00 \pm 0.21$ & $0.31 \pm 0.05^{\dagger}$ & $1.00 \pm 0.16$ & $0.5^{*} \pm 0.17$ \\
Thrombomodulin & $1.00 \pm 0.16$ & $0.87 \pm 0.15$ & $1.00 \pm 0.17$ & $1.30 \pm 0.12$ \\
BAX & $1.00 \pm 0.08$ & $0.72 \pm 0.09^{*}$ & $1.00 \pm 0.13$ & $0.82 \pm 0.07$ \\
Bcl-2 & $1.00 \pm 0.08$ & $0.56 \pm 0.08 \dagger$ & $1.00 \pm 0.10$ & $0.77 \pm 0.08$ \\
KLF2 & $1.00 \pm 0.16$ & $1.00 \pm 0.38$ & $1.00 \pm 0.27$ & $0.61 \pm 0.11$ \\
\hline
\end{tabular}

Relative expression levels \pm SEM are shown. $n=6$ experiments for each condition. Expression levels of PFAECs were used as reference and set at 1.0. $* P<0.05, \dagger P<0.01, \ddagger P<0.001$ 

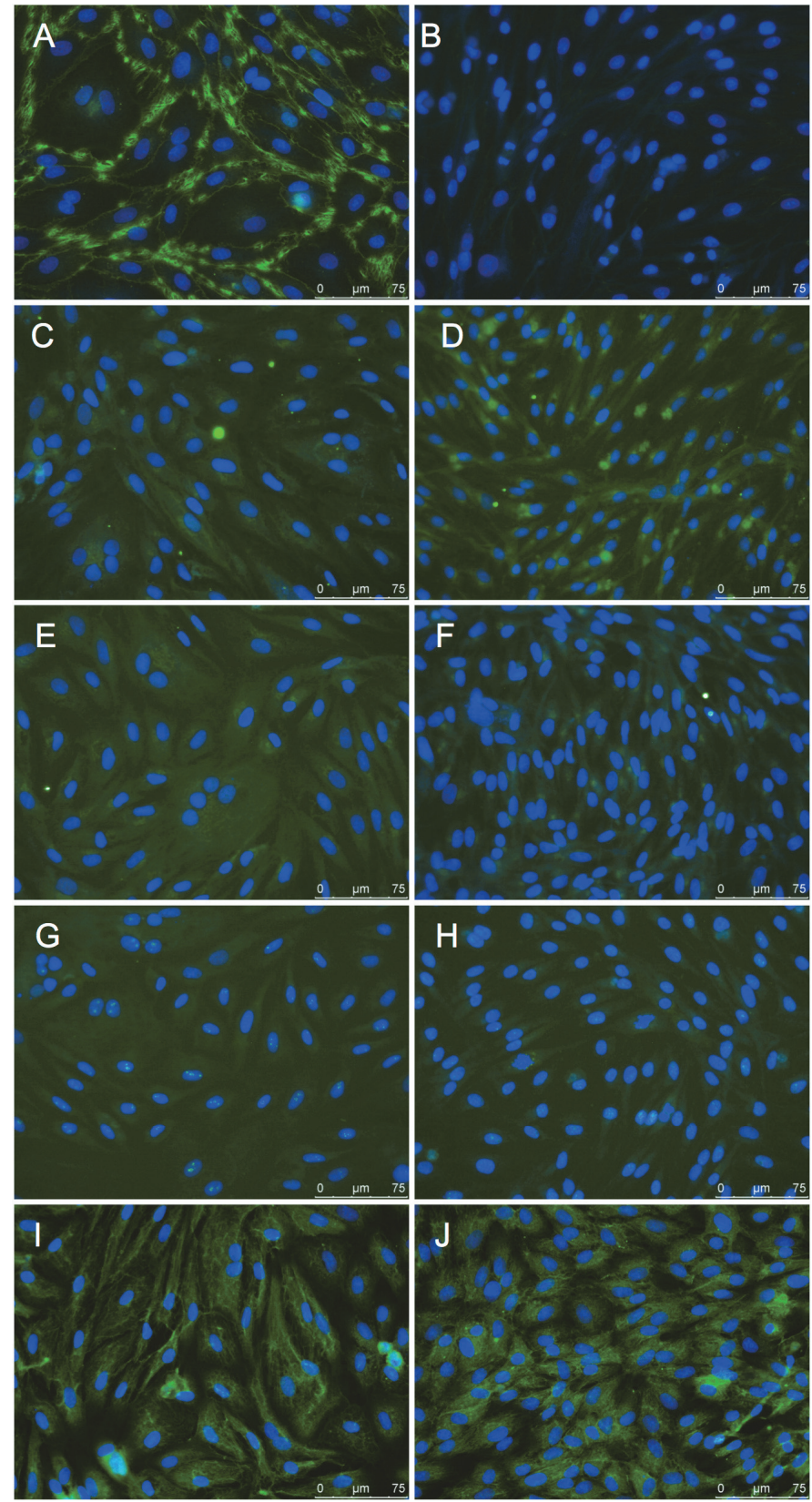

Figure 3.2. Immunohistochemistry of $\operatorname{PFAECs}(A, C, E, G, I)$ and $\operatorname{PFVECs}(B, D, F, H, J)$. VE-cadherin is strongly expressed on the cell membrane of PFAECS (A) and absent in PFVECs (B). ICAM-1 (C, D) expression is similar but appears to be present in the cytoplasm in some PFVECs (D). VCAM-1 (E, F), E-selectin $(G, H)$ and P-selectin $(I, J)$ expression are comparable between PFAECs (left panel) and PFVECs (right panel). 


\section{IMMUNOFLUORESCENCE OF VE-CADHERIN AND ADHESION MOLECULES}

The cellular localization of VE-cadherin and the adhesion molecules ICAM-1, VCAM-1, E-selectin and P-selectin was visualized by means of immunofluorescent staining (Figure 3.2). VE-cadherin was strongly expressed at the cell membrane of PFAECs (Figure 3.2A), and absent in PFVECs (Figure 3.2B) conforming our gene expression analysis. Except for lower VCAM-1 expression in PFVECs after exposure to flow, no differences in gene expression for adhesion molecules were observed and this was confirmed by the immunofluorescent stainings for ICAM-1 (Figure 3.2C, D), VCAM-1 (Figure 3.2E, F), P-selectin (Figure 3.2 G, H) and E-selectin (Figure 3.2I, J) showing no differences between cell types. Stained cells were cultured in static conditions and consequently VCAM-1 expression did not differ between cell types. In PFVECs, ICAM-1 appeared to be present in the cytoplasm in some PFVECs (Figure 3.2D), which was not seen in PFAECs (Figure 3.2C).

\section{FUNCTIONAL CHARACTERISTICS OF PFAECS AND PFVECS}

Cell growth rate of PFAECs and PFVECs was similar during cell culturing, which was determined using the MTS assay (Figure 3.3A). Absorbance measured at day four amounted $1.00 \pm 0.07$ for PFAEC and $1.07 \pm 0.09$ for PFVEC.

To test migration, a wound healing assay was performed. After 24 hours, PFAECs showed better wound closure $(80 \pm 12 \%$ vs. $62 \pm 13 \%$ for PFVECs, $P<0.01$, high serum conditions). The ability of cells to migrate was significantly reduced when they were kept in low serum (0.5\% FBS) conditions, nonetheless the migration rate was still higher for PFAECs as compared to PFVECs (66 $515 \%$ vs. $50 \pm 8 \%, P<0.01$ (Figure $3.3 \mathrm{~B}$ ).

For EC seeding to be successful in TE in a potentially high flow environment, adhesion of cells to the substrate needs to be sufficient to create a uniform shear-resistant cell layer. We measured static adhesion to different substrates in vitro after 30 minutes (Figure $3.3 \mathrm{C}$ ). Adhesion was maximal to fibronectin and comparable between cell types $\left(10.4 \times 10^{3} \pm 318\right.$ FU for PFAECs vs. $10.2 \times 10^{3} \pm 663$ FU for PFVECs). Adhesion to collagen-I and polystyrene was significantly higher for PFAECs as compared to PFVECs (respectively $7.48 \times 10^{3} \pm 705$ and $5.66 \times 10^{3} \pm 111 \mathrm{FU}, P<0.05$ ). 

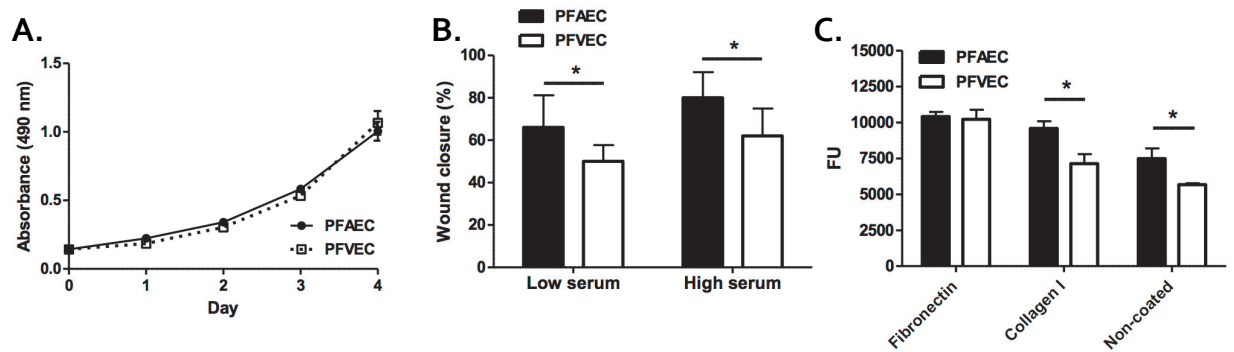

Figure 3.3. Functional characteristics of PFAECs and PFVECs. A. Analysis of proliferation at different time points showing similar growth rates for PFAECs and PFVECs. B. Migration of PFAECs and PFVECs under low $(0.5 \%)$ and high (5\%) serum conditions was assessed with a wound-healing assay. Wound closure after 24 hours was higher for PFAECs compared to PFVECs in both conditions indicating higher migratory capacity $(* P<0.01)$. C. Static adhesion of ECs after 30 minutes was maximal for fibronectin. Adhesion to collagen and non-coated polystyrene was higher for PFAECs compared to PFVECs. FU=fluorescent units $\left({ }^{*} P<0.05\right)$. Means are shown and error bars represent $S D(n=4$ for $A$ and $B, n=3$ for $C)$.

\section{EFFECTS OF DIFFERENT COATINGS ON CELL BEHAVIOUR}

The influence of different coatings was assessed under flow conditions using arterial shear stress (2.0 Pa). Collagen-I and fibronectin coated $\mu$-slides VI 0.4 Luer (Ibidi) were seeded with ECs and after 30 minutes, arterial shear stress was applied for 10 minutes. The total amount of adhered cells was significantly lower after 10 minutes but not after 5 , compared to $t=0$ except for PFAECs on fibronectin. On collagen more PFAECs remained adhered as compared to the fraction of PFVECs adhering after 10 minutes (0.88 \pm 0.03 vs. $0.83 \pm 0.04, P<0.05$ ) (Figure $3.4 \mathrm{~A}$ ).

Proliferation was assessed on collagen-I and fibronectin coated slides after 24,48 and 72 hours and compared to $t=0$. Proliferation rate was highest for PFVECs that were cultured on fibronectin, however this was not significantly different due to substantial variation (Figure $3.4 \mathrm{~B}$ ).

After 72 hours of arterial shear stress, slides were fixated and stained for VWF, which resulted in highest fluorescence intensity on collagen. PFVECs on collagen expressed more vWF compared to PFAECs (3.56 \pm 0.25 vs. $3.23 \pm 0.25$ RFU/cell, $P<0.05$ ) (Table 3.3, Figure $3.4 \mathrm{C}$ ). 
A.

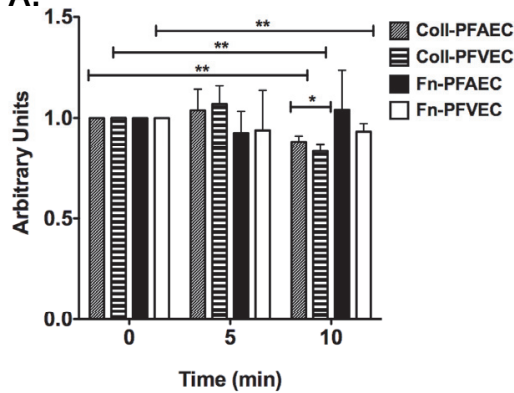

C.
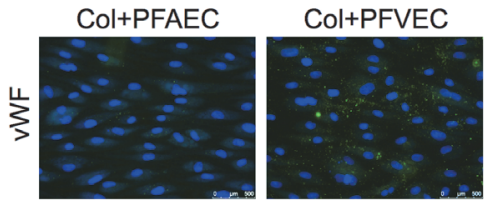

B.

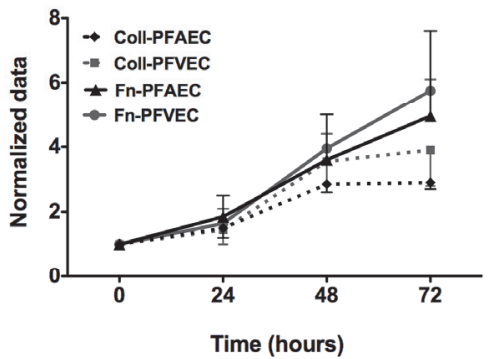

Fn+PFAEC

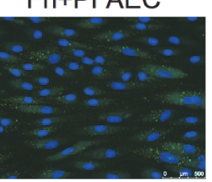

Fn+PFVEC

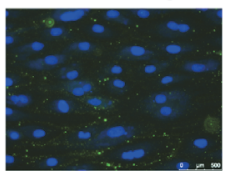

Figure 3.4. Effect of flow and different coatings on arterial and venous ECs. A. Adhesion under arterial shear stress conditions (2.0 Pa) on collagen-I and fibronectin coated slides. ECs were allowed to adhere for 30 minutes before flow exposure. Amount of cells at time $=0$ was used as a reference and set at 1.0. Adhesion of PFAECs was stronger compared to PFVECs at $\mathrm{t}=10$ minutes when seeded on collagen $\left({ }^{*} P<0.05,{ }^{* *} P<0.01\right)$. B. Proliferation seems to be higher on fibronectin compared to collagen when cells were exposed to arterial shear stress (2.0 Pa), however this was not significantly different. C. vWF expression of ECs seeded on different coatings and exposed to arterial shear stress for 72 hours. Means are shown and error bars represent SD ( $n=6$ for $\mathrm{A}$ and $n=8$ for $\mathrm{B}$ ).

Table 3.3. vWF expression in ECs under flow

\begin{tabular}{lll}
\hline & PFAEC & PFVEC \\
& (RFU/Cell) & (RFU/Cell) \\
\hline Collagen-I & $3.23 \pm 0.25^{\dagger}$ & $3.56 \pm 0.25^{*}$ \\
Fibronectin & $2.38 \pm 0.11$ & $2.91 \pm 0.82$ \\
\hline
\end{tabular}

$\mathrm{RFU}=$ relative fluorescent units. Means $\pm \mathrm{SD}$ are shown, $n=8 .{ }^{*} P<0.05$ compared to PFAEC. ${ }^{\dagger} P<0.05$ compared to fibronectin.

\section{THROMBOGENIC ASPECTS OF PFAECS AND PFVECS}

Initiators and regulators of coagulation expressed by ECs were assessed by means of thrombin generation in human plasma, in which the lag time is influenced by EC-derived tissue factor and the presence of thrombomodulin can be deduced from differences in peak height between normal plasma and plasma from patients with a protein C-deficiency. PFAECs had higher TF presence than PFVECs as suggested by a shorter lag time $(4.25 \pm 0.28$ respectively $5.00 \pm 0.24, P<0.01)$ of the thrombin generation curve (Figure 3.5A, Table 3.4). 
After TNFa stimulation, the lag time decreased in both cell types (i.e. higher TF-expression). The difference in peak height between normal plasma and protein $C$ deficient plasma was higher for PFVECs indicating more thrombomodulin expression on the surface of venous ECs compared to arterial ones (Table 3.4).
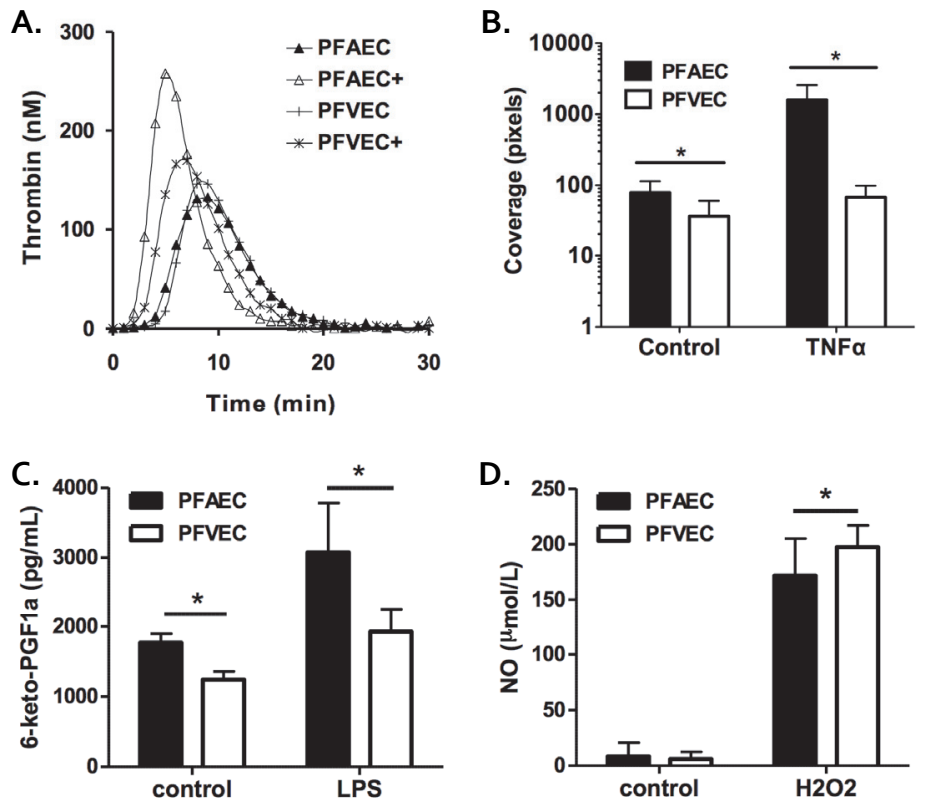

Figure 3.5. Thrombogenic characteristics of PFAECs and PFVECs. A. Cell based thrombin generation on nonstimulated and TNF $\alpha$ ( $80 \mathrm{ng} / \mathrm{mL}, 16$ hours) treated (+) cells. PFAECs revealed a shorter lag time compared to PFVECs, indicating stronger TF-activity. Stimulation with TNF $\alpha$ resulted in shorter lag time for both cell types and higher peaks (A, Table 3). B. Human platelet adhesion to a confluent layer of PFAECs and PFVECs measured under flow $(2.28 \mathrm{ml} / \mathrm{min})$ with ADP (10 mM) stimulated platelets and/or TNF $\alpha$ ( $80 \mathrm{ng} / \mathrm{ml}, 16$ hours) stimulated ECs. Cells were exposed to arterial shear stress for 72 hours prior to the experiment. Platelet adhesion was significantly stronger to PFAECs in stimulated and non-stimulated conditions $\left({ }^{\star} P<0.05\right)$. C. Basal and LPS $(1 \mu \mathrm{g} / \mathrm{ml}, 24$ hours) stimulated production of prostacyclin was higher in PFAECs. D. NO production was comparable between cell types but treatment with $\mathrm{H}_{2} \mathrm{O}_{2}$ (150 mM, 24 hours) resulted in strong increase in NO production that was higher $( \pm 15 \%)$ in PFVECs. $\left({ }^{*} P<0.05\right)$ Means are shown and error bars represent $\mathrm{SD}$ ( $n=4$ for $\mathrm{A}$ and $\mathrm{B}, n=6$ for $\mathrm{C}$ and $\mathrm{D})$.

Platelet adhesion was assessed under flow by a perfusion system with ADP-activated platelets. Cells were exposed to arterial shear stress for 72 hours prior to the experiment. Stimulation of ECs with TNF $\alpha$ resulted in increased platelet adhesion. As shown in Figure 3.5B, PFAECs bound more platelets than PFVECs under stimulated and non-stimulated conditions. Surface coverage amounted $79.2 \pm 35$ pixels for PFAECs and $35.6 \pm 23$ pixels for PFVECs (equal surfaces measured, $P<0.05$ ) in non-stimulated 
conditions and after TNF $\alpha$ values increased up to $1,580 \pm 996$ (PFAECs) and $68 \pm 31$ (PFVECS), $P<0.05$.

Table 3.4. Thrombin generation analysis in presence of ECs

\begin{tabular}{lllll}
\hline & Condition & PFAECs & PFVECs & P-value \\
\hline Lag time (s) & NP & $4 \cdot 3 \pm 0.3$ & $5.0 \pm 0.2$ & $<0.01$ \\
& Protein C def & $4 \cdot 3 \pm 0.4$ & $5.6 \pm 0.3$ & $<0.01$ \\
& TNF $\alpha$ & $2.3 \pm 0.1$ & $3.1 \pm 0.6$ & $<0.05$ \\
Peak (nM) & NP & $134 \pm 26$ & $155 \pm 61$ & $\mathrm{NS}$ \\
& Protein C def & $139 \pm 13$ & $182 \pm 29$ & $<0.05$ \\
& TNF & $262 \pm 36$ & $175 \pm 39$ & $<0.05$ \\
\hline
\end{tabular}

$\mathrm{NP}=$ normal human pooled plasma, TNF $\alpha=$ cells treated with TNF $\alpha$ ( 16 hours, $80 \mathrm{ng} / \mathrm{ml}$ ), Protein $\mathrm{C}$ def=Protein $C$ deficient plasma, NS=non significant

\section{PROSTACYCLIN AND NO PRODUCTION IN PFAECS AND PFVECS}

6-keto-PGF1 $\alpha$ levels were measured in cell culture supernatant and turned out to be higher for PFAECs under LPS stimulated $(3,071 \pm 707$ for PFAECs and $1,925 \pm 330 \mathrm{pg} / \mathrm{ml}$ for PFVECs, $P<0.01)$ and non-stimulated conditions $(1,767 \pm 128$ for arterial and $1,239 \pm 120 \mathrm{pg} / \mathrm{ml}$ of venous cells, $P<0.01$, Figure $3.5 \mathrm{C}$ ).

There were no differences in $\mathrm{NO}$ production in non-stimulated conditions, as assessed by the Griess reaction. However, after addition of $\mathrm{H}_{2} \mathrm{O}_{21}$ PFVECs produced $15 \%$ more NO than PFAECs (198 \pm 33 vs. $172 \pm 20 \mu \mathrm{mol} / \mathrm{l}, P<0.05$, Figure $3.5 \mathrm{D}$ ).

\section{DISCUSSION}

Vascular TE graft integrity is highly dependent on inflammatory and thrombogenic risks. These risks can be reduced by applying ECs to the luminal lining of the graft. This study aimed to compare arterial (PFAECs) and venous ECs (PFVECs) of vessels from an anatomically comparable region taking into account specific properties relevant for vascular TE. As expected, typical features of ECs such as ac-LDL uptake and $C_{31}$ expression were present in both cell types, whereas VWF was expressed in a lower amount in PFAECs, in accordance with previous reports. ${ }^{14}$ Staining for vWF was also performed after 72 hours of arterial shear stress and showed slightly stronger expression in PFVECs when seeded on collagen compared to PFAECs. Proliferation was highly comparable between PFAECs and PFVECs. From our data it can be concluded that both EC types present with high viability ex vivo and retain EC characteristics during culturing until at least passage 12. The higher migration and 
adhesion to collagen I and non-coated polystyrene of PFAEC reflect differences in adherence and migration capacity between both sources and might be of importance for the seeding and coverage of TE grafts with a confluent EC layer in situ.

In our extensive gene expression analysis we found differences regarding arterial and venous specification markers like EphrinB2 (higher expressed in PFAECs) and COUPTFII (increased in PFVECs). Arterial shear stress appears to diminish EphrinB2 expression in both arterial and venous $\mathrm{ECs}^{31}$ although Egorova et al. did not observe this effect. ${ }^{32}$ Our data show persisting higher EphrinB2 expression in arterial ECs under static and flow conditions. VE-cadherin was also higher expressed by arterial ECs, which was confirmed by immunofluorescence. However, no literature regarding distinct expression of VE-cadherin is available hence we consider this a new finding. ENOS, the pro-apoptotic BAX gene and anti-apoptotic Bcl-2 were all expressed at lower levels in venous ECs under static conditions but this difference disappeared after exposure to arterial shear stress.

It has been reported that venous endothelium has stronger inflammatory properties, reflected in, for example, expression of adhesion molecules responsible for leukocyte adhesion to the endothelium and a higher responsiveness to TNF ${ }^{18,33}$ Our gene expression analysis showed similar expression of ICAM-1, E-selectin and P-selectin, whereas VCAM-1 was higher expressed in arterial ECs after exposure to shear stress. Additional immunofluorescent staining for adhesion molecules also showed comparable differences in levels of expression. Liu et al. mainly looked at in vivo and in vitro TNF $\alpha$ induction of adhesion molecules, which was not evaluated in our study, and reported that expression levels in cell culture did not differ significantly between human umbilical arterial ECs (HUAECs) and human umbilical venous ECs (HUVECs). ${ }^{33}$ The higher expression of VCAM-1 in arterial ECs as reported by us was also observed in mice aortas compared to vena cava endothelium in vivo in the study of Eriksson et al. ${ }^{18}$ Endothelial secretory functions considered to be important for preventing thrombotic events and to inhibit leukocyte adhesion, such as NO and prostacyclin production, were different between EC types. Prostacyclin was produced in larger amounts by PFAECs. NO production differed only in $\mathrm{H}_{2} \mathrm{O}_{2}$ stimulated conditions, and was higher for PFVECs.

One of the key functions of the endothelial layer in TE conduits is to prevent thrombosis, which is generally the result of platelet adhesion and coagulation. Platelet adhesion was tested on ECs exposed to arterial shear stress for 72 hours prior to the experiment. In these circumstances, venous ECs appeared to be less thrombogenic than arterial ECs. Only arterial shear stress was applied as these conditions can be expected in vivo as well when implanting TE grafts. Investigating the effect of TNF $\alpha$ 
under shear stress conditions seemed also more physiologic to us as shear stress modulates this response in ECs. Changes in inflammatory and thrombogenic gene expression were counteracted by shear stress in TNF $\alpha$-stimulated ECs. ${ }^{34,35}$ Thus, shear stress renders ECs more resistant to inflammatory stress. The higher expression of VWF in PFVECs did not lead to increased platelet adhesion compared to PFAECs, interestingly. To our knowledge, platelet adhesion has not been compared between arterial and venous ECs yet.

The coagulation potential of the ECs was assessed with the thrombin generation assay in plasma in which the contribution of EC-derived TF and thrombomodulin are reflected. This methodology was shown to be very robust to study plasma samples from patients with coagulation defects. ${ }^{36-38}$ For this study, the method was modified to study EC initiated or modulated coagulation. This novel approach showed that PFAECs have high TF-activity as demonstrated by a left-shift in lag time. Zwaginga et al showed that TF expression can vary between ECs with lack of expression on HUVECs under basal conditions and clear expression for ECs from omentum and atrial endocardial cells in vitro. ${ }^{39}$ This emphasizes the heterogeneity of endothelial cell sources and the consequence for EC studies in vitro. Our finding that arterial ECs express more TF confirms observations by Silverman et al. in ECs from human aorta and vena cava. ${ }^{40}$ The difference in peak height between normal plasma and protein $C$ deficient plasma was higher for PFVECs, indicating more thrombomodulin activity for venous ECs. These results are in accordance with our static gene expression analysis showing lower TF and higher thrombomodulin expression in venous ECs. An earlier report on a vein-grafting model in rabbits also indicated higher thrombomodulin expression in venous ECs. This phenomenon was lost when a vein graft was placed in an arterial position ${ }^{41}$ and also our gene expression profiles after arterial shear stress exposure complies with these data. Indeed, thrombomodulin expression seems to be regulated in a shear stress-dependent manner via Krüppel-like factor family members. ${ }^{42,43}$ However, no data are currently available yet regarding the phenotypic stability of cells after in vitro culture and reimplantation in vivo. Future research is needed to clarify this topic.

For tissue engineering, ECs will be seeded on a bare biodegradable scaffold, or a scaffold already seeded with SMC-like cells (myofibroblasts, SMCs, MSCs) in most cases. In this study we did not include bare scaffold material, nor SMC-like cells to evaluate arterial and venous endothelial behavior on these surfaces. Instead, we examined the effect of the extracellular matrix proteins collagen and fibronectin on EC 
behavior. When SMC-like cells are cultured in a scaffold these will produce an extracellular matrix on which ECs will be seeded later on. ${ }^{44,45}$ In case of endothelial seeding on bare scaffolds, coatings like fibronectin are often used to enhance cellular incorporation. Therefore, we consider our results to reflect endothelial behavior on TE grafts. After exposure to flow, PFVECs expressed more vWF on collagen compared to PFAECs but not on fibronectin, and proliferation rate was comparable. PFVECs adhered less to collagen compared to PFAECs after 10 minutes of flow, but staining after 72 hours showed confluent PFVEC layers indicating sufficient adhesion. Therefore, we conclude that PFVECs are suitable for TE in arterial flow conditions and fibronectin is preferred for coating TE scaffolds.

In this study we compared venous and arterial ECs from healthy porcine blood vessels. The prevalent clinical scenario however will include many if not all patients who are compromised by cardiovascular disease or risk factors. The TE potential of ECs from these patients has to be investigated as well, as these cells might show reduced proliferation rates or increased inflammatory or thrombogenic properties resulting from the exposure to cardiovascular risk factors such as hypertension or smoking. These questions need to be answered before clinical implementation of TE with autologous cells can be realized on a large scale.

We consider this study to provide new insights in arterial-venous endothelial differences showing specific culture characteristics that are especially relevant for the upcoming research field of vascular TE. In the past, a number of in vitro studies have compared arterial-venous endothelial characteristics but these studies were limited to human umbilical arterial ECs (HUAECs) and HUVECs and ECs from the lung circulation 20 that are not the prime EC source for TE in the patient. Cells from the umbilical circulation differ from ECs from adult donors and indeed Kalogeris et al. observed a different expression pattern of VCAM-1 than we have seen in adult venous and arterial cells. ${ }^{19}$

\section{CONCLUSION}

Based on our findings, venous ECs appear to be suitable for vascular TE. Regarding anti-thrombogenic properties, venous ECs even perform better than arterial ECs under the conditions used. As veins are easier accessible for harvesting primary vascular cells from patients, the use of venous ECs for TE of small caliber vascular grafts is preferable. 


\section{REFERENCES}

1. Manchio JV, Gu J, Romar L, Brown J, Gammie J, Pierson RN, 3rd, et al. Disruption of graft endothelium correlates with early failure after off-pump coronary artery bypass surgery. Ann Thorac Surg. 2005; 79(6): 1991-8.

2. Deutsch M, Meinhart J, Zilla P, Howanietz N, Gorlitzer M, Froeschl A, et al. Long-term experience in autologous in vitro endothelialization of infrainguinal ePTFE grafts. J Vasc Surg. 2009; 49(2): 352-62.

3. Ortenwall $P$, Wadenvik $H$, Risberg $B$. Reduced platelet deposition on seeded versus unseeded segments of expanded polytetrafluoroethylene grafts: clinical observations after a 6-month follow-up. J Vasc Surg. 1989; 10(4): 374-80.

4. Quint C, Kondo Y, Manson RJ, Lawson JH, Dardik A, Niklason LE. Decellularized tissue-engineered blood vessel as an arterial conduit. Proceedings of the National Academy of Sciences of the United States of America. 2011; 108(22): 9214-9.

5. Jarrell BE, Williams SK, Stokes G, Hubbard FA, Carabasi RA, Koolpe E, et al. Use of freshly isolated capillary endothelial cells for the immediate establishment of a monolayer on a vascular graft at surgery. Surgery. 1986; 100(2): 392-9.

6. Shirota $\mathrm{T}, \mathrm{He} \mathrm{H}$, Yasui $\mathrm{H}$, Matsuda $\mathrm{T}$. Human endothelial progenitor cell-seeded hybrid graft: proliferative and antithrombogenic potentials in vitro and fabrication processing. Tissue Eng. 2003; 9(1): 127-36.

7. Allen J, Khan S, Serrano MC, Ameer G. Characterization of porcine circulating progenitor cells: toward a functional endothelium. Tissue Eng Part A. 2008; 14(1): 183-94.

8. Goldman S, Zadina K, Moritz T, Ovitt T, Sethi G, Copeland JG, et al. Long-term patency of saphenous vein and left internal mammary artery grafts after coronary artery bypass surgery: results from a Department of Veterans Affairs Cooperative Study. J Am Coll Cardiol. 2004; 44(11): 2149-56.

9. Motwani JG, Topol EJ. Aortocoronary saphenous vein graft disease: Pathogenesis, Predisposition, and Prevention. Circulation. 1998; 97(9): 916-31.

10. Ramos JR, Berger K, Mansfield PB, Sauvage LR. Histologic fate and endothelial changes of distended and nondistended vein grafts. Ann Surg. 1976; 183(3): 205-28.

11. Aird WC. Phenotypic Heterogeneity of the endothelium: II. Representative vascular beds. Circ Res. 2007; 100(2): 174-90.

12. Lanner F, Sohl M, Farnebo F. Functional arterial and venous fate is determined by graded VEGF signaling and notch status during embryonic stem cell differentiation. Arterioscler Thromb Vasc Biol. 2007; 27(3): 487-93.

13. Chi J-T, Chang HY, Haraldsen G, Jahnsen FL, Troyanskaya OG, Chang DS, et al. Endothelial cell diversity revealed by global expression profiling. Proc Natl Acad Sci U S A. 2003; 100(19): 10623-8.

14. Cho JS, Ouriel K. Differential thrombogenicity of artery and vein: The role of von Willebrand factor. Ann Vasc Surg. 1995; 9(1): 60-70.

15. Simionescu M, Simionescu N, Palade GE. Segmental differentiations of cell junctions in the vascular endothelium. Arteries and veins. J Cell Biol. 1976; 68(3): 705-23.

16. Yang Z, Ruschitzka F, Rabelink TJ, Noll G, Julmy F, Joch $H$, et al. Different Effects of Thrombin Receptor Activation on Endothelium and Smooth Muscle Cells of Human Coronary Bypass Vessels : Implications for Venous Bypass Graft Failure. Circulation. 1997; 95(7): 1870-6.

17. Chang YS, Munn LL, Hillsley MV, Dull RO, Yuan J, Lakshminarayanan S, et al. Effect of vascular endothelial growth factor on cultured endothelial cell monolayer transport properties. Microvasc Res. 2000; 59(2): 265-77.

18. Eriksson EE, Karlof E, Lundmark K, Rotzius $\mathrm{P}$, Hedin U, Xie X. Powerful Inflammatory properties of large vein endothelium in vivo. Arterioscler Thromb Vasc Biol. 2005; 25(4): 723-8.

19. Kalogeris TJ, Kevil CG, Laroux FS, Coe LL, Phifer TJ, Alexander JS. Differential monocyte adhesion and adhesion molecule expression in venous and arterial endothelial cells. Am J Physiol Lung Cell Mol Physiol. 1999; 276(1): L9-19.

20. Johnson AR. Human Pulmonary Endothelial cells in culture activities of cells from arteries and cells from veins. J Clin Invest. 1980; 65(4): 841-50. 
21. Chaikhouni A, Crawford FA, Kochel PJ, Olanoff LS, Halushka PV. Human internal mammary artery produces more prostacyclin than saphenous vein. J Thorac Cardiovasc Surg. 1986; 92(1): 88-91.

22. Luscher TF, Diederich $D$, Siebenmann $R$, Lehmann $K$, Stulz $P$, von Segesser $L$, et al. Difference between endothelium-dependent relaxation in arterial and in venous coronary bypass grafts. $\mathrm{N}$ Engl J Med. 1988; 319(8): 462-7.

23. Shapira OM, XU A, Aldea GS, Vita JA, Shemin RJ, Keaney JF, Jr. Enhanced nitric oxide-mediated vascular relaxation in radial artery compared with internal mammary Artery or Saphenous Vein. Circulation. 1999; 100(90002): Il-322-7.

24. Brown MA, Wallace CS, Angelos M, Truskey GA. Characterization of umbilical cord blood-derived late outgrowth endothelial progenitor cells exposed to laminar shear stress. Tissue Eng Part A. 2009; 15(11): 3575-87.

25. Schnell AM, Hoerstrup SP, Zund G, Kolb S, Sodian R, Visjager JF, et al. Optimal cell source for cardiovascular tissue engineering: venous vs. aortic human myofibroblasts. Thorac Cardiovasc Surg. 2001; 49(4): 221-5.

26. Cines DB, Pollak ES, Buck CA, Loscalzo J, Zimmerman GA, McEver RP, et al. Endothelial cells in physiology and in the pathophysiology of vascular disorders. Blood. 1998; 91(10): 3527-61.

27. Pober JS, Sessa WC. Evolving functions of endothelial cells in inflammation. Nat Rev Immunol. 2007; 7(10): 803-15.

28. Mahabeleshwar GH, Byzova TV. Vascular integrin signaling. Methods Enzymol. 2008; 443: 199-226.

29. Geback T, Schulz MM, Koumoutsakos P, Detmar M. TScratch: a novel and simple software tool for automated analysis of monolayer wound healing assays. Biotechniques. 2009; 46(4): 265-74.

30. Hemker HC, Giesen P, AlDieri R, Regnault V, de Smed E, Wagenvoord R, et al. The calibrated automated thrombogram (CAT): a universal routine test for hyper- and hypocoagulability. Pathophysiol Haemost Thromb. 2002; 32(5-6): 249-53.

31. Goettsch W, Augustin HG, Morawietz H. Down-regulation of endothelial ephrinB2 expression by laminar shear stress. Endothelium. 2004; 11(5-6): 259-65.

32. Egorova AD, DeRuiter MC, de Boer HC, van de Pas S, Gittenberger-de Groot AC, van Zonneveld AJ, et al. Endothelial colony-forming cells show a mature transcriptional response to shear stress. In Vitro Cell Dev Biol Anim. 2012; 48(1): 21-9.

33. Liu M, Kluger MS, D'Alessio A, Garcia-Cardena G, Pober JS. Regulation of arterial-venous differences in tumor necrosis factor responsiveness of endothelial cells by anatomic context. Am J Pathol. 2008; 172(4): 1088-99.

34. Bergh N, Ulfhammer E, Glise K, Jern S, Karlsson L. Influence of TNF-Î̃ and biomechanical stress on endothelial anti- and prothrombotic genes. Biochem Biophys Res Commun. 2009; 385(3): 314-8.

35. Matsumoto $Y$, Kawai Y, Watanabe K, Sakai K, Murata M, Handa M, et al. Fluid shear stress attenuates tumor necrosis factor- $\alpha$-induced tissue factor expression in cultured human endothelial cells. Blood. 1998; 91(11): 4164-72.

36. ten Cate-Hoek AJ, Dielis AW, Spronk HM, van Oerle R, Hamulyak K, Prins MH, et al. Thrombin generation in patients after acute deep-vein thrombosis. Thromb Haemost. 2008; 100(2): 240-5.

37. Spronk HM, Dielis AW, De Smedt E, van Oerle R, Fens D, Prins MH, et al. Assessment of thrombin generation II: Validation of the calibrated automated thrombogram in platelet-poor plasma in a clinical laboratory. Thromb Haemost. 2008; 100(2): 362-4.

38. Marchetti M, Castoldi E, Spronk HM, van Oerle R, Balducci D, Barbui T, et al. Thrombin generation and activated protein $C$ resistance in patients with essential thrombocythemia and polycythemia vera. Blood. 2008; 112(10): 4061-8.

39. Zwaginga JJ, de Boer HC, ljsseldijk MJ, Kerkhof A, Muller-Berghaus G, Gruhlichhenn J, et al. Thrombogenicity of vascular cells. Comparison between endothelial cells isolated from different sources and smooth muscle cells and fibroblasts. Arterioscler Thromb Vasc Biol. 1990; 10(3): 437-48.

40. Silverman MD, Waters CR, Hayman GT, Wigboldus J, Samet MM, Lelkes PI. Tissue factor activity is increased in human endothelial cells cultured under elevated static pressure. Am J Physiol Cell Physiol. 1999; 277(2): C233-42. 
41. Kim AY, Walinsky PL, Kolodgie FD, Bian C, Sperry JL, Deming CB, et al. Early loss of thrombomodulin expression impairs vein graft thromboresistance: implications for vein graft failure. Circ Res. 2002; 90(2): 205-12.

42. Dekker RJ, Boon RA, Rondaij MG, Kragt A, Volger OL, Elderkamp YW, et al. KLF2 provokes a gene expression pattern that establishes functional quiescent differentiation of the endothelium. Blood. 2006; 107(11): 4354-63.

43. Hamik A, Lin Z, Kumar A, Balcells M, Sinha S, Katz J, et al. Kruppel-like factor 4 regulates endothelial inflammation. J Biol Chem. 2007; 282(18): 13769-79.

44. Heydarkhan-Hagvall S, Esguerra M, Helenius G, Soderberg R, Johansson BR, Risberg B. Production of extracellular matrix components in tissue-engineered blood vessels. Tissue Eng. 2006; 12(4): 831-42.

45. L'Heureux N, Paquet S, Labbe R, Germain L, Auger FA. A completely biological tissue-engineered human blood vessel. Faseb J. 1998; 12(1): 47-56. 


\section{SUPPLEMENTAL MATERIAL}

\section{METHODS}

\section{QUANTIFICATION OF VWF EXPRESSION}

Cultured PFAECs and PFVECs ( $n=3$ per group) were stained for vWF in one batch and imaged and analyzed under same conditions to limit inter-sample variation. Pictures (3 times 6 per group) were made with a Leica DMl30ooB inverted fluorescence microscope equipped with a Leica DFC350 FX camera and Leica LAS AF (version 2.4.1) software (all Leica Microsystems $\mathrm{GmbH}$, Wetzlar Germany). Files were imported in ImageJ (ImageJ 1.410 NIH, USA) and processed with preset threshold (range 0-235). Sum of pixels above threshold per picture were defined, and data were subjected to statistic analysis (t-test) and plotted by using GraphPad Prism (version 5.01; GraphPad Software Inc. La Jolla, CA, USA). Data are depicted as mean ratio of total positive area between both groups with SEM, $n=3$, and arterial expression set at 1 . 

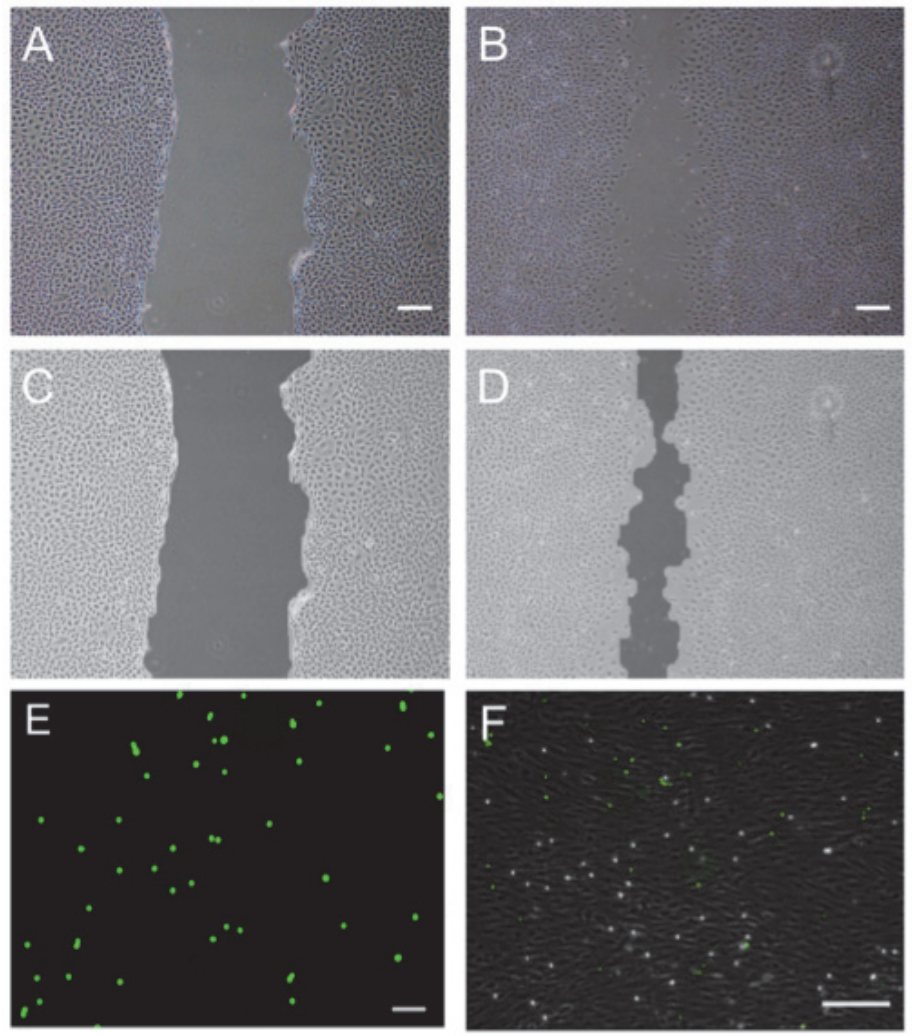

Figure S3.1. Representative images of the migration, adhesion and platelet adhesion assays. Brightfield images of the scratch assay after o hours $(A)$ and 24 hours $(B)$ and the corresponding images of the analysis by T-scratch (C, D) are shown. E. Fluorescence image of adhered cells labeled with calcein-AM after 30 minutes. For final analysis, total fluorescence was measured with a multiplate reader. F. Brightfield image with fluorescent overlay of adhered platelets (green label) to ECs under flow conditions. Cells were flowed with 2.0 Pa for 72 hours prior to exposure to platelets. Scale bars represent $100 \mu \mathrm{m}$.

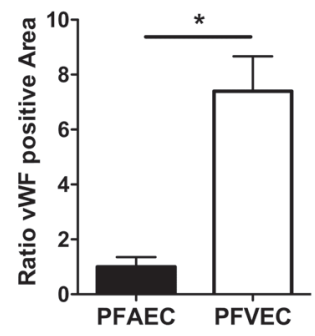

Figure S3.2. vWF expression. Difference in vWF expression between PFAECs and PFVECs showing a significant 7.4 fold higher expression $(n=3, * P<0.01)$ for venous cells as compared with arterials cell that were cultured under the same conditions. Data are depicted as mean ratio of total positive area between both groups with SEM and arterial expression set at 1. 


\section{CHAPTER 4}

Phenotypic Fitness of Primary Endothelial Cells Cultured from Patients with High Cardiovascular Risk or Chronic Kidney Disease for Vascular Tissue Engineering

Irma LA Geenen, Sanne Verbruggen, Daniel GM Molin, Henri MH Spronk, Jos G Maessen, Berry Meesters, Geert Willem H Schurink, Mark J Post 


\section{ABSTRACT}

Vascular tissue engineering relies on the combination of patient-derived cells and biomaterials to create new vessels. For clinical application, data regarding function and behavior of patient-derived cells are needed. We investigated cell growth and functional characteristics of human venous endothelial cells (HVECs) from coronary arterial bypass graft (CABG), chronic kidney disease (CKD) and control patients.

HVECs were isolated from venous specimens obtained during elective surgical procedures by means of collagenase digestion. Gene expression, proliferation, migration, secretory functions and thrombogenic characteristics were evaluated using high-throughput assays.

A total of 48 cell batches (14 control, 19 CABG and 15 CKD subjects) were assessed. Proliferation, population doubling times and migration of HVECs derived from CABG and CKD patients did not differ from controls. Thrombomodulin expression was higher in CABG-HVECs compared to controls. HVECs-induced thrombin formation in plasma did not differ between groups and the contact activation pathway was the major contributor to coagulation. Patient-derived HVECs were able to attach and survive on polycaprolactone scaffolds coated with fibrin.

HVECs from cardiovascular-diseased and CKD patients showed comparable functional characteristics with HVECs derived from uncompromised patients. We therefore conclude that endothelial cells from aged patients with comorbidities can be safely used for isolation and in vitro expansion for vascular tissue engineering. 


\section{INTRODUCTION}

Small diameter tissue-engineered vascular grafts (TEVG) are considered to become the ideal alternative for autologous venous bypasses when autologous veins have insufficient quality or when these are no longer available. TEVGs can also be implanted as an arteriovenous (AV) shunt providing vascular access for the benefit of hemodialysis in end-stage renal disease.

Long-term feasibility of TEVGs implanted in high- and low-pressure circuits has been proven in several animal studies already. ${ }^{1-6}$ In humans, successful results in small trials have been reported with TEVGs used for repair of congenital heart defects, cavopulmonary connections and for creation of an AV shunt for hemodialysis. ${ }^{7,8}$ TEVGs offer the benefit of autologous material with superior anti-thrombogenic, antiimmunologic and biomechanical properties compared to conventional prosthetic grafts. ${ }^{7,9}$ TEVGs can be produced using a sheet-based technology with autologous skin fibroblasts ${ }^{2,10}$ or by seeding primary smooth muscle cells $(S M C s)^{11}$, myofibroblasts ${ }^{12}$ or mesenchymal stem cells ${ }^{13}$ on a biodegradable scaffold followed by a period of in vitro remodeling. Hereafter, endothelial cells (ECs) or endothelial progenitor cells (EPCs) are seeded intraluminally to provide an anti-thrombogenic lining..${ }^{914}$ Both techniques rely on the use of autologous primary or stem cells.

In order to apply TEVGs in clinical settings on a large scale, more information regarding quality and variability of cell sources is required, in particular for primary cells as their regenerative capacity is limited. Proper function of (patient-derived) vascular cells is crucial for creation of a reliable TEVG that can be used for human implantation, with excellent anti-thrombogenic and anti-immunologic characteristics. Exposure to cardiovascular risk factors in vivo could affect -particularly endothelial- cell function that persists throughout the expansion of these cells through culture. So far, only a few reports have evaluated the influence of patient-related factors on endothelial behavior. ${ }^{15-18}$ More precisely, ECs derived from smokers ${ }^{15}$ and hyperlipidemic patients have shown reduced growth potential in vitro ${ }^{16}$, whereas extensive exposure to cardiovascular disease risk factors seems to induce accelerated senescence as observed in ECs derived from CABG patients. ${ }^{17}$ Early senescence is disadvantageous when cells need to be passaged several times to obtain sufficient numbers of cells required for seeding the lumen of a TEVG.

We hypothesized that besides delayed cell growth, functions of ECs that are pertinent to vascular tissue engineering, such as production of nitric oxide (NO) and prostacyclin and maintenance of a quiescent and anti-coagulant state will be negatively affected when ECs are exposed to long-term smoking, hypertension, hyperlipidemia or uremia. 
In vivo, this is known to occur ${ }^{19-22}$ but it remains unclear whether cultured cells will keep this dysfunctional phenotype.

Therefore, we aimed to investigate the proliferative capacity and functional characteristics of human venous ECS (HVECs) derived from the target population for future application of TEVGs. We evaluated the endothelial phenotype of cardiovascular diseased patients, chronic kidney disease (CKD) patients and compared these results to non-cardiovascular and non-uremic compromised controls. Venous samples were obtained during elective surgical procedures for coronary artery bypass grafting (CABG group), kidney transplantations (CKD group), and inguinal hernia repairs or donor nephrectomies (control group). HVECs were subsequently isolated by means of collagenase digestion and cultured for functional analysis. Then, proliferation, migration, gene expression, secretory functions and thrombogenic phenotype were assessed. To determine whether patient-derived ECs were able to attach and survive on tissue engineering material, ECs were seeded and cultured on polycaprolactone $(P C L)$ coated with fibrin.

\section{SUBJECTS AND METHODS}

\section{PATIENTS}

This study included three patient groups. Patients who received a CABG for coronary artery disease were included for the cardiovascular disease group (CABG group). Leftover specimens of the vena saphena magna (VSM) were collected by the end of the CABG procedure and taken to the lab. Patients with CKD were excluded for this group. The second group consisted of patients with CKD undergoing kidney transplantation (CKD group). After incision, the surgeon isolated the superior epigastric vein for EC isolation. In the control group, patients who served as donors for elective family kidney transplantations were included and part of the spermatic or ovarian vein was removed during the nephrectomy. Patients undergoing open inguinal hernia repair were also included in this group and in these patients a small part of the superficial epigastric vein was used for cell isolation. Patient characteristics are shown in Table 4.1.

The study protocol was approved by the Institutional Review Board of the Maastricht University Medical Center and patients signed informed consent prior to inclusion in the study. Patient characteristics, presence of cardiovascular risk factors, relevant medical history and medication use were collected from medical records. 
Table 4.1. Patient characteristics

\begin{tabular}{lllll}
\hline & Control $(n=14)$ & CABG $(n=19)$ & CKD $(n=15)$ & $P$-value \\
\hline Age (years) & $50 \pm 13$ & $66 \pm 10$ & $45 \pm 18$ & 0.0001 \\
Sex (M/F) & $8 / 6$ & $11 / 8$ & $10 / 5$ & NS \\
BMI (kg/m $\left.{ }^{2}\right)$ & $25.1 \pm 3.6$ & $26.6 \pm 3.3$ & $25.5 \pm 5.7$ & NS \\
CAD (\%) & 0 & 100 & 7 & $<0.0001$ \\
DM (\%) & 0 & 16 & 20 & $<0.0001$ \\
Hypertension (\%) & 0 & 32 & 73 & $<0.0001$ \\
Hyperlipidemia (\%) & 0 & 79 & 20 & $<0.0001$ \\
Smoking (\%) & & & & $<0.0001$ \\
- Ex & 0 & 11 & 40 & \\
-Current & 0 & 21 & 23 & $<0.0001$ \\
Family history of CAD (\%) & 0 & 63 & 7 & $<0.0001$ \\
Statin use (\%) & 0 & 89 & 33 & \\
\hline
\end{tabular}

$\mathrm{M}=$ Male, $\mathrm{F}=$ Female, $\mathrm{BMI}=$ body mass index, $\mathrm{CAD}=$ Coronary artery disease, $\mathrm{DM}=$ Diabetes mellitus

\section{CELL ISOLATION AND CULTURING}

Venous samples were collected in the operation room and put in Dulbecco's Modified Eagle's Medium (DMEM) (Lonza, Basel, Switzerland) with penicillin/streptomycin for transport to the laboratory. Isolation of HVECs was carried out by collagenase digestion the same day. Briefly, vessels were connected to a flushing system and flushed with warm $\left(37^{\circ} \mathrm{C}\right)$ phosphate buffered saline (PBS). Collagenase type I (Worthington, Lakewood, NJ, USA) was dissolved in DMEM with $0.1 \%$ bovine serum albumin (BSA) with a final concentration of $0.1 \%$ collagenase. Vessels were incubated for 15 minutes in $37^{\circ} \mathrm{C}$ with collagenase solution. Next, the collagenase solution containing detached cells was collected and the lumen was flushed with DMEM/fetal bovine serum (FBS) 10\% (Lonza) to gather remaining cells. After centrifugation, cells were resuspended and cultured in fibronectin $(10 \mu \mathrm{g} / \mathrm{ml})$ coated 12 -wells plates in EBM2-medium supplemented with the EGM-2-MV bullet kit (Lonza) at $37^{\circ} \mathrm{C} / 5 \% \mathrm{CO}_{2}$. When cells reached confluency, cells were detached using trypsin/EDTA and treated afterwards with a trypsin neutralization solution (Lonza). After centrifugation cells were resuspended in T25 flasks (Greiner Bio-One BV, Alphen a/d Rijn, The Netherlands) and when confluence was reached cells were trypsinized and cryopreserved in liquid nitrogen for later culture and analysis. Cells were tested for functional characteristics during two subsequent passages starting from passage 3-5. Doubling time was calculated after another subsequent passage. Cell counts were performed by means of the Countess ${ }^{\circledR}$ Automated Cell Counter (Invitrogen, Life Technologies Europe BV, Bleiswijk, The Netherlands). 


\section{IMMUNOFLUORESCENCE}

ECs were stained for several endothelial markers by means of immunofluorescent staining. Cells were grown in 96-well plates (Greiner) until confluence, fixed 20 min at RT with $2 \%$ paraformaldehyde in PBS, and washed with PBS. Cells were blocked with $2 \%$ BSA in PBS/0.05\% Tween. Cells were incubated overnight with polyclonal goat anti-mouse CD31 (1:50, Santa Cruz, Dallas, TX, U.S.A.), monoclonal rabbit antihuman von Willebrand Factor (vWF (1:100, DakoCytomation, Glostrup, Denmark) and polyclonal rabbit anti-bovine endothelial nitric oxide synthase (eNOS) (1:100, Thermo Scientific, Breda, The Netherlands). Then, the cells were incubated with the corresponding Alexa fluor-labeled secondary antibody (Invitrogen, Merelbeke, Belgium) for 1 hour and stained with DAPI (1:1000, Invitrogen) for 5 min. After washing with PBS, photographs were taken with a Leica DMl300oB inverted microscope with a DFC 350 FX camera (Leica, Bannockburn, IL, USA). The eNOS-positive stained area was quantified by automatic analysis including a correction for cell number, with BD AttoVision software (BD Biosciences, Heidelberg, Germany).

\section{GENE EXPRESSION}

HVECs were seeded in 6-wells plates (Greiner) with a seeding density of 5,000 cells $/ \mathrm{cm}^{2}$. Medium was refreshed after two days, and after five days, cells were confluent and total RNA was collected using the RNeasy micro-kit Qiagen with DNAse treatment (Qiagen, $\mathrm{GmbH}$, Hilden, Germany). The concentration of isolated RNA was determined with the NanoDrop microspectrophotometer (NanoDrop Products, Wilmington, DE, USA). A total of $100 \mathrm{ng}$ RNA per sample was subjected to reverse transcription (RT) with QScript cDNA synthese kit (Quanta Biosciences, Gaithersburg, MD, USA). PCR was performed by using PerfeCTa SYBR Green for iQ (Quanta Biosciences) and primer concentration of $10 \mu \mathrm{M}$. qPCR reactions were run on a MyiQ Single-Color Real time PCR detection system (Bio-Rad, Veenendaal, the Netherlands). Primers were designed with Oligoperfect ${ }^{\mathrm{TM}}$ Designer (Invitrogen), Primerz and Mfold (http://www.idtdna.com/scitools/Application/mfold/) and were synthesized by Eurogentec (Seraing, Belgium). Primer sequences are provided in the Supplementary material (Table S4.1). Samples were normalized for input based on both $\beta$-Actin and GAPDH values. Gene expression levels of HVECs from the control group were used as reference and set at 1.0. 


\section{PROLIFERATION}

Population doubling times were calculated during three subsequent passages in a standardized manner using the formula $P D T=\left(\log 2 /\left(\log N_{t}-\log N_{0}\right)\right) * t$, in which $\mathrm{PDT}=$ population doubling time, $\mathrm{t}=$ time in culture, $\mathrm{Nt}=$ number of cells after $\mathrm{t}$ and $\mathrm{N}_{0}=$ number of cells at $\mathrm{t}=\mathrm{0}$, as previously described. ${ }^{23}$

Cellular growth was also assessed using a high-throughput proliferation assay. Cells were seeded with a low confluency $\left(5,000\right.$ cells $\left./ \mathrm{cm}^{2}\right)$ in 96 -wells plates coated with fibronectin and starved overnight before start of the assay. Then, cells were stained with Hoechst and the whole well was imaged with the BD Pathway High-Content Bioimager 855 (BD Biosciences) ( $t=0$ ). This procedure was repeated at 24,48 , and 72 hours after start of the assay. During this period cells were cultured in regular EC-medium. The number of Hoechst positive cells per well was automatically analyzed with BD AttoVision software (BD Biosciences). Amount of cells quantified at $\mathrm{t}=\mathrm{o}$ was used as a reference and set at 1.0.

\section{MIGRATION}

Migratory capacity of HVECs was assessed using the Oris ${ }^{\mathrm{TM}}$ Cell Migration Assay (Platypus Technologies, Madison, WI, US), in which fibronectin coated 96 -wells plates containing centrally placed stoppers were seeded with 50,000 cells $/ \mathrm{cm}^{2}$. Cells were allowed to adhere for 6 hours and were then starved overnight. After staining cells with Calcein AM (Invitrogen), Oris ${ }^{\mathrm{TM}}$ stoppers were removed in a standardized manner. Pictures were made at $\mathrm{t}=\mathrm{o}$ hours and after 24 hours, pictures were obtained again (4 per well) with the BD Pathway High-Content Bioimager 855 with BD AttoVision software (BD Biosciences). Amount of cells in the central area was automatically calculated using the BD AttoVision software.

\section{NO AND PROSTACYCLIN PRODUCTION}

Medium from cells grown for gene expression analysis in 6-wells plates $(1,5 \mathrm{ml}$ per well) was collected after 48 hours of incubation with cells, and stored for $\mathrm{NO}$ and prostacyclin detection. NO-levels were measured using the Griess reaction for NO detection (Assay Designs, Inc, Ann Harbor, MI, USA) and (Assay Designs). Prostacyclin was detected by means of an enzyme assay for 6-keto-PGF1a, a stable hydrolysis product of prostacyclin (Assay Designs). 


\section{MODIFIED CALIBRATED AUTOMATED THROMBOGRAM (MCAT)}

Endothelial-induced thrombin generation in human platelet-poor plasma was measured by means of a modified calibrated automated thrombogram (mCAT) method (Thrombinoscope BV, Maastricht, The Netherlands) as previously described. ${ }^{24}$ In brief, the method employs a low affinity fluorogenic substrate for thrombin (Z-GlyGly-Arg-AMC) to continuously monitor thrombin activity in clotting plasma. Normal platelet poor-plasma was obtained from pooling plasmas of 80-90 healthy donors, according to the standard procedure of the Laboratory of Haematology, Maastricht University Medical Center. Cells were seeded in 96-wells plates with a high seeding density $\left(60,000\right.$ cells $\left./ \mathrm{cm}^{2}\right)$ and cultured with serum-free culture medium in which FBS in normal EC-medium was replaced by human factor XII deficient (FXII-deficient) plasma. Cells were starved overnight before the assay. Then, cells were washed with HEPES buffer and a previously described thrombin generation assay was performed. ${ }^{24}$ Measurements were conducted in $80 \mu \mathrm{L}$ human platelet-poor normal pooled plasma (NP) or FXII-deficient plasma in a total volume of $120 \mu \mathrm{l}$. To the $80 \mu \mathrm{l}$ plasma sample, $20 \mu \mathrm{l}$ trigger reagent (o pM tissue factor (TF), $24 \mu \mathrm{M}$ phospholipids at 20:20:60 mol\% (phosphatidylserine:phosphatidylethanolamine:phosphatidylcholine, PS:PE:PC) was added. After 10 minutes incubation at $37^{\circ} \mathrm{C}, 20 \mu$ of fluorogenic substrate with calcium chloride (FluCa) was added to start recording of the thrombin generation. Recombinant active site inhibited factor VIla (ASIS; kindly provided by L.C. Petersen, Health Care Discovery, Novo Nordisk A/S, Måløv and Bagsværd, Denmark) was added to a final concentration of $30 \mathrm{nM}$ and corn trypsin inhibitor (CTI; Haematologic Technologies Inc., Essex Junction, VT, US) was applied at a reaction concentration of $25 \mu \mathrm{g} / \mathrm{ml}$.

To correct for inner-filter effects and substrate consumption, each thrombin generation measurement was calibrated against the fluorescence curve obtained in a sample from the same plasma $(80 \mu \mathrm{l})$, added with a fixed amount of thrombin- $\alpha 2-$ macroglobulin complex ( $20 \mu \mathrm{l}$ Thrombin Calibrator, Thrombinoscope BV) and $20 \mu \mathrm{l}$ FluCa. Fluorescence was read in a Fluoroskan Ascent reader (Thermo Labsystems OY, Helsinki, Finland) equipped with a 390/460 filter set and thrombin generation curves were calculated with the Thrombinoscope software (Thrombinoscope BV). Three parameters were derived from the thrombin generation curves: lag time (initiation phase of coagulation), peak height, and endogenous thrombin potential (ETP; area under the thrombin generation curve). 


\section{CELL SEEDING ON SCAFFOLDS}

ECs were seeded on PCL electrospun scaffolds (Xeltis, Eindhoven, The Netherlands) with a seeding density of 75,000 cells $/ \mathrm{cm}^{2}$. Before cell seeding, scaffolds were coated twice with fibrin gel (fibrinogen, $12 \mathrm{mg} / \mathrm{ml}$ and thrombin, $200 \mathrm{U} / \mathrm{ml}$, Sigma-Aldrich, St. Louis, MO, USA). Cell-seeded grafts were cultured for 7 days after which the grafts were fixated with paraformaldehyde $2 \%$. ECs were stained for $C_{31}$ and imaged like mentioned above.

\section{STATISTICAL ANALYSIS}

All data are expressed as mean \pm SD. Data were analyzed with Prism 5.oc for Mac (GraphPad Software, San Diego, CA, USA) and Microsoft Excel for Mac 2011. Groups were compared using one-way analysis of variance (ANOVA) with Tukey's post-hoc testing for pairwise comparison and two-way ANOVA repeated measured for timebound analysis. When data were not normally distributed the Kruskal-Wallis test was applied and in case of missing data points, the Friedman test was employed. $P$-values $<0.05$ were considered significant. An additional statistical analysis addressing a possible correlation between patient characteristics and cellular growth is presented in the Supplemental material.

\section{RESULTS}

\section{PATIENTS}

A total number of 66 venous samples were collected in the surgical theatre. Eighteen batches could not be used for further analysis, due to low cell yield after isolation $(n=6)$ related to small vessel specimens (4/6), or insufficient cell growth (2/6). Eight samples were contaminated by bacteria or fungi and in one isolation no ECs were found. Three batches did not survive cryopreservation.

A total of 14 control patient-derived, 19 CABG patient-derived and 15 CKD patientderived cell batches were cultured and evaluated for proliferative capacity and functional characteristics. Patient characteristics are shown in Table 4.1. There were no significant differences regarding gender and body mass index (BMI). Mean age was significantly higher in CABG patients compared to controls and CKD subjects. Per study design, comorbidities were different between groups. 


\section{IMMUNOFLUORESCENCE}

ECs were stained for $C D_{31}$, VWF and eNOS. Representative images are shown in Figure 4.1A-C. All cells were positive for the endothelial marker $C_{31}$ (Figure 4.1A). vWF could be seen in the majority of cells and positive eNOS staining was observed in all HVECs. The amount of eNOS-stained area was quantified per patient and corrected for cell numbers, however no significant differences between patient groups were found (Figure 4.1D).
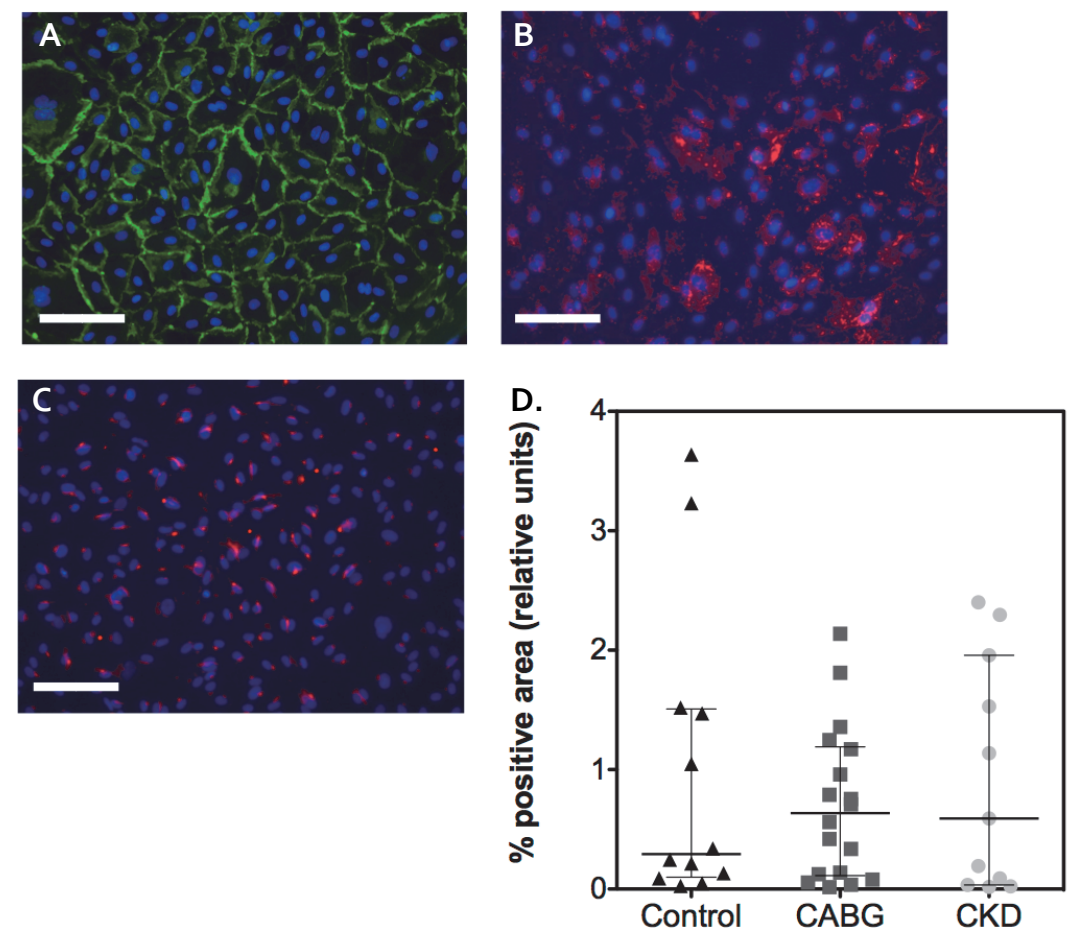

Figure 4.1. Representative immuno-histochemical images of HVECs. A. CD31 is expressed on the cell membrane. B. Positive staining for von Willebrand Factor in a characteristic pattern. C. Endothelial nitric oxide synthase (eNOS) is present intracellularly. Scale bars represent $100 \mu \mathrm{m}$ (magnification 100x). D. Amount of eNOS-stained area quantified per patient and corrected for cell numbers is comparable between groups. 


\section{GENE EXPRESSION}

Expression of $C_{31}$, vWF, eNOS, intercellular adhesion molecule (ICAM), vascular cell adhesion molecule (VCAM), tissue factor pathway inhibitor (TFPI), TF, thrombomodulin, vascular endothelial growth factor receptor 2 (VEGFR2) and platelet-derived growth factor receptor $\alpha$ (PDGFR $\alpha$ ) was determined in confluent cell layers.

All genes were expressed at comparable levels for different patient categories except for thrombomodulin, which was higher expressed in CABG-patient derived HVECs than in control HVECs (Table 4.2).

There was a trend towards higher expression of towards decreased PDGFR $\alpha(P=0.05)$ and increased eNOS expression $(P=0.07)$ in HVECs derived from CABG patients.

Table 4.2. Gene expression levels

\begin{tabular}{lllll}
\hline & Control $(n=14)$ & CABG $(n=19)$ & CKD $(n=15)$ & $P$-value \\
\hline CD31 & $1.00 \pm 0.29$ & $1.08 \pm 0.48$ & $1.02 \pm 0.25$ & 0.82 \\
VWF & $1.00 \pm 0.59$ & $1.33 \pm 0.80$ & $1.16 \pm 0.60$ & 0.40 \\
eNOS & $1.00 \pm 0.29$ & $1.32 \pm 0.49$ & $1.03 \pm 0.45$ & 0.07 \\
ICAM-1 & $1.00 \pm 0.56$ & $1.44 \pm 1.06$ & $1.27 \pm 0.77$ & 0.35 \\
VCAM-1 & $1.00 \pm 1.08$ & $1.39 \pm 1.73$ & $1.80 \pm 1.47$ & 0.37 \\
TF & $1.00 \pm 0.48$ & $0.96 \pm 0.35$ & $1.32 \pm 0.62$ & 0.11 \\
TFPI & $1.00 \pm 0.57$ & $0.85 \pm 0.53$ & $0.89 \pm 0.37$ & 0.69 \\
Thrombomodulin & $1.00 \pm 0.48$ & $1.77 \pm 0.87$ & $1.29 \pm 0.96$ & $<0.05^{*}$ \\
VEGFR2 & $1.00 \pm 0.57$ & $0.85 \pm 52$ & $1.12 \pm 0.64$ & 0.41 \\
PDGFR & $1.00 \pm 0.82$ & $0.55 \pm 0.32$ & $1.05 \pm 0.71$ & 0.05 \\
\hline
\end{tabular}

Expression levels of genes in the control group were used as reference and set at 1.0. ${ }^{*} \mathrm{CABG}$ compared to control. $v W F=v o n$ Willebrand Factor, TF=tissue factor, TFPI=tissue factor pathway inhibitor, VEGFR2=vascular endothelial growth factor receptor 2, PDGFR $\alpha=$ platelet-derived growth factor receptor $\alpha$.

\section{CELL GROWTH}

Cell growth was assessed by calculating population doubling time in a standardized manner from three subsequent passages, starting with passage 3-5. Average doubling time per passage did not increase during these three passages in all three groups (Figure $4.2 \mathrm{~A}$ ). Overall mean population doubling time was $42 \pm 30$ hours and no differences in doubling time were observed between the groups. In all groups, large interindividual differences were observed (Figure 4.2A).

Proliferation rate was also evaluated over a time period of 4 days using a highthroughput proliferation assay in which cells were seeded at low confluence and the amount of cells was determined every 24 hours. HVECs derived from CABG patients showed the highest proliferation rate but this was not statistically different $(p=0.07$, Friedman test). 
Regression analysis was performed to determine a possible correlation between cell growth and patient characteristics. A significant correlation between sex and mean population doubling time was found, showing lower population doubling times in ECs derived from females. Other factors like age, BMI or smoking were not correlated with population doubling time or proliferation (Supplemental material).
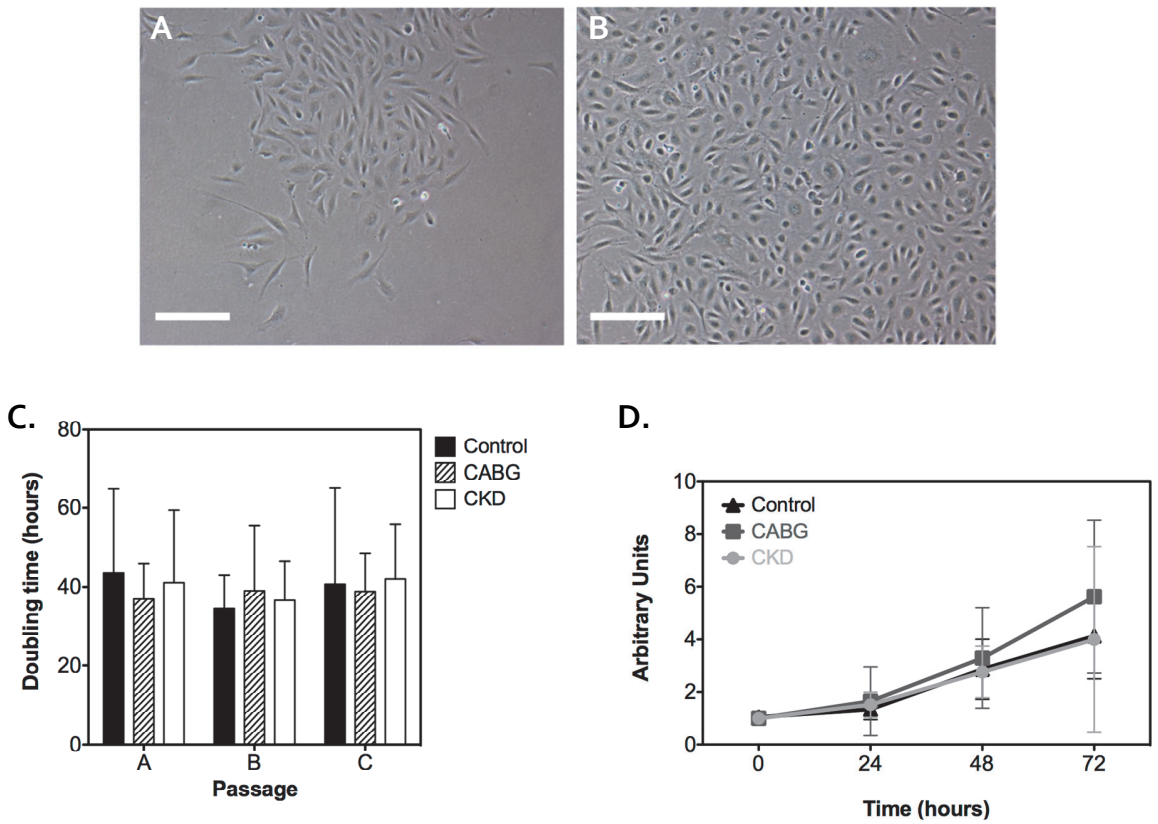

Figure 4.2. Cell growth of primary HVECs derived from different patient categories. A. Representative image of HVECs six days after isolation. B. Same batch of HVECs in passage 1. C. Population doubling time of HVECs in three subsequent passages does not increase over time and is comparable for different patient groups. D. Proliferation measured over 72 hours is not significantly different ( $n=3$ per patient per time point). Means are shown and error bars represent SD. Scale bars indicate $100 \mu \mathrm{m}$ (magnification 100x).

\section{MIGRATION}

The migratory capacity of HVECs was evaluated using a high-throughput migration assay in which centrally-placed circular inserts in wells of a previously cell-seeded 96-wells plate are removed in a controlled manner.

The amount of migrated cells in this area was determined after 24 hours using Hoechst staining (Figure 4.3A). Migration of HVECs derived from CABG and CKD patients was comparable to control patients (control: 294 \pm 143, CABG: $224 \pm 85$, CKD: $217 \pm 85$ migrated cells/HPF; $P=0.12$ ) (Figure $4 \cdot 3 \mathrm{~B}$ ). 

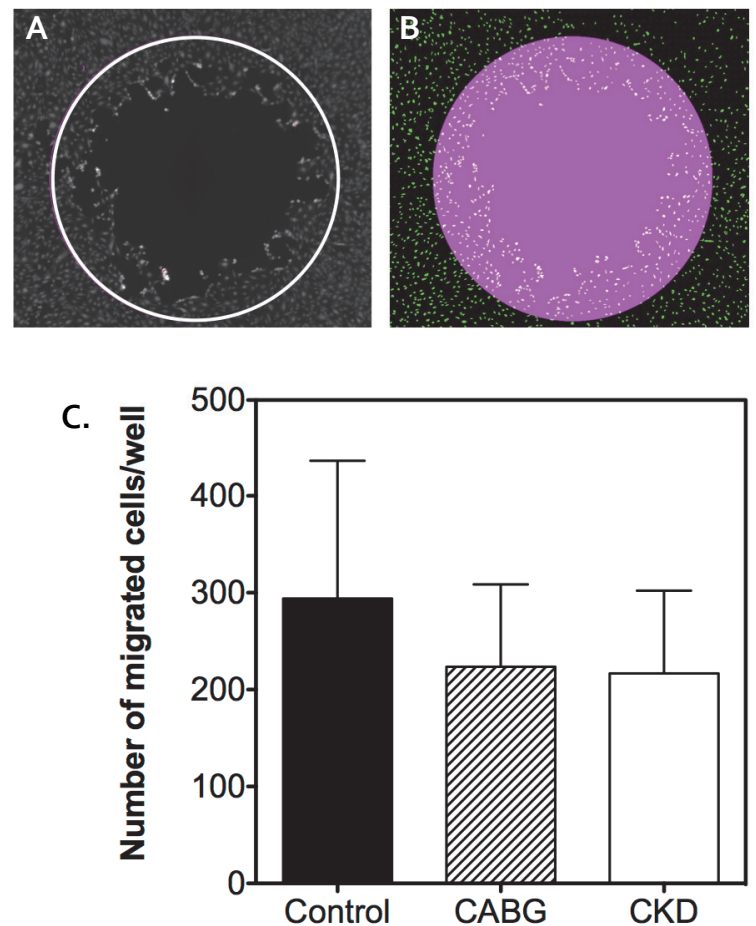

Figure 4.3. High-throughput migration assay of HVECs after overnight starvation. Cells were allowed to migrate in normal endothelial medium. A. Representative image of migration assay after 24 hours. Circle indicates migration area. B. Representative image of digital output of analysis software of same image as shown in (A). C. Number of migrated cells per well after 24 hours is comparable for all patient categories ( $n=6$ per patient). Means are shown and error bars represent SD.

\section{NO AND PROSTACYCLIN PRODUCTION}

Basal production of NO and 6-keto-prostaglandin $\mathrm{F}_{1} \alpha$, a stable hydrolysis product of prostacyclin, was measured in cell culture supernatant after 48 hours in non-stimulated conditions. Cell layers were confluent by the time of medium collection. NO levels from CABG and CKD patients were comparable to control patients (Figure 4.4A). The amount of 6-keto-PGF1 $\alpha$ did not differ between groups either (Figure $4.4 \mathrm{~B}$ ). 
A.

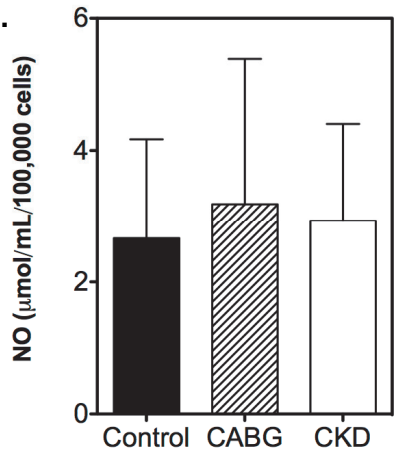

B.

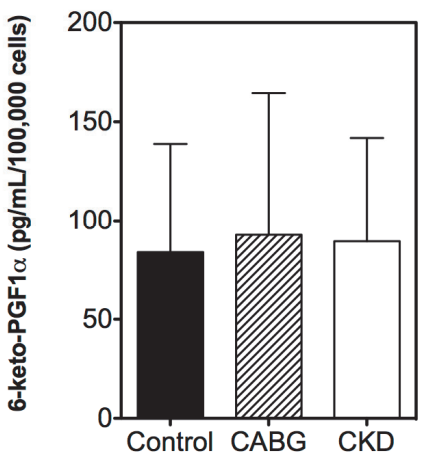

Figure 4.4. Production of nitric oxide (NO) and prostacyclin in cell culture supernatant collected after 48 hours in normal endothelial medium. A. Levels of NO measured with the Griess reaction did not differ between groups ( $n=2$ per patient). B. Prostacyclin levels were evaluated by determining 6-keto-PGF1 $\alpha(n=2$ per patient). Levels were comparable for all groups.

\section{THROMBOGENICITY}

The endothelial lining of blood vessels contributes to plasma coagulation in various stimulatory and inhibitory mechanisms. Together, they realize an important anticoagulant activity that may be perturbed in various diseases. By studying -in the presence of cultured ECs- coagulation of exogenous platelet poor plasma (NP) or FXIIdeficient plasma, we were able to characterize the anti-coagulant function of patient derived ECs (mCAT). Using the TF-inhibitor ASIS and the contact pathway inhibitor $\mathrm{CTI}$, we further dissected the contribution of both pathways to coagulation in a patient-specific manner. Each thrombogram curve is characterized by a lag time, peak height and area under the curve, or endogenous thrombin potential (ETP).

In normal plasma, the lag time, i.e. the time before start of thrombin generation (Figure 4.5A) was comparable with controls for CABG and CKD-derived HVECs. Addition of both CTI and ASIS to NP resulted in an increased lag time in all groups. Substantial interindividual variation could be observed in the CKD group. However, as the thrombogram parameters did not correlate with other clinical or biometric variables the existence of subgroups could not be supported.

The total amount of thrombin formed reflected by the area under the curve (ETP) was lowest for the control group in NP conditions but these results did not reach statistical significance (Figure 4.5B). For the CABG group, CTI decreased the ETP significantly compared to NP+ASIS, suggesting substantial contact pathway activation.

The maximum amount of thrombin formed (peak height) was not significantly different between groups (Figure ${ }_{4 \cdot 5 \mathrm{C}}$ ) but $\mathrm{ASIS}+\mathrm{CTI}$ decreased peak height 
significantly within the CABG and CKD groups compared to NP alone, again suggesting contact pathway activity.

Overall, the addition of ASIS (inhibition of the TF-pathway) did not reveal substantial influence on mCAT parameters. Interestingly, inhibition of the contact activation system by means of CTI led to significantly decreased coagulation in all groups. This is in concordance with the results in FXII-deficient plasma in which only a minority of patient-derived HVECs was able to induce thrombin formation (controls: $n=2 ;$ CABG: $n=3$ and CKD: $n=6$ patients). Thus, coagulation was mainly due to the contact activation pathway with a small contribution of TF in few samples.
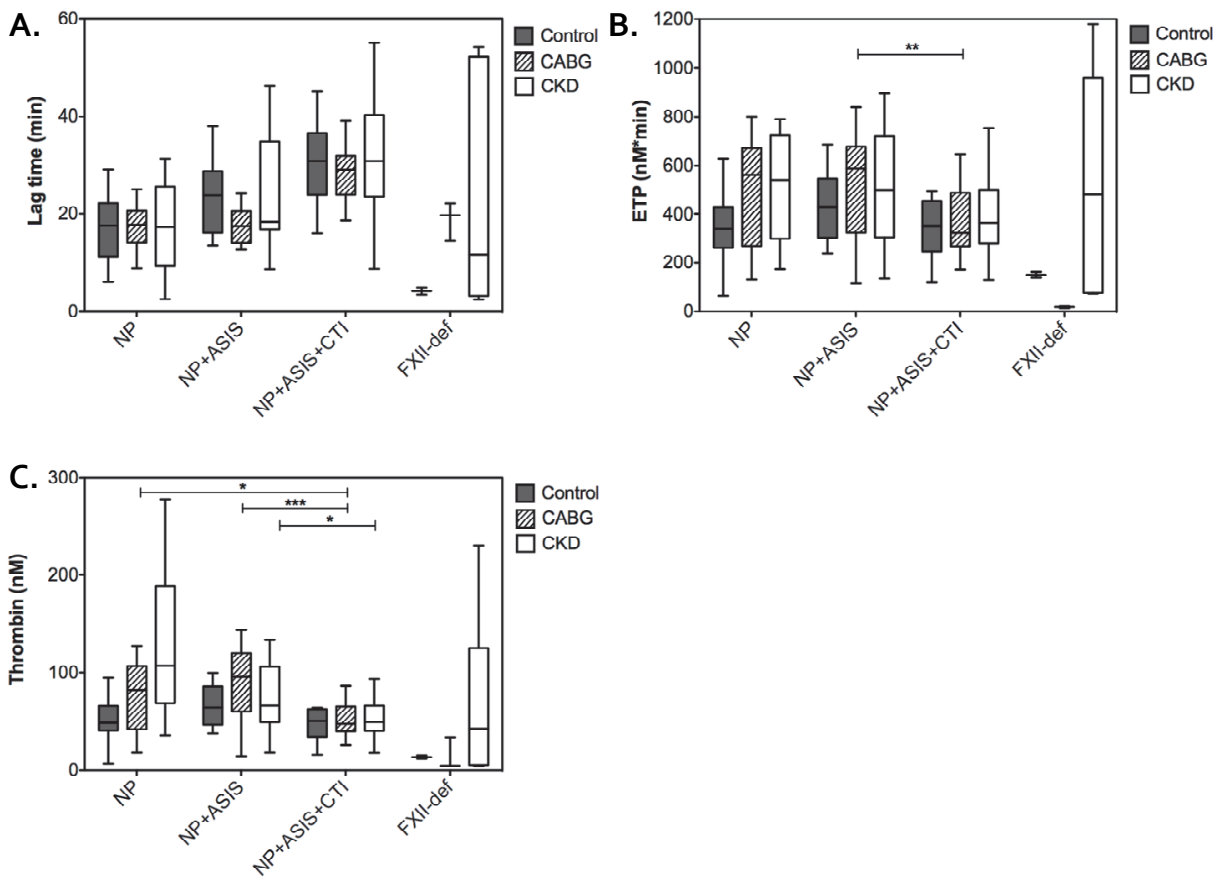

Figure 4.5. Thrombogenic characteristics of patient-derived HVECs assessed with the mCAT method. Thrombin generation curves were generated in normal-pooled plasma (NP) with addition of ASIS to block the TF-pathway and CTI for blocking contact activation. FXII-deficient plasma (FXII-def) was used as well. A. Time before start of thrombin generation, i.e. the lag time, was not different between groups. Addition of $\mathrm{CTI}$ to NP+ASIS increased lag time significantly in the CABG group. Addition of ASIS+CTI to NP alone resulted in an increased lag time in all groups. B. Total amount of thrombin generated; the endogenous thrombin potential (ETP), was comparable. Addition of CTI led to a decrease in ETP in the CABG group. $C$. The maximum peak height of the thrombin generation curves was not different between groups and was decreased by addition of ASIS and CTI in the CABG group and CTI in the CKD group as well. $n=4$ per patient per condition. ${ }^{*} P<0.05,{ }^{* *} P<0.01,{ }^{* * *} P<0.001$ 


\section{ENDOTHELIAL CELL SEEDING}

The ability of patient-derived ECs to attach and survive on PCL-scaffolds coated with fibrin gel was assessed after seeding and culturing the cellularized grafts for seven days in normal EC-medium. All grafts showed living, attached cells after seven days with CD31 expression. Representative images are shown in Figure 4.6.
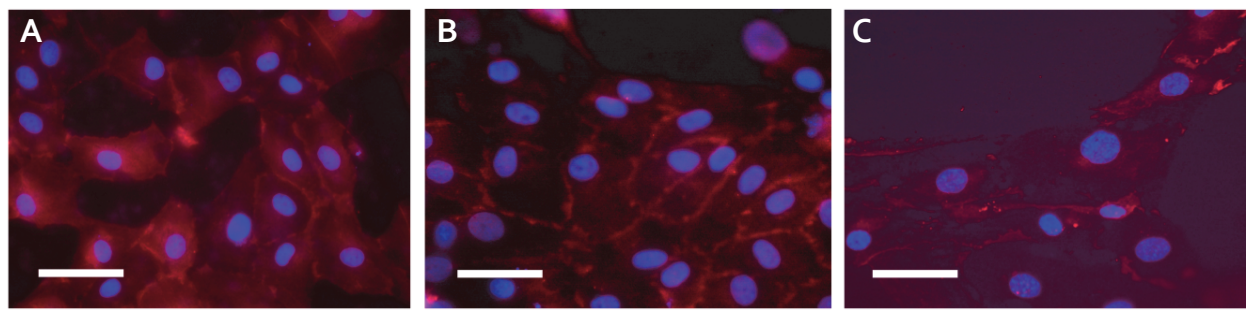

Figure 4.6. $\mathrm{CD}_{31}$ staining of HVECs seeded on fibrin coated PCL scaffolds. HVECs from (A) control patient, B. CKD patient and C. CABG patient. Scale bars represent $50 \mu \mathrm{m}$ (magnification 400x)

\section{DISCUSSION}

For final application of tissue-engineered constructs in daily clinical practice, knowledge regarding behavior and characteristics of patient-derived cells is required. Much research has focused on biomaterials and biomaterial-cellular interactions. However, we feel that one of the factors of major influence, being the patient, has not attracted much scientific attention yet. In the concept of tissue engineering, an autologous approach is followed in which donor cells are expanded in vitro where after these are seeded on a scaffold and transplanted back in vivo. The process of isolation and in vitro expansion could theoretically influence cellular performance. Also, the donor/receiver is usually of advance age and will likely have one or several comorbidities. Especially in the case of primary cells, patient-related comorbidities could influence later in vitro cellular growth and function. In this study, HVECs were isolated from cardiovascular diseased, uremic, and control patients. We were able to include a substantial amount of patients resulting in 48 individual cell batches. After several subculture passages, cell growth, gene expression, secretory and thrombogenic characteristics were evaluated.

Success rate of isolations amounted 48 out of 65 , an acceptable number. Lack of cell growth after isolation occurred in only 2 batches, which we consider a rather low 
failure rate. Both batches were derived from CABG patients. We evaluated population doubling times in a standardized manner during three subsequent passages. In accordance with a previous report ${ }^{25}$, we observed no difference in population doubling times during the relatively early passages, with 18-20 population doublings. Wagner et al. reported a maximum of 65 population doublings before senescence was reached ${ }^{26}$, but this was performed with human umbilical vein ECs (HUVECs) that will likely reach senescence at a later stage than adult primary ECs. Voghel et al. cultured arterial ECs from CABG patients and reported increased senescence in patients with longer exposure to risk factors for CAD. ${ }^{17}$ However, we have not observed any problems with the growth of ECs from aged, diseased patients. Interestingly, regression analysis revealed a lower mean population doubling time for HVECs derived from females. To our knowledge, this has not earlier been described in literature.

In a study by Poh et al. who used primary SMCs to create tissue-engineered constructs, tissue made of cells derived from aged patients was very weak and telomerase stimulation was used to recover cell growth and matrix production. ${ }^{27}$ In this light it should be noted that cell numbers required for EC lining of a TEVG are much less than for populating the media. In fact, the amount of ECs required for seeding a graft can theoretically be reached within 5 passages. When using a seeding density of 500,000 cells $/ \mathrm{cm}^{2}$ for a graft of $60 \mathrm{~cm}$ with a diameter of $0.3 \mathrm{~cm}, 30,000,000$ cells are needed. Taking into account an expansion rate of 1:5 per passage, one should have more than $50,000,000$ cells in confluent culture flasks by the end of the fifth passage. In addition to the normal exponential growth characteristics, we did not observe other signs of senescence such as changes in cellular morphology or increasing population doubling times in our cell cohort. Thus, we believe that senescence is not a realistic threat to usage of primary ECs for tissue engineering.

Migration of ECs is also required to establish a confluent endothelial layer on tissueengineered constructs after the seeding procedure. Therefore, we evaluated the migration potential of HVECs in a high-throughput manner. Migration was not maximal after 24 hours, which allowed us to assess differences between patient groups. However, HVECs from either control patients or CABG and CKD patients demonstrated comparable migratory potential.

In our in vitro conditions $\mathrm{NO}$ and PGI levels in supernatant were not decreased in EC cultures derived from CKD or CABG patients, however these were non-stimulated circumstances. Annuk et al. investigated endothelium-dependent vasodilation in vivo which is mediated by $\mathrm{NO}$, and found diminished vasorelaxation in CKD patients. ${ }^{28}$ Decreased vasorelaxation in response to acetylcholine has also been reported in 
resistance arteries in uremic humans ${ }^{29}$ but not in uremic rats. ${ }^{30,31}$ The mechanism of reduced endothelium-dependent vasorelaxation is still unknown.

The most important function of ECs seeded in a TEVG is prevention of intraluminal thrombus formation. By using the mCAT method we were able to study antithrombogenicity of cultured ECs in a high-throughput manner. Krenning used a comparable assay to assess thrombin formation resistance of cultured EPCs from patients. ${ }^{32}$ EPCs derived from end-stage renal disease subjects showed increased thrombin formation potential compared to healthy subjects. ${ }^{32}$ In our analysis, no significant differences were seen, which is possibly related to large variation in the CKD group, as we showed enhanced thrombin generation on CABG-derived HVECs compared to controls in an earlier report. ${ }^{24}$ Patients included in the CKD group varied substantially in duration of renal failure as well as in patient characteristics such as age and comorbidities. Several studies have reported a relationship between thrombin generation in plasma and coronary arterial disease (CAD) $)^{33,34}$ although results are not very consistent. ${ }^{35}$ The relevance of the contact pathway for thrombin generation as we showed before ${ }^{24}$ was also demonstrated in the current study, as inhibition of the TFpathway did not result in significant differences and thrombin generation in FXIIdeficient plasma was absent for the majority of patients. This can be of interest for current research into future therapies with FXII-inhibitors. ${ }^{36-38}$

An interesting finding in our gene expression analysis was the higher expression of thrombomodulin, and a trend towards decreased PDGFR $\alpha$ and increased eNOS expression in HVECs derived from CABG patients compared with control subjects. Decreased responses to PDGF in CABG-derived ECs resulting in lower proliferation and migration could be disadvantageous. PDGF is not a regularly used growth factor in endothelial cell culture media, and indeed we did not observe any differences in our proliferation and migration assays. Differences in gene expression even after subculturing for 3-5 passages, might be attributable to phenotypic influence of disease leading to persistent changes in the cell caused for instance by epigenetic modifications. ${ }^{39-41}$ Also, all CABG patients used statins, which are known to induce Kruppel-like factor 2 (KLF-2) that serves as a transcription factor for thrombomodulin and eNOS..$^{2}$ However, in our immunofluorescent analysis for eNOS expression, we could not detect any differences.

On the other hand, recovery of ECs from the diseased in vivo milieu has been described as well that would explain the lack of differences in growth and other functional characteristics. ${ }^{39}$ Another explanation for the variable gene expression pattern could be the different origin of vessels used for EC isolation. This is a drawback of our study. However, this was inevitable due to practical restrictions as access to vessels was 
limited by the applied surgical procedures. Although differential expression of thrombomodulin and other genes in ECs within the vascular bed have been described ${ }^{43,44}$, no studies have compared cells from the epigastric vein with the saphenous vein to our knowledge so we cannot provide a definitive explanation for these differences. To further increase robustness of the findings, comparison of ECs from the same vessels from different patient categories would be ideal. Furthermore, it is desirable to investigate larger numbers of subjects.

The capacity of patient-derived HVECs to populate a tissue-engineered graft was demonstrated by seeding HVECs on PCL-scaffolds coated with fibrin gel. Cells remained viable and $C_{31}$ positive after seven days of culture.

Besides our evaluation of patient-derived EC performance we aimed to set-up a logistic, high-throughput assembly to culture large amount of cells from an extensive number of patients. Using high-throughput proliferation, migration, and thrombin generation assays, we were able to study and compare cellular function in a standardized, reproducible manner. Not only are these tests required to determine the immediate success of employing autologous cells, but they may also be predictive of future graft behavior such as late thrombosis, intimal hyperplasia, atherosclerosis development and potential oncogenicity. The latter obviously requires intermediate to long-term follow up studies after implantation.

\section{CONCLUSION}

As HVECs from either cardiovascular diseased and CKD patients did not reveal inferior cell growth, nor other major dysfunctional characteristics compared to HVECs derived from uncompromised patients, we believe ECs from aged patients with comorbidities can be safely used for isolation and in vitro expansion for creation of tissue-engineered constructs. 


\section{REFERENCES}

1. Campbell JH, Efendy JL, Campbell GR. Novel Vascular Graft Grown Within Recipient's Own Peritoneal Cavity. Circ Res. 1999; 85(12): 1173-8.

2. L'Heureux N, Dusserre N, Konig G, Victor B, Keire P, Wight TN, et al. Human tissue-engineered blood vessels for adult arterial revascularization. Nat Med. 2006; 12(3): 361-5.

3. Hoerstrup SP, Cummings Mrcs I, Lachat M, Schoen FJ, Jenni R, Leschka S, et al. Functional growth in tissue-engineered living, vascular grafts: follow-up at 100 weeks in a large animal model. Circulation. 2006; 114(1 Suppl): l159-66.

4. Cho SW, Kim IK, Kang JM, Song KW, Kim HS, Park CH, et al. Evidence for In Vivo Growth Potential and Vascular Remodeling of Tissue-Engineered Artery. Tissue Eng Part A. 2008.

5. Nieponice A, Soletti L, Guan J, Hong Y, Gharaibeh B, Maul TM, et al. In vivo assessment of a tissueengineered vascular graft combining a biodegradable elastomeric scaffold and muscle-derived stem cells in a rat model. Tissue Eng Part A. 2010; 16(4): 1215-23.

6. Koch S, Flanagan TC, Sachweh JS, Tanios F, Schnoering H, Deichmann T, et al. Fibrin-polylactidebased tissue-engineered vascular graft in the arterial circulation. Biomaterials. 2010; 31(17): 4731-9.

7. Shin'oka T, Matsumura G, Hibino N, Naito Y, Watanabe M, Konuma T, et al. Midterm clinical result of tissue-engineered vascular autografts seeded with autologous bone marrow cells. J Thorac Cardiovasc Surg. $2005 ; 129(6)$ : 1330-8.

8. McAllister TN, Maruszewski M, Garrido SA, Wystrychowski W, Dusserre N, Marini A, et al. Effectiveness of haemodialysis access with an autologous tissue-engineered vascular graft: a multicentre cohort study. Lancet. 2009; 373(9673): 1440-6.

9. Vara DS, Salacinski HJ, Kannan RY, Bordenave L, Hamilton G, Seifalian AM. Cardiovascular tissue engineering: state of the art. Pathol Biol (Paris). 2005; 53(10): 599-612.

10. L'Heureux N, Paquet S, Labbe R, Germain L, Auger FA. A completely biological tissue-engineered human blood vessel. FASEB J. 1998; 12(1): 47-56.

11. Niklason LE, Gao J, Abbott WM, Hirschi KK, Houser S, Marini R, et al. Functional arteries grown in vitro. Science. 1999; 284(5413): 489-93.

12. Stekelenburg M, Rutten MC, Snoeckx LH, Baaijens FP. Dynamic straining combined with fibrin gel cell seeding improves strength of tissue-engineered small-diameter vascular grafts. Tissue Eng Part A. 2009; 15(5): 1081-9.

13. Gong Z, Niklason LE. Small-diameter human vessel wall engineered from bone marrow-derived mesenchymal stem cells (hMSCs). FASEB J. 2008; 22(6): 1635-48.

14. L'Heureux N, Dusserre N, Marini A, Garrido S, de la Fuente L, McAllister T. Technology insight: the evolution of tissue-engineered vascular grafts--from research to clinical practice. Nat Clin Pract Cardiovasc Med. 2007; 4(7): 389-95.

15. Zilla P, Siedler S, Fasol R, Sharefkin JB. Reduced reproductive capacity of freshly harvested endothelial cells in smokers: a possible shortcoming in the success of seeding? J Vasc Surg. 1989; 10(2): 143-8.

16. Meinhart J, Halbmayer W-M, Deutsch M, Zilla P. Hyperlipidemia Coincides with Reversible Growth Impairment of Cultured Human Autologous Endothelial Cells. Endothelium. 2002; 9(4): 239 - 46.

17. Voghel G, Thorin-Trescases N, Farhat N, Nguyen A, Villeneuve L, Mamarbachi AM, et al. Cellular senescence in endothelial cells from atherosclerotic patients is accelerated by oxidative stress associated with cardiovascular risk factors. Mech Ageing Dev. 128(11-12): 662-71.

18. Stroncek JD, Grant BS, Brown MA, Povsic TJ, Truskey GA, Reichert WM. Comparison of Endothelial Cell Phenotypic Markers of Late-Outgrowth Endothelial Progenitor Cells Isolated from Patients with Coronary Artery Disease and Healthy Volunteers. Tissue Eng Part A. o(o).

19. Celermajer DS, Sorensen KE, Gooch VM, Miller, Sullivan ID, Lloyd JK, et al. Non-invasive detection of endothelial dysfunction in children and adults at risk of atherosclerosis. Lancet. 1992; 340(8828): 11115 .

20. Zeiher AM, Schächinger V, Minners J. Long-term Cigarette Smoking Impairs Endothelium-Dependent Coronary Arterial Vasodilator Function. Circulation. 1995; 92(5): 1094-100. 
21. Küng CF, Lüscher TF. Different Mechanisms of Endothelial Dysfunction With Aging and Hypertension in Rat Aorta. Hypertension. 1995; 25(2): 194-200.

22. Thambyrajah J, Landray MJ, McGlynn FJ, Jones HJ, Wheeler DC, Townend JN. Abnormalities of endothelial function in patients with predialysis renal failure. Heart. 2000; 83(2): 205-9.

23. Zhang HN, Leng $P$, Wang $Y Z$, Zhang J. Treating human meniscal fibrochondrocytes with hIGF-1 gene by liposome. Clin Orthop Relat Res. 2009; 467(12): 3175-82.

24. Geenen IL, Post MJ, Molin DG, Schurink GW, Maessen JG, R VO, et al. Coagulation on endothelial cells: The underexposed part of Virchow's Triad. Thromb Haemost. 2012; 108(5).

25. Maciag T, Hoover GA, Stemerman MB, Weinstein R. Serial propagation of human endothelial cells in vitro. J Cell Biol. 1981; 91(2 Pt 1): 420-6.

26. Wagner M, Hampel B, Bernhard D, Hala M, Zwerschke W, Jansen-Durr P. Replicative senescence of human endothelial cells in vitro involves $G_{1}$ arrest, polyploidization and senescence-associated apoptosis. Exp Gerontol. 2001; 36(8): 1327-47.

27. Poh M, Boyer M, Solan A, Dahl SL, Pedrotty D, Banik SS, et al. Blood vessels engineered from human cells. Lancet. 2005; 365(9477): 2122-4.

28. Annuk M, Zilmer M, Lind L, Linde T, Fellstrom B. Oxidative Stress and Endothelial Function in Chronic Renal Failure. J Am Soc Nephrol. 2001; 12(12): 2747-52.

29. Morris STW, McMurray JJV, Spiers A, Jardine AG. Impaired endothelial function in isolated human uremic resistance arteries. Kidney Int. 2001; 6o(3): 1077-82.

30. Thuraisingham R, Raine A. Maintenance of normal agonist-induced endothelium-dependent relaxation in uraemic and hypertensive resistance vessels. Nephrol Dial Transplant. 1999; 14(1): 70-5.

31. Jolma P, Kalliovalkama J, Tolvanen JP, Koobi P, Kahonen M, Saha H, et al. Preserved endotheliumdependent but impaired beta-adrenergic relaxation of the resistance vessels in experimental renal failure. Exp Nephrol. 2002; 10(5-6): 348-54.

32. Krenning G, Dankers PYW, Drouven JW, Waanders F, Franssen CFM, van Luyn MJA, et al. Endothelial progenitor cell dysfunction in patients with progressive chronic kidney disease. Am J Physiol Renal Physiol. 2009; 296(6): F1314-22.

33. Borissoff JI, Joosen IA, Versteylen MO, Spronk HM, ten Cate H, Hofstra L. Accelerated in vivo thrombin formation independently predicts the presence and severity of CT angiographic coronary atherosclerosis. JACC Cardiovasc Imaging. 2012; 5(12): 1201-10.

34. Merlini PA, Baver KA, Oltrona L, Ardissino D, Cattaneo M, Belli C, et al. Persistent activation of coagulation mechanism in unstable angina and myocardial infarction. Circulation. 1994; 90(1): 61-8.

35. Carcaillon L, Alhenc-Gelas M, Bejot Y, Spaft C, Ducimetiere P, Ritchie K, et al. Increased thrombin generation is associated with acute ischemic stroke but not with coronary heart disease in the elderly: the Three-City cohort study. Arterioscler Thromb Vasc Biol. 2011; 31(6): 1445-51.

36. Renné T, Pozgajova M, Gruner S, Schuh K, Pauer HU, Burfeind P, et al. Defective thrombus formation in mice lacking coagulation factor XII. J Exp Med. 2005; 202(2): 271-81.

37. Kleinschnitz C, Stoll G, Bendszus M, Schuh $K$, Pauer $H-U$, Burfeind $P$, et al. Targeting coagulation factor XII provides protection from pathological thrombosis in cerebral ischemia without interfering with hemostasis. J Exp Med. 2006; 203(3): 513-8.

38. Renné T, Gailani D. Role of Factor XII in hemostasis and thrombosis: clinical implications. Expert Rev Cardiovasc Ther. 2007; 5(4): 733-41.

39. Aird WC. Spatial and temporal dynamics of the endothelium. J Thromb Haemost. 2005; 3(7): $1392-406$.

40. Ordovas JM, Smith CE. Epigenetics and cardiovascular disease. Nat Rev Cardiol. 2010; 7(9): 510-9.

41. Kim M, Long TI, Arakawa K, Wang R, YU MC, Laird PW. DNA methylation as a biomarker for cardiovascular disease risk. PLoS ONE. 2010; 5(3): eg692.

42. Sen-Banerjee S, Mir S, Lin Z, Hamik A, Atkins GB, Das H, et al. Kruppel-Like Factor 2 as a Novel Mediator of Statin Effects in Endothelial Cells. Circulation. 2005; 112(5): 720-6.

43. Chi J-T, Chang HY, Haraldsen G, Jahnsen FL, Troyanskaya OG, Chang DS, et al. Endothelial cell diversity revealed by global expression profiling. Proc Natl Acad Sci U S A. 2003; 100(19): 10623-8.

44. Aird WC. Phenotypic Heterogeneity of the Endothelium: II. Representative Vascular Beds. Circ Res. 2007; 100(2): 174-90. 


\section{SUPPLEMENTAL MATERIAL}

\section{METHODS}

\section{STATISTICAL ANALYSIS}

To determine a possible correlation between patient characteristics and cellular growth, univariate analyses were performed. Pearson correlations were calculated to study continuous risk factors (age, BMI) and Independent-Samples $\mathrm{T}$ tests were carried out to analyze categorical factors (sex, CAD, CKD, dyslipidemia, hypertension, diabetes, smoking). Multivariate analyses were then performed based on the results obtained in the univariate analyses. For each parameter, the multiple linear regression model was adjusted and only variables with a $P$ value $<0.3$ in univariate analysis were used for the multiple model process. The variable 'patient category' was also included in the model. The selection of significant variables in the final model was performed by a "backward" procedure. The significance level was fixed to 0.05 .

\section{RESULTS}

The correlation of clinical parameters and cellular growth reflected in mean doubling time and proliferation rate at 72 hours were evaluated by means of univariate analysis. Gender had a significant influence on mean doubling time (males: $43.3 \pm 12.2$, females: 37.1 \pm 7.0 hours, $P=0.03)$. For the multiple linear regression analysis, the parameters age $(\mathrm{r}=-0.26, P=-0.08), \mathrm{BMI}(\mathrm{r}=-0.23, P=0.14)$ and hypertension $(P=0.12)$ were also used.

There was no significant correlation between any of the patient characteristics and proliferation rate at $\mathrm{t} 72$.

Using multivariate analysis, the following model was found:

Mean doubling time $=44.07-7.02 *$ sex

in which male $=0$ and female $=1$.

This indicates that ECs derived from females show faster cellular growth than malederived ECs. 


\section{CHAPTER 5}

\section{NO Resistance Reduces AV Fistula Maturation in Chronic Kidney Disease}

Irma LA Geenen, Felix F Kolk, Daniel GM Molin, Allard Wagenaar, Mathijs G Compeer, Jan H Tordoir, Geert WH Schurink, Jo G De Mey, Mark J Post 


\section{ABSTRACT}

Autologous arteriovenous (AV) fistulas are the first choice for vascular access but have a high risk of non-maturation due to insufficient vessel adaptation, a process dependent on nitric oxide (NO)-signaling. Chronic Kidney Disease (CKD) is associated with oxidative stress that can disturb NO-signaling. Here, we evaluated the influence of CKD on AV fistula maturation and NO-signaling.

CKD was established in rats by a $5 / 6^{\text {th }}$ nephrectomy and after 6 weeks, an AV fistula was created between the carotid artery and jugular vein, which was followed up at 3 weeks with ultrasound and flow assessments. CKD animals showed lower flow rates, smaller fistula diameters and increased oxidative stress levels in the vessel wall. Vasoreactivity was determined in a wire myograph for control and CKD animals, showing normal endothelium-dependent relaxation and diminished relaxation after sodium nitroprusside in CKD vessels. This indicates NO resistance of the NO-receptor soluble guanylate cyclase ( $\mathrm{sGC}$ ), which was confirmed by stimulation with the sGC-activator BAY 60-2770 resulting in increased vasorelaxation in CKD vessels. Oral administration of BAY 60-2770 to CKD animals induced larger fistula diameters, however; flow was not significantly different from vehicle-treated CKD animals.

We conclude that CKD induces oxidative stress resulting in NO resistance that can hamper AV fistula maturation. sGC activators like BAY 60-2770 could offer therapeutic potential to increase AV fistula maturation. 


\section{INTRODUCTION}

The prevalence of end-stage renal disease (ESRD) has increased during the last decade and amounted over 500.000 patients in the United States in 2009. ${ }^{1}$ The majority of patients rely on hemodialysis, and for them a functional vascular access is essential. According to the National Kidney Foundation Kidney Disease Outcomes Quality Initiative and the European Best Practices Guidelines for vascular access, first choice for vascular access is an autologous arteriovenous (AV) fistula because of its superior long-term patency compared to prosthetic (PTFE) grafts and central vein catheters. ${ }^{2,3}$ However, at short term, AV fistulas show rather high primary failure rates due to nonmaturation. Non-maturation occurs in $28-53 \%$ of the radiocephalic fistulas, with higher incidence in older, female patients and patients with extensive vascular disease. ${ }^{4,5}$ According to the Dialysis Access Consortium, maturation of an AV fistula is defined as the ability to use the fistula for dialysis within 4 months after fistula creation, and a minimum flow of $300 \mathrm{~mL} / \mathrm{min}$ for at least 8 dialysis sessions during the ensuing 30 days. $^{6}$

The key requirements for fistula maturation are dilation of the arterial and venous vessel segments to generate a sufficient flow required for hemodialysis and to prevent thrombosis. ${ }^{7}$ After creation of the arterial-venous anastomosis, a low-resistance circuit is established and as a result, blood flow will increase. Increased flow will raise shear stress and stimulate endothelial cells (ECs) to synthesize and release nitric oxide (NO) that induces vessel dilation via cyclic guanosine monophosphate (cGMP) signaling. ${ }^{8-10}$ NO binds to its cognate receptor soluble guanylate cyclase (sGC) in the smooth muscle cell (SMC), facilitating the conversion of guanosine triphosphate (GTP) into the second messenger cGMP. cGMP stimulates SMC relaxation via protein kinase G (PKG) activation followed by a decrease in intracellular calcium levels. ${ }^{11-13}$

It has been hypothesized that one of the key events in AV fistula maturation failure is endothelial dysfunction ${ }^{7,14}$ as a result of uremia-induced oxidative stress. ${ }^{15-18}$ Endothelial dysfunction in uremia is characterized by, amongst others, a decrease in NO bioavailability due to decreased endothelial NO synthase (eNOS) expression ${ }^{19}$, reduced tetrahydrobiopterin $\left(\mathrm{BH}_{4}\right)$ levels that will result in eNOS uncoupling ${ }^{20,21}$, high amounts of the endogenous eNOS-inhibitor asymmetric dimethylarginine (ADMA) ${ }^{22}$ and scavenging of NO by free radicals. ${ }^{18}$ Insufficient NO availability reduces the capacity of blood vessels to dilate in the event of an increase in shear stress. Diminished NO levels can also increase neointima formation ${ }^{23}$ and induce platelet adhesion. $^{24}$ 
Previous reports on the influence of chronic kidney disease (CKD) on AV fistula function showed increased neointima formation due to higher cell-turnover in $C K D^{25}$ and an enhanced migratory phenotype of SMCs. ${ }^{26}$ However, the influence of CKD on $\mathrm{NO}$-signaling and AV fistula maturation has not been investigated yet.

Therefore, we aimed to investigate the influence of CKD on endothelial and SMC function in relation to AV fistula maturation. Nephrectomized and control rats underwent $\mathrm{AV}$ fistula creation between the carotid artery and jugular vein. Endothelial and SMC function were studied ex vivo in vessel rings from CKD rats and controls in a wire myograph and NO-signaling was assessed by means of $1 \mathrm{H}-[1,2,4]$ oxadiazolo[4,3-2] quinoxalin-1-one (ODQ, an oxidator of sGC), the SGC stimulator BAY 41-2272 and SGC activator BAY 60-2770. We observed decreased flow and smaller vessel diameters in CKD animals. Moreover, CKD arteries appeared to be NO resistant and sensitive to BAY 60-2770. Therefore, BAY 60-2770 was administered to CKD animals receiving an $A V$ fistula in order to enhance vessel dilation and improve $A V$ fistula flow.

\section{ANIMALS AND METHODS}

\section{ANIMALS}

Wistar rats weighting 275-325 grams, 9-11 weeks old, were purchased from Harlan Laboratories (Horst, The Netherlands). Animals were housed in normal cages with free access to water and standard chow diet and were kept in climate-controlled rooms $\left(21^{\circ} \mathrm{C}\right.$ and $55 \%$ relative humidity) with a $12 \mathrm{~h}$ cycle of light and darkness. Experimental protocols were conducted according to international guidelines (American Physiological Society Guiding Principles for the Care and Use of Vertebrate Animals in Research and Training) and were approved by the local Ethics Committee on Experimental Animal Welfare. All surgical procedures were carried out under general anesthesia with isoflurane $2 \%$ combined with an analgesic (buprenorphin $0.03 \mathrm{mg} / \mathrm{kg}$ ) under sterile conditions.

Rats underwent $5 / 6^{\text {th }}$ nephrectomy as described previously ${ }^{27}$ by removing the right kidney and ligating two of the three main arterial branches of the left kidney. Care was taken to ensure that two third of the kidney appeared ischemic, if necessary an additional branch was ligated. In sham animals, the abdomen was opened and kidneys were exposed but left intact.

Blood pressure was measured with a tail-cuff system (CODA ${ }^{T M}$, Kent Scientific Corporation, Torrington, CT, USA) before AV fistula surgery and before euthanasia. To prevent stress-effects, animals were trained before measurements. At least 5 accurate 
measurements per animal were used for analysis of diastolic, mean and systolic pressure.

\section{AV FISTULA CREATION}

Six weeks after $5 / 6^{\text {th }}$ nephrectomy or sham procedure, an AV fistula of the jugular vein and the carotid artery was created (Figure 5.1, Flgure 5.2A). After opening of the skin, the jugular vein was exposed and an end-to-side anastomosis was created to the ipsilateral carotid artery with eight interrupted sutures of 10-0 monofilament (Monosof ${ }^{\mathrm{TM}}$, Covidien, Mansfield, MA, USA). The distal part of the carotid artery was ligated.

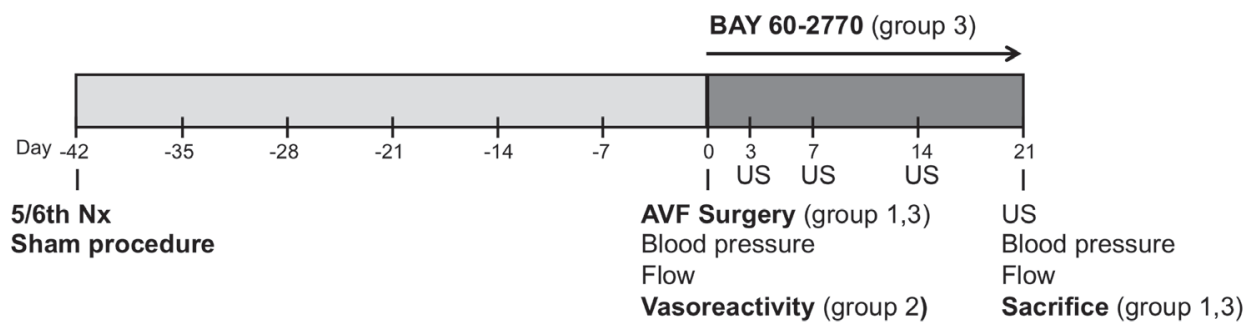

Figure 5.1. Study design. Animals underwent a $5 / 6^{\text {th }}$ nephrectomy or sham procedure. After six weeks, an AV fistula was created. Group 2 was euthanized after these six weeks for measurements of vasoreactivity. AV fistula animals (group 1,3) were monitored for another 21 days with ultrasound measurements conducted after 3, 7, 14 and 21 days. Hereafter, animals were euthanized after blood pressure and flow assessment. Group 3 was treated with BAY 6o-2770 or vehicle after AV fistula surgery and underwent similar follow-up as animals in group 1.

\section{AV FISTULA FOLLOW-UP}

Immediately after AV fistula creation and three weeks later, flow through the arterialized vein was measured with an ultrasonic flow probe (Transonic Systems BV, Maastricht, The Netherlands). Mean diameter of the AV fistula was determined with ultrasound measurements in anesthetized animals (isoflurane 2.8\%). Measurements were conducted at 3, 7, 14 and 21 days (Figure 5.1) after AV fistula creation with the VEVO 770 and a $30 \mathrm{MHz}$ transducer (VisualSonics Inc., Toronto, Canada). B-mode images were obtained from the proximal carotid artery and the arterialized vein (Figure 5.2C).

After three weeks of follow-up, animals were euthanized under anesthesia by means of aortic puncture and complete blood removal. Serum was collected for creatinine and 
urea assessment. Post-mortem, animals were flushed with saline and perfusion-fixed with $2 \%$ formalin at $100 \mathrm{mmHg}$ pressure to preserve vessel morphology. The AV fistula was removed en bloc, stored in formalin overnight and then transferred to ethanol $70 \%$ for later paraffin embedding. Heart weight and left kidney weight were recorded. Serum analyses were performed in the clinical laboratory by autoanalyzer techniques.
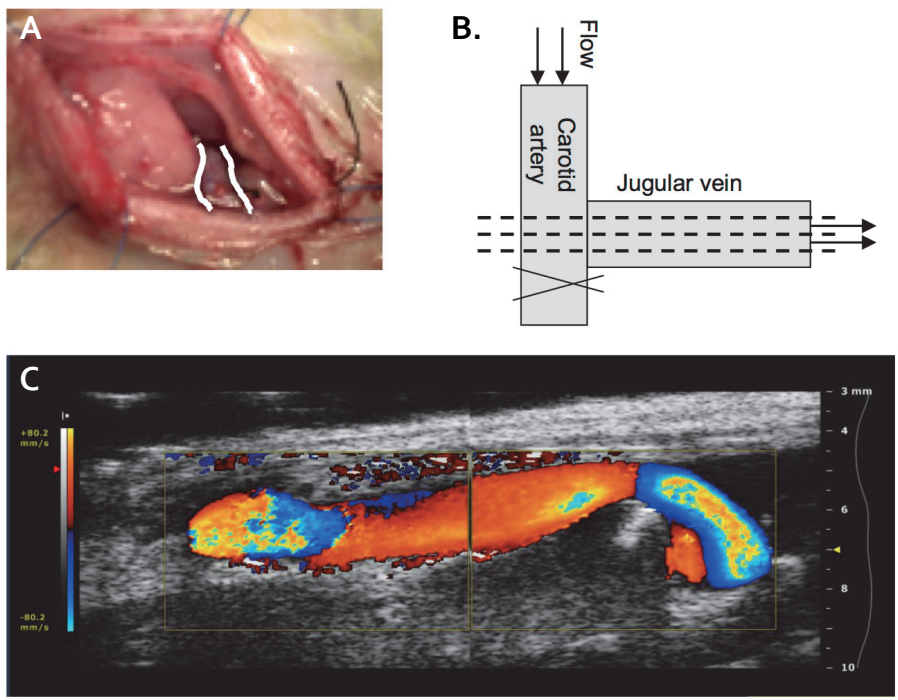

Figure 5.2. A. AV fistula created by anastomosing the jugular vein to the carotid artery in an end-to-side manner. The venous part is depicted with white lines. B. For the purpose of (immuno)histochemistry longitudinal sections were cut through the AV fistula (dashed lines). C. Representative color Doppler ultrasound image of AV fistula (distal part at the left side).

\section{TREATMENT WITH BAY 60-2770}

The effect of BAY 60-2770 on AV fistula maturation was studied in CKD animals. After creation of the AV fistula, animals were treated with BAY $60-2770(0.3 \mathrm{mg} / \mathrm{kg})$ or vehicle for 3 weeks until euthanasia. BAY 60-2770 was dissolved in the vehicle consisting of transcutol $10 \%$, cremophor $20 \%$ and $\mathrm{H}_{2} \mathrm{O} 70 \%$ and was administered by daily oral gavage. ${ }^{28}$

\section{HISTOLOGY AND MORPHOMETRY}

Serial sections of $5 \mu \mathrm{m}$ thickness were obtained every $120 \mu \mathrm{m}$ throughout the AV anastomosis as depicted in Figure 2B. Hematoxylin and eosin staining was performed 
with (Mayer's Hematoxyline and Eosine Y (0.2\%) (Klinipath, Duiven, The Netherlands) and Elastin von Gieson (EvG) staining was performed according to the manufacturer's protocol (Merck, Darmstadt, Germany). Sections were stained for SMCs with mouse

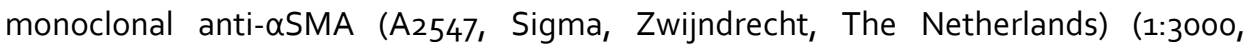
overnight) and for oxidative stress with rabbit polyclonal anti-nitrotyrosine. After incubation with the appropriate secondary antibody, they were subjected to avidinbiotin horseradish peroxidase-DAB procedure (Vector Labs, Burlingame, CA, USA and DakoCytomation, Dako Netherlands BV, Heverlee, Belgium, respectively) and counterstained with haematoxylin (Klinipath, Duiven, the Netherlands). To determine the amount of intimal hyperplasia, EvG sections were photographed with a Leica DMI 300B (Rijswijk, The Netherlands). Morphometric analysis for intima and media thickness was automated ( $Q$ win $V_{3}$, Leica) and performed on two high-power fields of the AV fistula in 3 sections per animal (Figure 5.2B). Average thickness was calculated by dividing surface area by the length of the vessel segment. Amount of DAB-stained pixels in anti-nitrotyrosine stained sections was quantified by automatic analysis in Image-Pro Plus (MediaCybernetics, Rockville, MD, USA) and the analysis was blinded to treatment and experimental group.

\section{ISOMETRIC TENSION MEASUREMENTS}

Six weeks after $5 / 6^{\text {th }}$ nephrectomy or sham procedure, animals were euthanized by inducing hypovolemia via aortic puncture. The carotid arteries were carefully dissected without damaging the endothelium and $2 \mathrm{~mm}$ long segments were mounted in a wire myograph (DMT, Aarhus, Denmark). During contraction with phenylephrine (10 $\mu \mathrm{M})$ endothelial-dependent relaxation was studied by means of stimulation with acetylcholine (ACh, $10^{-10}-10^{-5} \mathrm{M}$, both Sigma). Blocking of NOS with L-NAME (10 $\mu \mathrm{M}$, Sigma) was also performed to control for non-NO mediated effects of ACh. The NOdonor sodium nitroprusside (SNP, $10^{-10}-10^{-5} \mathrm{M}$, Sigma) was used to evaluate the relaxation capacity of SMCs. BAY 41-2272, a stimulator of sGC (Bayer, Leverkusen, Germany) and BAY 60-2770, an activator of oxidized sGC (Bayer) (both kindly provided by Dr. J.P. Stasch, Bayer) were used to evaluate the oxidative state of sGC. $1 \mathrm{H}$ $[1,2,4]$ oxadiazolo[4,3-a]quinoxalin-1-one (ODQ, Sigma) was used to actively oxidize sGC in combination with the BAY compounds.

\section{WESTERN BLOTS}

Using complete radio-immunoprecipitation assay lysis buffer (Santa-Cruz Technology, Santa Cruz, USA), with additional proteases and phosphatases inhibitors (Thermo 
Fisher, Aalst, Belgium), vessels were boiled at $95^{\circ} \mathrm{C}$ for 10 minutes. The partially lysed vessels were transferred to a BeadBeater (Biospec Products, Barlesville, USA) and beated for $2 \times 30$ seconds and cooled on ice in between. Protein concentration was determined using the bicinchoninic acid method (Pierce, Rockford, USA) and mixed with 4x sample loading buffer (BioRad, Veenendaal, The Netherlands), 20x reducing agent (BioRad) before boiling for 5 minutes at $95^{\circ} \mathrm{C}$. Samples were cooled down to RT, centrifuged for 1 minute at $13,400 \mathrm{~g}$ and loaded on a gel (4-12\% Bis-Tris, BioRad). The gel was blotted on a polyvinylidene difluoride membrane (BioRad) overnight $30 \mathrm{~V}$ at $4^{\circ} \mathrm{C}$. The blotting membrane was blocked by incubation with $3 \%$ milk powder in TBS-Tween and incubated with a primary antibody against SGC or $\beta$-actin (Abcam, Cambridge, UK and Sigma). Next, the blot was incubated with a peroxidase conjugated secondary antibody and bands were detected using the SuperSignal West Femto substrate (Pierce, Thermo Scientific, Rockford, IL, USA). Visualization was performed using the ChemiDoc XRS system (BioRad).

\section{STATISTICAL ANALYSIS}

All data are expressed as mean \pm standard error of the mean (SEM). Contractile responses are depicted as percentage of relaxation after phenylephrine precontraction. Curves were fitted and data were analyzed with Prism 5.0c for Mac (GraphPad Software, San Diego, CA, USA) and Microsoft Excel for Mac 2011. Groups were compared using Student's t test and two-way ANOVA repeated measured for time-bound analysis. $P$-values $<0.05$ were considered significant.

\section{RESULTS}

\section{EFFECTS OF $5 / 6^{\text {TH }}$ NEPHRECTOMY}

Animals were exposed to CKD for six weeks before AV fistula creation. CKD was induced by $5 / 6^{\text {th }}$ nephrectomy $(n=10)$ and control animals were submitted to a sham operation $(n=11)$. Serum creatinine $(85 \pm 12.5$ vs. $33 \pm 1.5 \mu \mathrm{mol} / \mathrm{l}, P<0.05)$ and urea $(17.9 \pm 2.8$ vs. $7.5 \pm 0.5 \mathrm{mmol} / \mathrm{l}, P<0.05)$ were significantly higher in CKD animals compared to controls. Systolic blood pressure was elevated in CKD animals before and after AV fistula creation. Interestingly, heart weight was also higher in CKD animals ( $2.51 \pm 0.28$ vs. $2.14 \pm 0.31$ gram, $P<0.05$ ) (Table 5.1). 
Table 5.1. Animal characteristics

\begin{tabular}{|c|c|c|c|}
\hline & & $\begin{array}{l}\text { Control } \\
(n=11)\end{array}$ & $\begin{array}{l}\text { CKD } \\
(n=10)\end{array}$ \\
\hline \multicolumn{2}{|l|}{ Weight (g) } & $421 \pm 14$ & $395 \pm 13$ \\
\hline \multicolumn{2}{|c|}{ Serum creatinine $(\mu \mathrm{mol} / \mathrm{l}) *$} & $33 \pm 1.5$ & $85 \pm 12.5^{* *}$ \\
\hline \multicolumn{2}{|c|}{ Serum urea $(\mathrm{mmol} /)$} & $7 \cdot 5 \pm 0.5$ & $17.9 \pm 2.8^{* *}$ \\
\hline \multicolumn{4}{|c|}{ Blood pressure $(\mathrm{mmHg})$} \\
\hline \multirow[t]{2}{*}{ Diastolic } & $t=42$ & $105 \pm 7$ & $129 \pm 14$ \\
\hline & $t=63$ & $89 \pm 3$ & $94 \pm 5$ \\
\hline \multirow[t]{2}{*}{ Systolic } & $t=42$ & $147 \pm 8$ & $174 \pm 12^{*}$ \\
\hline & $t=63$ & $130 \pm 4$ & $146 \pm 5^{*}$ \\
\hline \multirow[t]{2}{*}{ Mean } & $t=42$ & $118 \pm 7$ & $144 \pm 14$ \\
\hline & $t=63$ & $102 \pm 4$ & $111 \pm 5$ \\
\hline \multicolumn{2}{|c|}{ Heart weight (mg) } & $2.14 \pm 0.11$ & $2.51 \pm 0.09^{*}$ \\
\hline
\end{tabular}

Means \pm SEM are shown. ${ }^{*} P<0.05,{ }^{* *} P<0.01$ compared to control

\section{CKD ANIMALS HAVE DIMINISHED AV FISTULA FLOW}

An AV fistula was created between the carotid artery and the jugular vein in and endto-side manner (Figure 5.2A) after six weeks of CKD. Blood flow through the AV fistula was measured directly after $\mathrm{AV}$ fistula creation and three weeks post-operatively. Flow increased over time for both control and CKD animals.

However, AV fistula flow was significantly lower in CKD animals compared to controls at both time points (to: $11.4 \pm 2.2$ vs. $28.8 \pm 5.1 \mathrm{ml} / \mathrm{min}$, and t21: $84 \pm 8 \mathrm{vs.} 122 \pm 10 \mathrm{ml} / \mathrm{min}$, $P<0.05$; Figure 5.3A). To determine vessel diameters, ultrasound measurements were performed at 3, 7, 14 and 21 days after AV fistula surgery, showing an increase in diameter over time for both groups. AV fistula diameters were significantly lower in CKD $(P<0.01$; Figure 5.3B).

\section{INCREASED OXIDATIVE STRESS IN AV FISTULAS OF CKD ANIMALS}

HE-stained sections of AV fistulas showed areas of intima hyperplasia close to the anastomosis and also more distal in the venous outflow tract (Figure 5.4A,B). Immunohistochemical staining for aSMA cells indicated that SMCs were the most abundant cells in the intima hyperplasia lesions (Figure $5.4 \mathrm{C}$ ).

As decreased AV fistula flow could be related to increased intima hyperplasia, vessel morphometry was determined in EvG stained sections. Neither intima and media thickness, nor their ratio differed between controls and CKD animals (measured in 3 sections per animal, Table 5.2, Figure 5.4D).

Oxidative stress was ascertained by nitrotyrosine staining. Presence of nitrotyrosine was most prominent in the media and adventitia, and AV fistulas from CKD animals 
showed higher levels of nitrotyrosine compared to controls indicating increased oxidative stress (Table 5.2, Figure 5.4E,F).
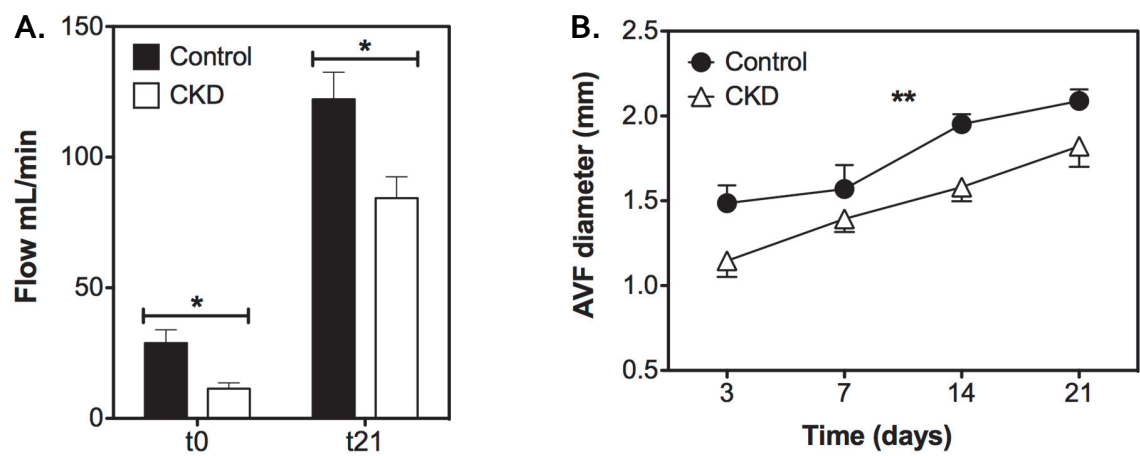

Figure 5.3. A. AV fistula flow increased over time and was significantly decreased in CKD ( $n=10)$ animals compared with controls $(n=11)$ at both time points. B. Ultrasound measurements at different time points revealed an increase in diameter over time. AV fistula diameter was significantly larger in controls $(n=11)$ compared with CKD animals $(n=10)$. Data are expressed as mean \pm SEM. ${ }^{*} P<0.05,{ }^{* *} P<0.01$.

Table 5.2. Histologic analysis

\begin{tabular}{lllll}
\hline & $\begin{array}{l}\text { Intima thickness } \\
(\mathrm{mm})\end{array}$ & $\begin{array}{l}\text { Media thickness } \\
(\mathrm{mm})\end{array}$ & $\begin{array}{l}\text { Intima/media } \\
\text { ratio }\end{array}$ & $\begin{array}{l}\text { Oxidative stress } \\
\text { (\% DAB positive pixels) }\end{array}$ \\
\hline Control & $25.7 \pm 5.1 .0$ & $46.8 \pm 3.9$ & $0.63 \pm 0.15$ & $13.7 \pm 2.9$ \\
CKD & $29.2 \pm 4.0$ & $46.9 \pm 3.0$ & $0.65 \pm 0.09$ & $28.4 \pm 6.1^{*}$ \\
\hline
\end{tabular}

Means \pm SEM are shown. ${ }^{*} P<0.05$ compared to control

\section{CKD LEADS TO NO RESISTANCE}

To determine the potential cause of decreased AV fistula flow and reduced outward remodeling, as well as the hypothesized and observed increase in oxidative stress levels, vasomotor responses of carotid arteries from CKD animals and controls were recorded in organ chambers (wire myograph) after six weeks of CKD.

Vessel diameters and wall tension after precontraction with phenylephrine were not different between groups (data not shown). Endothelium-dependent relaxation by ACh did not differ between CKD and controls (Figure $5 \mathrm{~A}$ ) indicating normal endothelial function. 

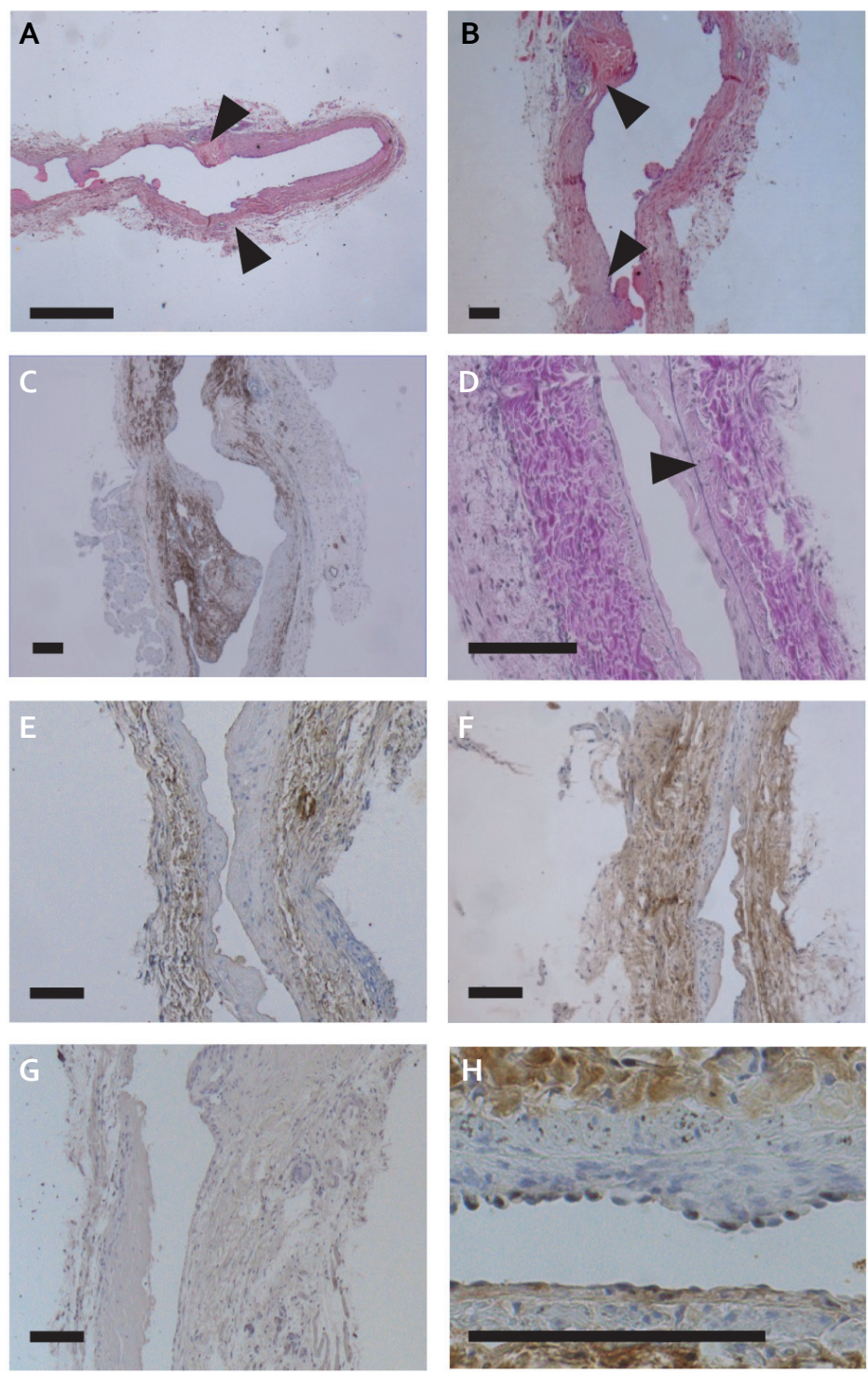

Figure 5.4. Histology of AV fistulas. A. HE staining of AV fistula. Arroheads indicate anastomosis. Arterial part located on the right side. B. HE staining showed intima hyperplasia (arrowheads) close to the anastomosis site as well as more distal in the venous outflow tract. C. Staining for $\alpha$ SMA demonstrated that SMCs are the most abundant cell type in the intima hyperplasia lesions. D. Determination of intima and media thickness was based on EvG stained sections using the internal and external elastic membrane as boundaries (arrowheads). E. Oxidative stress was displayed by staining for nitrotyrosine. Oxidative stress was most prominent in the media and adventitia. AV fistula from control animal. F. Substantial amount of nitrotyrosine in AV fistula from CKD animal. G. Negative control for anti-nitrotyrosine staining. Scale bars represent $50 \mu \mathrm{m}(\mathrm{A})$ and $100 \mu \mathrm{m}(\mathrm{B}-\mathrm{F})$. 
Blocking of eNOS by L-NAME abrogated ACh-induced relaxation (data not shown), confirming that endothelium-dependent relaxation was completely attributable to NO-directed vasodilation. In contrast, vessel relaxation in response to SNP (endothelium-independent relaxation) was decreased in the CKD group (LogIC 50 : $-7.83 \pm 0.29 \mathrm{M}$ vs. $-7.13 \pm 0.16 \mathrm{M} P<0.0001$; Figure $5 \mathrm{~B}$ ), which suggests resistance for $\mathrm{NO}$ of the NO-receptor $s G C$.

NO resistance of SGC was further characterized with BAY 41-2272 and BAY 60-2770 stimulation. Sensitivity for BAY 41-2272, a heme-dependent SGC stimulator was decreased in CKD animals ( LoglC $_{50}$ : $-6.82 \pm 0.08 \mathrm{M}$ vs. $-7.21 \pm 0.41 \mathrm{M}, P<0.001$; Figure $5.5 \mathrm{C}$ ) further supporting NO resistance of sGC. In contrast, stimulation with the hemeindependent SGC activator BAY 60-2770 showed higher sensitivity in CKD animals (LoglC 50: $-8.35 \pm 0.23 \mathrm{M}$ vs. $-7.62 \pm 0.34 \mathrm{M}, P<0.0001$; Figure 5.5D). Together, these data indicate that the heme group of $s G C$ in CKD animals is oxidated or reduced.

A.

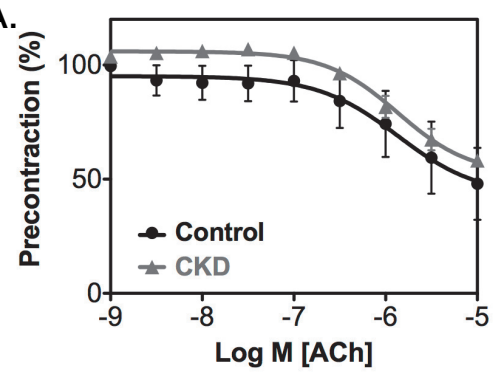

C.

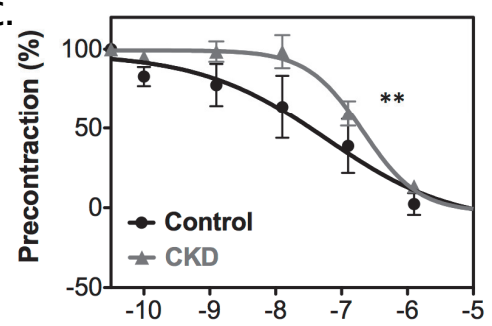

Log M [BAY 41-2272]
B.

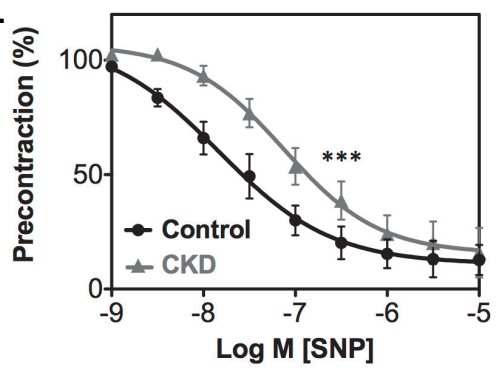

D.

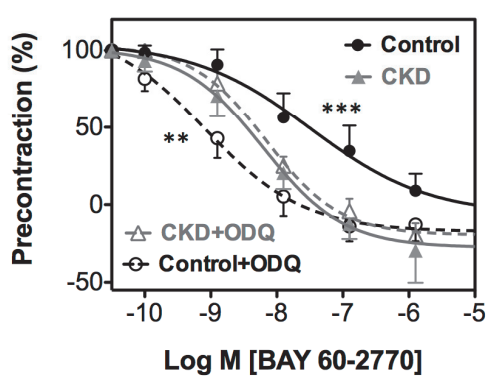

Figure 5.5. Vasoreactivity of arteries from CKD animals and controls. Endothelium-dependent relaxation after ACh was comparable for CKD and controls (A). Stimulation with SNP, which resembles endotheliumindependent relaxation, $(B)$ and heme-dependent BAY 41-2272 (C) resulted in decreased relaxation for the CKD group compared to controls. Relaxation induced by heme-independent BAY 60-2770 caused an augmented response in CKD animals ( $D$, filled symbols). After artificial oxidation, BAY 60-2770 stimulation resulted in increased relaxation of control vessels $(D$, open symbols). Data are expressed as mean $\pm S E M$. $n=6$ at least. ${ }^{* *} P<0.001,{ }^{* * *} P<0.0001$ 
To further investigate this phenomenon, the sGC heme group was actively oxidized with ODQ, after which vessel rings were stimulated with BAY 60-2770. This resulted in an increased sensitivity of control vessels compared to CKD arteries for BAY 60-2770 (LoglC 50: $-9.10 \pm 0.38 \mathrm{M}$ vs. $-8.33 \pm 0.12 \mathrm{M}, P<0.001$; Figure $5 \mathrm{~F}$ ) suggesting that $\mathrm{SGC}$ is oxidized in CKD, which explains the response profiles to the BAY compounds.

\section{SGC EXPRESSION IS DECREASED IN CKD ANIMALS}

After SGC oxidation with ODQ, control vessels turned out to be more sensitive to BAY 6o-2770 compared to CKD vessels, which could be related to a decrease in SGC in CKD. Therefore, sGC expression was analyzed by means of Western Blot. Indeed, arteries from CKD animals expressed significantly less $s G C$ than control animals $(0.13 \pm 0.05$ vs $1.00 \pm 0.36, P<0.05 ;$ Figure 5.6A,B).

A. sGC

$\beta$-act

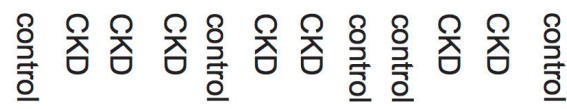

B.

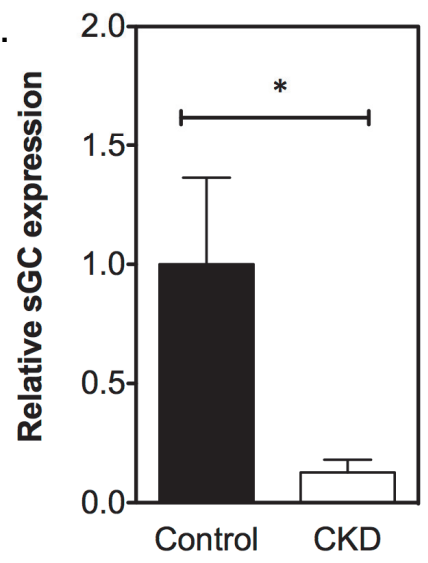

Figure 5.6. Protein expression of sGC was assessed by means of Western Blot analysis (A). Expression was calculated using BioRad Quanty One and corrected for input using $\beta$-actin (B). sGC was significantly lower expressed in CKD arteries $(n=7)$ compared to controls $(n=6)$. Controls were used as reference and set at 1.0. Data are expressed as mean \pm SEM. ${ }^{*} P<0.05$ 


\section{BAY 60-2770 INCREASES AV FISTULA DIAMETER IN CKD ANIMALS}

We hypothesized that as a result of NO resistance of SMCs in CKD, vessel relaxation is diminished leading to decreased AV fistula flow. Therefore, BAY 60-2770 was administered after creation of an AV fistula in CKD animals, to increase AV fistula flow. CKD rats were placed on a regime of daily oral BAY 60-2770 or vehicle administration. Chronic treatment with BAY 60-2770 did not significantly modify blood pressure (data not shown). Diameters of AV fistulas of BAY 60-2770 treated animals were significantly larger compared to the vehicle group $(P<0.05 ;$ Figure $5.7 \mathrm{~A})$. However, this increment in diameter did not result in increased flow; with flow at both time points (to and t21) being not significantly different between groups (to vehicle vs. BAY 60-2770: $25 \pm 6$ vs. $37 \pm 9 \mathrm{ml} / \mathrm{min}$; t21 vehicle vs. BAY 6o-2770, $126 \pm 14 \mathrm{vs.} 128 \pm 6 \mathrm{ml} / \mathrm{min}$; Figure 5.7B). The effect of BAY 60-2770 on vascular wall structure was determined in EvG stained sections. No effects on intima and media thickness were observed, and levels of oxidative stress were also not affected by BAY 60-2770 (Table 5.3).
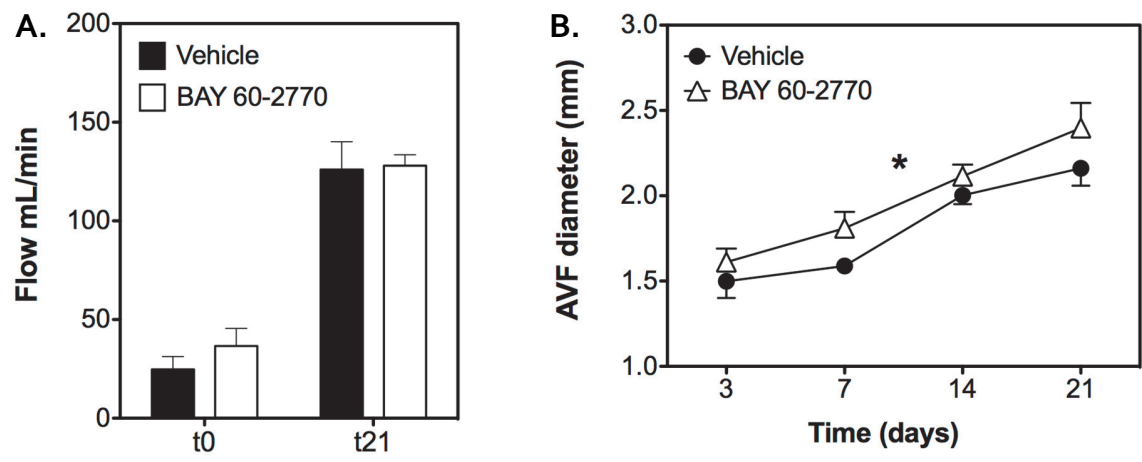

Figure 5.7. Influence of treatment with BAY 60-2770 on AV fistula function. A. BAY 60-2770 $(n=6)$ increased AV fistula diameter compared to vehicle treated animals $(n=7)$. B. Flow increased over time and did not differ between groups. Data are expressed as mean \pm SEM. ${ }^{*} P<0.05$

Table 5.3. Histologic analysis after BAY 60-2770 treatment

\begin{tabular}{lllll}
\hline & $\begin{array}{l}\text { Intima thickness } \\
(\mathrm{mm})\end{array}$ & $\begin{array}{l}\text { Media thickness } \\
(\mathrm{mm})\end{array}$ & $\begin{array}{l}\text { Intima/media } \\
\text { ratio }\end{array}$ & $\begin{array}{l}\text { Oxidative stress } \\
\text { (\% DAB positive pixels) }\end{array}$ \\
\hline Vehicle & $22.7 \pm 5.7$ & $49.3 \pm 4.1$ & $0.53 \pm 0.15$ & $32.0 \pm 11.8$ \\
BAY 60-2770 & $18.5 \pm 5.1$ & $44.4 \pm 7.4$ & $0.44 \pm 0.14$ & $21.1 \pm 8.6$ \\
\hline
\end{tabular}

Means \pm SEM are shown. 


\section{DISCUSSION}

Despite the fact that much research has addressed neointima formation and its relation to AV fistula failure in the long-term, early failure as a result of non-maturation has not been investigated extensively. In this study, we investigated the relationship between CKD, NO-signaling and early AV fistula function. The uremic state of CKD was associated with decreased AV fistula maturation, as hypothesized by several authors. ${ }^{714,29}$ Immediately after surgery and three weeks after AV fistula creation, flow was decreased in CKD animals compared to non-uremic animals, which can be explained by diminished fistula diameters in CKD animals as observed by longitudinal ultrasound examinations. We also demonstrated increased levels of oxidative stress in the vessel wall of uremic animals, by staining for nitrotyrosine, a known marker for oxidation levels in tissue..$^{30}$ Oxidative stress can lead to endothelial dysfunction ${ }^{31,32}$ and diminished NO-signaling by means of superoxide production and NO depletion by eNOS uncoupling. ${ }^{19,20,22,33}$ To demonstrate diminished NO-signaling in CKD we studied endothelial and SMC function in isolated vessel segments from uremic animals and controls in a wire myograph, a widely accepted method to assess vasoreactivity. Hereby, we demonstrated for the first time NO resistance of arterial smooth muscle in CKD-animals. Isolated carotid arteries of CKD-animals had normal vasorelaxating responses to $\mathrm{ACh}$ and diminished relaxation in response to SNP indicating disturbed SMC function. This could be ascribed to NO resistance of the NO-receptor SGC as shown by an increased vasorelaxation of uremic vessels to BAY 60-2770, an activator of sGC, that exhibits an optimal effect when the heme group of $s G C$ is oxidized or absent. ${ }^{28,34}$ In accordance, incubation with ODQ, a very potent oxidizing agent of sGC increased the sensitivity of control vessels to BAY 60-2770, but not in uremic vessels, confirming that $\mathrm{SGC}$ is maximally oxidized in CKD. Our results regarding the normal response to $A C h$ in uremic vessels with NO resistant SGC suggest an endotheliumdependent mechanism that compensates for diminished NO sensitivity. Indeed, increased eNOS expression as a result of diminished NO-signaling was reported by Vaziri et al. and could explain our normal endothelium-dependent response in CKD animals ${ }^{35}$ in the presence of NO resistant sGC.

As recently described by Roy-Chaudbury, the pathogenesis of early AV fistula failure is multifactorial and includes small arteries or veins, surgical injury, accessory veins and hemodynamic stressors. ${ }^{29}$ According to Asif et al. ${ }^{14}$, one of the major determinants of the lack of arterial or venous dilation in non-maturation is the poor vascular status of uremic patients, in particular if other comorbidities are present. Uremia is potentially 
linked to endothelial dysfunction as a result of increased oxidative stress. We observed normal endothelial function in uremic vessels, which is in concordance with earlier studies reporting preserved endothelium-dependent relaxation in uremic resistance vessels. ${ }^{36-38}$ Thus, it seems that endothelial dysfunction is not severely compromised in CKD, in contrast with SMC function that was clearly diminished due to NO resistance of the NO-receptor $S G C$.

sGC is the soluble form of guanylate cyclase, a widely distributed signal-transduction enzyme that converts GTP into the second messenger cyclic GMP in response to NO and carbon monoxide. ${ }^{39}$ It consists of two heterodimers, a larger $\alpha$-subunit and a heme-binding $\beta$-unit, that in its normal $\mathrm{Fe}^{2+}$ state acts as the binding site for NO. In case of oxidative stress, sGC can become oxidized resulting in an altered redox state $\left(\mathrm{Fe}^{3+}\right)$ and/or loss of the heme group, after which $\mathrm{SGC}$ can no longer be activated by $\mathrm{NO}$, also referred to as NO resistance. ${ }^{40,41}$

The syndrome of NO resistance can be targeted by a new group of pharmacologic agents including BAY 60-2770, that are possible to either stimulate sGC in a NOdependent way, or activate $S G C$ in an NO-independent manner. The latter effect is enhanced when SGC exists in its NO resistant heme-free or oxidized form. Next to our results that indicate $\mathrm{NO}$ resistance in $\mathrm{CKD}$, increased vasorelaxing responses have also been reported in resistance arteries from diabetes type II patients, hypercholesterolemic rabbits and hypertensive rats in response to another SGC activator, BAY $58-2667 .^{40}$ This agent has a similar mode of action as BAY $60-2770^{34}$, suggesting the presence of NO resistance in these vascular diseases as well. BAY 58-2667 is currently under clinical investigation for the treatment of acute decompensated heart failure, although hypotension appears to be a serious adverse effect next to its beneficial effects for unloading the heart. ${ }^{42}$ Other potential applications of sGC stimulators/activators such as the treatment of liver fibrosis, pulmonary hypertension and prevention of ischemia-reperfusion injury are currently under investigation. ${ }^{28,43,44}$

To investigate a potential beneficial effect of BAY 60-2770 on AV fistula maturation in vivo, this compound was administered daily to CKD animals after creation of the AV fistula. Interestingly, venous diameters increased compared to vehicle-treated CKD animals, but AV fistula flow remained the same. As blood pressure and intima thickness were not significantly different, we cannot explain the lack of increase in flow in BAY 60-2770 treated animals. Although blood pressure was not significantly affected by BAY 60-2770, we cannot exclude the possibility that systemic hemodynamic changes in for instance peripheral resistance or compliance negate the flow effect of an increased diameter at the level of the fistula. 
Another factor responsible for AV fistula failure is neointima formation, which is characterized by proliferation and migration of SMCs from the media into the intima, a process that can be inhibited by NO. As a result of increased NO-signaling in SMCs after BAY 60-2770 treatment it can be hypothesized that neointima formation will decrease, however, intima thickness was not diminished in BAY 60-2770 treated animals in our study. This could be related to the short follow-up period of three weeks. Indeed, in the first part of our research no differences in neointima formation were found in CKD animals compared to controls either, while other studies with a longer follow-up period reported increased intima thickness in AV fistulas from CKD animals. ${ }^{25,26}$ One of these studies was also carried out with a different animal model, using an adenine diet to induce renal failure in rats instead of our nephrectomy model, in which the diet itself could theoretically influence the development of neointima formation. ${ }^{25}$ As recently reviewed by Rothuizen et al., inadequate outward remodeling can also hamper AV fistula function and is thought to be the result of vascular calcification and insufficient vascular dilatation. ${ }^{45,46}$ Thus, NO resistance with subsequent decreased SMC relaxation could be an important aspect of diminished outward remodeling as well.

In our animals, CKD led to increased systolic blood pressures before and after AV fistula creation. Kokubo et al. reported lower blood pressures in CKD mice compared to controls measured under anesthesia ${ }^{26}$, while others did not find any differences with the tail-cuff method. ${ }^{47}$ Apparently the effect of CKD on blood pressure differs between animal studies, although in humans renal failure is associated with hypertension ${ }^{48}$, which indicates that our animal model accurately reflects the human situation. A potential hypotensive effect of BAY 60-2770 as a result of systemic vasodilation was not observed in our study, but this effect could have been blunted by the presence of the AV fistula. The lack in short-term increase in flow accompanied by larger fistula diameters at the same time needs further investigation. Moreover, it can be of interest to evaluate long-term effects of BAY 60-2770 treatment on neointima formation.

\section{CONCLUSION}

CKD is associated with decreased AV fistula maturation and NO resistance of SGC in vascular smooth muscle. The SGC-activator BAY 60-2770 can induce vasodilation in CKD that could prevent non-maturation in uremic patients by increasing vessel diameter, although a direct effect on fistula flow was not found in this study. 


\section{REFERENCES}

1. U S Renal Data System, USRDS 2011 Annual Data Report: Atlas of Chronic Kidney Disease and EndStage Renal Disease in the United States. 2011 ed. Bethesda, MD, USA: National Institutes of Health, National Institute of Diabetes and Digestive and Kidney Diseases; 2011.

2. Clinical Practice Guidelines for Vascular Access. Am J Kidney Dis. 2006; 48, Supplement 1(0): S176S247.

3. Tordoir J, Canaud B, Haage P, Konner K, Basci A, Fouque D, et al. EBPG on Vascular access. Nephrol Dial Transplant 2007; 22(suppl 2): ii88-ii117.

4. Tordoir JHM, Rooyens P, Dammers R, van der Sande FM, de Haan M, Yo TI. Prospective evaluation of failure modes in autogenous radiocephalic wrist access for haemodialysis. Nephrol Dial Transplant 2003; 18(2): 378-83.

5. Allon M, Robbin ML. Increasing arteriovenous fistulas in hemodialysis patients: problems and solutions. Kidney Int. 2002; 62(4): 1109-24.

6. Dember LM, Holmberg EF, Kaufman JS. Randomized controlled trial of prophylactic repair of hemodialysis arteriovenous graft stenosis. Kidney Int. 2004; 66(1): 390-8.

7. Dixon BS. Why don't fistulas mature? Kidney Int. 2006; 70(8): 1413-22.

8. Joannides R, Haefeli WE, Linder L, Richard V, Bakkali EH, Thuillez C, et al. Nitric oxide Is responsible for flow-dependent dilatation of human peripheral conduit arteries in vivo. Circulation. 1995; 91(5): 1314-9.

9. Ben Driss A, Benessiano J, Poitevin P, Levy BI, Michel JB. Arterial expansive remodeling induced by high flow rates. Am J Physiol. 1997; 272(2 Pt 2): H851-8.

10. Tronc F, Wassef M, Esposito B, Henrion D, Glagov S, Tedgui A. Role of NO in Flow-Induced Remodeling of the Rabbit Common Carotid Artery. Arterioscler Thromb Vasc Biol. 1996; 16(10): 1256-62.

11. Furchgott RF, Zawadzki JV. The obligatory role of endothelial cells in the relaxation of arterial smooth muscle by acetylcholine. Nature. 1980; 288(5789): 373-6.

12. Lucas KA, Pitari GM, Kazerounian S, Ruiz-Stewart I, Park J, Schulz S, et al. Guanylyl cyclases and signaling by cyclic GMP. Pharmacol Rev. 2000; 52(3): 375-414.

13. Hofmann F, Ammendola A, Schlossmann J. Rising behind NO: cGMP-dependent protein kinases. J Cell Sci. 2000; 113(10): 1671-6.

14. Asif A, Roy-Chaudhury P, Beathard GA. Early arteriovenous fistula failure: A logical proposal for when and how to intervene. Clin J Am Soc Nephrol. 2006; 1(2): 332-9.

15. Mezzano D, Pais EO, Aranda E, Panes O, Downey $P$, Ortiz $M$, et al. Inflammation, not hyperhomocysteinemia, is related to oxidative stress and hemostatic and endothelial dysfunction in uremia. Kidney Int. 2001; 60(5): 1844-50.

16. Friedlander MA, Witko-Sarsat V, Nguyen AT, Wu YC, Labrunte M, Verger $C$, et al. The advanced glycation endproduct pentosidine and monocyte activation in uremia. Clin Nephrol. 1996; 45(6): 379-82.

17. Witko-Sarsat V, Friedlander M, Nguyen Khoa T, Capeillere-Blandin C, Nguyen AT, Canteloup S, et al. Advanced oxidation protein products as novel mediators of inflammation and monocyte activation in chronic renal failure. J Immunol. 1998; 161(5): 2524-32.

18. Vaziri ND. Oxidative stress in uremia: nature, mechanisms, and potential consequences. Semin Nephrol. 2004; 24(5): 469-73.

19. Tatematsu S, Wakino S, Kanda T, Homma K, Yoshioka K, Hasegawa K, et al. Role of nitric oxideproducing and -degrading pathways in coronary endothelial dysfunction in chronic kidney disease. J Am Soc Nephrol. 2007; 18(3): 741-9.

20. Shinozaki K, Kashiwagi A, Nishio Y, Okamura T, Yoshida Y, Masada M, et al. Abnormal biopterin metabolism is a major cause of impaired endothelium-dependent relaxation through nitric oxide/O2imbalance in insulin-resistant rat aorta. Diabetes. 1999; 48(12): 2437-45. 
21. Yamamizu K, Shinozaki K, Ayajiki K, Gemba M, Okamura T. Oral administration of both tetrahydrobiopterin and $\mathrm{L}$-arginine prevents endothelial dysfunction in rats with chronic renal failure. J Cardiovasc Pharm. 2007; 49(3): 131-9.

22. Vallance $P$, Leone A, Calver A, Collier J, Moncada S. Accumulation of an endogenous inhibitor of nitric oxide synthesis in chronic renal failure. Lancet. 1992; 339(8793): 572-5.

23. Cayatte AJ, Palacino JJ, Horten K, Cohen RA. Chronic inhibition of nitric oxide production accelerates neointima formation and impairs endothelial function in hypercholesterolemic rabbits. Arterioscler Thromb Vasc Biol. 1994; 14(5): 753-9.

24. Radomski M, Palmer R, Moncada S. Endogenous nitric oxide inhibits human platelet adhesion to vascular endothelium. Lancet. 1987; 330(8567): 1057-8.

25. Langer S, Kokozidou M, Heiss C, Kranz J, Kessler T, Paulus N, et al. Chronic kidney disease aggravates arteriovenous fistula damage in rats. Kidney Int. 2010; 78(12): 1312-21

26. Kokubo T, Ishikawa N, Uchida H, Chasnoff SE, Xie X, Mathew S, et al. CKD Accelerates development of neointimal hyperplasia in arteriovenous fistulas. J Am Soc Nephrol. 2009; 20(6): 1236-45.

27. Roy-Chaudhury P, Sukhatme VP, Cheung AK. Hemodialysis vascular access dysfunction: A cellular and molecular viewpoint. J Am Soc Nephrol. 2006; 17(4): 1112-27.

28. Beckman JS, Koppenol WH. Nitric oxide, superoxide, and peroxynitrite: the good, the bad, and ugly. Am J Physiol-Cell Ph. 1996; 271(5): C1424-C37.

29. Ross R. Atherosclerosis--an inflammatory disease. N Engl J Med. 1999; 340(2): 115-26.

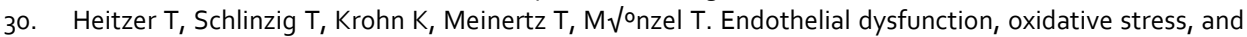
risk of cardiovascular events in patients with coronary artery disease. Circulation. 2001; 104(22): 2673-8.

31. Schram MT, Stehouwer CD. Endothelial dysfunction, cellular adhesion molecules and the metabolic syndrome. Horm Metab Res. 2005; 37 Suppl 1: 49-55.

32. Knorr A, Hirth-Dietrich C, Alonso-Alija C, Harter M, Hahn M, Keim Y, et al. Nitric oxide-independent activation of soluble guanylate cyclase by BAY 60-2770 in experimental liver fibrosis. ArzneiForschung. 2008; 58(2): 71-80.

33. Schmidt HH, Schmidt PM, Stasch J-P. NO-and haem-independent soluble guanylate cyclase activators. cGMP: Generators, Effectors and Therapeutic Implications: Springer; 2009. p. 309-39.

34. Vaziri ND, Wang XO. cGMP-Mediated negative-feedback regulation of endothelial nitric oxide synthase expression by nitric oxide. Hypertension. 1999; 34(6): 1237-41.

35. Jolma P, Kalliovalkama J, Tolvanen JP, Koobi $P$, Kahonen $M$, Saha $H$, et al. Preserved endotheliumdependent but impaired beta-adrenergic relaxation of the resistance vessels in experimental renal failure. Exp Nephrol. 2002; 10(5-6): 348-54.

36. Thuraisingham RC, Raine AE. Maintenance of normal agonist-induced endothelium-dependent relaxation in uraemic and hypertensive resistance vessels. Nephrol Dial Transplant 1999; 14(1): 70-5.

37. Wang SP, West MW, Dresner LS, Fleishhacker JF, Distant DA, Mueller CM, et al. Effects of diabetes and uremia on mesenteric vascular reactivity. Surgery. 1996; 120(2): 328-36.

38. Derbyshire ER, Marletta MA. Structure and regulation of soluble guanylate cyclase. Annu Rev Biochem. 2012; 81: 533-59.

39. Stasch J-P, Schmidt PM, Nedvetsky PI, Nedvetskaya TY, H.S AK, Meurer S, et al. Targeting the hemeoxidized nitric oxide receptor for selective vasodilatation of diseased blood vessels. J Clin Invest. 2006; 116(9): 2552-61.

40. Evgenov OV, Pacher P, Schmidt PM, Hasko G, Schmidt HH, Stasch JP. NO-independent stimulators and activators of soluble guanylate cyclase: discovery and therapeutic potential. Nat Rev Drug Discov. 2006; 5(9): 755-68.

41. Erdmann E, Semigran MJ, Nieminen MS, Gheorghiade M, Agrawal R, Mitrovic V, et al. Cinaciguat, a soluble guanylate cyclase activator, unloads the heart but also causes hypotension in acute decompensated heart failure. Eur Heart J. 2013; 34(1): 57-67.

42. Radovits T, Korkmaz S, Miesel-Gröschel C, Seidel B, Stasch J-P, Merkely B, et al. Pre-conditioning with the soluble guanylate cyclase activator Cinaciguat reduces ischaemia-reperfusion injury after cardiopulmonary bypass. Eur J Cardio-Thorac. 2011; 39(2): 248-55. 
43. Dumitrascu R, Weissmann N, Ghofrani HA, Dony E, Beuerlein K, Schmidt H, et al. Activation of soluble guanylate cyclase reverses experimental pulmonary hypertension and vascular remodeling. Circulation. 2006; 113(2): 286-95.

44. Rothuizen TC, Wong C, Quax PHA, van Zonneveld AJ, Rabelink TJ, Rotmans JI. Arteriovenous access failure: more than just intimal hyperplasia? Nephrol Dial Transplant. 2013; 28(5): 1085-92.

45. Corpataux JM, Haesler E, Silacci P, Ris HB, Hayoz D. Low-pressure environment and remodelling of the forearm vein in Brescia-Cimino haemodialysis access. Nephrol Dial Transplant. 2002; 17(6): 1057-62.

46. Gagnon RF, Gallimore B. Characterization of a mouse model of chronic uremia. Urol Res. 1988; 16(2): 119-26.

47. Mailloux LU, Haley WE. Hypertension in the ESRD patient: pathophysiology, therapy, outcomes, and future directions. Am J Kidney Dis. 1998; 32(5): 705-19.

48. Windt WA, Henning RH, Kluppel $A C, X u Y$, de Zeeuw D, van Dokkum RP. Myocardial infarction does not further impair renal damage in 5/6 nephrectomized rats. Nephrol Dial Transplant. 2008; 23(10): 3103-10. 


\section{CHAPTER}

Feasibility of Tissue-engineered Vascular Grafts in a Porcine Model

Irma LA Geenen, Maria Stekelenburg, Rolf AA Pullens, Henny Schulten, Daniel GM Molin, Mark J Post 


\section{ABSTRACT}

In case of a lack of veins, patients requiring vascular bypass grafting need prosthetic alternatives. These prosthetic conduits however, are associated with high infection, thrombotic and stenotic complication rates. Tissue-engineered, autologous grafts with anti-thrombotic, anti-immunologic and better biomechanical properties could offer a decent alternative. In this study, feasibility of small diameter $(3 \mathrm{~mm})$ tissue-engineered vascular grafts was evaluated in a porcine model.

Myofibroblasts and endothelial cells (ECs) were isolated from the jugular vein and cultured to gain sufficient cell numbers. Myofibroblasts were seeded on biodegradable scaffolds made of poly-4-hydroxybutyrate ( $\mathrm{P}_{4} \mathrm{HB}$ ) coated poly-glycolic acid (PGA) in a fibrin gel and cultured in a bioreactor for four weeks. After this time, ECs were seeded intraluminally and 2 days later grafts were implanted in an autologous manner as a carotid interposition model. Burst pressures varied from $300 \mathrm{mmHg}$ up to $1000 \mathrm{mmHg}$. Eight out of nine grafts were successfully implanted although suture strength was rather low in several grafts. Within two days three pigs died as a result of hypovolemic shock after graft rupture. Regular ultrasound examinations showed patent grafts after two weeks in the remaining animals. After the total follow-up period of four weeks, angiography showed one open graft and the other four grafts appeared to be occluded. Histologic analysis revealed a substantial foreign body reaction in all grafts and neointima formation in the open, dilated graft. DNA and glycosaminoglycan contents were higher than in native arterial tissue but collagen content was lower in graft tissue.

We conclude that the carotid interposition model is very suitable for testing tissueengineered vascular grafts. The $\mathrm{PGA}_{\mathrm{P}} 4 \mathrm{HB}$ grafts implanted had insufficient biomechanical strength and induced a substantial foreign body response leading to graft occlusion. Further optimization of graft material and possibly culture process is required. 


\section{INTRODUCTION}

Vascular grafts are applied in coronary and peripheral arterial bypass surgery, as well as for vascular access creation for hemodialysis. Native arteries are the first choice for grafting, with autologous veins as a good alternative. Venous grafts are considered adequate conduits for placement in the arterial circulation, though long-term results are suboptimal due to intimal hyperplasia and enhanced atherosclerosis development. ${ }^{1,2}$ In case patients lack veins of sufficient quality for revascularization and vascular access creation or when all suitable veins have been used in previous procedures, fully artificial grafts such as expanded polytetra-fluoroethylene (ePTFE) prostheses serve as a fallback ${ }^{3,4}$, in particular for long peripheral artery bypasses and arteriovenous (AV) shunts. However, prosthetic grafts are associated with limited patency rates and high reintervention rates with substantial patient morbidity ${ }^{5}$, due to increased risk of infection and thrombotic complications compared to venous conduits. $^{6-8}$ In particular for small diameter $(<6 \mathrm{~mm})$ conduits, usage of prosthetic grafts is avoided because of the high thrombotic risk in low flow conditions and intendancy to develop neointima formation..$^{9-11}$

A potential solution and alternative for prosthetic grafts is a tissue-engineered small diameter graft produced by seeding patient-derived (autologous) cells on a biodegradable scaffold. These grafts may offer advantages as risk of infection is expected to be low and thrombotic risk can be reduced by means of endothelial lining of the graft. However, a substantial drawback of current strategies for vascular tissue engineering is the long culture period before implantation can take place. The only currently applied small diameter vascular graft in humans required an in vitro culture period up to 9 months ${ }^{12}$, making it inappropriate for patients that are in need of shortterm cardiac or peripheral revascularization after diagnosis.

Shortening the manufacturing process of such a graft will enlarge the potential group of patients who could benefit from these therapies and will also reduce costs. Hence, our group developed a culture protocol in which grafts can be produced within 2 months. After isolation and expansion of vascular primary cells, scaffolds with an inner diameter of $3 \mathrm{~mm}$ made of biodegradable poly-4-hydroxybutyrate ( $\left.\mathrm{P}_{4} \mathrm{HB}\right)$ coated poly-glycolic acid (PGA) scaffold were seeded with myofibroblasts (MFs) in a fibrin gel $^{13,14}$ and cultured and conditioned in a home-made bioreactor. This procedure resulted in abundant extracellular matrix deposition comprising cross-linked collagen. By the end of the culture process, endothelial cells (ECs) were seeded on the luminal side. In vitro testing proved that these constructs have mechanical behavior comparable to the LIMA when tested in the physiologically relevant range up to 
pressures of $300 \mathrm{mmHg} .{ }^{13}$ The final burst pressure amounted $900 \mathrm{mmHg}$, which is still below the burst pressure of the human saphenous vein (SV) of $1680 \mathrm{mmHg}{ }^{15}$ However, it is hypothesized that grafts will gain sufficient strength after in vivo implantation as a result of ongoing remodeling.

The minimal criteria for a successful functioning tissue-engineered vascular graft consist of biocompatibility, i.e. non-thrombogenicity, non-immunogenicity, and resistance to infection. Furthermore, sufficient biomechanical strength to withstand arterial hemodynamics is of uttermost importance. For proper implantation, ease of handling and suturability are relevant. ${ }^{16}$ After extensive in vitro testing ${ }^{17}$, the aim of this study was to investigate the feasibility, in vivo behaviour and remodelling of our shortterm cultured, small-diameter tissue-engineered vascular grafts in an arterial setting in a large animal model using an autologous cell approach. Cells were isolated from porcine jugular veins and used to created tissue-engineered vascular grafts based on $\mathrm{PGA} / \mathrm{P}_{4} \mathrm{HB}$. Grafts were implanted in the donor animals as carotid interposition grafts with four weeks of follow-up with regular ultrasound monitoring and a final angiography. After explantation, histological characteristics were evaluated.

\section{ANIMALS AND METHODS}

\section{ANIMALS}

A total of 9 Dutch landrace pigs (5 males, 4 females; ID-Lelystad farm, The Netherlands) weighing approximately $28 \mathrm{~kg}$ were used. Experimental protocols were conducted according to international guidelines (American Phvysiological Society Guiding Principles for the Care and Use of Vertebrate Animals in Research and Training) and were approved by the local Ethics Committee on Experimental Animal Welfare. Animals were housed socially and fed according to the standard guidelines for animal care.

For surgical procedures, animals were anesthesized, intubated and put in supine position. After careful dissection of the neck, $3 \mathrm{~cm}$ of external jugular vein was harvested for cell isolation. Proximal and distal end of the remaining in situ vein were ligated. After 8 weeks, autologous tissue-engineered grafts were implanted as a carotid interposition graft on the contralateral side. For this purpose, the common carotid artery was dissected and a proximal anastomosis was created with 6-o prolene with continuous sutures. Two $\mathrm{cm}$ of native carotid artery was removed and the distal anastomosis was carried out in the same manner as the proximal one. After flushing, the distal anastomosis was completed and hemostasis was obtained before closing the 
wound with 3-0 vicryl. All animals received Plavix ${ }^{\circledR}$ (clopidogrel) $75 \mathrm{mg}$ once daily during the follow-up period of 28 days.

Regular ultrasounds of the implanted grafts were performed on day 2, 13 and 28 postoperative using a $5 \mathrm{MHz}$ probe from a Picus machine (Esaote, Maastricht, The Netherlands). Angiography was performed on day 28 before sacrifice, using a JR4 $6 \mathrm{~F}$ angiographic catheter and a $7 \mathrm{~F}$ sheath placed in the femoral artery. Animals were euthanized with a high dose of thiopental, after which the grafts were explanted and dissected for (immuno)histochemical analyses.

\section{CELL CULTURING}

ECs were isolated from jugular veins by means of collagenase digestion. Harvested veins were flushed with phosphate buffered solution (PBS), infused with collagenase type I $0.2 \%$ (Sigma-Aldrich, St. Louis, MO, USA) and incubated for 20 minutes at room temperature. Detached ECs were collected and put in culture dishes with EGM-2 medium supplemented with $20 \%$ fetal bovine serum (FBS) and the EGM-2 bullet kit containing hydrocortisone, fibroblast growth factor $B$, vascular endothelial growth factor, insulin-like growth factor, ascorbic acid, epidermal growth factor, heparin and gentamicin sulphate amphotericin-B (Lonza, Basel, Switzerland). Cell cultures containing cells that did not show endothelial-like cobblestone morphology, were treated with $C_{31}$-coated magnetic beads to purify the EC population.

Using the outgrowth method, MFs were harvested from the jugular veins after EC isolation. Veins were cut in pieces of approximately $1 \mathrm{~mm}$ and put in 6-well culture plates with Dulbecco's Modified Eagle Medium (DMEM) advanced medium (Life Technologies Europe BV, Bleiswijk, The Netherlands) supplemented with FBS 10\%, glutamax $1 \%$ and gentamycin $0.1 \%$. After 7-10 days cell cultures reached confluence and were subcultured for four weeks.

\section{GRAFT PREPARATION}

Scaffolds were prepared according to the same protocol previously described. ${ }^{13}$ Briefly, a sheet of $80 \mathrm{~mm}$ long, $7 \mathrm{~mm}$ wide and $1 \mathrm{~mm}$ thickness of non-woven PGA fiber mesh (Cellon, Luxembourg) was wrapped around a stainless steel rod with a diameter of $3 \mathrm{~mm}$. Afterwards, constructs were dip-coated in $1 \mathrm{w} / \mathrm{v} \%$ of $\mathrm{P}_{4} \mathrm{HB}$ (Symetis Inc., Lausanne, Switzerland) in tetrahydrofuran. The resulting scaffolds were approximately $4 \mathrm{~cm}$ in length and had a wall thickness of $1 \mathrm{~mm}$.

MFs were seeded on scaffolds using fibrin gel as a cell carrier, which was prepared by mixing bovine thrombin soluction (Sigma-Aldrich) with cells and adding this to a 
fibrinogen solution (10 $\mathrm{mg}$ actual protein/mL medium) in a 1:1 mixture. The cell solution was dripped onto the scaffolds with $25 \times 10^{6}$ cells $/ \mathrm{ml}$ ( $150 \mu \mathrm{l} / \mathrm{strip}$ and $1000 \mu \mathrm{l} /$ tubular construct). Constructs were cultured in MF medium with additional L-ascorbic acid 2-phosphate $0.25 \mathrm{mg} / \mathrm{ml}$ (Sigma-Aldrich). Per animal, three tubular $\mathrm{PGA} / \mathrm{P}_{4} \mathrm{HB}$ scaffolds were seeded together with three $2 \mathrm{D}$ strips for additional mechanical testing. Grafts were connected to steel rods with a silicon tube with a $3 \mathrm{~mm}$ outer diameter place on the inside of the grafts. After four weeks of culturing in the inhouse developed bioreactor, silicon tubes were removed and ECs were seeded intraluminally. For this purpose, grafts were filled with an EC suspension containing $5 \times 10^{5}$ cells $/ \mathrm{mL}$ and the bioreactor containing the graft was mounted in a rotation device that rotated at $0.5 \mathrm{rpm}$ to establish even distribution of ECs. After 3 hours, grafts were gently flushed and cultured for two more days before implantation.

\section{BIOMECHANICAL ANALYSIS}

Mechanical properties of the control strips were determined by uniaxial tensile tests. A tensile tester equipped with a $20 \mathrm{~N}$ load cell (Kammrath-Weiss, Dortmund, Germany) was used and stress-strain curves were obtained at a strain rate equal to the initial sample length per minute. The stress was defined as the engineering stress, equaling the measured force divided by the initial cross-sectional area. From the resulting stress-strain curves, ultimate tensile strength (UTS) was deducted. Based on this UTS, the wall thickness of the constructs, and the average internal radius ( $1.5 \mathrm{~mm})$, burst pressure can be estimated, as described previously ${ }^{18}$ using thin wall assumptions and Laplace's relationship: $\mathrm{P} \times \mathrm{r}=\sigma \times \mathrm{h}$, where $\mathrm{P}$ is the pressure; $r$ the radius; $\sigma$ the Cauchy stress; and $h$ the wall thickness.

\section{BIOCHEMICAL ANALYSIS}

Tissue formation in the grafts was measured in control grafts by lyophilizing the tissue samples using a papain solution (100 mM phosphate buffer, $5 \mathrm{mM}$ L-cyteine, $5 \mathrm{mM}$ ethylene-diaminetetraacetic acid (EDTA), and papain $125 \mu \mathrm{g} / \mathrm{ml}$ ) at $60^{\circ} \mathrm{C}$ for 16 hours. The hydroxyproline content was evaluated by a modified assay based on the protocol of Huszar et al. ${ }^{19}$ with a reference of trans-4-hydroxyproline (Sigma-Aldrich). The sulfated glycosaminoglycan (GAG) amount was determined using a modification of the assay described by Farndale et al. (1986) and a shark cartilage reference (SigmaAldrich). Total DNA reflecting the amount of cells per graft was determined by the Hoechst dye method. ${ }^{20}$ 


\section{HISTOLOGY}

For (immuno)histochemistry, grafts were fixated in paraformaldehyde $4 \%$ overnight and transferred to ethanol $70 \%$ the next day. Subsequently, they were embedded in paraffin and cut in $5 \mu \mathrm{m}$ sections. Haematoxylin Eosin (HE) and Masson's trichrome staining were performed according to standard protocols. Antibodies used for

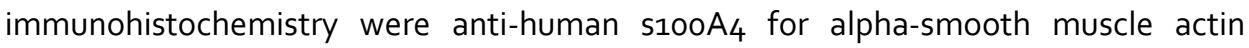
staining (DakoCytomation, Glostrup, Denmark) (1:1000), anti-smooth muscle myosin (BTI, Stoughton, MA, USA) (1:200), anti-macrophages/monocytes (AbD Serotec, Oxford, UK) (1:100), pig anti-CD31 (AbD Serotec) (1:100) and anti-vWF (DakoCytomation) (1:400). After incubation with the corresponding secondary antibodies, immune-stains were subjected to avidin-biotin horseradish peroxidaseDAB procedure (Vector Labs, Burlingame, CA, US and DakoCytomation, respectively) and counterstained with haematoxylin (Klinipath, Duiven, the Netherlands).

\section{RESULTS}

\section{CELL CULTURE AND GRAFT PRODUCTION}

MFs were successfully isolated and subcultured from all nine animals. Isolation of ECs failed in two cases likely due to technical errors during the isolation procedures. Hence, these animals received grafts without endothelial lining. For all animals, three tubular constructs and three 2D strips could be cultured.

\section{BIOMECHANICAL CHARACTERISTICS OF CONTROL STRIPS}

In parallel with the culture of tubular constructs, strips were grown with the same cells as seeded on the $3 \mathrm{D}$ constructs. Uniaxial tensile testing was performed on these control strips and results are shown in Figure 6.1. Stress-strain curves were comparable with native carotid artery in the physiological range up to $200 \mathrm{mmHg}$ except for pig $\mathrm{nr}$. 2. Based on the stress-strain curves, burst pressure was estimated. Variation in burst pressure seemed to be substantial between different pigs. Interestingly, the graft with the highest burst pressure, (nr. 8) was the only graft that was open after 28 days. However, this could also have been related to more profound outward remodelling compared to other grafts. 

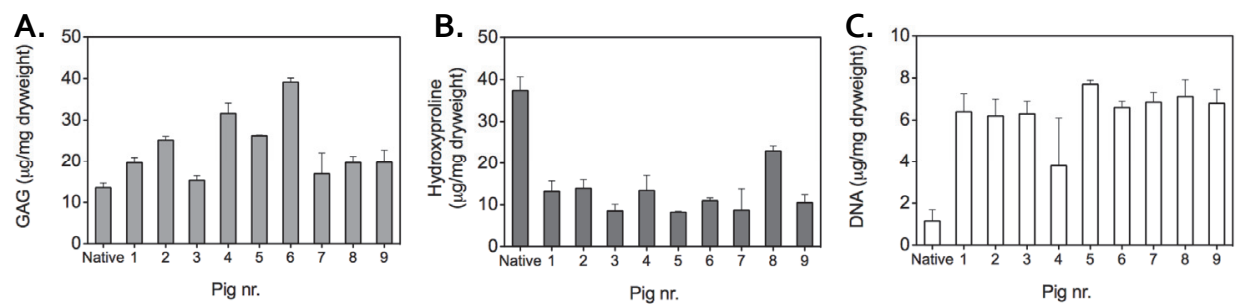

Figure 6.1. Mechanical analyses of control grafts. A. Pressure-strain curves of control strips. Nr. 8 was the only open graft. Nr. 4 could not be implanted due to insufficient suture strength. Nrs. 5, 6 and 9 ruptured. Nrs. 1, 2, and 7 were occluded after 28 days and $\mathrm{nr} 3$. showed a rupture with a local, contained hematoma. B. Pressure-strain curves of tissue-engineered grafts show comparable behaviour with native porcine carotid artery in the physiological stress range. C. Based on pressure-strain curves, burst pressures were calculated.

\section{BIOCHEMICAL CHARACTERISTICS OF CONTROL STRIPS}

The amount of GAGs, hydroxyproline and DNA was determined in control strips after 4 weeks of in vitro culturing, as well as in native carotid artery tissue. All strips showed higher amount of GAGs compared to the native sample (Figure 6.2A), however, a large interindividual variation between constructs was seen as well as for hydroxyproline (Figure 6.2B). Hydroxyproline, the major component of collagen, was lower in all tissue-engineered constructs compared to native arterial tissue. The amount of cells in the strips was evaluated by measuring DNA content and was comparable between all strips (Figure 6.2C) except for nr. 4, showing a decreased DNA content. In comparison with native tissue, there was approximately 6 times more DNA present in tissueengineered constructs.

\section{IMPLANTATION PROCEDURES}

The same experienced vascular surgeon performed all implantations. One animal was excluded from the study as implantation failed as a result of several ruptures in multiple constructs during the implantation procedure. In two other animals, arterial patches had to be used for small tears that occurred during creation of the anastomoses, indicating insufficient suture strength of the constructs. However, hemostasis was established in all eight cases and all grafts were open by the end of the implantation procedures. 

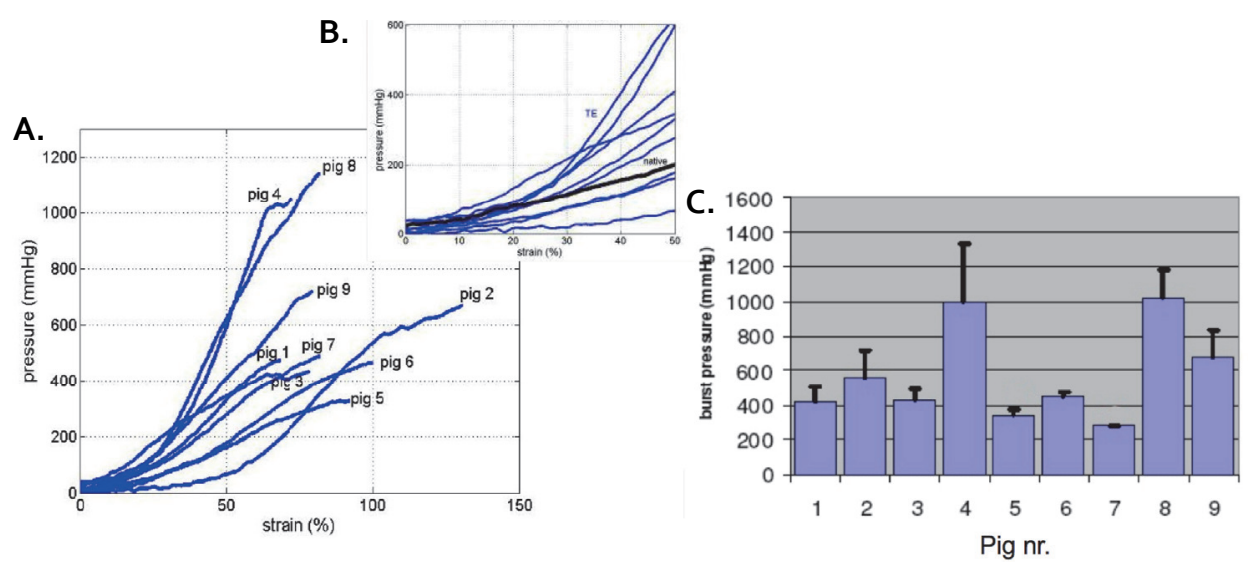

Figure 6.2. Biochemical analyses of control grafts. A. Amount of glycasaminoglycans (GAG) per mg dryweight. B. Hydroxyproline content per mg dryweight indicating the amount of collagen. All strips contained less hydroxyproline than native artery. C. Total amount of cells is reflected by the amount DNA/mg dryweight showing increased cellular content compared to native arterial tissue. Porcine carotid artery was used as native tissue. $n=3$, means \pm SEM are shown.

\section{FOLLOW-UP}

During the follow-up period of four weeks, three animals died within two days postoperative because of ruptured grafts resulting in severe arterial bleeding with hypovolemic shock.

Post-mortem examination of these grafts showed fatigue ruptures near both anastomoses in two grafts and in the other graft a rupture in the middle was found, probably related to insufficient burst pressure (Figure 6.3). One animal showed signs of a wound infection at day 1 post-operatively, which was treated with oral antibiotics for three days. During explantation of this graft a local hematoma was found suggesting a contained rupture. Another animal showed a late superficial wound infection at day 13 that was also treated with antibiotics for three days.

\section{ULTRASOUND SCANS}

Ultrasound scans were performed at day 2, 13 and 28 post-operatively. All animals showed substantial edema around the wound at day 2 after implantation. At day 13, all six remaining animals appeared to have a graft with an open lumen as suggested by a pulsatile duplex signal throughout the operated area. Unfortunately, the scan resolution was insufficient to assess graft morphology. Representative images of the open and one final occluded graft are shown in Figure 6.4. 


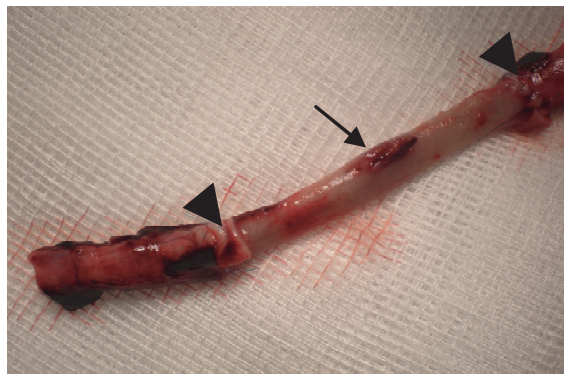

Figure 6.3. Ruptured graft one day after in vivo placement. Arrow indicates rupture, arrowheads indicate anastomoses
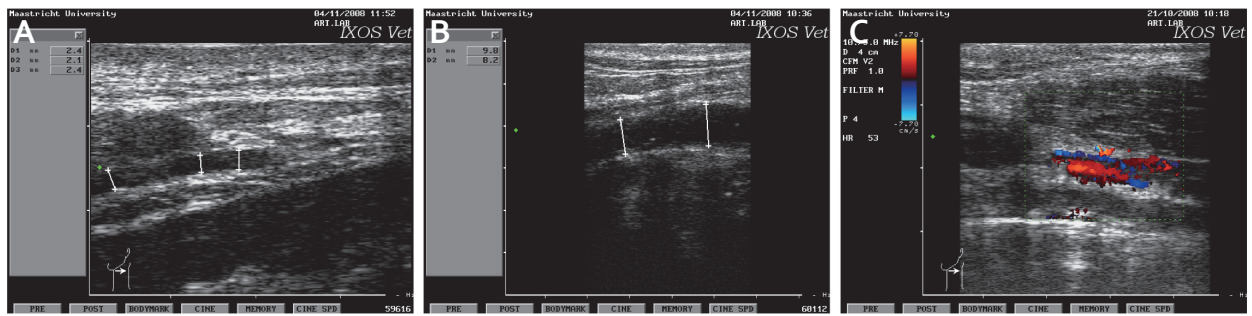

Figure 6.4. Ultrasound images sequenced at day 14 post-operative showing a normal diameter (a) and an outward remodelled graft with a large diameter (b). C. Representative color duplex ultrasound image of open graft at day 14 post-operative.

\section{ANGIOGRAPHY}

At day 28 post-operatively, angiographies of the grafts and ipsilateral carotid arteries were performed before explantation. Four out of five grafts appeared to be occluded. The one open graft showed only a small lumen compared to the adjacent carotid artery, over the whole length of the graft (Figure 6.5). Ultrasound of this particular graft obtained at day 13 post-operative revealed an outer diameter of $9.8 \mathrm{~mm}$ (Figure $6.4 \mathrm{C}$ ). An overview of the results is shown in Table 6.1. 


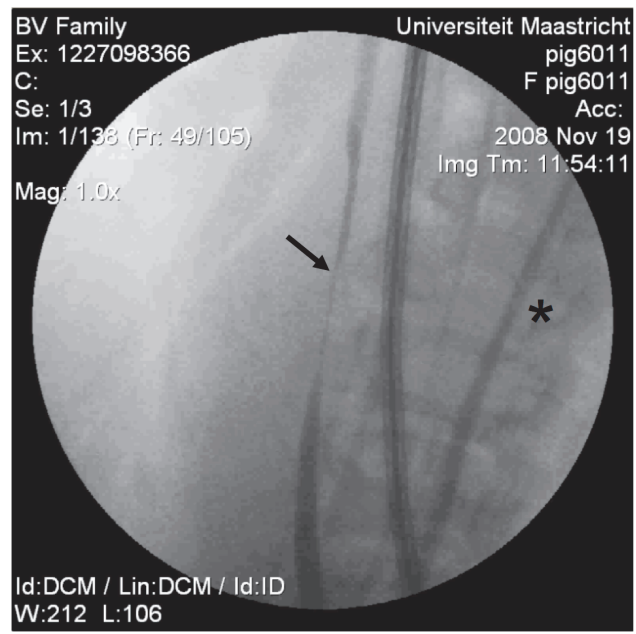

Figure 6.5. Image from angiography of open graft after 28 days post-operative. Arrow indicates stenosed graft. Asterisk indicates contralateral carotid artery.

Table 6.1. Results

\begin{tabular}{llll}
\hline Outcome & Remarks & $\begin{array}{l}\mathrm{n} \\
(\%)\end{array}$ & $\begin{array}{l}\text { Time } \\
\text { (post-operative day) }\end{array}$ \\
\hline Graft open & Outward remodeling, neointima with & $1(11 \%)$ & End follow-up \\
Small lumen & & \\
Gupt occluded & Death & $4(44 \%)$ & $\mathrm{D}_{14-\mathrm{D} 28}$ \\
& & $3(33 \%)$ & $\mathrm{D}_{1}(n=2), \mathrm{D}_{2}(n=1)$ \\
& Contained rupture (occluded) & $1(11 \%)$ & unknown \\
Graft not implantable & Insufficient suture strength & $1(11 \%)$ & 0 \\
\hline
\end{tabular}

\section{MACROSCOPY GRAFTS}

All grafts showed an extensive local tissue reaction. In three grafts, transversal sections showed an occluded lumen with non-specific tissue without signs of thrombosis (Figure 6.6a). One graft showed partial disruption, degradation, and a local thrombus (Figure 6.6b). The only open graft presented with a very small lumen, surrounded by several tissue layers (Figure 6.6c). 

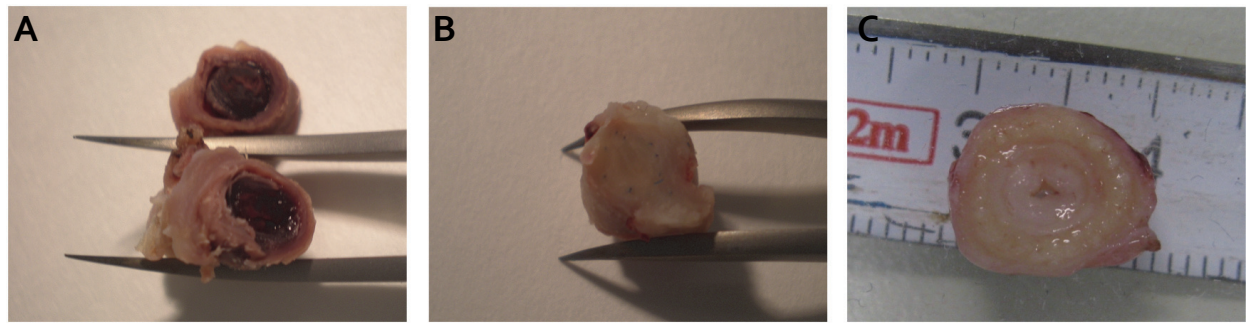

Figure 6.6. Grafts post-explantation. A. Transversal section of occluded graft. B. Partially degraded graft with thrombus. C. Open graft after explantation.

\section{MICROSCOPY GRAFTS}

Grafts explanted at day 1 and 2 because of lethal rupture showed influx of neutrophils and eosinophilic granulocytes on HE stained graft sections (Figure 6.7A), especially at the luminal side. The grafts contained a substantial amount of PGA fibers, and between the fibers open areas devoid of cells were observed (Figure 6.7A,B,C). Staining for $\alpha$ SMA showed presence of SMCs throughout the graft with a higher abundance on the adventitial side of the grafts (Figure 6.7B).

Macrophages/monocytes staining revealed vast presence of large amounts of myeloid cells and in particular in close proximity of the scaffold fibers (Figure $6.7 \mathrm{C}$ ). Cell-free areas were not seen in $\mathrm{HE}$-stained section of native carotid artery (Figure 6.7D), suggesting that these were not due to histological artefacts.

Large granulomas could be observed in $\mathrm{HE}$-stained sections of all grafts explanted at day 28 , post-operative (Figure $6.8 \mathrm{~A}, \mathrm{~B}, \mathrm{D}$ ). In the open graft, a substantial neointimal area was seen with granulomas in the subintimal layer (Figure 6.8A). Only a few scaffold residues could be seen (Figure 6.8B). Giant cells and macrophages were abundantly present, indicating a foreign body reaction to the scaffold material (Figure $6.8 \mathrm{~B}, \mathrm{C}$ and F). Staining for macrophages/monocytes revealed presence of these cells predominantly in the granulomas (Figure 6.8C,F). Masson's trichrome staining showed collagen deposition (blue) in the outer layer and presence of SMCs throughout the whole graft (Figure 6.8E). 

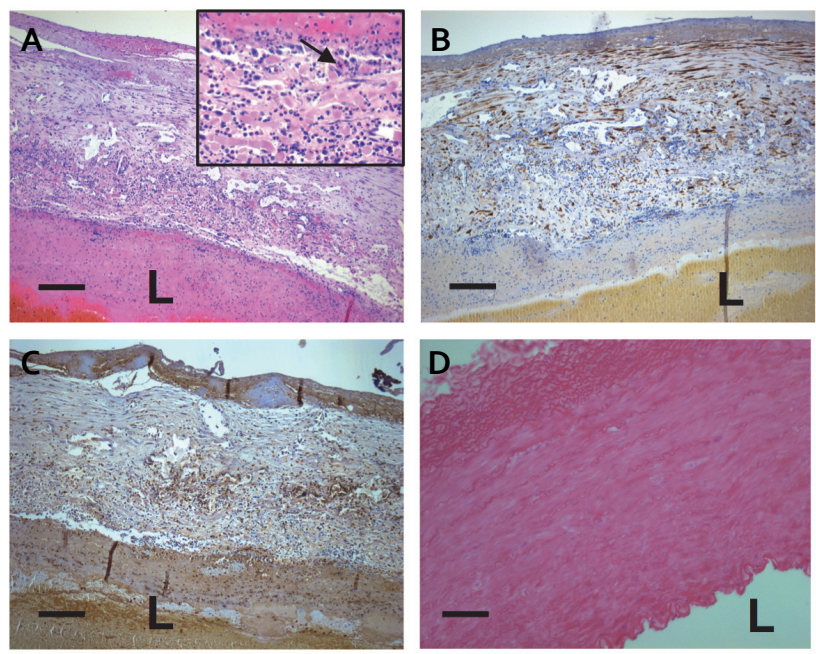

Figure 6.7. Histology of native carotid artery and ruptured grafts. Grafts were cut longitudinally. A. HEstaining. Numerous neutrophils and eosinophilic granulocytes (arrow) are present in the graft. B. anti- $\alpha$ SMA staining showing aligned SMCs in the outer layer. C. Macrophages/monocytes staining. Myeloid cellular influx is present already one day after in vivo placement. D. HE-staining native carotid artery. L indicates luminal side. Scale bars represent $100 \mu \mathrm{m}$.
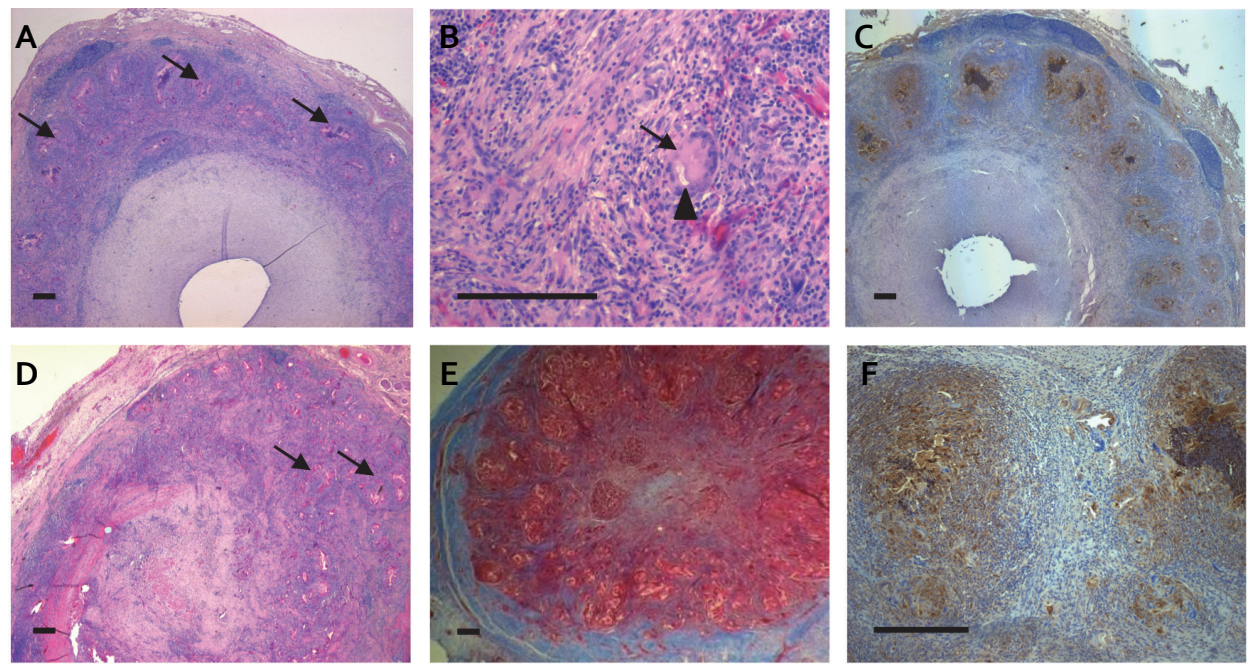

Figure 6.8. Histology grafts post-explantation. A, D. HE-staining of open graft (A) showing multiple granulomas (arrows) and an occluded graft (D) with remnants of native carotid artery on the left side. B. Higher magnification of HE-stained open graft showing a giant cells (arrow) and scaffold remnant (arrowhead). C, F. Macro-phages/monocytes staining. Myeloid cells are predominantly present in granulomas. E. Masson's trichrome staining of occluded graft in which collagen (blue) is present in the outer layer, and smooth muscle cells are stained red. Scale bars represent $100 \mu \mathrm{m}$. 
Staining for $\alpha$-SMA and SM-MHC demonstrated presence of SMCs in all grafts. In the open graft, several layers in the wall could be distinguished. All layers contained SMCs, which were randomly orientated except for a thin layer below the former scaffold showing circular oriented SMCs (Figure 6.9A). Neovascularization was observed in the outer layers of all grafts (Figure 6.9B). Most cells in the neointimal layer were $\alpha$-SMA positive (Figure 6.9C). The majority of cells in the grafts also expressed SM-MHC (Figure 6.9D).
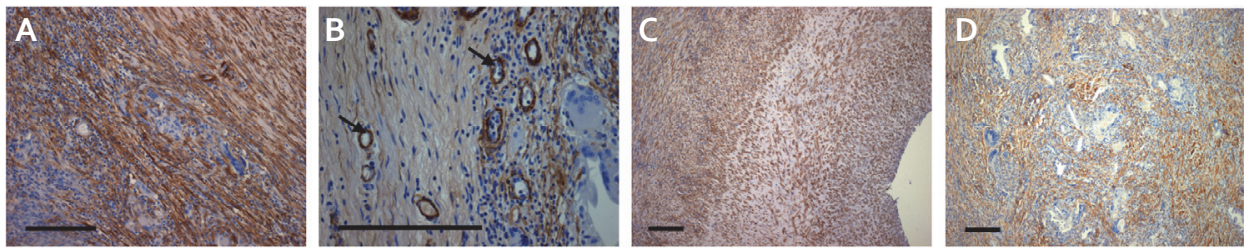

Figure 6.9. Immunhistochemistry for SMC-markers post-explantation. Anti $\alpha$-SMA staining $(A, B, C)$ was positive throughout the whole graft. B. Neovascularization was present in the outer layers. C. Cells in the neointima layer are predominantly $\alpha$-SMA positive. D. Anti-Smooth muscle myochain heavy (SM-MHC) staining. Scale bars represent $100 \mu \mathrm{m}$ ??

\section{DISCUSSION}

This feasibility study evaluated a small diameter tissue-engineered vascular graft, implanted in a porcine model as a carotid interposition graft with a follow-up of 4 weeks. Grafts were created from MFs seeded in a fibrin gel on a PGA/P4HB scaffold. After 4 weeks of in vitro culturing, ECs were seeded intraluminally and grafts were implanted in the autologous donor pigs. The anticipated outcomes after 4 weeks were patent, non-aneursysmatic grafts. The current tested type of grafts however did not fulfil these minimal criteria.

First, suture strength was rather low even leading to exclusion of one construct that could not be anastomosed to the carotid artery. Several other grafts required usage of patches to repair suture holes during the implantation procedure. Second, the burst pressure of four out of eight $(50 \%)$ of the implanted constructs appeared to be insufficient to withstand arterial hemodynamic forces. Of these ruptured grafts, three out of four animals died immediately due to hypovolemic shock, an unacceptable outcome. During the culture process, less dense tissue was observed in some grafts at some sites, possibly leading to local weaknesses. It is therefore reasonable that burst pressure has varied locally within the graft, resulting in a rupture at the 'weakest' spot. The heterogeneous composition of the grafts might be related to the production 
process in which PGA is manually wrapped around a mandrel. This allows local differences in thickness of scaffold material and subsequently tissue composition. It is debatable whether the often mentioned minimal burst pressure of $1600 \mathrm{mmHg}$ which is derived from the saphenous venous burst pressure, is necessary per se as grafts from which control constructs had a lower estimated burst pressure, did not show rupture in our model. Nonetheless, the existence of weak spots requires a better standardization of the manufacturing process and an adjusted pre-implantation testing protocol.

Besides the considerable rupture rate, a high occlusion rate of three out of four $(75 \%)$ was found in the remaining grafts, due to an extensive foreign body reaction. Histological analysis showed presence of granulomas in all grafts containing monocytes and multinucleated macrophage giant cells, known hallmarks of a foreign body response. The ruptured grafts collected during post-mortem autopsy at day 1 and 2 also showed influx of myeloid cells and eosinophilic granulocytes, indicating an acute inflammatory response. A foreign body response usually starts with formation of thrombus at the blood/material interface and formation of a provisional matrix. ${ }^{21}$ Subsequently, various plasma and extracellular matrix proteins are deposited on this matrix serving as mitogens and chemoattractants thereby facilitating adhesion of monocytes. These will subsequently differentiate into macrophages that will finally fuse to form foreign body giant cells. ${ }^{21,22}$ It can be expected that the scaffold material used is the prime source of the profound foreign body response. A comparable, substantial foreign body reaction has also been reported by van der Giessen et al. after implanting several different polymer-coated stents in pig coronary arteries, including polyglycolic acid/polylactid acid (PGLA). After four weeks, an inflammatory, proliferative response with giant cells and a granulomatous appearance comparable to our data was observed. This led to a significant decrease in the luminal area of most of the tested polymers. The authors proposed the asymmetric shape of the constructs as a possible explanations, however, a foreign body reaction initiated by the nature of the polymers seems more plausible taking into account our similar histologic findings. ${ }^{23}$ $\mathrm{PGA} / \mathrm{P}_{4} \mathrm{HB}$ is approved for clinical application in the United Stated by the FDA and thus expected to be safe when implanted in a living animal. The presence of giant cells around remnants of a PGA/P4HB scaffold was reported by Hoerstrup et al. ${ }^{24}$ as well, but such an extensive tissue reaction as in the current study has not been reported yet in relation to $P G A / P_{4} H B$. Due to differences in the fabrication and sterilization processes, either $\mathrm{PGA}$ or $\mathrm{P}_{4} \mathrm{HB}$ could still have induced this foreign body response. It should be considered that because of hydrolysis and ongoing degradation, the $\mathrm{pH}$ within the graft has probably decreased thereby influencing the immune system as 
well. ${ }^{25,26}$ Another stimulus for the strong immune reaction could involve proteins derived from the culture medium, most likely the fetal bovine serum. As the vascular graft constructs were not flushed before implantation, components from fetal bovine serum might have activated the porcine immune system. For future studies it should be considered to test biomaterials first in a subcutaneous manner to assess their compatibility with the host immune system, though one should keep in mind that exposure to the circulation might result in different immune reactions than subcutaneous implantations.

Next to the local fatigue of several grafts, a large variation in biomechanical strength of parallel cultured strips from different pigs was also apparent. This could have been related to differences in biochemical composition especially for GAG and hydroxyproline content, which is interesting as all pigs were of the same age and were young, healthy subjects. Thus, the difference in extracellular matrix production cannot be explained by different donor characteristics as such and might have been the result of a heterogeneous cell population after autologous cell isolation by means of the outgrowth method. Next to myofibroblasts, SMCs and fibroblasts; ECs and pericytes might also have been present in these isolates. Nonetheless, this procedure is widely accepted to obtain myofibroblasts from vascular tissue. ${ }^{27}$ To prevent large interindividual differences, cell populations need to be characterized and screened for number of myofibroblasts before seeding on scaffolds. The amount of DNA appeared to be 6 times higher in tissue-engineered constructs compared to native artery. In contrast, hydroxyproline content was considerably lower in TEVGs, suggesting that mechanical strength could be increased in TEVGs by decreasing the cellular/matrix ratio. Studies to enhance collagen production during the conditioning process in vitro are currently ongoing.

Unfortunately, ECs could no be seeded in all constructs. The isolation protocol used at that time was suboptimal for porcine ECs and resulted in failure of isolation in two animals and non-pure cell populations in two other animals. This could be resolved by magnetic beads selection for $\mathrm{CD}_{31}$ positive cells. For future studies using pigs, an optimized porcine endothelial isolation protocol as described in this thesis (Chapter 3 ) should be employed. ${ }^{28}$

Although this graft offers the advantage of a relative short 'culture' time, compared to grafts with manufacturing periods up to 9 months, the disappointing results of our feasibility study deem the current approach unsuitable for further in vivo testing and require further in vitro optimization. Since Weinberg and Bell reported the first proof of concept of vascular tissue engineering ${ }^{29}$, many others have published promising results 
of functioning tissue-engineered vascular grafts in the arterial circulation in small animal models ${ }^{30,31}$ and larger animals, like pigs ${ }^{32}, \operatorname{dog} s^{33,34}$, sheep ${ }^{35}$ and primates. ${ }^{33}$ However, until now only one study has been published showing acceptable outcomes of small diameter tissue-engineered grafts used in humans. Based on these facts, and our own experience, it can be stated that realisation of the ideal tissue-engineered vascular substitute for daily clinical practice remains challenging and is not expected to be realized at short notice. Nonetheless, new developments in the BMM iValve project on vascular grafts show promising results for electrospun bis-urea polymeric grafts in an abdominal aorta interposition model in rats.

\section{CONCLUSION}

The porcine carotid interposition model is suitable for testing small-calibre tissueengineered vascular grafts in the arterial circulation. Our tissue-engineered constructs, based on PGA/P4HB scaffolds seeded with myofibroblasts and ECs, with a short-term culture approach induce a strong foreign-body reaction leading to occlusion of the majority of grafts. Secondly, the grafts are of insufficient strength to withstand arterial pressures. Graft material, culture and conditioning protocols require adjustments and further optimization to enhance mechanical strength and immunologic properties. 


\section{REFERENCES}

1. Vara DS, Salacinski HJ, Kannan RY, Bordenave L, Hamilton G, Seifalian AM. Cardiovascular tissue engineering: state of the art. Pathol Biol (Paris). 2005; 53(10): 599-612.

2. Motwani JG, Topol EJ. Aortocoronary saphenous vein graft disease: Pathogenesis, predisposition, and prevention. Circulation. 1998; 97(9): 916-31.

3. K/DOQI clinical practice guidelines for cardiovascular disease in dialysis patients. Am J Kidney Dis. 2005; 45(4 Suppl 3): S1-153.

4. Hirsch AT, Haskal ZJ, Hertzer NR, Bakal CW, Creager MA, Halperin JL, et al. ACC/AHA 2005 Practice Guidelines for the management of patients with peripheral arterial disease (lower extremity, renal, mesenteric, and abdominal aortic): a collaborative report from the American Association for Vascular Surgery/Society for Vascular Surgery, Society for Cardiovascular Angiography and Interventions, Society for Vascular Medicine and Biology, Society of Interventional Radiology, and the ACC/AHA Task Force on Practice Guidelines (Writing Committee to Develop Guidelines for the Management of Patients With Peripheral Arterial Disease): endorsed by the American Association of Cardiovascular and Pulmonary Rehabilitation; National Heart, Lung, and Blood Institute; Society for Vascular Nursing; TransAtlantic Inter-Society Consensus; and Vascular Disease Foundation. Circulation. 2006; 113(11): e463-654.

5. Nicoloff AD, Taylor LM, Jr., McLafferty RB, Moneta GL, Porter JM. Patient recovery after infrainguinal bypass grafting for limb salvage. J Vasc Surg. 1998; 27(2): 256-63; discussion 64-6.

6. Johnson WC, Lee KK, members of the Department of Veteran Affairs CS. A comparative evaluation of polytetrafluoroethylene, umbilical vein, and saphenous vein bypass grafts for femoral-popliteal aboveknee revascularization: A prospective randomized Department of Veterans Affairs cooperative study. J Vasc Surg. 2000; 32(2): 268-77.

7. Wilson YG, Wyatt MG, Currie IC, Baird RN, Lamont PM. Preferential use of vein for above-knee femoropopliteal grafts. Eur J Vasc Endovasc Surg. 1995; 10(2): 220-5.

8. Geenen IL, Nyilas L, Stephen MS, Makeham V, White GH, Verran DJ. Prosthetic lower extremity hemodialysis access grafts have satisfactory patency despite a high incidence of infection. J Vasc Surg. 2010; 52(6): 1546-50.

9. Sapsford RN, Oakley GD, Talbot S. Early and late patency of expanded polytetrafluoroethylene vascular grafts in aorta-coronary bypass. J Thor Cardiovasc Surg. 1981; 81(6): 860-4.

10. Chard RB, Johnson DC, Nunn GR, Cartmill TB. Aorta-coronary bypass grafting with polytetrafluoroethylene conduits. Early and late outcome in eight patients. J Thor Cardiovasc Surg 1987; 94(1): 132-4.

11. Canver CC. Conduit options in coronary artery bypass surgery. Chest. $1995 ; 108(4)$ : 1150-5.

12. McAllister TN, Maruszewski M, Garrido SA, Wystrychowski W, Dusserre N, Marini A, et al. Effectiveness of haemodialysis access with an autologous tissue-engineered vascular graft: a multicentre cohort study. Lancet. 2009; 373(9673): 1440-6.

13. Stekelenburg M, Rutten MC, Snoeckx LH, Baaijens FP. Dynamic Straining Combined with Fibrin Gel Cell Seeding Improves Strength of Tissue-Engineered Small-Diameter Vascular Grafts. Tissue Eng Part A. 2008. 15(5): 1081-9.

14. Pullens RAA, Stekelenburg M, Baaijens FPT, Post MJ. The influence of ECs on the ECM composition of 3D engineered cardiovascular constructs. J Tissue Eng Regen Med. 2009; 3(1): 11-8.

15. L'heureux N, Pâquet S, Labbé R, Germain L, Auger FA. A completely biological tissue-engineered human blood vessel. FASEB J. 1998; 12(1): 47-56.

16. Isenberg BC, Williams C, Tranquillo RT. Small-diameter artificial arteries engineered in vitro. Circ Res. 2006; 98(1): 25-35.

17. Stekelenburg M, Rutten MC, Snoeckx LH, Baaijens FP. Dynamic straining combined with fibrin gel cell seeding improves strength of tissue-engineered small-diameter vascular grafts. Tissue Eng Part $A$. 2009; 15(5): 1081-9.

18. Berglund JD, Nerem RM, Sambanis A. Incorporation of intact elastin scaffolds in tissue-engineered collagen-based vascular grafts. Tissue Eng. 2004; 10(9-10): 1526-35. 
19. Huszar G, Maiocco J, Naftolin F. Monitoring of collagen and collagen fragments in chromatography of protein mixtures. Anal Biochem. 1980; 105(2): 424-9.

20. Cesarone $\mathrm{CF}$, Bolognesi C, Santi L. Improved microfluorometric DNA determination in biological material using 33258 Hoechst. Anal Biochem. 1979; 100(1): 188-97.

21. Anderson JM, Rodriguez A, Chang DT. Foreign body reaction to biomaterials. Semin Immunol. 2008; 20(2): 86-100.

22. Luttikhuizen DT, Harmsen MC, Van Luyn MJ. Cellular and molecular dynamics in the foreign body reaction. Tissue Eng. 2006; 12(7): 1955-70.

23. van der Giessen WJ, Lincoff AM, Schwartz RS, van Beusekom HMM, Serruys PW, Holmes DR, et al. Marked inflammatory sequelae to implantation of biodegradable and nonbiodegradable polymers in porcine coronary arteries. Circulation. 1996; 94(7): 1690-7.

24. Hoerstrup SP, Cummings Mrcs I, Lachat M, Schoen FJ, Jenni R, Leschka S, et al. Functional growth in tissue-engineered living, vascular grafts: follow-up at 100 weeks in a large animal model. Circulation. 2006; 114(1 Suppl): l159-66.

25. Kellum JA, Song M, Li J. Science review: extracellular acidosis and the immune response: clinical and physiologic implications. Crit Care. 2004; 8(5): 331-6.

26. Lardner A. The effects of extracellular pH on immune function. J Leukoc Biol. 2001; 69(4): 522-30.

27. Schnell AM, Hoerstrup SP, Zund G, Kolb S, Sodian R, Visjager JF, et al. Optimal cell source for cardiovascular tissue engineering: venous vs. aortic human myofibroblasts. Thorac Cardiovasc Surg. 2001; 49(4): 221-5.

28. Geenen IL, Molin DG, van den Akker NM, Jeukens F, Spronk HM, Schurink GW, et al. Endothelial cells (ECs) for vascular tissue engineering: venous ECs are less thrombogenic than arterial ECs. J TIssue Eng Reg Med. 2012. Nov 19.

29. Weinberg $C B$, Bell E. A blood vessel model constructed from collagen and cultured vascular cells. Science. 1986; 231(4736): 397-400.

30. Nelson GN, Mirensky T, Brennan MP, Roh JD, Yi T, Wang Y, et al. Functional small-diameter human tissue-engineered arterial grafts in an immunodeficient mouse model: preliminary findings. Arch Surg. 2008; 143(5): 488-94.

31. Nieponice A, Soletti L, Guan J, Hong Y, Gharaibeh B, Maul TM, et al. In vivo assessment of a tissueengineered vascular graft combining a biodegradable elastomeric scaffold and muscle-derived stem cells in a rat model. Tissue Eng Part A. 2010; 16(4): 1215-23.

32. Cho SW, Kim IK, Kang JM, Song KW, Kim HS, Park CH, et al. Evidence for in vivo growth potential and vascular remodeling of tissue-engineered artery. Tissue Eng Part A. 2008.

33. L'Heureux N, Dusserre N, Konig G, Victor B, Keire P, Wight TN, et al. Human tissue-engineered blood vessels for adult arterial revascularization. Nat Med. 2006; 12(3): 361-5.

34. Chue WL, Campbell GR, Caplice N, Muhammed A, Berry CL, Thomas AC, et al. Dog peritoneal and pleural cavities as bioreactors to grow autologous vascular grafts. J Vasc Surg. 2004; 39(4): 859-67.

35. Koch S, Flanagan TC, Sachweh JS, Tanios F, Schnoering H, Deichmann T, et al. Fibrin-polylactidebased tissue-engineered vascular graft in the arterial circulation. Biomaterials. 31(17): 4731-9. 


\section{CHAPTER 7}

General Discussion 
CHAPTER 7 
Since years, scientists have been looking for ultimate solutions for degenerative diseases. For atherosclerosis, replacement of diseased vessels by tissue-engineered vascular grafts seems a promising strategy. This kind of grafts could also offer benefits for the creation of vascular access for dialysis and repair of congenital cardiovascular defects.

In this thesis, a number of preclinical studies on vascular tissue engineering are presented. We aimed to take several steps in the field of endothelial research necessary for translation of laboratory results into clinical application for vascular tissue engineering. Therefore, we focused on functional aspects of ECs regarding their potential for vascular tissue engineering, which are described in the first chapters. Besides an extensive in vitro analysis of porcine ECs and an EC cell line (i.e. EA.hyg26) with a stable phenotype, patient-derived ECs were also investigated for their functional phenotype (Chapters 2, 3, 4). The last two chapters comprise two animal models dedicated to the study of arteriovenous (AV) fistula function (Chapter 5) and tissue-engineered grafts (Chapter 6).

\section{THE ORIGIN OF CELLS}

Research into endothelial potential for vascular tissue engineering has been carried out with venous endothelial ${ }^{1-4}$, endothelial progenitor ${ }^{5-8}$ or mesenchymal stem cells (MSCs). ${ }^{9,10}$ The choice of using primary, end-differentiated ECs for this thesis was based on previous research carried out by R. Pullens and described in his thesis "Functional endothelium on tissue engineered small diameter vascular grafts". ${ }^{11}$ The well-defined function, prior application of ECs for clinical use $\mathrm{e}^{12,13}$ and ongoing debate regarding definition of MSCS were additional arguments for choosing ECs. Furthermore, there was no evidence of inferior quality of these cells compared to endothelial progenitor cells (EPCs) ${ }^{14}$ or MSCs. ${ }^{10}$

Schnell et al. demonstrated for myofibroblasts from venous origin superior collagen formation and better mechanical properties compared to arterial myofibroblasts. ${ }^{15}$ However, for ECs, a lack of insight into characteristics relevant for vascular tissue engineering of venous and arterial ECs still existed. For the benefit of future application of primary ECs in vascular tissue engineering there was a need for a robust comparison between these arterial and venous endothelium sources, which was addressed in Chapter 3. We hypothesized that arterial ECs would show superior performance, especially when cells were exposed to arterial flow circumstances. Therefore, we included arterial shear stress conditions in our experimental set-up. 
The choice of endothelial cell source for vascular tissue engineering is predominantly defined by the anti-thrombogenicity of the source, next to cell growth. Interestingly, we showed that venous ECs have a more beneficial anti-thrombogenic profile as compared to arterially derived ECs. These venous ECs displayed less platelet adhesion after exposure to arterial shear stress compared to arterial equivalents, despite higher vWF expression in venous ECs. It should be noted that these differences in expression were based on mRNA levels and immunofluorescence, including intracellular vWF (stored in Weibel-Palade bodies), which does not reflect vWF activity on the cell membrane that is responsible for platelet adhesion in the end. Next to platelet adhesion, the mCAT assay as described in Chapter 2 was carried out with both types of ECs. Venous ECs revealed a longer lag time and increased thrombomodulin activity, in concordance with higher thrombomodulin levels in gene expression analysis. Taken together it can be concluded that venous ECs appeared to have a more beneficial thrombogenic profile than arterial ECs. These findings combined with the less harmful harvesting procedure of venous specimens make venous ECs the preferred source for usage in tissue engineering compared to arterial ones.

In addition to porcine cells, we also evaluated performance of ECs derived from two main target patient populations that are subjected to receiving vascular tissueengineered grafts in the future, being coronary arterial bypass graft (CABG) patients and patients with chronic kidney disease (CKD). At the same time, ECs from control patients without cardiovascular or renal disease were isolated as well. Function of cells from these three categories was determined and presented in Chapter 4. Based on our findings in Chapter 3, we decided to use venous ECs for this comparison.

Dysfunction of the endothelium has been described in coronary arterial disease $(C A D)^{16,17}$ and $C K D^{18,19}$, and is thought to contribute to the development of atherosclerosis. ${ }^{20,21}$ For example, endothelium-mediated vasomotor responses are diminished in both the peripheral and coronary circulation in patients with CAD. ${ }^{16,17}$ In CKD, vWF secretion appeared to be higher and endothelium-dependent vasodilation was diminished compared to controls. ${ }^{18,19}$ Given the dysfunctional state of the endothelium in CAD and CKD patients, we hypothesized that ECs derived from these patient categories would show inferior quality, reflected in lower isolation rates, proliferation, migration and disadvantageous thrombogenic characteristics.

ECs were isolated from venous surgical leftover specimens. Our isolation protocol turned out to be rather robust, as the success rate of cell isolations was high (51/66, $77 \%$ ). Failure of cell isolation/culture was mostly related to early culture infections, which happened less frequently after introducing more stringent sterilization 
procedures. We also concluded that the minimal required size of vessel segments for endothelial isolation should be at least $1 \mathrm{~cm}$.

We hypothesized that proliferation in particular would be compromised in the CABG and CKD groups, but growth rates reflected in population doubling times, as well as proliferation rates measured over four days of time, were similar to controls. In literature, several authors have reported detrimental effects on endothelial growth as a result of exposure to cardiovascular risk factors. Zilla et al. focused on the effect of smoking on endothelial growth rates in vitro and observed diminished proliferation rates compared to ECs derived from non-smokers. ${ }^{22}$ Hyperlipidemia was also associated with decreased proliferative potential according to Meinhart et al. ${ }^{23}$ In our study, regression analysis for a possible correlation between cell growth and patient characteristics or risk factors did not reveal an effect of smoking or hyperlipidemia on endothelial growth. However, female gender turned out to be correlated with decreased mean population doubling time, a finding not described earlier in literature.

In addition to functional measurements, we also analyzed gene expression on patientderived ECs. These analyses showed higher thrombomodulin expression in CABGderived ECs, and a trend towards lower platelet derived growth factor $\alpha$ (PDGFR- $\alpha$ ) and higher endothelial nitric oxide synthase (eNOS) expression compared to control ECs. These persisting differences despite a substantial amount of population doublings in vitro could relate to epigenetic regulatory mechanisms as a result of disease or medication use. Repressive effects of LDL-cholesterol on Kruppel-like factor 2 (KLF2), a transcription factor for thrombomodulin, have been reported recently. ${ }^{24}$ Thus, lower LDL levels induced by the use of statins in the CABG group could have resulted in increased thrombomodulin levels.

Nonetheless, it cannot be excluded that the different vascular beds used for isolation of ECs could also have played a role in the different genetic expression profiles. Chi et al. performed an extensive gene expression analysis of ECs derived from different vascular origins and clearly demonstrated arterial-venous differences in addition to variations in gene expression profiles in veins from different anatomical regions. ${ }^{25}$ However, due to practical, in fact surgical, limitations it is impossible to use the same type of vein for cell isolations in the three different patient categories. Thus, we cannot fully explain whether differences between cells from patient groups are based on different patient profiles or different venous cell source.

In addition to our extensive functional analysis, we demonstrate the ability of patientderived ECs to attach and survive for at least seven days on fibrin coated 
polycaprolactone scaffolds (Chapter 4). Cells stained positive for $\mathrm{CD}_{3} 1$ and were able to form a monolayer, under the used static conditions. For future research, it would be of interest to apply shear stress in order to assess attachment and phenotype of seeded ECs. Shear stress can be a strong stimulator of endothelial behavior and could theoretically result in different responses of patient-derived ECs. For our arterialvenous comparison in Chapter 3, we seeded ECs in flow chambers and applied arterial shear stress for 72 hours. Venous ECs were able to withstand arterial shear stress and had higher proliferation rates and comparable adhesion numbers when seeded on fibronectin.

Based on the absence of diminished endothelial function of ECs derived from pat ients with cardiovascular disease and CKD, as described in Chapter 4, we conclude that cells derived from these patient categories can safely be used for vascular tissue engineering. Although in vivo performance was not evaluated due to the practical consequences of such a study, we feel that we assessed cells thoroughly in vitro, and that growth potential was clearly demonstrated by our prolonged culture time until passage 6-8. As described in Chapter 4, culturing ECs isolated from a small venous specimen up to passage 6 would be sufficient to endothelialize a small-diameter graft of $60 \mathrm{~cm}$ length.

Instead of using ECs, a trend towards usage of EPCs for vascular tissue engineering can be seen in recent literature, because of easier access to these cells. ${ }^{5-8,26} E P C s$, which are circulating cells with potential for endothelial differentiation when cultured in appropriate conditions ${ }^{27}$, can be isolated from a peripheral blood sample in contrast to primary ECs that need to be isolated from small vessel biopsies. However, superiority of EPCs derived from humans ${ }^{6}$ and pigs $^{8}$ above primary ECs has not been demonstrated. Success rate of proliferative colonies from peripheral blood (100 $\mathrm{mL}$ ) can be rather low $(18 \%)^{6}$, a problem more often reported ${ }^{28}$ and also encountered in our own laboratory (N. v.d. Akker, personal communication). In addition, for final creation of a tissue-engineered graft, cells that are appropriate for populating the medial layer e.g. smooth muscle cells (SMCs) or SMC-like cells are also required. For this purpose, either a vessel biopsy or tissue/bone marrow sample containing MSCs, which can be different iated into SMCs, is required, making the non-invasive way of EPC harvesting a less obvious advantage for vascular tissue engineering. Using MSCs as a source for both endothelial and medial cells is another alternative. ${ }^{29,30}$ However, in pigs it was recently shown that despite several stimulatory regimens, bone marrow-derived cells do not differentiate into ECs. ${ }^{10}$ Indeed, there is a lack of studies using MSCs for generating an endothelial layer ${ }^{31}$, although for populating the media of tissueengineered grafts, they seem a promising source. . $130,32^{2}$ 


\section{PROTECTION FROM THROMBUS FORMATION}

The most important advantage that tissue-engineered vascular grafts could offer compared to current prosthetic grafts is superior anti-thrombogenicity due to the use of endothelial-like cells on the luminal side. For optimizing the creation of an endothelial layer on tissue-engineered grafts, insight in their anti-thrombogenic properties is crucial. In the first chapter of this thesis (Chapter 2) we describe a method to evaluate thrombogenic characteristics of ECs in vitro in a standardized, highthroughput manner.

Thrombogenicity of ECs can be assessed by determining expression of (anti) thrombogenic proteins, nonetheless it is highly preferable to assess the endothelial balance between pro and anti-thrombogenic proteins by exposing ECs to blood components or whole blood ${ }^{33}$. Platelet adhesion assays $s^{34,35}$ such as applied in Chapter 3 , activated coagulation factor measurements ${ }^{36}$, fibrin deposition ${ }^{37}$ and whole blood clotting times ${ }^{38}$, have been used in the past to specifically determine thrombogenicity of ECs or endothelialized surfaces. ${ }^{33}$ These techniques however, are labor-intensive due to their frequent sampling protocol, can only assess small sample sizes or have a limited reproducibility. In Chapter 2, we successfully adapted the calibrated automated thrombogram (CAT), a well-known high-throughput assay for measuring thrombin generation in plasma samples ${ }^{39-41}$, to incorporate cells (modified CAT; mCAT).

Thrombin generation in the presence of ECs appeared to be primarily dependent on contact activation. When plasma deficient for factor XII was used, thrombin generation was limited whilst normal plasma pooled from 80 healthy volunteers showed substantial thrombin generation. Moreover, the tissue factor (TF) inhibitor act ive site inhibited factor VIla (ASIS) had a negligible effect on thrombin generation in normal plasma, suggesting little involvement of TF. Together, these results indicate that the contact activation pathway contributes most to the initiation of coagulation on ECs. This novel finding shows a clear role for contact activation, whilst previous studies excluded the contact activation pathway in their experimental set-up. . $^{6,42,43}$ This was probably related to the observation that patients lacking factor XII do not have a bleeding phenotype. ${ }^{44,45}$ However, recent animal studies show that factor XII is able to enhance pathologic thrombus format ion ${ }^{46-48}$, which actually offers therapeutic potential for factor XII-inhibitors in the prevention of thrombo-embolic events. Considering the lack of bleeding symptoms in patients with factor XII deficiency, it is expected that bleeding complications, associated with other anti-coagulants like vitamin $\mathrm{K}$ antagonists, will be absent when patients are treated with factor XII- 
inhibitors. The clinical potential of pharmacologic inhibitors of factor XII is currently under investigation. ${ }^{49}$

The exact way of activation of factor XII in the presence of ECs is still unknown, although several possibilities for binding of factor XII to ECs have been reported. This binding can either involve receptor complexes including urokinase-like plasminogen activator receptor (U-PAR), cytokerat in 1 or $\mathrm{gC} 1 \mathrm{qR}^{5}{ }^{50-52}$, or an $\mathrm{ECM}$ protein that is most likely fibronectin. ${ }^{53}$ The question remains whether binding of factor XII to ECS is sufficient for activation of factor XII, or whether other signals are required as well. Another way of activation of the contact pathway includes binding of factor XI and factor Xla to ECs in the presence of high-molecular-weight kininogen (HK), which in turn can activate factor IX.54,55 However, this cannot explain the contact activation in our experimental setting as factor XII was a prerequisite for the formation of thrombin when TF was blocked. Thus, further research is required to clarify the exact pathway of factor XII activation on ECs.

The finding of primary contact activation on ECs as described in Chapter 2 was confirmed in patient-derived ECs (Chapter 2, 4). ECs derived from CABG patients showed increased thrombin generation potential compared to ECs from controls, which was the result of stronger contact activation. Although several reports on increased thrombin generation in plasma from cardiovascular compromised subjects have been published, ${ }^{56,57}$ this phenomenon was not known for ECs from this category of patients. Our findings might be of interest for the before-mentioned attention to factor XII-inhibitors. ${ }^{49,5^{8}}$ Certain patient-derived cell batches showed TF pathway activation (Chapter 2,4), while in the majority of cell batches TF activity was absent. In an attempt to clarify the TF activation pattern, we looked at TF gene expression (Chapter 4). Levels of TF-expression in individual batches were not related to thrombin generation in factor XII-deficient plasma assayed on cells from these same individuals. It is known that TF on the cell membrane can present in an encrypted, non-active form. ${ }^{59,60}$ Exposure to phosphatidylserine that is able to decrypt TF, a process regulated by protein disulfide isomerase, could possibly play a role in the different activation pattern of the extrinsic pathway. ${ }^{61}$

Surprisingly, the significant differences in Chapter 2 regarding increased thrombin generation on ECs from CABG patients compared to control-derived ECs were not found in our larger analysis presented in Chapter 4 including ECs from CKD patients. This peculiar difference could relate to the substantial variance in MCAT outcomes found for the CKD group. This patient category comprised a very heterogenous group with large differences in age and comorbidities, which might hold relation with the 
cellular phenotype and thus thrombogenic potential. In line, Krenning et al., have shown reduced growth and anti-thrombogenic function in EPCS from CKD patients, and these impairments became more apparent with the progression of CKD. ${ }^{62}$

Next to intrinsic differences, cell phenotype might also be compromised by the process of cell culture. As described by Aird, cellular phenotype in vivo is defined by the micro-environment together with (epi)genetic influences, resulting in different endothelial phenotypes in arteries/veins and in different cell donors. During cell culture in vitro, these interindividual different phenotypes will gradually disappear, but it is unknown when and to which extent this exactly happens. ${ }^{63}$ For future research, investigating patient-related factors that influence the anti-thrombogenic phenotype of their ECs could be interesting for vascular tissue engineering. Furthermore, combining plasma derived from diseased patients with their autologous ECs would be of interest as well.

The final clinical consequences of a divergent thrombin generation profile in vitro of cell batches have to be established. Therefore, the correlation of mCAT results with in vivo thrombotic complications when cells are seeded on grafts in the end, needs to be evaluated in future follow-up studies. Reducing the thrombogenic potential of patient-derived ECs could result in better performance of grafts seeded with these cells and should be a future goal. Interventions could include stimulation of activity of the protein $C$ pathway by elevating the expression of thrombomodulin or endothelial protein $\mathrm{C}$ receptor. For cell batches in which TF-mediated coagulation did contribute to thrombin generation, inhibition of TF or stimulation of TF pathway inhibitor could be beneficial. Individualized anti-thrombotic therapy or prevention might thus be dictated by the outcome of these analyses.

Besides the two pathways of coagulation that result in thrombin generation, the complex process of clot formation and lysis comprises fibrinogen/fibrin and fibrinolytic processes as well. The mCAT method we applied does not include fibrinogen and fibrinolytic mechanisms. Fibrinolysis in particular can also be modulated by ECs, though we did not evaluate this. However, all other coagulation factors are incorporated in the assay and we feel this is a robust and fairly comprehensive method to investigate the process of hemostasis in the presence of ECs. For future studies, it can be of interest to look at the activity of tissue plasminogen activator (tPA) and plasminogen act ivator inhibitor-1 (PAI-1) on ECs. 


\section{UREMIA; ENDOTHELIAL CELLS AND THE NEIGHBORS}

As described in Chapter 4, dysfunction of ECs derived from CKD patients was anticipated as a result of higher oxidative stress levels in their uremic milieu. Patients with end-stage renal failure requiring vascular access are considered the first target population for final clinical application of tissue-engineered vascular grafts. ${ }^{12}$ Reasons for this are the urgent need for better alternatives for vascular access as current therapies, in particular prosthetic grafts, have high failure rates and require frequent interventions to maintain access patency. Second; in the case of failure of implanted tissue-engineered grafts eventual graft failure would rarely be limb or life threatening in hemodialysis patients, as an alternative for vascular access in the form of a central venous line is readily available. Third; frequent hemodialysis visits allow close monitoring of graft function.

At the same time, this patient category possesses a vast challenge for graft durability and remodeling capacity due to the uremic environment, co-existing morbidities such as hypertension and increased atherosclerosis. Furthermore, grafts require extensive regenerative capacity to heal injuries caused by repeated punctures required for hemodialysis. Therefore, for optimal in vivo testing of small diameter tissueengineered vascular grafts, we decided to develop a uremic animal model in which tissue-engineered vascular grafts could be implanted as an AV shunt.

We chose to develop such a model in the rat by first using native vessels to define the potential detrimental influences of the uremic environment on AV fistula function, which will influence tissue-engineered graft patency as well. So far, only two reports describe the effects of CKD on AV fistulas. ${ }^{64,65}$ Thus, in Chapter 5 , the influence of CKD on $\mathrm{AV}$ fistula function is presented, with special emphasis on endothelial and smooth muscle function.

Endothelial dysfunction has been postulated as causal factor in AV fistula failure as a result of uremia-induced oxidative stress. ${ }^{66,67}$ Indeed, we demonstrated higher levels of oxidative stress in the vascular wall of CKD animals, whereas no endothelial dysfunction was found in our vasoreactivity measurements. This is actually in concordance with several studies showing no reduction in endothelial function in uremia. $^{68-70}$ It also fits our results in Chapter 4 in which we observed normal endothelial function in vitro of ECs derived from CKD patients.

NO produced in ECs diffuses to the neighboring compartment, formed by the SMCs in the medial layer of the vessel wall, that will respond to NO via activation of their NOreceptor soluble guanylyl cyclase (sGC). In contrast with normal endothelial function in CKD animals, the smooth muscle compartment appeared to be compromised 
compared to controls, as shown by diminished relaxation after NO-stimulation, also referred to as NO resistance. This could be ascribed to oxidation of the receptor for NO, soluble guanylate cyclase (sGC), as shown by stimulation with a sGC activator, BAY 60-2770. BAY 60-2770 is able to enhance sGC function when the enzyme is oxidized, resulting in increased vasorelaxation. Indeed, our uremic vessels showed increased relaxation compared to controls in response to BAY 60-2770. Moreover, preincubation with an external oxidator (ODQ) additionally showed that SGC was maximally oxidized in uremic vessels. Hereby, we demonstrate for the first time NO resistance in CKD. Evidence for the existence of NO resistance has already been provided for diabetes type II patients, hypercholesterolemic rabbits and hypertensive rats. $^{71}$

In the light of higher cardiovascular mortality ratios in $C K D^{72,73}$, much research in CKD has focused on vascular dysfunction and disturbed NO-signaling. In CKD; decreased eNOS expression ${ }^{74}$, reduced tetrahydrobiopterin $\left(\mathrm{BH}_{4}\right)$ resulting in eNOS uncoupling ${ }^{75,76}$, high amounts of the endogenous eNOS-inhibitor asymmetric dimethylarginine (ADMA) $)^{77}$ and scavenging of $\mathrm{NO}$ by free radicals ${ }^{78}$ have all been described. Our new finding of NO resistance of $\mathrm{SGC}$ gives additional insight in the pathophysiology of diminished NO-signaling and cardiovascular disease in CKD. SGC activators like BAY 60-2770 offer therapeutic potential for prevention of cardiovascular complications in this patient category with increased oxidative stress levels due to their uremic internal milieu.

In addition to our in vitro experiments with BAY 60-2770, we also treated CKD animals with BAY 60-2770 thereby aiming to restore smooth muscle function and enhance AV fistula dilation and flow. No adverse events were observed during the three weeks follow-up. Fistula diameters were indeed larger but -unfortunately- flow was not significantly higher than vehicle-treated CKD animals. These outcomes are not completely understood, especially considering that blood pressure and neointima formation were comparable between groups. It could be hypothesized that peripheral vascular resistance in the pulmonary circulation was lower in BAY 60-2770 treated animals, thereby reducing flow through the AV fistula. Future studies are needed to elucidate this. For the benefit of vascular tissue engineering, substances like BAY 6o2770 could be beneficial when incorporated in scaffolds with a slow release technique or when administered to subjects after graft implantation, in which NO resistance can also occur. Possible dysfunctional remodeling as a result of oxidative stress could hereby be prevented. 
Previous reports on the influence of CKD on AV fistula function showed an increase in neointima formation. ${ }^{64,65}$ This led to smaller AV fistula diameter and seemed to coincide with increased calcification and higher amounts of myofibroblasts in the fistula wall. ${ }^{65}$ Also, SMCs appeared to have a more migratory phenotype, causing increased neointimal lesions in CKD. ${ }^{64}$ Interestingly, we did not find an increase in neoint ima formation in our study. This discrepancy could relate to our short follow-up period of three weeks, and usage of a different CKD model in the rat compared to Langer et al. who used an adenine diet to induce CKD that is known to stimulate vascular calcification. ${ }^{65}$ The most important parameter of AV fistula function is flow, which was not measured in the above-mentioned studies. We found decreased flow in our CKD group directly post-operatively and after three weeks, proving that AV fistula function indeed is compromised by the presence of CKD.

\section{BETWEEN BENCH AND BEDSIDE; GRAFTS IN VIVO}

For proper in vivo evaluation of tissue-engineered grafts, pert inent animal models are required. The animal model of CKD described in Chapter 5 was established by a 5/6th nephrectomy. After 6 weeks, a typical elevation of serum creatinine and urea of twice basal levels, as well as hypertension were evident. Considering the resemblance with clinical symptoms found in CKD patients we can conclude that the rat 5/6th nephrectomy is a valid model of CKD. We choose to create an AV fistula in the neck, an easily accessible location for surgery and ultrasound examination. The risk for cerebral infarction was found to be low and occurred only in one rat, probably as a result of an embolus. Instead of using the jugular vein, a small-diameter vascular graft can easily be inserted between the carotid artery and jugular vein. In general, we believe this model is highly suitable for testing tissue-engineered vascular grafts in the CKD setting.

Although the introduction of CKD in a (small) animal model in which tissueengineered grafts can be evaluated comes more close to the human and, clinical situation, other aspects of future use need to be addressed in preclinical animal testing as well. For example, the influence of hypertension or hypercholesterolemia could be interesting for assessment of long-term graft functioning. Also, recovery of repeated puncturing should be investigated.

For vascular research, the pig is considered the optimal animal model. In Chapter 6, we describe a carotid interposition model in the pig in which small diameter tissue- 
engineered grafts can be evaluated. In this model, we tested tissue-engineered grafts developed at the Eindhoven University of Technology, The Netherlands. These grafts were based on $\mathrm{PGA} / \mathrm{P}_{4} \mathrm{HB}$ scaffolds and seeded with autologous myofibroblasts and ECs, and their performance was tested in vivo for the first time, after several years of in vitro development and opt imization.

The outcomes of this feasibility study were not as expected. Seven out of eight implanted grafts failed as a result of early rupture or luminal occlusion by granulation tissue induced by a strong foreign body reaction. Despite these negative outcomes, these data also give substantial input for further optimization of tissue-engineered vascular grafts. The most prominent issue leading to occlusion of most grafts appeared to be the extensive immune reaction. Such a foreign body reaction to $P G A / P_{4} H B$ characterized by the presence of monocytes, multinucleated macrophage giant cells and granuloma formation, was also described in arterial patches ${ }^{79}$ and by Hoerstrup et al. in heart valves ${ }^{80}$, both implanted in sheep. In the latter, valve function was not affected by the presence of granulation tissue. However, in the case of small-diameter vascular grafts, the development of large amounts of granulation tissue is a vast risk because of the low tolerance in small lumen grafts. These grafts can easily occlude, in contrast with valve function that will not be compromised to such an extent. To prevent graft occlusion in the future, alternative biodegradable materials associated with a less profound foreign body response should be considered.

Our ultrasound examinations of implanted grafts after two weeks showed patent grafts, thus early thrombosis within two weeks after implantation did not occur in our EC-seeded tissue-engineered vascular grafts. From these data it can also be concluded that the inward-remodeling response triggered by the strong foreign body reaction appeared to develop predominantly in the last two weeks of our (four week) follow-up period. Another issue observed in this study was the aneurysmatic appearance of the only patent graft, with a maximal outer diameter of $9.8 \mathrm{~mm}$. Granulomas were also observed in this graft but as a result of the dilation of the graft no luminal occlusion occurred. In addition, a neointimal layer was seen, but thrombus formation was absent. Thus, the seeded ECs were able to prevent thrombosis but did not inhibit neointima formation. The extensive graft dilation indicates inadequate fatigue strength, possibly as a result of rapid scaffold degradation leading to mechanical weakness as seeded cells were not able to compensate for the loss of mechanical support.

From the occurrence of graft rupture within 2 days of implantation in three grafts we concluded that burst pressure was insufficient in these grafts, probably as a result of local weak spots. This could be ascribed to inhomogenous distribution of graft tissue 
which seems to be related to the manufacturing process that involved manual 'wrapping' of the scaffold around a mandrel. The existence of weak spots either requires a better standardization of the manufacturing process or a different preimplantation testing protocol (sterile, non-destruct ive pressure test).

Instead of PGA-based scaffolds, there is a trend towards usage of polycaprolactone $(\mathrm{PCL})$, polylactic acid (PLA) and collagen based scaffolds. ${ }^{32,81-84}$ For our next generation of grafts, we also decided to use $\mathrm{PCL}$. This biodegradable polyester has a longer degradation time than PGA, that loses its strength within four weeks and is completely absorbed within six months. ${ }^{8,85}$ The longer breakdown period of $P C L$ of approximately 15 weeks ${ }^{85}$ offers sustained biomechanical support compared to PGAbased grafts. The use of a coating like $\mathrm{P}_{4} \mathrm{HB}$ can also be omitted thereby possibly reducing the foreign body reaction. So far, acellular implanted $P C L$ grafts showed no inflammatory response after 1 month in vivo. ${ }^{82}$ Currently, in vivo experiments in rats with arterially placed bare PCL grafts are ongoing in our laboratory.

In this thesis, most in vitro studies were performed with cells seeded on ECM protein coatings. We especially compared the influence of the substrates fibronectin and collagen on cellular adhesion, proliferation and vWF expression (Chapter 3). From our data, we conclude that fibronect in is the preferred protein for coating. Scaffolds can be coated easily before seeding ECs. Moreover, ECs are also known to produce their own ECM. ${ }^{86}$ Indeed, effects of substrate seem to be minor as the observed influences of graft substrate on EC function disappear when cells reach confluency. ${ }^{87,88}$ Thus, obtaining a maximum cell density with excellent cell adhesion when grafts are placed in the circulation, should have priority during the seeding procedure.

Although we gained a lot of experience with isolating and culturing patient-derived ECs of a large number of patients (Chapter 4 ), for future clinical purposes more specific conditions are required that should follow Good Manufacturing Practice (GMP) guidelines. Serum-free culture is one of the requirements described in this set of principles and standards for production of medicinal products. ${ }^{89,90}$ In Chapter 2, we cultured ECs in a serum-free condition for thrombin generation measurements on human ECs. Fetal bovine serum (FBS) appeared to initiate very strong contact activation-mediated coagulation. By using human factor XII-deficient plasma that did not hamper cell growth, we found a proper replacement for FBS. This approach also offers opportunit ies for future human applications.

The classical approach to produce a tissue-engineered vascular graft comprises in vitro seeding of SMC-like cells followed by a period of graft culturing in order to gain ECM for sufficient mechanical strength, after which endothelial-like cells are intraluminally 
seeded..$^{91}$ However, the need for seeding grafts before placement in vivo is currently questioned. In recent animal studies, grafts have also been implanted without any cells. ${ }^{84,92,93}$ These grafts recruit cells in vivo, which gradually take over the mechanical support of the scaffold. Using this approach, seeding of ECs on the luminal side is also left out. Nevertheless, one of the considered advantages of tissue-engineered vascular grafts is the reduced thrombotic risk compared to classic prosthetic grafts, as a result of the presence of an endothelial lining on tissue-engineered vascular grafts. Animal studies with unseeded grafts showed presence of luminal ECs quite early after implantation. ${ }^{84,92}$ Thus, based on these studies, the need for endothelial seeding before implantation could be questioned.

However, the process of endothelialization of implanted vascular devices is insufficient and different in humans compared to animals. ${ }^{94,95}$ In humans, endothelial coverage of prosthetic grafts in situ develops by ingrowth of ECs from the anastomoses and does not exceed more than $10 \mathrm{~mm}$ distance from the anastomosis, even after a long-term period of implantation. ${ }^{9495}$ This is in contrast with animal studies, showing complete coverage of grafts within 3 months. ${ }^{83,84,92,95-97}$ Possible explanat ions for the discrepancy in endothelialization rate include the young, healthy status of animals in contrast with elderly human patients with comorbidities like diabetes and hypertension. Meinhart et al. demonstrated improved patency with EC-seeded ePTFE grafts compared to unseeded grafts in a large clinical cohort. ${ }^{13}$ Therefore, we believe that seeding of ECs on tissue-engineered vascular grafts is still indicated for human purposes, unless endothelialization in situ can be very quickly established after implantation. Implanting acellular small diameter vascular grafts in humans might not guarantee clinical success despite successful experimental results in animals.

An alternative to omit seeding ECs before implantation consists of coating of grafts with capture molecules that actively recruit circulating ECs or EPCs. Examples of these ligands include aptamers, peptides and antibodies like anti-VEGFR2 or anti-CD34. ${ }^{98-103}$ The latter was applied by Rotmans et al., resulting in complete endothelial coverage of ePTFE grafts in pigs but also -on the down side- increased neointima formation. ${ }^{98}$ It seems that a definitive solution for endothelialization of tissue-engineered vascular grafts has not been found yet, and preseeding with cultured ECs still seems a safe and appropriate method to prevent early thrombosis. 


\section{FUTURE DIRECTIONS}

For final translation of preclinical results of TE-based therapies into clinical practice, several hurdles need to be taken, both worldwide but also in our own laboratory. According to Sung, two translational blocks exist that impede the translation of basic science discoveries into clinical studies and of clinical studies into medical practice and health decision making in systems of care. ${ }^{104}$ These roadblocks involve the transfer of new understandings of disease mechanisms gained in the laboratory into the development of new methods for diagnosis, therapy, prevention and their first test ing in humans. The second roadblock is described as "the translation of results from clinical studies into everyday clinical practice and health decision making". ${ }^{104,105}$ To remove these blocks on a (inter)national level, collaborative efforts from multiple system stakeholders are required. ${ }^{104}$

For our own research consortium, we propose the following set-up for the coming years, to let patients finally benefit from tissue-engineered therapies developed in the laboratorial setting.

1) Development of a small diameter tissue-engineered graft with sufficient mechanical strength and a minimal immunologic and thrombotic response in vivo.

Based on Chapter 6, we feel that a short-term follow-up study in vivo including a minimal burst pressure test before implantation, should be the first step to evaluate feasibility of a new graft. This can be performed in a small, uremic animal model as described in Chapter 5. To gain more insight in in vivo behaviour and for comparison of different graft materials, this small animal model is also very suitable. Long-term function as well as recovery from repeated puncturing, should also be assessed in a uremic animal model with a minimal follow-up of 12 months.

As shown in Chapter 2, increased thrombin generation on ECs from CABG-patients could be a risk. Reducing their thrombogenic potential could result in better performance of grafts seeded with these cells and should be a future goal.

2) Define minimal criteria that patient-derived cells should fulfill.

Based on results presented in Chapter 4 in this thesis, requirements regarding cell growth, migration and thrombogenicity can be described. Before seeding of cells on a graft, cells have to be assessed in a standardized manner using the high-throughput assays described in Chapter 4 (e.g. proliferation, migration, mCAT, RT-qPCR). In vitro results should be correlated with prospectively collected follow-up results after final in vivo implantation. 
3) Establishment of GMP-facilities to isolate and culture venous ECS and SMCs from a small venous biopsy, for example the great saphenous vein.

Based on the results described in Chapter 2 and Chapter 4, we propose the use of venous ECs for production of tissue-engineered vascular grafts. A small biopsy of $>1$ $\mathrm{cm}$ length is required to isolate and culture a sufficient amount of ECs for seeding a graft with a diameter of $0.3 \mathrm{~cm}$ and a length of $60 \mathrm{~cm}$ (Chapter 4 ). Regarding SMCs, more data on their growth potential are required.

4) Initiation of a phase I clinical trial. Implantation of autologous tissue-engineered vascular grafts as an AV fistula in CKD patients, which require vascular access and have insufficient veins for native AV fistula creation.

Patients that have to undergo vascular access creation but lack veins of sufficient quality can be enrolled for tissue-engineered graft implantation. Close monitoring of graft function has to be established. If grafts show satisfying results after one year, at least comparable to prosthet ic grafts, enrollment of patients can be extended to other categories like pat ients requiring coronary artery or peripheral artery bypass grafting. 


\section{REFERENCES}

1. L'Heureux N, Germain L, Labbe R, Auger FA. In vitro construction of a human blood vessel from cultured vascular cells: a morphologic study. J Vasc Surg. 1993; 17(3): 499-509.

2. L'Heureux N, Paquet S, Labbe R, Germain L, Auger FA. A completely biological tissue-engineered human blood vessel. FASEB J. 1998; 12(1): 47-56.

3. Hoerstrup SP, Zünd G, Sodian R, Schnell AM, Grünenfelder J, Turina MI. Tissue engineering of small caliber vascular grafts. Eur J Cardiothorac Surg. 2001; 20(1): 164-9.

4. Pullens RA, Stekelenburg M, Baaijens FP, Post MJ. The influence of endothelial cells on the ECM composition of 3 D engineered cardiovascular constructs. JTissue Eng Regen Med. 2009; 3(1): 11-8.

5. Wu X, Rabkin-Aikawa E, Guleserian KJ, Perry TE, Masuda Y, Sutherland FW, et al. Tissue-engineered microvessels on three-dimensional biodegradable scaffolds using human endothelial progenitor cells. Am J Physiol Heart Circ Physiol. 2004; 287(2): $\mathrm{H}_{4} 80-7$.

6. Shirota $T, \mathrm{He} H$, Yasui $H$, Matsuda T. Human endothelial progenitor cell-seeded hybrid graft: proliferative and antithrombogenic potentials in vitro and fabrication processing. Tissue Eng. 2003; 9(1): 127-36.

7. Quint C, Kondo Y, Manson RJ, Lawson JH, Dardik A, Niklason LE. Decellularized tissue-engineered blood vessel as an arterial conduit. Proc Natl Acad Sci U S A. 2011; 108(22): 9214-9.

8. Allen J, Khan S, Serrano MC, Ameer G. Characterization of porcine circulating progenitor cells: toward a functional endothelium. Tissue Eng Part A. 2008.

9. Cao Y, Sun Z, Liao L, Meng Y, Han Q, Zhao RC. Human adipose tissue-derived stem cells differentiate into endothelial cells in vitro and improve postnatal neovascularization in vivo. Biochem Biophys Res Commun. 2005; 332(2): 370-9.

10. van den Akker NM, Kolk FF, Jeukens F, Verbruggen S, Gagliardi M, Dullens S, et al. Vascular potency of Sus scrofa bone marrow-derived mesenchymal stem cells: a progenitor source of medial but not endothelial cells. Tissue Eng Part A. 2012; 18(7-8): 828-39.

11. Pullens RA. Functional endothelium on tissue engineered small diameter vascular grafts. 2009: 1-118.

12. McAllister TN, Maruszewski M, Garrido SA, Wystrychowski W, Dusserre N, Marini A, et al. Effectiveness of haemodialysis access with an autologous tissue-engineered vascular graft: a multicentre cohort study. Lancet. 2009; 373(9673): 1440-6.

13. Meinhart JG, Deutsch M, Fischlein T, Howanietz N, Fröschl A, Zilla P. Clinical autologous in vitro endothelialization of 153 infrainguinal ePTFE grafts. Ann Thorac Surg. 2001; 71(5, Supplement 1): S327S31.

14. Allen J, Khan S, Serrano MC, Ameer G. Characterization of porcine circulating progenitor cells: toward a functional endothelium. Tissue Eng Part A. 2008; 14(1): 183-94.

15. Schnell AM, Hoerstrup SP, Zund G, Kolb S, Sodian R, Visjager JF, et al. Optimal cell source for cardiovascular tissue engineering: venous vs. aortic human myofibroblasts. Thorac Cardiovasc Surg. 2001; 49(4): 221-5.

16. Zeiher AM, Drexler $\mathrm{H}$, Wollschlager $\mathrm{H}$, Just $\mathrm{H}$. Modulation of coronary vasomotor tone in humans. Progressive endothelial dysfunction with different early stages of coronary atherosclerosis. Circulation. 1991; 83(2): 391-401.

17. Neunteufl T, Katzenschlager R, Hassan A, Klaar U, Schwarzacher S, Glogar D, et al. Systemic endothelial dysfunction is related to the extent and severity of coronary artery disease. Atherosclerosis. 1997; 129(1): 111-8.

18. Thambyrajah J, Landray MJ, McGlynn FJ, Jones HJ, Wheeler DC, Townend JN. Abnormalities of endothelial function in patients with predialysis renal failure. Heart. 2000; 83(2): 205-9.

19. Yildiz A, Oflaz H, Pusuroglu H, Mercanoglu F, Genchallac H, Akkaya V, et al. Left ventricular hypertrophy and endothelial dysfunction in chronic hemodialysis patients. Am J Kidney Dis. 2003; 41(3): 616-23.

20. Epstein FH, Ross R. Atherosclerosis - an inflammatory disease. N Engl J Med. 1999; 340(2): 115-26.

21. Endemann DH, Schiffrin EL. Endothelial Dysfunction. J Am Soc Nephrol. 2004; 15(8): 1983-92. 
22. Zilla P, Siedler S, Fasol R, Sharefkin JB. Reduced reproductive capacity of freshly harvested endothelial cells in smokers: a possible shortcoming in the success of seeding? J Vasc Surg. 1989; 10(2): 143-8.

23. Meinhart J, Halbmayer W-M, Deutsch M, Zilla P. Hyperlipidemia Coincides with reversible growth impairment of cultured human autologous endothelial cells. Endothelium. 2002; 9(4): $239-46$.

24. Kumar A, Kumar S, Vikram A, Hoffman TA, Naqvi A, Lewarchik CM, et al. Histone and DNA methylation-mediated epigenetic downregulation of endothelial Kruppel-like factor 2 by low-density lipoprotein cholesterol. Arterioscler Thromb Vasc Biol. 2013.

25. Chi J-T, Chang HY, Haraldsen G, Jahnsen FL, Troyanskaya OG, Chang DS, et al. Endothelial cell diversity revealed by global expression profiling. Proc Natl Acad Sci U S A. 2003; 100(19): 10623-8.

26. Simcock JW, Penington AJ, Morrison WA, Thompson EW, Mitchell GM. Endothelial precursor cells home to a vascularized tissue engineering chamber by application of the angiogenic Chemokine CXCL12. Tissue Eng Part A. 2008.

27. Asahara T, Murohara T, Sullivan A, Silver M, van der Zee R, Li T, et al. Isolation of putative progenitor endothelial cells for angiogenesis. Science. 1997; 275(5302): 964-6.

28. Hernandez DA, Townsend LE, Uzieblo MR, Haan ME, Callahan RE, Bendick PJ, et al. Human endothelial cell cultures from progenitor cells obtained by leukapheresis. Am Surg. 2000; 66(4): 355 .

29. Oswald J, Boxberger S, Jorgensen B, Feldmann S, Ehninger G, Bornhauser $M$, et al. Mesenchymal stem cells can be different iated into endothelial cells in vitro. Stem Cells. 2004; 22(3): 377-84.

30. Gong Z, Niklason LE. Small-diameter human vessel wall engineered from bone marrow-derived mesenchymal stem cells (hMSCs). FASEB J. 2008; 22(6): 1635-48.

31. Kim S, von Recum $\mathrm{H}$. Endothelial stem cells and precursors for tissue engineering: cell source, differentiation, selection, and application. Tissue Eng Part B Rev. 2008; 14(1): 133-47.

32. Shin'oka T, Matsumura G, Hibino N, Naito Y, Watanabe M, Konuma T, et al. Midterm clinical result of tissue-engineered vascular autografts seeded with autologous bone marrow cells. J Thorac Cardiovasc Surg. $2005 ; 129(6)$ : 1330-8.

33. McGuigan AP, Sefton MV. The influence of biomaterials on endothelial cell thrombogenicity. Biomaterials. 2007; 28(16): 2547-71.

34. Wechezak A, Holbrook K, Way S, Mansfield P. Platelet adherence in endothelial cell cultures. Blood Vessels. 1979; 16(1): 35-42.

35. Gimbrone MA, Buchanan MR. Interactions of platelets and leukocytese with vascular endothelium: In vitro studies. Ann NY Acad Sci. 1982; 401(1): 171-82.

36. Roberts HR, Hoffman M, Monroe DM. A Cell-based model of thrombin generation. Semin Thromb Hemost. 2006; 32(S 1): 032,8.

37. Diquelou A, Dupouy D, Gaspin D, Constans J, Sie P, Boneu B, et al. Relationship between endothelial tissue factor and thrombogenesis under blood flow conditions. Thromb Haemost. 1995; 74(2): 778-83.

38. Biedermann B, Rosenmund A, Muller M, Kohler H-P, Haeberli A, Straub P. Human endothelial cells suppress prothrombin activation in nonanticoagulated whole blood in vitro. J Lab Clin Med. 1994; 124(3): 339.

39. Hemker HC, Giesen P, AlDieri R, Regnault V, de Smed E, Wagenvoord R, et al. The calibrated automated thrombogram (CAT): a universal routine test for hyper- and hypocoagulability. Pathophysiol Haemost Thromb. 2002; 32(5-6): 249-53.

40. Spronk HM, Dielis AW, De Smedt E, van Oerle R, Fens D, Prins MH, et al. Assessment of thrombin generation II: Validation of the calibrated automated thrombogram in platelet-poor plasma in a clinical laboratory. Thromb Haemost. 2008; 100(2): 362-4.

41. ten Cate-Hoek AJ, Dielis AW, Spronk HM, van Oerle R, Hamulyak K, Prins $\mathrm{MH}$, et al. Thrombin generation in patients after acute deep-vein thrombosis. Thromb Haemost. 2008; 100(2): 240-5.

42. Campbell JE, Brummel-Ziedins KE, Butenas S, Mann KG. Cellular regulation of blood coagulation: a model for venous stasis. Blood. 2010; 116(26): 6082-91.

43. Campbell RA, Overmyer KA, Selzman CH, Sheridan BC, Wolberg AS. Contributions of extravascular and intravascular cells to fibrin network formation, structure, and stability. Blood. 2009; 114(23): 488696.

44. Furie B, Furie BC. Mechanisms of Thrombus Formation. N Engl J Med. 2008; 359(9): 938-49. 
45. Gailani D, Renné T. The intrinsic pathway of coagulation: a target for treating thromboembolic disease? JThromb Haemost. 2007; 5(6): 1106-12.

46. Renné T, Pozgajova M, Gruner S, Schuh K, Pauer HU, Burfeind P, et al. Defective thrombus formation in mice lacking coagulation factor XII. J Exp Med. 2005; 202(2): 271-81.

47. Kleinschnitz C, Stoll G, Bendszus M, Schuh K, Pauer H-U, Burfeind P, et al. Target ing coagulation factor XII provides protection from pathological thrombosis in cerebral ischemia without interfering with hemostasis. J Exp Med. 2006; 203(3): 513-8.

48. Cheng Q, Tucker El, Pine MS, Sisler I, Matafonov A, Sun M-f, et al. A role for factor Xlla-mediated factor $\mathrm{XI}$ activation in thrombus formation in vivo. Blood. 2010; 116(19): 3981-9.

49. Baeriswyl V, Calzavarini S, Gerschheimer C, Diderich P, Angelillo-Scherrer A, Heinis C. Development of a selective peptide macrocycle inhibitor of coagulation factor XII toward the generation of a safe antithrombotic therapy. J Med Chem. 2013.

50. Mahdi F, Madar ZS, Figueroa CD, Schmaier AH. Factor XII interacts with the multiprotein assembly of urokinase plasminogen activator receptor, $\mathrm{gC} 1 \mathrm{qR}$, and cytokerat in 1 on endothelial cell membranes. Blood. 2002; 99(10): 3585-96.

51. Joseph K, Tholanikunnel BG, Ghebrehiwet B, Kaplan AP. Interaction of high molecular weight kininogen binding proteins on endothelial cells. Thromb Haemost. 2004; 91(1): 61-70.

52. Schousboe I, Thomsen $P$, Van Deurs B. Factor XII binding to endothelial cells depends on caveolae. Eur J Biochem. 2004; 271(14): 2998-3005.

53. Schousboe I. Endothelial cells express a matrix protein which binds activated factor XII in a zincindependent manner. Thromb Haemost. 2006; 95(2): 312-9.

54. Shariat-Madar Z, Mahdi F, Schmaier AH. Factor XI assembly and activation on human umbilical vein endothelial cells in culture. Thromb Haemost. 2001; 85(3): 544-51.

55. Berrettini M, Schleef RR, Heeb MJ, Hopmeier P, Griffin JH. Assembly and expression of an intrinsic factor IX activator complex on the surface of cultured human endothelial cells. J Biol Chem. 1992; 267(28): 19833-9.

56. Borissoff $\mathrm{Jl}$, Joosen IA, Versteylen MO, Spronk HM, ten Cate H, Hofstra L. Accelerated in vivo thrombin formation independently predicts the presence and severity of CT angiographic coronary atherosclerosis. JACC Cardiovasc Imaging. 2012; 5(12): 1201-10.

57. Merlini PA, Baver KA, Oltrona L, Ardissino D, Cattaneo M, Belli C, et al. Persistent activation of coagulation mechanism in unstable angina and myocardial infarction. Circulation. 1994; 90(1): 61-8.

58. Renné T, Gailani D. Role of Factor XII in hemostasis and thrombosis: clinical implications. Expert Rev Cardiovasc Ther. 2007; 5(4): 733-41.

59. Bach R, Rifkin DB. Expression of tissue factor procoagulant activity: regulation by cytosolic calcium. Proc Natl Acad Sci U S A. 1990; 87(18): 6995-9.

6o. Bach RR. Tissue factor encryption. Arterioscler Thromb Vac Biol. 2006; 26(3): 456-61.

61. Popescu NI, Lupu C, Lupu F. Extracellular protein disulfide isomerase regulates coagulation on endothelial cells through modulation of phosphat idylserine exposure. Blood. 2010; 116(6): 993-1001.

62. Krenning G, Dankers PYW, Drouven JW, Waanders F, Franssen CFM, van Luyn MJA, et al. Endothelial progenitor cell dysfunction in patients with progressive chronic kidney disease. Am J Physiol Renal Physiol. 2009; 296(6): F1314-22.

63. Aird WC. Spatial and temporal dynamics of the endothelium. J Thromb Haemost. 2005; 3(7): $1392-406$.

64. Kokubo T, Ishikawa N, Uchida H, Chasnoff SE, Xie X, Mathew S, et al. CKD accelerates development of neoint imal hyperplasia in arteriovenous fistulas. J Am Soc Nephrol. 2009; 20(6): 1236-45.

65. Langer S, Kokozidou M, Heiss C, Kranz J, Kessler T, Paulus N, et al. Chronic kidney disease aggravates arteriovenous fistula damage in rats. Kidney Int. 2010. 78(12): 1312-21

66. Asif A, Roy-Chaudhury P, Beathard GA. Early arteriovenous fistula failure: A logical proposal for when and how to intervene. Clin J Am Soc Nephrol. 2006; 1(2): 332-9.

67. Dixon BS. Why don't fistulas mature? Kidney Int. 2006; 70(8): 1413-22.

68. Wang SP, West MW, Dresner LS, Fleishhacker JF, Distant DA, Mueller CM, et al. Effects of diabetes and uremia on mesenteric vascular react ivity. Surgery. 1996; 120(2): 328-36.

69. Thuraisingham RC, Raine AE. Maintenance of normal agonist-induced endothelium-dependent relaxation in uraemic and hypertensive resistance vessels. Nephrol Dial Transplant 1999; 14(1): 70-5. 
70. Jolma P, Kalliovalkama J, Tolvanen JP, Koobi P, Kahonen M, Saha $H$, et al. Preserved endotheliumdependent but impaired beta-adrenergic relaxation of the resistance vessels in experimental renal failure. Exp Nephrol. 2002; 10(5-6): 348-54.

71. Stasch J-P, Schmidt PM, Nedvetsky PI, Nedvetskaya TY, H.S AK, Meurer S, et al. Target ing the hemeoxidized nitric oxide receptor for selective vasodilatation of diseased blood vessels. J Clin Invest. 2006; 116(9): 2552-61.

72. Baigent $C$, Burbury $K$, Wheeler D. Premature cardiovascular disease in chronic renal failure. Lancet. 2000; 356(9224): 147-52.

73. Foley RN, Parfrey PS, Sarnak MJ. Clinical epidemiology of cardiovascular disease in chronic renal disease. Am J Kidney Dis. 1998; 32(5 Suppl 3): S112.

74. Tatematsu S, Wakino S, Kanda T, Homma K, Yoshioka K, Hasegawa K, et al. Role of nitric oxideproducing and -degrading pathways in coronary endothelial dysfunction in chronic kidney disease. J Am Soc Nephrol. 2007; 18(3): 741-9.

75. Shinozaki K, Kashiwagi A, Nishio Y, Okamura T, Yoshida Y, Masada M, et al. Abnormal biopterin metabolism is a major cause of impaired endothelium-dependent relaxation through nitric oxide/O2imbalance in insulin-resistant rat aorta. Diabetes. 1999; 48(12): 2437-45.

76. Yamamizu K, Shinozaki K, Ayajiki K, Gemba M, Okamura T. Oral administration of both tetrahydrobiopterin and L-arginine prevents endothelial dysfunction in rats with chronic renal failure. J Cardiovasc Pharm. 2007; 49(3): 131-9.

77. Vallance $P$, Leone A, Calver A, Collier J, Moncada S. Accumulation of an endogenous inhibitor of nitric oxide synthesis in chronic renal failure. Lancet. 1992; 339(8793): 572-5.

78. Vaziri ND. Oxidative stress in uremia: nature, mechanisms, and potential consequences. Semin Nephrol. 2004; 24(5): 469-73.

79. Mendelson K, Aikawa E, Mettler BA, Sales V, Martin D, Mayer JE, et al. Healing and remodeling of bioengineered pulmonary artery patches implanted in sheep. Cardiovasc Pathol. 16(5): 277-82.

8o. Hoerstrup SP, Cummings Mrcs I, Lachat M, Schoen FJ, Jenni R, Leschka S, et al. Functional growth in tissue-engineered living, vascular grafts: follow-up at 100 weeks in a large animal model. Circulation. 2006; 114(1 Suppl): l159-66.

81. Williamson MR, Black R, Kielty C. PCL-PU composite vascular scaffold production for vascular tissue engineering: attachment, proliferation and bioactivity of human vascular endothelial cells. Biomaterials. 2006; 27(19): 3608-16.

82. Tillman BW, Yazdani SK, Lee SJ, Geary RL, Atala A, Yoo JJ. The in vivo stability of electrospun polycaprolactone-collagen scaffolds in vascular reconstruction. Biomaterials. 2009; 30(4): 583-8.

83. Kuwabara F, Narita Y, Yamawaki-Ogata A, Satake M, Kaneko H, Oshima H, et al. Long-term results of tissue-engineered small-caliber vascular grafts in a rat carotid arterial replacement model. J Artif Organs. 2012; 15(4): 399-405.

84. Kumar VA, Caves JM, Haller CA, Dai E, Li L, Grainger S, et al. Acellular vascular grafts generated from collagen and elast in analogues. Acta Biomater. 2013; 9(9): 8067-74

85. Couet F, Rajan N, Mantovani D. Macromolecular biomaterials for scaffold-based vascular tissue engineering. Macromol Biosci. 2007; 7(5): 701-18.

86. Gospodarowicz D, Greenburg G, Foidart J, Savion N. The production and localization of laminin in cultured vascular and corneal endothelial cells. J Cell Physiol 1981; 107(2): 171-83.

87. Penhoat J, Sigot-Luizard MF, Warocquier-Clerout R. Prostacyclin secretion by human endothelial cells grown on carbodiimide cross-linked proteins: an assessment of the cytocompatibility of a substratum. Biomaterials. 1993; 14(7): 503-6.

88. Wissink MJ, Beernink R, Poot AA, Engbers GH, Beugeling T, van Aken WG, et al. Relation between cell density and the secretion of von Willebrand factor and prostacyclin by human umbilical vein endothelial cells. Biomaterials. 2001; 22(16): 2283-90.

89. Commission E. Commission Directive 2003/94/EC of 8 October 2003 laying down the principles and guidelines of good manufacturing practice in respect of medicinal products for human use and invest igational medicinal products for human use. Official J Eur Comm L. 2003; 262: 22-6. 
90. Rauch C, Feifel E, Amann E-M, Peter Spötl H, Schennach H, Pfaller W, et al. Alternatives to the use of fetal bovine serum: human platelet lysates as a serum substitute in cell culture media. ALTEX. 2011; 28(4): 305 .

91. Vara DS, Salacinski HJ, Kannan RY, Bordenave L, Hamilton G, Seifalian AM. Cardiovascular tissue engineering: state of the art. Pathol Biol (Paris). 2005; 53(10): 599-612.

92. Pektok E, Nottelet B, Tille JC, Gurny R, Kalangos A, Moeller M, et al. Degradation and healing characteristics of small-diameter poly(epsilon-caprolactone) vascular grafts in the rat systemic arterial circulation. Circulation. 2008; 118(24): 2563-70.

93. Cattaneo I, Figliuzzi M, Azzollini N, Catto V, Faro S, Tanzi MC, et al. In vivo regeneration of elastic lamina on fibroin biodegradable vascular scaffold. Int J Art if Organs. 2013: 0-.

94. Berger K, Sauvage LR, Rao AM, Wood SJ. Healing of arterial prostheses in man: its incompleteness. Ann Surg. 1972; 175(1): 118.

95. Zilla P, Bezuidenhout D, Human P. Prosthetic vascular grafts: wrong models, wrong questions and no healing. Biomaterials. 2007; 28(34): 5009-27.

96. Clowes A, Kirkman TR, Reidy M. Mechanisms of arterial graft healing. Rapid transmural capillary ingrowth provides a source of int imal endothelium and smooth muscle in porous PTFE prostheses. Am J Pathol. 1986; 123(2): 220.

97. Golden MA, Hanson SR, Kirkman TR, Schneider PA, Clowes AW. Healing of polytetrafluoroethylene arterial grafts is influenced by graft porosity. JVasc Surg. 1990; 11(6): 838-45.

98. Rotmans Jl, Heyligers JM, Verhagen HJ, Velema E, Nagtegaal MM, de Kleijn DP, et al. In vivo cell seeding with anti-CD34 antibodies successfully accelerates endothelialization but stimulates intimal hyperplasia in porcine arteriovenous expanded polytetrafluoroethylene grafts. Circulation. 2005; 112(1): 12-8.

99. Hoffmann J, Paul A, Harwardt M, Groll Jr, Reeswinkel T, Klee D, et al. Immobilized DNA aptamers used as potent attractors for porcine endothelial precursor cells. J Biomed Mater Res A. 2008; 84(3): 614-21.

100. Markway BD, McCarty OJ, Marzec UM, Courtman DW, Hanson SR, Hinds MT. Capture of flowing endothelial cells using surface-immobilized anti-kinase insert domain receptor antibody. Tissue Eng Part C. 2008; 14(2): 97-105.

101. Avci-Adali M, Stoll H, Wilhelm N, Perle N, Schlensak C, Wendel H. In vivo tissue engineering: Mimicry of homing factors for self-endothelialization of blood-contacting materials. Pathobiology. 2012; 8o(4): 176-81.

102. Melchiorri AJ, Hibino N, Fisher JP. Strategies and techniques to enhance the in situ endothelialization of small-diameter biodegradable polymeric vascular grafts. Tissue Eng Part B Rev. 2013.

103. Joner M, Cheng Q, Schönhofer-Merl S, Lopez M, Neubauer S, Mas-Moruno C, et al. Polymer-free immobilization of a cyclic RGD peptide on a nitinol stent promotes integrin-dependent endothelial coverage of strut surfaces. J Biomed Mater Res B. 2012; 100B(3): 637-45.

104. Sung NS, Crowley WF, Jr., Genel M, Salber P, Sandy L, Sherwood LM, et al. Central challenges facing the national clinical research enterprise. Jama. 2003; 289(10): 1278-87.

105. Woolf SH. The meaning of translational research and why it matters. JAMA. 2008; 299(2): 211-3. 


\section{Summary}




\section{SUMMARY}

Small diameter vascular tissue-engineered grafts offer therapeutic potential for patients in need for vascular repair as a result of significant atherosclerosis, congenital defects or to create a vascular access. Current prosthetic alternatives for venous conduits are associated with high failure rates due to thrombotic and infectious complications. Autologous, cell-seeded vascular grafts grown in vitro on a biodegradable scaffold are considered to be less susceptible to these risks and considered a suitable alternative for clinical practice. Endothelial cells (ECs) seeded on the luminal side of such tissue-engineered grafts could provide an anti-thrombotic, anti-immunologic layer and control smooth muscle cell (SMC) function in the medial layer.

To accomplish clinical application of vascular tissue engineered grafts, several validation steps are essential that involve both animal models and patient-derived cells. A number of assays and animal models for studying endothelial function and tissue-engineered vascular grafts are described in this thesis. In Chapter 2, a modified thrombin generation assay is presented that allows analysis of endothelial thrombogenicity in a high-throughput manner. After removal of serum from culture medium, ECs appeared to support coagulation initiated mainly via the contact activation pathway. ECs derived from cardiovascular-diseased patients showed increased thrombin generation compared to ECs from control subjects.

The preference for venous ECs in vascular tissue engineering does no longer have to be based on practical arguments, (i.e. easier access than arterial ones) and can be justified now as well by their more beneficial anti-thrombogenic profile, as shown in Chapter 3. Except for migratory potential and prostacyclin production, other important cellular functions like proliferation and adhesion to fibronect in were comparable to arterial ECs, even for cells grown under arterial shear stress conditions. To gain more insight in performance and behavior of ECs derived from diseased patients, a large study to evaluate ECs derived from two main target patient populations was initiated in Chapter 4 . Patients undergoing coronary arterial bypass grafting (CABG) and patients with chronic kidney disease (CKD) were enrolled, and compared with control subjects. Except for higher thrombodulin expression in CABG patients, a potential beneficial phenomenon, ECs from the two patient categories did not show inferior performance.

Studying small diameter tissue-engineered vascular grafts in vivo should ideally be performed in a small, uremic animal model, as vascular access in CKD patients is one of the first clinical applications of these grafts. Therefore, such a model was developed in 
the rat (Chapter 5), and a native arteriovenous (AV) fistula was created in the neck. Fistula maturation was studied and was reduced in uremic animals due to nitric oxide (NO) resistance of SMCs, while endothelial function was normal. NO resistance could be ascribed to oxidation of the NO-receptor soluble guanylate cyclase (sGC) and could be treated by using a new pharmacological compound for oxidized sGC, BAY 60-2770. Treatment of uremic animals with BAY 60-2770 enlarged AV fistula diameters without increasing flow.

Before applying tissue-engineered vascular grafts in a clinical setting, these grafts need to be evaluated in a large animal model as well. In Chapter 6, grafts were implanted as carotid interposition conduits in pigs and their feasibility was evaluated. Mechanical strength of these grafts appeared to be insufficient, as shown by inferior suture strength and rupture of several grafts. Furthermore, a significant immunologic reaction occurred that resulted in luminal occlusion in most grafts. Using this model, a number of important aspects of inferior graft performance became apparent and provided leads for further improvement. A switch towards using different scaffold material (polycaprolactone) was made, and a minimal burst pressure test will be included in future in vivo studies.

Altogether, extensive insights in endothelial functions relevant for vascular tissue engineering are provided in this thesis. Evaluation of thrombogenicity can now be carried out in a high-throughput manner. By studying performance of patient-derived cells, an important translational step is set forward. The newly described syndrome of NO resistance in CKD is relevant for implantation of grafts in CKD patients, as smooth muscle function appears to be compromised by the presence of oxidative stress. Prevention of diminished vascular remodeling as a result of these uremic complications might be established by using SGC activators like BAY 60-2770. For further in vivo evaluation and optimization of tissue-engineered vascular grafts two animal models are presented, thereby bringing closer translation of tissue engineering techniques towards clinical application. 
Nederlandse Samenvatting 


\section{SAMENVATTING}

Veel patiënten met hart- en vaatziekten of nierfalen hebben kunstmatige vaatprotheses nodig ter vervanging van hun eigen, zieke bloedvaten. Getissueengineerde grafts worden in het laboratorium gemaakt door middel van het zaaien van cellen op een bio-afbreekbare mal waarna deze in een bioreactor gekweekt wordt tot een kunstmatig bloedvat. In de laatste fase worden endotheelcellen, cellen die de binnenkant van bloedvaten bekleden, in deze grafts gezaaid. Cellen die nodig zijn voor het produceren van deze grafts worden geïsoleerd uit de patiënten die uiteindelijk ook de graft zullen ontvangen.

De huidige therapieën waarbij kunststof vaatprotheses worden gebruikt, zijn geassocieerd met een hoog complicatierisico als gevolg van trombosering (stolling), infecties en het ontstaan van vaatvernauwingen. Getissue-engineerde grafts bieden mogelijk een beter alternatief voor deze kunststof protheses vooral in situaties waar slagaderen met een kleine diameter moeten worden vervangen. Voor toekomstig gebruik van deze getissue-engineerde grafts in de klinische praktijk is er behoefte aan zogenaamde translationele studies, die onderzoeksresultaten uit het laboratorium kunnen vertalen naar toepassing in patiënten. In dit proefschrift worden een aantal translationele studies op het gebied van endotheelcellen gepresenteerd met als doel klinische toepassing van getissueengineerde grafts te bevorderen.

Endotheelcellen dienen als een anti-trombotische en anti-immunologische laag om bloedstolling en ontsteking te voorkomen. In Hoofdstuk 2 wordt de door ons ontwikkelde gemodificeerde trombine generatie assay beschreven, een methode waarmee bloedstolling op endotheelcellen kan worden gemeten in een groot aantal samples tegelijk ('high-throughput'). Hierbij bleek dat met name een specifieke route, namelijk contact activatie, van belang was om stolling te initiëren op deze endotheelcellen. Endotheelcellen van patiënten met coronairlijden (vernauwingen in de kransslagaders) bleken een hogere mate van stolling te veroorzaken dan cellen van controle personen.

Vaatprotheses worden meestal ter vervanging van een slagader gebruikt. Echter, voor onderzoek op het gebied van tissue engineering werden in het verleden altijd endotheelcellen uit aders (venes) gebruikt, in plaats van cellen uit slagaders (arteriën). In Hoofdstuk 3 is onderzocht of deze veneuze endotheelcellen even goed functioneren als arteriële endotheelcellen. Met name functies die van belang zijn voor het gebruik van endotheelcellen in tissue engineering van bloedvaten, zoals celvermeerdering tijdens kweek, migratie van cellen, hechting 
van cellen en anti-stolling werden onderzocht. Hoewel celmigratie verminderd was ten opzichte van arterieel endotheel, lieten veneuze cellen een vergelijkbare groei en hechting zien onder arteriële bloedstroomcondities. Daarnaast hadden veneuze cellen ook een gunstiger anti-stollingsprofiel dan arteriële cellen.

Voor gebruik van getissue-engineerde grafts in de kliniek is het noodzakelijk inzicht te hebben in de functie van endotheelcellen van patiënten die in de toekomst gebruikt worden voor het maken van deze grafts. Om dit te onderzoeken zijn in Hoofdstuk 4 endotheelcellen van patiënten met coronairlijden en patiënten met nierfalen vergeleken met cellen van controle personen. Hoewel in Hoofdstuk 2 in een kleinere groep patiënten met alleen coronairlijden en controles wel verschillen in mate van stollingsactivatie zichtbaar waren, liet een uitgebreidere analyse tussen 3 groepen geen verschil zien. Ook op het gebied van groei, genexpressie, celmigratie en productie van vaatverwijdende stoffen functioneren endotheelcellen van patiënten net zo goed als die van controle personen.

Nierpatiënten hebben dialyse nodig waarbij gebruik wordt gemaakt van een shunt (bloedvat of vaatprothese om twee bloedvaten te verbinden). Voor effectieve dialyse is een gerijpte, wijde shunt met voldoende bloeddoorstroming essentieel. Onder andere vanwege de frequente complicaties met kunststof shunts, worden get issue-engineerde grafts momenteel al in nierpatiënten getest. Voor het onderzoeken van get issue-engineerde grafts is dus een (klein) diermodel met nierfalen een zeer geschikt experimenteel model. Voor Hoofdstuk 5 werd een rattenmodel met nierfalen ontwikkeld met een shunt in de nek. De functie van deze shunt werd na 3 weken geëvalueerd waarbij bleek dat nierfalen een negatieve invloed had op de verwijding en doorstroming van de shunt. Dit lijkt te maken te hebben met een verminderde werking van de sensor voor stikstofmonoxide (NO), een vaatverwijdende stof. Om deze sensor beter te laten functioneren werd een nieuw medicijn, BAY 60-2770, onderzocht. Dagelijkse toediening van dit medicijn leidde wel tot een grotere shuntdiameter, maar niet tot een betere doorstroming van de shunt.

Tenslotte is in Hoofdstuk 6 bekeken hoe getissue-engineerde grafts in de halsslagader van varkens functioneerden. Aangezien enkele grafts kort na implantatie scheurden, bleek de mechanische sterkte onvoldoende. Tevens was er een aanzienlijke ontstekingsreactie zichtbaar die in de meeste gevallen tot een afsluiting van de graft leidde. Op basis van deze resultaten worden momenteel nieuwe, verbeterde grafts geproduceerd, van andere materialen met een betere sterkte. 
De resultaten uit de overige hoofdstukken bieden nieuwe aanknopingspunten voor het gebruik van endotheelcellen voor tissue engineering, en laten zien dat cellen van patiënten voldoende functioneren voor gebruik in toekomstige grafts. Klinische toepassing van getissue-engineerde grafts komt door de studies in dit proefschrift weer een stap dichterbij. 
Dankwoord 


\section{DANKWOORD}

Zonder de hulp van velen had ik dit proefschrift nooit kunnen voltooien en ik ben allen die hier aan hebben bijgedragen zeer erkentelijk.

Professor M.J. Post, beste Mark, mijn dank voor jouw begeleiding bij mijn proefschrift is groot. Je stimuleerde me in het diepe te duiken en was een voorstander van 'learning by doing' op vele vlakken. Hoewel ik soms het idee om weer een nieuwe techniek onder de knie te moeten krijgen, wellicht niet altijd met evenveel enthousiasme begroette, kijk ik nu met zeer veel plezier op mijn onderzoekstijd terug. Op wetenschappelijk én persoonlijk vlak heb ik ontzettend veel van je geleerd!

Professor G.W.H. Schurink, beste Geert-Willem, zonder jou was ik nooit aan dit promotietraject begonnen. Naast het feit dat ik je erg dankbaar ben dat je mij deze kans hebt geboden, heb ik je klinische begeleiding door de jaren heen erg gewaardeerd. Het heeft tot een mooi staaltje translationeel onderzoek geleid.

Beste Daniel, dank voor je supervisie de afgelopen jaren. Met prangende vragen en netelige lab kwesties kon ik altijd bij je terecht. Jouw kritische blik bij het lezen van de manuscripten heeft onze artikelen ongetwijfeld naar een hoger niveau gebracht.

Leden van de beoordelingscommissie, professor H.A.J. Struijker-Boudier, professor C.V.C. Bouten, professor T.M. Hackeng, professor S. Jockenhövel en professor C.J. Zeebregts. Ik dank u allen voor uw snelle en vakkundige beoordeling van het manuscript.

Professor J.G. Maessen en Monique Miesen van de cardio-thoracale chirurgie, dank voor de hulp bij het verzamelen van venes van CABG-patiënten. Professor L.W. Van Heurn en Berry Meesters, ook jullie hulp bij het verkrijgen van veneus materiaal was zeer welkom.

Henry Spronk, ik ben je erg dankbaar voor de vruchtbare samenwerking op het gebied van thrombose en endotheelcellen. Ook René, Patricia en Diane, dank voor jullie flexibiliteit en alle technische ondersteuning. Jan Tordoir, dank voor alle antwoorden op mijn vragen op het gebied van AV-shunts. Professor Jo de Mey, ik ben u zeer erkentelijk voor de hulp bij de vasoreactiviteit studies en het ontrafelen van 'the syndrome of NO resistance'. Thijs, in een mum van tijd leerde jij me met de myograaf om te gaan. Gregorio, voor histologische analyse adviezen kon ik altijd bij je aankloppen. 
Mark V., dankjewel voor alle conversaties op wetenschappelijk gebied danwel meer georiënteerd op de algemene zin des levens. En nu ben je ook nog mijn paranimf, hoezee!

Felix en Allard, dank voor jullie bijdrage aan de rattenstudie. Felix, succes bij jouw laatste loodjes! Sanne, jouw eeuwige geduld en tomeloze inzet, in het bijzonder bij onze 'patiëntenstudie' waren van onschatbare waarde. Roomies Vincenza, Geertje and Nastaran, thank you for your company and dull moments that cheered up the lab work through the years! Bart en Kelly, gedeelde smart is halve smart; onze koffiemomentjes had ik niet kunnen missen. Vivian en Bianca, dank voor jullie secretariële assistentie. Nynke, je praktische adviezen en onze gesprekken over wetenschap bedrijven heb ik erg gewaardeerd. Ali, Papendal-maatje van het eerste uur. Ik ben je erg dankbaar voor de support en adviezen vanuit Zwolle en voor de laatste final check van mijn boekje!

Bewoners en vaste bezoekers van DE kamer, waar ik mijn eerste stappen op vasculair onderzoeksgebied zette; Femke, jij hebt me onderzoek leren doen. Je bent een grote inspiratiebron voor me geweest. Aron, Rick en Stella, dank voor alle serieuze en minder serieuze momenten onder het genot van een goede Nespresso.

Collega's van de vaatchirurgie en de algemene heelkunde; ik voelde me altijd welkom bij jullie. Dank voor alle gezelligheid, in het bijzonder: Charlotte, Tiara, Mechteld, Freek, Givan, Guy, Joep, Marc, Mo, Nina, Kim, Kostan, Kaatje, Bas, Simon, Liliane, Johanne, Maarten, Eva, Pieter, Tim, Edgar, Aart, Luc en Froukje.

Ik mag mij zeer gelukkig prijzen met een aantal mensen om mij heen die ieder voor zich met hun speciale karakters samen mijn leven leuk maken! Anke; het is je toch gelukt, en slechts 2 straten verderop! Dankjewel dat ik altijd mijn sores met je kon delen. Yvonne G., Stef, Fleur, Isabelle, Auke, Yvonne vd P., Sophie, Floor, Talitha en Tinus; dank voor jullie niet aflatende interesse in mijn onderzoek en alle afleiding die jullie mij boden.

Tenslotte, leden van "Unastraat 25". Bram, je andere kijk op de dingen werkt erg verfrissend, het is altijd fijn om met jou van gedachten te wisselen. Astrid, groot zusje van me, bedankt dat je mijn paranimf wilt zijn! De pieken en dalen in wetenschapsland heb ik altijd met je kunnen delen. Je luisterend oor en adviezen waren zeer welkom! Lieve papa en mama, het gevoel dat ik altijd op jullie kon rekenen gaf veel rust. Dank voor jullie onvoorwaardelijke steun en het vertrouwen dat ik dit tot een goed einde ging brengen. 
About the Author 


\section{ABOUT THE AUTHOR}

Irma Geenen was born on December $11^{\text {th }}, 1983$ in Valkenswaard, the Netherlands. She attended high school at the Were Di Scholengemeenschap in Valkenswaard were she graduated VWO (Cum Laude) in 2002. Thereafter, she studied Medicine at Maastricht University. During her internships, she assisted in the research project of dr. F. Hellenthal in the department of Surgery (Prof. dr. G.W.H. Schurink). After graduation in 2008, she started working as a PhD-student at the departments of Physiology and Surgery under the supervision of Prof. dr. M.J. Post and Prof. dr. G.W.H. Schurink. From September 2012 until July 2013, she worked as a resident at the Intensive Care Unit at the Meander Medical Center, Amersfoort. In July 2013, she started her training in Anesthesiology at the VU medical center, Amsterdam (Prof. dr. S.A. Loer). 


\section{List of Publications}




\section{LIST OF PUBLICATIONS}

Geenen IL, Verbruggen S, Molin DG, Spronk HM, Maessen JG, Meesters B, Schurink GW, Post MJ. Phenotypic Fitness of Primary Endothelial Cells Cultured from Patients with High Cardiovascular Risk or Chronic Kidney Disease for Vascular Tissue Engineering.

Tissue Engineering Part A. 2014 Mar;20(5-6):1049-59

Geenen IL, Molin DG, van den Akker NM, Jeukens F, Spronk HM, Schurink GW, Post MJ. Endothelial Cells (ECs) for Vascular Tissue Engineering; Venous ECs are Less Thrombogenic than Arterial ECs.

Journal of Tissue Engineering and Regenerative Medicine. 2012 Nov 19. doi: 10.1002/term.1642. [Epub ahead of print]

Geenen IL, Post MJ, Molin DG, Schurink GW, Maessen JG, van Oerle R, Ten Cate H, Spronk HM. Coagulation on Endothelial Cells; the Underexposed Part of Virchow's Triad.

Thrombosis and Haemostasis. 2012 Nov;108(5):863-71

Geenen IL, Nyilas L, Stephen MS, Makeham V, White GH, Verran DJ. Prosthetic lower extremity hemodialysis access grafts have satisfactory patency despite a high incidence of infection.

Journal of Vascular Surgery. 2010 Dec;52(6):1546-50

Geenen IL, Sosef MN, Shun A, Crawford M, Gallagher J, Strasser S, Stormon M, McCaughan $G$, Verran DJ. Usage and outcomes of deceased donor liver allografts with preprocurement injury from blunt trauma. Liver Transplantation. 2009 Mar;15(3):321-5 Reply to comment: Geenen IL, Sosef MN, Verran DJ. Reply: Severe preprocurement blunt trauma to the liver-Is there a need for back-table cutdown? Liver Transplantation. 2009 Nov; 15(11):1649

Hellenthal FA, Geenen IL, Teijink JA, Heeneman S, Schurink GW. Histological features of human abdominal aortic aneurysm are not related to clinical characteristics.

Cardiovascular Pathology. 2009 Sep-Oct;18(5):286-93 
